\title{
SEISMIC RESPONSE EVALUATION OF THE LINKED COLUMN FRAME SYSTEM
}

\author{
Mohammad Malakoutian
}

\author{
A dissertation \\ submitted in partial fulfillment of the \\ requirements for the degree of \\ Doctor of Philosophy \\ University of Washington \\ 2012 \\ Reading Committee: \\ Jeffrey W. Berman, Chair \\ Charles W. Roeder \\ Laura N. Lowes
}

Program Authorized to Offer Degree:

Civil \& Environmental Engineering 
University of Washington

\title{
Abstract \\ SEISMIC RESPONSE EVALUATION OF THE LINKED COLUMN FRAME SYSTEM
}

\author{
Mohammad Malakoutian \\ Chair of the Supervisory Committee: \\ Professor Jeffrey W. Berman \\ Civil and Environmental Engineering
}

The Linked Column Frame system (LCF) is a new structural steel frame system capable of achieving enhanced seismic performance and safely providing continued occupancy of buildings impacted by moderate earthquake events. The LCF consists of two components: a primary lateral system, denoted the linked column, which is made up of dual columns interconnected with replaceable link beams; and a secondary moment frame lateral/gravity system that is a flexible moment resisting frame with beams having fully restrained connections at one end and simple connections at the other.

The linked columns are designed to limit seismic forces and provide energy dissipation through yielding of the links, while preventing damage to the moment frame under certain earthquake hazard levels. A design procedure is proposed that ensures the links of the linked column yield at a significantly lower story drift than the beams of the moment frame, enabling design of this system for two distinct performance states: rapid repair, where only link damage occurs and relatively quick link replacement is possible; and collapse prevention, where both the linked column and moment frame may be damaged.

Nonlinear dynamic analyses of prototype buildings were conducted using OpenSees and the results identified how the system's parameters impact the ability of the LCF to achieve the performance objectives and the adequacy of the proposed design procedure. It was found that in general the LCF system provides collapse prevention for longer return period 

events and enables rapid repair following earthquakes with shorter return periods.

The seismic performance factors for the LCF system, including the response modification coefficient, $R$, the system overstrength factor, $\Omega_{0}$, and the deflection amplification factor $\left(C_{d}\right)$ were established following recently established procedures described in FEMA P695 (2009). These parameters are necessary for inclusion of the system in the building codes.

Finally, models were developed in support of the experimental validation of the system's performance being done using hybrid simulation at the Network for Earthquake Engineering Simulation Laboratory at the University of California, Berkeley. Using the modeling techniques developed here, the numerical portion of the hybrid simulation specimen has been developed and used to predict the experimental response. The experiments are being conducted by collaborators at Portland State University. 



\section{TABLE OF CONTENTS}

Page

List of Figures $\ldots \ldots \ldots \ldots \ldots \ldots \ldots \ldots \ldots$. . . . . . . . . . . . . . . . .

List of Tables . . . . . . . . . . . . . . . . . . . . . . . . viii

Chapter 1: INTRODUCTION . . . . . . . . . . . . . . . . 1

1.1 General . . . . . . . . . . . . . . . . . . . . . . . . . . . . 1

1.2 Research Motivation and Objectives . . . . . . . . . . . . . . . . . . 2

1.3 Scope of Work $\ldots \ldots \ldots \ldots \ldots \ldots$

1.4 Organization of Dissertation . . . . . . . . . . . . . . 4

Chapter 2: LITERATURE REVIEW . . . . . . . . . . . . . . . . . . 6

2.1 Introduction . . . . . . . . . . . . . . . . . . . 6

2.2 Moment Resisting Frames . . . . . . . . . . . . . . . . . . . . . . . . 6

2.3 Eccentrically Braced Frames $\ldots \ldots \ldots \ldots$. . . . . . . . . . . . . . . . . . . . . . . . . . . . .

2.4 Structural Fuse Concept . . . . . . . . . . . . . . . . . . . . . 17

2.5 Replaceable Links in Long-Span Bridges . . . . . . . . . . . . . . . . . . 22

2.6 The Linked Column Frame System ․ . . . . . . . . . . . . . . . . . . 26

2.7 Summary . . . . . . . . . . . . . . . . . . . . . . . . 28

Chapter 3: LINKED COLUMN FRAME SYSTEM DESCRIPTION . . . . . . . . 30

Chapter $4:$ DESIGN PROCEDURE . . . . . . . . . . . . . . . . 36

4.1 Design Procedure Based on Story Drift Requirements . . . . . . . . . . . . 37

$4.2 \quad$ Design Procedure Based on Spectral Parameters . . . . . . . . . . . . . . . 40

Chapter 5: OVERVIEW OF PROTOTYPE DESIGNS $\ldots \ldots \ldots \ldots \ldots$

Chapter 6: ANALYTICAL MODELS . . . . . . . . . . . . . . 57

6.1 Link Models . . . . . . . . . . . . . . . . . . . . . . . . . 57

6.2 Beam and Column Models . . . . . . . . . . . . . . . . . . . . . . 64 
6.3 Connection Models . . . . . . . . . . . . . . . . . . . . . . 70

6.4 Frame Models . . . . . . . . . . . . . . . . . . . . . . . . . 78

Chapter 7: NONLINEAR ANALYSIS . . . . . . . . . . . . . . . . . . 84

7.1 Nonlinear Static (Pushover) Analysis . . . . . . . . . . . . . . . . 84

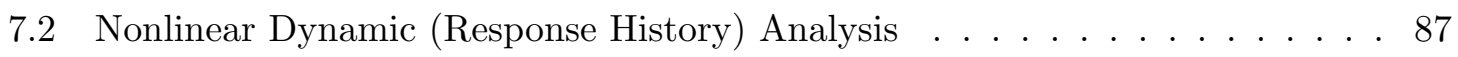

7.3 Response of Lower Stories in 6 and 9-story LCF. . . . . . . . . . . . 95

$7.4 \quad$ Evaluation of the Robustness of the Design Procedure for Different Seismic

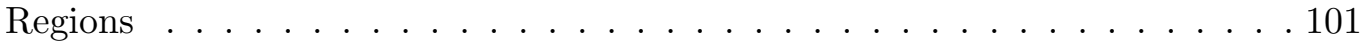

Chapter 8: PARAMETERS AFFECTING LCF EFFICIENCY . . . . . . . . . . . 111

8.1 Developing Closed Form Equations for LCF Stiffness . . . . . . . . . . . . 111

8.2 Improving LCF Efficiency Using Built-up Section . . . . . . . . . . . . . 118

\begin{tabular}{ll|}
\hline Chapter 9: & QUANTIFICATION of LCF SEISMIC PERFORMANCE FACTORS \\
\hline \hline & for USE in SEISMIC DESIGN $\ldots \ldots \ldots \ldots \ldots \ldots \ldots \ldots \ldots \ldots \ldots \ldots$
\end{tabular}

9.1 Introduction. . . . . . . . . . . . . . . . . . . . . . . 128

9.2 Development of the LCF Concept and Obtaining Required Information . . . 135

9.3 Archetype Development . . . . . . . . . . . . . . . . . . . . 140

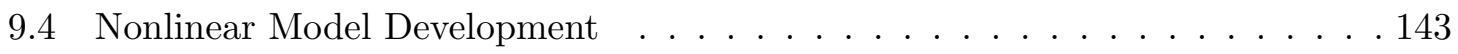

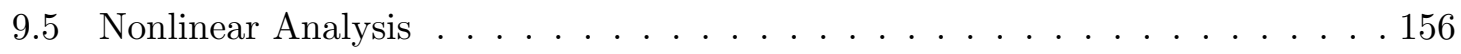

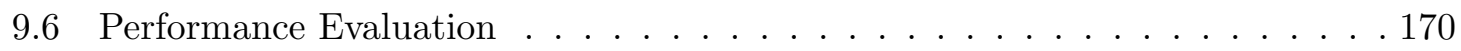

Chapter 10: $\quad$ DEVELOPMENT OF THE ANALYTICAL COMPONENT OF LCF HYBRID TESTING $\ldots \ldots \ldots \ldots \ldots \ldots \ldots$

10.1 Introduction $\ldots \ldots \ldots \ldots \ldots \ldots$

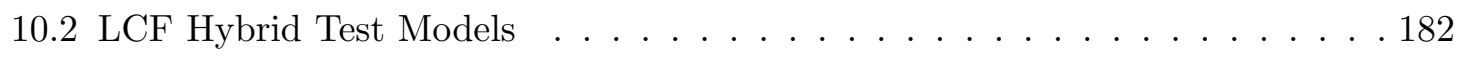

10.3 Experimental Component Model Analysis . . . . . . . . . . . . . . . 184

10.4 Computational Component Model Analysis . . . . . . . . . . . . 186

Chapter 11: SUMMARY, CONCLUSIONS AND FUTURE WORK . . . . . . . . . 198

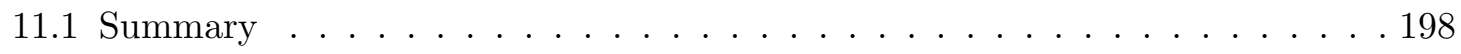

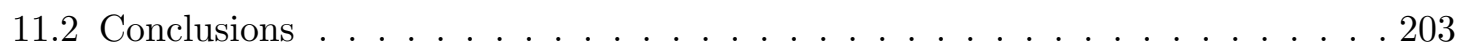

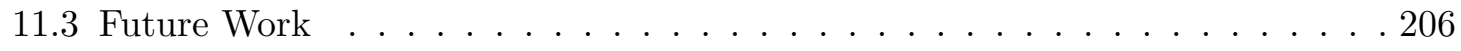




\section{LIST OF FIGURES}

Figure Number

Page

1.1 Plane Frame Elevation of a Building Bay with the Linked Column Frame

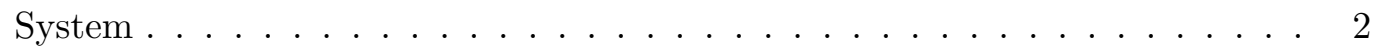

$2.1 \quad$ Plan and Elevation View of Post-Northridge Buildings (Lee and Foutch 2002) 10

2.2 Plan and Elevation View of Post-Northridge Buildings (Lee and Foutch 2002) 11

2.3 Different Types of Eccentrically Braced Steel Frames: (a) V-Bracing; (b) K-Bracing; (c) X-Bracing ; ( d) Y-Bracing (Ghobarah and Elfath, 2001) . . . 13

2.4 Experimental Set-up (Arce 2002) . . . . . . . . . . . . . . 15

2.5 Comparison Between Experimental and Analytical Results (Richards 2004) . 16

$2.6 \quad$ Details of the loading system (Okazaki 2004) $\ldots \ldots \ldots$. . . . . . . . . 18

2.7 Concept of Damage-Controlled Structure: (a) Actual Structure; (b) Primary Structure (Gravity Structure); (c) Brace System (Seismic-Resistant Structure) (Connor et al., 1997) . . . . . . . . . . . . . . . . . . . 19

2.8 Schematic Details Used For Buckling Restrained Braces (Black et al., 2004) . 20

2.9 The Behavior of ADAS Damper During Earthquake (Alehashem et al., 2008) 21

2.10 Example of Practically Applied Panel Damper and Its Arrangements in the Frame (Tanaka et al., 2000) f . . . . . . . . . . . . . . 22

2.11 View of the test set-up used for Shear Link Experiments (Itani (1997)) . . . . 23

2.12 Elavetion and Plan of the Self Anchored Suspension Bridge (Nader et al.2002) 24

2.13 Main Tower Model Bridge (Nader et al. 2002) . . . . . . . . . . . . . . . . 25

2.14 Seismic Displacement Demands (Nader et al. 2002) . . . . . . . . . . . . . . . 25

2.15 Pushover Analysis of the Single Tower (Nader et al. 2002) . . . . . . . . . . . 26

2.16 Lateral Load Displacement Ductility (Goodyear and Sun 2003) . . . . . . . . 26

2.17 Numerical Model Layout with Different Column Boundary (Dusicka and Iwai

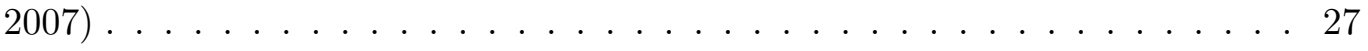

2.18 Pusheover Response of LCF in Comparison with SMRF (Dusicka and Iwai

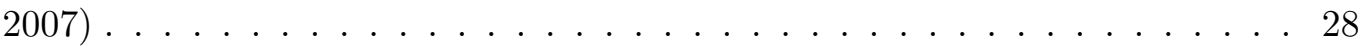

$3.1 \quad$ Plane Frame Elevation of a Building Bay with the Linked Column Frame

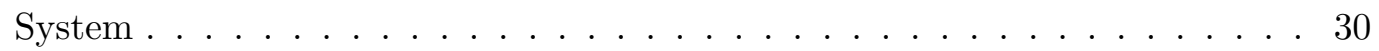

$3.2 \quad$ Idealized LCF and component Pushover Curves. . . . . . . . . . . . . . . . 32 
3.3 Link-to-Column Connection Detail with Bolted End-Plate and Parallel Web Stiffeners (adapted from Dusicka and Lewis (2010)). . . . . . . . . . . . . . 33

3.4 Test Set-Up and Link Failure Modes for Bolted End Plate Links with and without Parallel Web Stiffeners (Dusicka and Lewis, 2010). . . . . . . . . . . 33

3.5 Pattern of Plastic Hinge Formation (a) MF with Beam Fully Restrained at Each End (b) MF with Beam Fully Restrained at One End and Pinned at

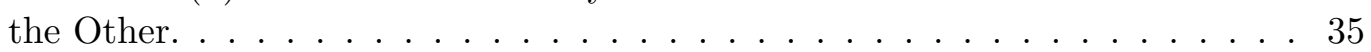

$4.1 \quad$ Damage States to Correlate Element Damage with Extent of Repair. . . . . . 37

4.2 Idealized Pushover Curve for LCF. . . . . . . . . . . . . . . . . . . . . . 40

4.3 The Capacity Spectrum Method Applied on the LCF3-SLC. . . . . . . . . . . 43

$4.4 \quad$ Idealized Pushover and Corresponding Capacity Spectrum Curve. . . . . . . . . 44

4.5 Target Response Spectra Values for Site Class D for 5\% Damping Level $($ FEMA-355 C $[2001) . \ldots \ldots \ldots \ldots \ldots$. . . . . . . . . . . . . 46

5.1 Frame Model of 3 Story. (a) SAC Model Special Moment Resisting Frame, (b) LCF Model Based on SAC Model. . . . . . . . . . . . . . . . . . . . . . . 49

5.29 Story LCF Elevations: (a) LCF with 3 Bays of Linked Columns, (b) LCF with 2 Bays of Linked Columns. . . . . . . . . . . . . . . . . 49

6.1 The Aggregate Procedure in OpenSees (Mazzoni et al.] 2009). . . . . . . . . . . 59

6.2 Hysteretic Material, OpenSees (Mazzoni et al. 2009). . . . . . . . . . . . . . 60

6.3 Experimental Link Shear vs. Link Rotation Results (a) Shear Link (b) Flexural Link. . . . . . . . . . . . . . . . . . . 6 61

6.4 Test Set-Up and Link Failure Modes for Bolted End-Plate Links with and without Parallel Web Stiffeners (Dusicka and Lewis, 2010). . . . . . . . . . . 65

6.5 Comparison of Experimental Link Shear vs. Link Rotation Results with the Developed OpenSees Model. . . . . . . . . . . . . . . . . . 66

6.6 Four Bolt Unstiffened and Eight Bolt Stiffened Extended End-plate Connection Configurations. . . . . . . . . . . . . . . . . . . . 69

6.7 WUF-W Moment Connection. . . . . . . . . . . . . . . . . . . . . . . 71

6.8 Comparison of Experimental Results with the Developed OpenSees Model (a) Four Bolt Extended Unstiffened Moment Rotation (b) Welded Unreinforced Flange Welded Web. . . . . . . . . . . . . . . . . . . . . 71

6.9 Different Methods of Modeling Beam-to-Column Connections (a) Actual Struc\begin{tabular}{ll|l} 
ture (b) Centerline Model (c) Rigid End Offset Model (d) Panel Zone Model. & 73 \\
\hline
\end{tabular}

6.10 Plan and Elevation View of Post-Northridge Buildings (Lee and Foutch 2002) 75

6.11 Comparison of the Pushover Response of Three Methods of Modeling Beamto-Column Connections for LCF3-SLC. . . . . . . . . . . . . . . . 75

6.12 Shear-tab Connection Model in OpenSees. . . . . . . . . . . . . . . . 76 
6.13 Bare-steel Shear-tab Moment-rotation Model (Liu and Astaneh-Asl[ [2004). 77

6.14 a) Load-drift Response for Specimens with and without the Floor Slab (Liu and Astaneh-Asl, 2004) b) Developed OpenSees Model for Shear-tab Con-

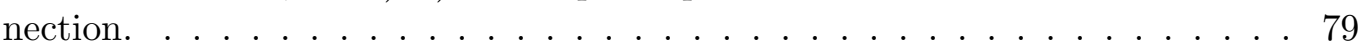

6.15 Comparison of the Pushover Response of LCF3-SLC with/without Modeling Slab and Connection. . . . . . . . . . . . . . . . 80

6.16 Pushover Response of 3-story LCF . . . . . . . . . . . . . . . . . . 81

6.17 Pushover Response of LCF (a) Cyclic Analysis (b) The First Link Yielding (c) The First Beam Yielding. . . . . . . . . . . . . . . . . . . . . 82

6.18 Pattern of Plastic Hinge Formation (a) The First Link Yield (b) The First Beam yield (c) Extensive Link and Beam Yield . . . . . . . . . . . . . . 83

$7.1 \quad$ Pushover Analysis of LCF in Comparison with SAC Moment Frame. . . . . . 87

7.2 Median and 84th percentile Story Drift Results for a 3,6 and 9-Story LCF Buildings. . . . . . . . . . . . . . . . . . 90

7.3 Median and 84th percentile Link Rotation Demand Results For a 3, 6 and 9-Story LCF. . . . . . . . . . . . . . . . . . . . . . . . 92

7.4 Median and 84th percentile Beam Rotation Demand Results For a 3,6 and 9-Story LCF. . . . . . . . . . . . . . . . . . . 93

7.5 Median and 84th Percentile Link Rotation Demand Results For a 6-Story LCF. 96

$7.6 \quad$ Different Column Boundary Condition for LCF, Additional Link at the First Floor and Fully Restrained Column Connections. . . . . . . . . . . . . . . 99

7.7 Median and 84th Percentile Story Drift, Link Rotation and Beam Rotation Results for LCF6-S-80, LCF 6-S-80-Add and LCF6-S-80-Fixed . . . . . . . . . 100

7.8 Median and 84th Percentile Story Drift Results for Seattle Models. . . . . . . 108

7.9 Median and 84th Percentile Link Rotation Demand for Seattle Models. . . . . 109

7.10 Median and 84th Percentile Beam Rotation Demand for Seattle Models. . . . 110

8.1 Frame Deformation Caused by the Shear Deformation of Links and Columns. 112

8.2 Frame Deformation Caused by the End Rotations of Beams and Columns. . . 113

$8.3 \quad$ Frame Deformation Caused by the Overturning Moments. . . . . . . . . . . . 114

8.4 Estimating Displacements Cause by the Overturning Moments by the Moment Area Method (Naeim, 2001). . . . . . . . . . . . . . 116

8.5 Structural Component Influence on the Overall Stiffness for 3-story LCF. . . 117

8.6 Structural Component Influence on the Overall Stiffness for 6-story LCF. . . 118

8.7 Pushover Response of LCFs and Their Components for 3-story LCF Model

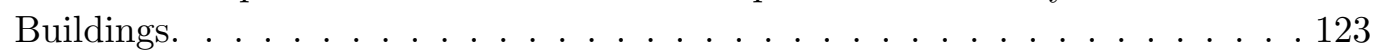


8.8 $\quad$ Pushover Response of LCFs and Their Components for 6-story LCF Model

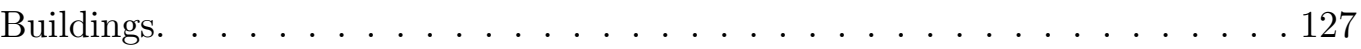

9.1 Illustration of Seismic Performance Factors, $\mathrm{R}, \Omega$ and $C_{d}$ a) as Defined by the Commentary to the NEHRP Recommended Provisions (FEMA 2004b) b) as Defined by the FEMA P695 Methodology (2008). . . . . . . . . . . . . 131

$9.2 \quad$ Schematic of a Building Bay with the Linked Column Frame System. . . . . . 135

9.3 Idealized LCF and Component Pushover Curves. . . . . . . . . . . . . . . . . 136

9.4 Frame Model of 3-Story. (a) Floor Plan for SAC Model Special Moment Resisting Frame and LCF Model (Based on SAC Model) (b) Elevations for SAC Model Special Moment Resisting Frame and LCF Model (Based on SAC

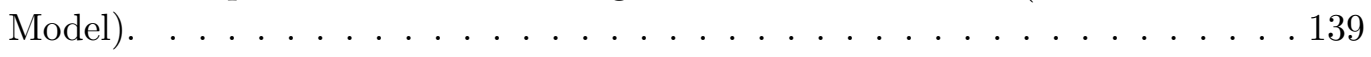

9.5 Different Characteristics Used to Define LCF Archetypes . . . . . . . . . . . . 143

9.6 Parameters of an Idealized Component Backbone Curve (FEMA P695, 2009). 155

9.7 Comparison of Experimental Results with the Developed OpenSees Model (a) Beam Model with Four Bolt Extended Unstiffened Moment Rotation (b) Link Model (Shear Link) (C) Link Model (Flexural Link) (d) Shear-tab Connection. 157

9.8 MCE Response Spectra for Collapse Evaluation of Structure Archetype for SSDC D. . . . . . . . . . . . . . . . . . . . . 159

9.9 Response Acceleration Spectra, Median, Scaled Response Spectra and Scaled Median Spectra for 3-Story LCF . . . . . . . . . . . . . . . . 163

9.10 Scaled Response Acceleration Spectra (a) 3-story $(\mathrm{T}=0.76 \mathrm{~s})$ (b) 6-story $(\mathrm{T}=1.27 \mathrm{~s})$ (c) 9-story $D_{M a x}(\mathrm{~T}=1.76 \mathrm{~s})(\mathrm{d}) 9$-story $D_{\text {Min }}(\mathrm{T}=1.89 \mathrm{~s})$.

9.11 Nonlinear Static Pushover Curve of Base Shear vs Maximum Drift (a) 3-story

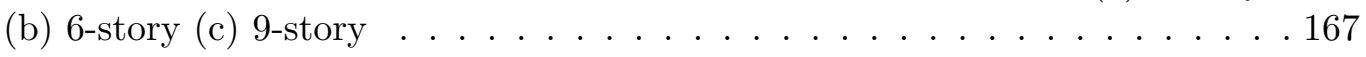

9.12 Incremental Dynamic Analysis Response Plot of Spectral Acceleration vs Maximum Drift (a) 3-story (b) 6-story (c) 9-story . . . . . . . . . . . . . 169

9.13 Spectral Shape Factor for SDC $D_{\max }-$ FEMA P695|(2009) Table 7-1b . . . . 171

9.14 Total System Collapse Uncertainty $\left(\beta_{T O T}\right)$ for Model Quality (B) Good FEMA P695[(2009) Table 7-2b. . . . . . . . . . . . . . . . 172

10.1 Hybrid Testing Method for LCF. . . . . . . . . . . . . . . . . . 183

10.2 Test Set-up Elevation (Lopez, 2013). . . . . . . . . . . . . . . . . . . . . 184

10.3 (a) Numerical LCF Model, 4-bay and 2-story (Computational Substructure)(b) Experimental LCF Model, 1-bay and 2-story (Physical Substructure). . . . . 184

10.4 Proposed Experimental Setup for the LCF (Lopez et al. [2012b). . . . . . . . 185 10.5 Experimental Model, 2-Story, 1-bay LCF. . . . . . . . . . . . . . . 186

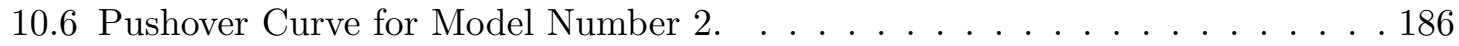


10.7 (a) Axial Demands for Model Number 2 (b) Moment and Shear Demands for Model Number 2. . . . . . . . . . . . . . . . . . . . . . . . 187

10.8 (a) Model Number One, Computational Model, 2-story, 4-bay LCF (b) Relation Between Computational and Experimental substructure (c) Model Number 2, the Simulation of the Moment Frame . . . . . . . . . . . . . . . . 188

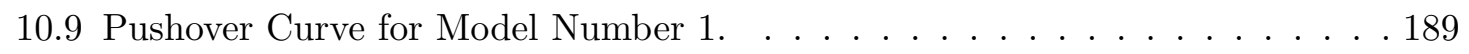

10.10Specific Loaction for Reading Components Demands. . . . . . . . . . . . . . . 189

10.11Link Demands Form Pushover Analysis for Model Number 1. . . . . . . . . 190

10.12Beam Demands Form Pushover Analysis for Model Number 1. . . . . . . . . 190

10.13 Column Demands Form Pushover Analysis for Model Number 1. . . . . . . . 191

10.14Dynamic Results, Maximum Story Drift and Link, Beam and Column Demands for Model Number 1. . . . . . . . . . . . . . . . . . . . . . . . . 191

10.15(a) Model 1 (b) Model 2 (c) Model 3 . . . . . . . . . . . . . . . . . . 193

10.16Dynamic Results, Maximum Story Drift and Link, Beam and Column Demands for Model Number 1. . . . . . . . . . . . . . . . . . . . . . . . . 194

10.17OpenSees Software Framework Components. . . . . . . . . . . . . . . . . 194

10.18OpenSees Domain Object with Added Experimental Element. . . . . . . . . . 195

10.19Comparison Between Hybrid Simulation Analysis Algorithm and Normal Analysis. . . . . . . . . . . . . . . . . . 196

10.20 Axial Demands in Truss Elements in Model Number 3. . . . . . . . . . . . . . 197 


\section{LIST OF TABLES}

Table Number $\quad$ Page

4.1 Response Spectra Values for LCF Design . . . . . . . . . . . . . . 46

5.1 Design Characteristics of LCF Buildings . . . . . . . . . . . . . . . . . 51

$5.2 \quad$ Design Details; Beam and Column section for LCF Model Buildings . . . . . 52

5.3 Design Details; Beam and Column section for 3-story Model Buildings . . . 53

5.4 Design Details; Beam and Column section for 6-story Model Buildings . . . 54

5.5 Design Details; Beam and Column section for 6-story Model Buildings . . . 55

5.6 Design Details; Beam and Column section for 9-story Model Buildings . . . 56

$6.1 \quad$ Links Used for Calibration of OpenSees Model . . . . . . . . . . . . . . . 64

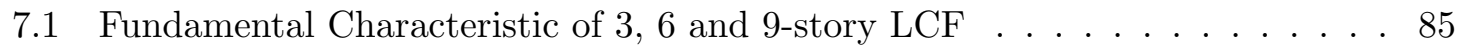

7.2 Response Spectra Values (in units of g) for Site Class D for 5\% Damping Level in Los Angeles area $\ldots \ldots \ldots . \ldots . \ldots 88$

7.3 Residual Story Drift (\%) Median and 84th Percentile Response From Nonlinear Analyses. . . . . . . . . . . . . . . . . . . 94

7.4 Tabulated Response Parameters From Nonlinear Analyses (2\%in 50 years)] . 96

7.5 Response Spectra Values (in units of g) for Site Class D for 5\% Damping Level in Seattle area . . . . . . . . . . . . . . . . . . . 102

7.6 Design Details; Beam and Column Section for 3-story Seattle Buildings . . . 104

7.7 Design Details; Beam and Column Section for 6-story Seattle Buildings . . . 105

7.8 Considered Link Sectional Properties . . . . . . . . . . . . . . . . . . 106

7.9 Fundamental Characteristic of 3- and 6-story Seattle LCF . . . . . . . . 106

8.1 LCF 6-I-120 Overall and Components' Stiffnesses. . . . . . . . . . . . . . . . 117

8.2 Design Details; Beam and Column Section for 3-story LCF Model Buildings . 120

8.3 Link Sectional Properties for 3-story LCF Model Buildings . . . . . . . . . . 121

8.4 Design Details; Weight (kips) for 3-story LCF Model Buildings . . . . . . . . 121

8.5 Fundamental Characteristic for 3-story LCF Model Buildings . . . . . . . . . 122

8.6 Design Details; Beam and Column Section for 6-story LCF Model Buildings . 124

8.7 Link Sectional Properties for 6-story LCF Model Buildings . . . . . . . . . . 125

8.8 Design Details; Weight (kips) for 6-story LCF Model Buildings . . . . . . . . 125 
8.9 Fundamental Characteristic for 6-story LCF Model Buildings . . . . . . . . . 126

$9.1 \quad$ Matrix of Index Archetype Configurations for LCF Buildings . . . . . . . . . 142

9.2 Design Spectral Values for Seismic Design Category D . . . . . . . . . . . . . 145

9.3 Design Details; Beam and Column Section for 3-story Index Archetype Designs 148

9.4 Design Details; Beam and Column Section for 6-story Index Archetype Designs 149

9.5 Design Details; Beam and Column Section for 6-story Index Archetype Designs Continued From Table 9.4 . . . . . . . . . . . . . . . . . . 150

9.6 Design Details; Beam and Column Section for 9-story Index Archetype Designs 151

9.7 Design Details; Beam and Column Section for 9-story Index Archetype Designs Continued From Table 9.6 . . . . . . . . . . . . . . . . . 152

9.8 Design Details; Beam and Column Section for 9-story Index Archetype Designs Continued From Table 9.7 . . . . . . . . . . . . . . . . . . 153

9.9 Design Details; Beam and Column Section for 9-story Index Archetype Designs Continued From Table $9.8 \ldots \ldots$. . . . . . . . . . . . . . 154

9.10 Considered Link Sectional Properties ． . . . . . . . . . . . . . . . . . . . . 160

9.11 Short-Period and 1-second Spectral Acceleration, Site Coefficients and Design Parameters Used for Collapse Evaluation of Seismic Design Category D . . . 160

9.12 Values of the Fundamental Period, T, for Index Archetype LCFs . . . . . . . 164

9.13 Earthquake Event, Station and Scaling Factors for the Far-Field Record Set 165

9.14 Total System Collapse Uncertainty, $\beta_{T O T}$ for Index Archetype Models . . . . 173

9.15 Acceptable Values of Adjusted Collapse Margin Ratio (ACMR10\% and ACMR20\%) adopted from $\mid$ FEMA P695[(2009)] . . . . . . . . . . . . . . . 174

9.16 Summary of the Evaluations of the Archetype for 5\% and 8\% Drift Limit State 176

9.17 Evaluating Index Archetype Designs Based on Acceptable Values of Adjusted Collapse Margin Ratio for 8\% Drift Limit. . . . . . . . . . . . . . . . . . . . . 177

9.18 Evaluating Index Archetype Designs Based on Acceptable Values of Adjusted Collapse Margin Ratio for 5\% Drift Limit. . . . . . . . . . . . . . . . . . . . 178 


\section{ACKNOWLEDGMENTS}

I would like to give my profound thanks and appreciation to my advisor Professor Jeff Beramn for his support and guidance throughout my graduate studies and especially towards my thesis work. His encouragement and motivation has helped me immensely in the preparation of my thesis. Additionally, I want acknowledge Professor Peter Dusicka for comments and advice along the way.

I also thank to other members of my thesis committee: Professor Charles Roeder, Professor Laura Lowes and Professor Daniel Abramson for their time, consideration and comments. I am grateful to Professor Peter Mackenzie, Professor John Stanton, Professor Gregory Miller and Professor Marc Eberhard for their insight.

I want to express my thanks to my friends and office mates for helping me during these past four years: Angi Calkins, Maurizio Chiaramonte, Ali Nejat, Arlindo Lopes, Patricia Clayton, Po-Chien Hsiao, Wang Bo Shiuan, Josh Pugh, Johnathan Weigand, Keith Palmer, Max Stephens, Olafur Haraldsson and Anna Birely. Without help from any of the above faculty, colleagues and friends, I would have not been able to achieve all that I did.

Finally this research was supported in part by the National Science Foundation under award number CMMI-0830414. Any opinions, findings, conclusions, and recommendations

presented in this paper are those of the author and do not necessarily reflect the views of the sponsors. 


\section{DEDICATION}

This thesis is dedicated to my family for their love, support, encouragement and inspiration. Dad, Mom, Sara and Sam. 



\section{Chapter 1}

\section{INTRODUCTION}

\subsection{General}

In this research, a new seismic load resisting system, called the Linked Column Frame system (LCF) is investigated and is shown in Figure 1.1. It is a structural steel frame system featuring easily replaceable yielding elements and is conceived to be capable of achieving enhanced seismic performance. The LCF consists of two components: (i) a primary lateral system, denoted the linked column, consisting of dual columns interconnected with replaceable link beams; and (ii) a secondary lateral/gravity system, which is a flexible moment resisting frame with beams having fully restrained connections at one end and simple connections at the other.

This LCF system utilizes replaceable link beams that provide initial stiffness and then act as yielding energy dissipators to provide nonlinear softening behavior, ductility, and energy dissipation while limiting the inelastic deformation and related damage to the structural members of the adjacent moment resisting frame. The LCF links behave similarly to links in eccentrically braced frames, in that they yield in shear and/or flexure depending on their length. The ease of link replacement, where connection details outlined in Dusicka and Lewis (2010) are used, as described later, ensures an expedited return to functionality of the building following a moderate earthquake. Similar systems have been proposed, designed and developed for tall bridge towers such as that of the new east spans of the San Francisco Oakland Bay Bridge (Nader et al., 2002; Goodyear and Sun, 2003). There, shear links used between the tower shafts, are designed to yield during a major earthquake and may need to be subsequently replaced. It is noted that in buildings, repair speed is also dependent upon repair needs for the floor system and non-structural component damage. 


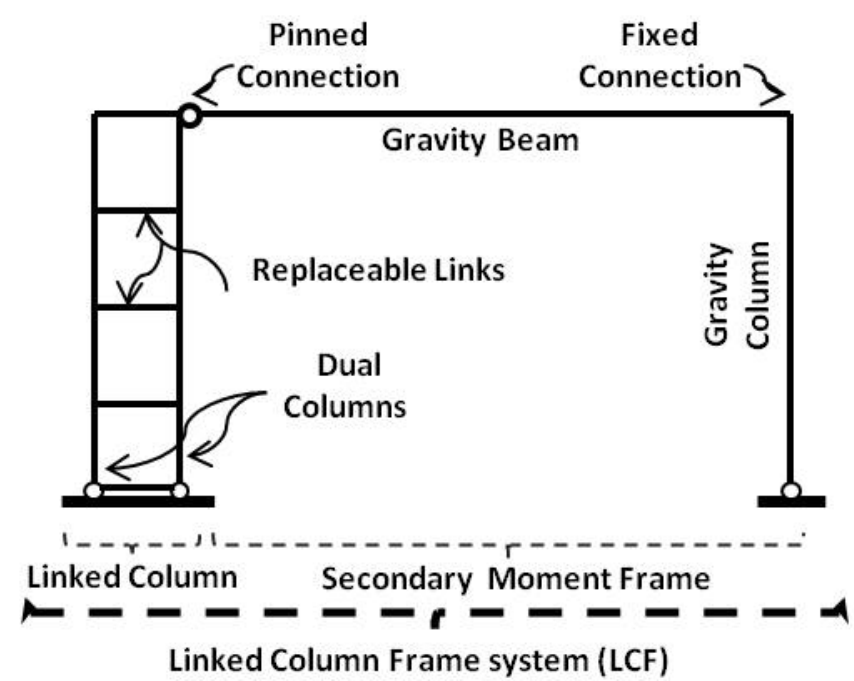

Figure 1.1: Plane Frame Elevation of a Building Bay with the Linked Column Frame System

\subsection{Research Motivation and Objectives}

Collapse prevention is the first priority in the seismic design of buildings. Recently, earthquake engineering researchers and practitioners have begun to address other seismic performance objectives and to develop systems that ensure structural integrity, enable more rapid repair and provide lower repair cost. Conventional seismic load resisting systems, such as moment resisting frames or braced frames, are typically designed to provide acceptable collapse prevention performance, but the economic impacts of inelastic deformation related damage and down-time impact can be significant. Therefore, there is a need for systems that not only ensure the critical purpose of protecting the lives of inhabitants following an earthquake, but are also easily repaired following a moderate earthquake.

Recent studies have focused on the development of various innovative structural systems and components that may be more easily repaired following moderate earthquakes. These include the development of buckling-restrained braces (BRBs) (Saeki et al. 1996; Aiken et al. 1999; Iwata et al., 2000, Sabelli et al., 2003), added damping and stiffness devices (ADAS) and triangular added damping and stiffness devices (TADAS) (Tsai et al., 1993; Dargush and Soong, 1995, Tena-Colunga, 1997), and steel shear panel devices (Nakashima, 
1995, Nakashima et al., 1995, Miyama et al., 1996, Shimizu et al., 1998; Tanaka et al., 1998). These systems are able to concentrate all damage in a ductile element, which is disposable and relatively easily repaired, allowing the main structure, including the gravity load resisting system, to remain essentially elastic and undamaged. Residual drifts may also be relatively small in such systems since the elastic response of the surrounding framing will help to at least partially recenter the system.

Similarly, the LCF system, which utilizes links that are intended to yield in shear and provide a plastic mechanism that limits the internal forces and protects the columns and gravity frame, may achieve three performance levels: elastic behavior, where the entire structure remains undamaged; rapid repair, where the links plastically deform, while the gravity frame remains undamaged; collapse prevention, where plastic hinges also occur in beams of the moment frame. The primary objectives of this research are to:

1. Develop a design procedure for the LCF system to enable design for multiple performance objectives.

2. Investigate the seismic performance of the LCF system and the impact of design decisions on that performance.

3. Develop recommended values for design parameters necessary for inclusion of the LCF system into the building code.

4. Provide nonlinear numerical models of the LCF system that can be used in hybrid simulation of the system as part of a larger collaborative research effort.

\subsection{Scope of Work}

To achieve the above research objectives the following scope of work was completed:

1. A method for nonlinear modeling of the LCF system was developed in the NEES supported structural analysis program OpenSees (Mazzoni et al., 2009). The model development includes the calibration of link models to experimental data from previous 
tests on short link beams considering all possible modes of link behavior. Moment frame connection behavior was also simulated and the model was calibrated to the prequalified connection types for use in connecting beams to columns in intermediate moment frames (IMFs). Models were also developed for capturing the contribution of the simple connections to the lateral resistance of the LCF system and these were also calibrated against experimental results available in the literature.

2. A preliminary assessment of LCF behavior, identification of critical design parameters and model validation were accomplished using a prototype 3-story LCF model and cyclic pushover analyses.

3. A series of 3-, 6-, and 9- story prototype LCF buildings were designed using the proposed design approach to investigate the system's performance and the adequacy of the design approach.

4. A parametric study of key design parameters was conducted to examine in more detail the contribution of the individual components to the strength and stiffness of the overall behavior of the LCF, to improve LCF performance and efficiency.

5. Recommended values for seismic design parameters, including the response modification coefficient, $R$, the system over-strength factor, $\Omega_{0}$, and the deflection amplification factor $\left(C_{d}\right)$ were developed according the procedures in FEMA P695 (FEMA 2009).

6. Finally, the LCF system and component behaviors are being investigated experimentally through hybrid testing at University of California, Berkeley. An OpenSees model was developed for use in the hybrid testing.

\subsection{Organization of Dissertation}

This document contains 11 chapters. This chapter provides the introduction and background of the LCF frame systems and scope of works. The literature review is in the second chapter and includes previous research on moment resisting frame, eccentrically brace frame and 
fuse concept, as well as link in bridge's tower; all components and concepts of LCF. The description and design procedures of LCF are explained in Chapters 3 and 4, respectively. Chapter 5 provides details for all prototype designs. The sixth chapter contains detailed description of the development and modeling techniques of the link, connections, and the LCF in OpenSees programs. Fundamental characteristics of each system and the result from dynamic response are provided in Chapter 7. Chapter 8 covers parameters that affect LCF efficiency while quantification of LCF seismic performance factors is investigated in Chapter 9. Hybrid experimental test data on LCF and corresponding OpenSees modeling is discussed in Chapter 10. The final chapter provides a summary and conclusion as well as a brief listing of the possible content for future work and research. 
Chapter 2

\section{LITERATURE REVIEW}

\subsection{Introduction}

As mentioned briefly in introduction, the LCF combines aspects of steel moment resisting frames and eccentrically braced frames. Previous research on these systems is extensive and both have current requirements for seismic design given in the AISC Seismic Design Provisions (AISC, 2005b) denoted The provisions herein. Thus, these systems and the pertinent literature will be briefly reviewed. Also reviewed here is research resulting in the formal development of the structural fuse concept, which will be used in this research to assist in developing design recommendations for the LCF. Finally replaceable links have been used in the piers of some recently designed long-span bridges. Literature regarding these implementations is reviewed as it directly relates to the development of the LCF system.

\subsection{Moment Resisting Frames}

\subsubsection{Introduction}

Moment-resisting steel frames (MRFs) are used frequently in low-rise and mid-rise buildings located in high seismic areas due to their high ductility and architectural flexibility. In this system, columns and beams are typically joined by fully restrained welded or bolted connections. The flexural resistance and stiffness of the members provides the lateral resistance and stiffness of the frames. The provisions define three types of steel moment frames; Ordinary Moment Frames (OMF), Intermediate Moment Frames (IMF) and Special Moment Frames (SMF). SMFs are expected to withstand significant inelastic deformations when subjected to the forces resulting from motions of the design earthquake. The inelastic deformation capacity of IMFs is more limited when compared to SMFs. OMFs are less ductile than IMFs, and are expected to have limited ductility within their components and connections. 
The provisions specify a strong-column weak-beam design approach to ensure for plastic hinges develop in the beams prior to the columns which increase system ductility and helps prevent concentrated deformations in single stories.

Steel moment resisting frames, especially their fully welded connections, were heavily and unexpectedly damaged during the 1994 Northridge and the 1995 Kobe earthquakes. Brittle failures in beam-to-column connections indicated design flaws and poor construction procedures, resulting in large economic loss and service disruption due to the damage. By far the most common type of damage was fracture initiating in the beam bottom flange at the root pass of the CJP groove weld (Kaufman and Fisher, 1995); (Kaufman et al., 1997). Lack of evidence of appreciable plastic deformation indicated that many of these connections failed before the development of any yielding in the beams, and therefore performed poorly. This unexpected and extensive damage gave reason to conduct immediate tests of preNorthridge connections after the earthquake. Tests by Popov et al. (1998), Hajjar et al. (1998), Shuey et al. (1996) and Uang et al. (1998) reproduced all the major types of damage seen in the field, and also exhibited little or no plastic deformation.

Extensive research following the Northridge Earthquake identified a number of factors that contributed to the premature fractures observed after the earthquake. This included factors related to the welding and factors related to the connection configuration, as well as others. Some of these factors have implications in developing the LCF and are discussed in the following sections. Comprehensive reports were produced on design, retrofit, analysis

and construction inspection of moment resisting frames (FEMA-354 (2000), FEMA-352 (2000), FEMA-350 (2000), FEMA-351 (2000), FEMA-353 (2000), FEMA-355 C (2001)) by the SAC Joint Venture Partnership and through support by the Federal Emergency Management Agency (FEMA).

\subsubsection{Welding}

Engelhardt and Sabol (1997) stressed that welding problems in pre-Northridge connections involved several aspects, ranging from the lack of fracture toughness of the weld metal, to poor workmanship and quality control, to configuration of the connection that interfered 
with placement of the weld and inspection, to the practice of leaving backing bars and weld tabs after completion of the weld. Kauffman (1997) confirmed that the Charpy V-Notch $(\mathrm{CVN})$ toughness requirements of $20 \mathrm{ft}-\mathrm{lbs}$ at minus $20^{\circ} \mathrm{F}$ were adequate for preventing the brittle fracture of the welds observed in pre-Northridge connections. The provisions require the filler metal used in seismic load resisting frames to be capable of producing welds that have a minimum CVN toughness of $20 \mathrm{ft}-1 \mathrm{bs}$ at minus $20^{\circ} \mathrm{F}$ and $40 \mathrm{ft}-\mathrm{lbs}$ at minus $70^{\circ} \mathrm{F}$. FEMA-350 (2000) suggests adhering to the following measures for beam flange CJP welds:

1. Remove the weld tabs from both the top and the bottom flanges

2. Provide a reinforcing fillet weld between the backing bar and column flange at the top flange

3. Remove the bottom backing bar, back gouge the weld root, and then provide a reinforcing fillet weld at the root of the bottom flange groove weld

\subsubsection{New Connection Development}

The pre-Northridge connection was inherently flawed due to the overall configuration that draws a significant portion of the beam stresses to the beam flanges where: the likelihood of weld defects located at the root of the bottom flange weld are high, additional stress concentrations are present due to the geometry of the weld access hole, and high triaxial stress is present due to the column flange. These factors combined with the caution against over-reliance on welding quality led to the suggestion in FEMA-267 (1995) that the intent of moment frame connection design should be to force the plastic hinge away from the face of the column. Various types of welded and bolted connections (reinforced and unreinforced connections and reduced beam section) are discussed in FEMA-350 (2000) and some are prequalified for use in seismic load resisting steel moment frames in The provisions.

AISC (2005a) specified the different requirements for beam-to-column connections for all three types of steel moment frames. OMFs are expected to withstand limited inelastic deformations in their connections as a result of lateral forces. IMFs are expected to withstand limited inelastic deformations in their connections as a result of lateral forces and 
require the use of pre-qualified connections or connections that have undergone and passed a qualifying cyclic test. IMF connections sustain an inter-story drift angle of up to 0.02 rad. SMFs are expected to withstand significant inelastic deformation in their connections as a result of lateral forces and require the use of pre-qualified connections or connections that have undergone and passed a qualifying cyclic test. SMFs must sustain an inter-story drift angle of up to 0.04 radians. One design goal for the LCF is to eliminate the need for costly SMFs connection details while maintaining similar ductile behavior.

\subsubsection{Span-to-Beam Depth}

Since the 1970's trend has been to reduce the number of fully rigid connections in the MRFs to achieve better economy (FEMA-267, 1995). It became quite typical to provide moment connections only in perimeter frames of the structure, or only in selected bays. Adoption of these designs with only a small number of moment frames led to significant increase in member sizes in the moment frames to meet code specified drift limits. The use of deep beams and columns to control drift led to beams with smaller span-to-depth ratios. However, a beam with a small span-to-beam ratio forces strain hardening to take place in a limited region near the beam ends. Such a beam must develop very severe plastic strain at the ends in order to supply plastic hinge rotation. FEMA-350 (2000) specifically addresses the span-to-beam ratio by limiting the use of prequalified connections to MRFs proportioned with span-to-beam ratios greater than a certain limit.

\subsubsection{Panel Zone Strength}

After the Northridge Earthquake, many analytical studies and tests were conducted to investigate the effect of strength balance between the panel zone and beam. Finite element analysis by Chi et al. (2000), Mao et al. (2001) and Ricles et al. (2002) suggests that large inelastic panel zone deformation can promote fracture of the beam flange, and thus, a stronger panel zone that limits inelastic deformation in the panel zone is desirable. The provisions permits limited yielding of the panel zone, but requires that the primary energy dissipation in moment frames still be provided by flexural plastic hinges in the beams. Also 
Foutch and Yun (2002) developed and compared the results of linear centerline models and models with panel zone included for six models of a 9-story MRF building that show the centerline model is conservative for use in new building design but is not recommended for performance evaluation of existing or damaged buildings. Figure 2.1 shows one of their models for panel zone that later on has been used in the LCF beam-to-column and link-tocolumn connections.

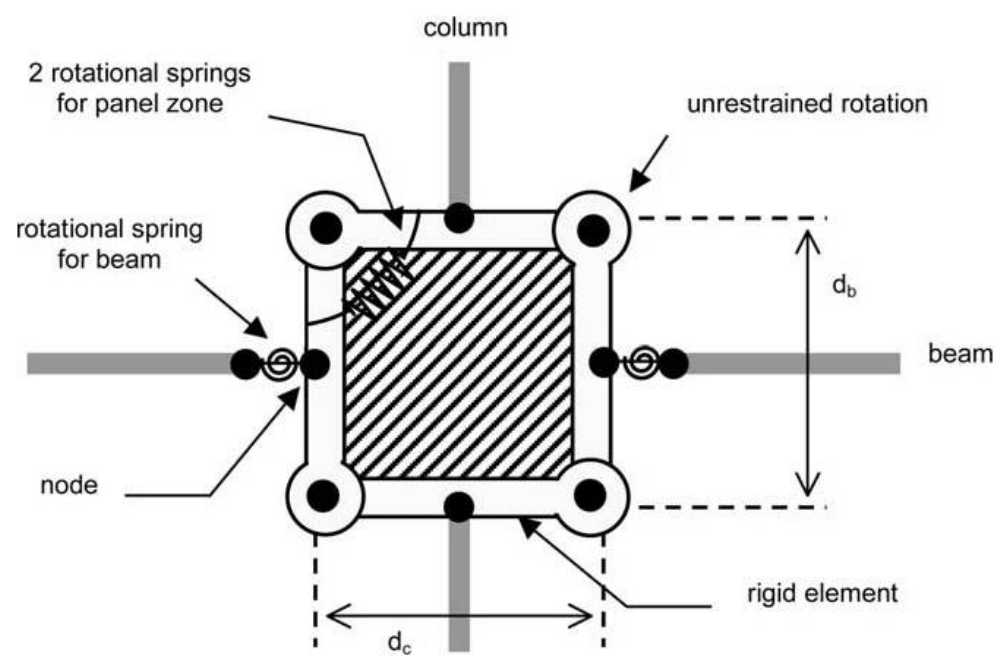

Figure 2.1: Plan and Elevation View of Post-Northridge Buildings (Lee and Foutch 2002)

\subsubsection{Performance evaluation of steel moment frame buildings}

The damage observed after the Northridge Earthquake exposed a weakness of design and construction procedures and led to the development of performance-based guidelines for design of new steel frame structures as part of the FEMA/SAC project.

Yun et al (2002) and Lee and Foutch (2002) carried out seismic performance evaluation for moment steel frames based on nonlinear dynamics and reliability theory. Their results showed that buildings designed in accordance with SAC regulations and prequalified connections have a significant confidence level for satisfying the collapse prevention performance level for a hazard that has less than a $2 \%$ probability of being exceeded in 50 years and immediate occupancy performance level or the 50\%-in-50 year hazard level, compared to the 
building constructed with pre-Northridge welded connections. They showed that the steel MRF structures designed in accordance with the 1997 NEHRP provisions and constructed with SAC prequalified connections are expected to perform better during earthquakes than pre-Northridge buildings.

Figure 2.2 illustrates plan views and elevations of the SAC 3-, 9- and 20-story model buildings. The LCF configurations were adopted from these SAC buildings.

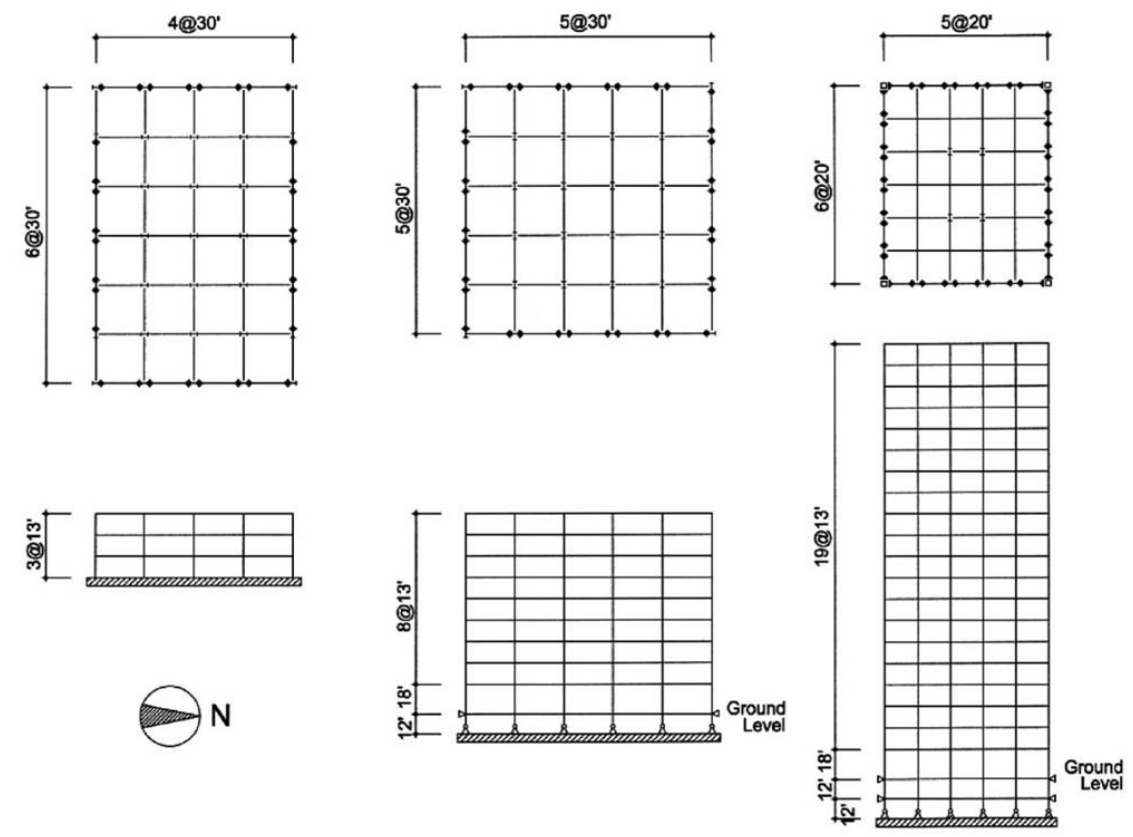

Figure 2.2: Plan and Elevation View of Post-Northridge Buildings (Lee and Foutch 2002)

Liao et al. (2007) developed a three-dimensional finite-element model based on ABAQUS to evaluate the performance of 3-story MRF under seismic load accurately considering preand post-Northridge connections to evaluate effects of connection fractures, contribution of gravity frame as well as the effects of panel zone and column deformations on building performance. The results indicate that as expected the pre-Northridge building has much higher failure probability in all performance categories from immediate occupancy to incipient collapse, therefore is much more vulnerable to future seismic excitation due to connection fractures. 
Asgarian et al. (2008) evaluated the extent of damage and vulnerability of SMF comparing to IMF and OMF through the use of nonlinear static and dynamic analyses as indicated in FEMA-350 (2000). Their major result shows that IO performance level is not exceeded for all frames, the CP performance level is not met for OMF considering the level of seismicity of the site and OMF connections are incapable of withstanding significant inelastic deformations and rotations.

In conclusion, the response of MRFs in the Northridge and Kobe earthquakes and the research that was mentioned demonstrated that inelastic behavior leads to structural damage, which in MRF means damage to the gravity load-carrying members. The loss of occupancy and costly repair of gravity system motivates the need for more easily repaired seismic load resisting systems that contain damage to elements that are not relied upon to support gravity loads.

\subsection{Eccentrically Braced Frames}

\subsubsection{Introduction}

Eccentrically braced frames (EBFs) can be viewed as a hybrid system between moment frames (high ductility and stable energy dissipation capacity) and concentrically braced frames (high elastic stiffness). EBFs combine the advantages and minimize the disadvantages of these two systems. In EBFs, forces are transferred to the brace members through bending and shear forces developed in the ductile steel link. The link is designed to act as a fuse by yielding and dissipating energy while preventing buckling of the brace members. Well-designed links provide a stable source of energy dissipation. Different brace patterns are used in eccentrically braced steel frames. Examples of these patterns include V-bracing, K-bracing, X-bracing and Y-bracing as shown in Figure 2.3 where the links are identified by the dimension $e$.

This system was first developed in Japan in the early 1970s. In the United States, it was investigated at the system and component levels through a series of analytical and experimental studies at the University of California, Berkeley throughout the 1980s (Roeder and Popov 1977; Hjelnstad and Popov 1983; Malley and Popov 1983; Kasai and Popov 1986; 
Ricles and Popov1987; Whittaker et al. 1987; Ricles and Popov 1989; Engelhardt and Popov 1992).

(a)

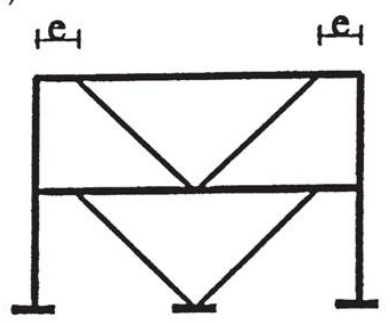

(c)

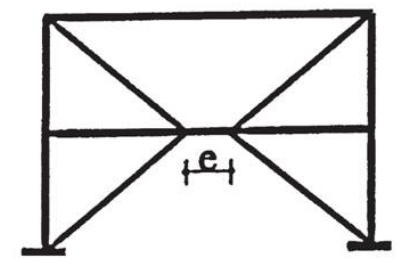

(b)

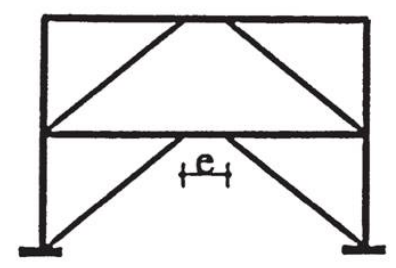

(d)

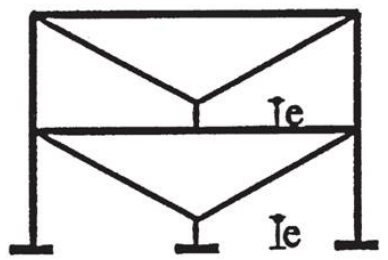

Figure 2.3: Different Types of Eccentrically Braced Steel Frames: (a) V-Bracing; (b) KBracing; (c) X-Bracing ; ( d) Y-Bracing (Ghobarah and Elfath, 2001)

\subsubsection{Overall Behavior}

Roder and Popov (1977) conducted 2-D nonlinear dynamic analyses on a set of EBF CBF and MRF models to compare their performance under severe ground motions. The analyses indicated that EBFs perform well compared to the other framing system due to their combined high stiffness and stable hysteretic behavior. Whittaker et al. (1987; 1989) examined the six story EBF-MRF dual structures by earthquake simulator tests of a ).30-scale model. Although the structure exhibited excellent cyclic behavior, it was observed that the energy dissipation and story drift was concentrated in the lower stories. Ricles and Popov (1994) performed 2-D nonlinear dynamic analyses of a six-story four-bay EBF. The analyses demonstrated the excellent performance of the frame, where the links accounted 
for the majority of energy dissipation. More recently, Richards and Uang (2003) conducted extensive 2-D nonlinear dynamic analyses of EBFs to investigated the deformation demands on shear yield links. These analyses also demonstrated that EBFs designed according to the current provisions perform adequately during severe earthquakes.

\subsubsection{Design Procedure}

In an appropriately designed EBF, inelastic action and damage is restricted primarily to the links. The provisions (section 15) are intended to ensure that cyclic yielding in the links can occur in a stable manner while the diagonal braces, columns and portions of the beam outside of the link remain essentially elastic under the fores that can be developed by fully yielded and strain-hardening links. In the capacity design procedure, the links are sized and detailed for code specified forces. Subsequently, all other members are designed for the forces developed in a fully yield and strain hardening link to remain essentially elastic. The provisions provide an estimate of the ultimate shear force and end moments that can be achieved by a link. After arranging the frame and sizing the members, a check must be carried out to assure that the link can accommodate the rotation demand corresponding to the frame drift requirement. The relation between the link rotation and ultimate drift can be approximated using the plastic mechanism. A similar procedure was used to design the $\mathrm{LCF}$ in this research.

The provisions specify the maximum width-thickness ratio allowed for links section to be identified to those limits for beams in SMFs and accounted for the effect of strain hardening by the link overstrength factor. Also it defines three different link length categories associated with three distinctive ranges of inelastic behavior as discussed in chapter 4 .

\subsubsection{Research on EBF Link}

Notably the majority of the experimental work performed was cyclic testing of single links, to evaluate link rotation capacities. Of particular interest here are those experimental studies that will be used to calibrate link models developed in this research. Therefore, these are the focus points of the following review. 
Arce (2002) investigated the impact of the flange width-to-thickness ratio on the rotation capacity and overstrength of links in EBFs. Sixteen links with four different wide flange sections and a wide variety of link lengths were tested at the University of Texas, Austin. The test setup consisted of a link welded to end plates that were bolted to a large beam and a large column as shown in Figure 2.4. The column was pushed up to induce a shear force and near-equal end moments in the link. The same beam and column were used throughout the testing; only the link section was replaced for each test. The predominant failure mode observed in these tests was the fracture of the link web initiating at the end of the stiffener welds. Overstrength data collected in these tests suggest that the current overstrength factors specified in The provisions for design of braces are reasonable. Sections with high ratios of flange to web areas did not exhibit unusually high overstrength factors, at least within the range of flange to web area ratios typical of rolled $\mathrm{W}$ - shapes.

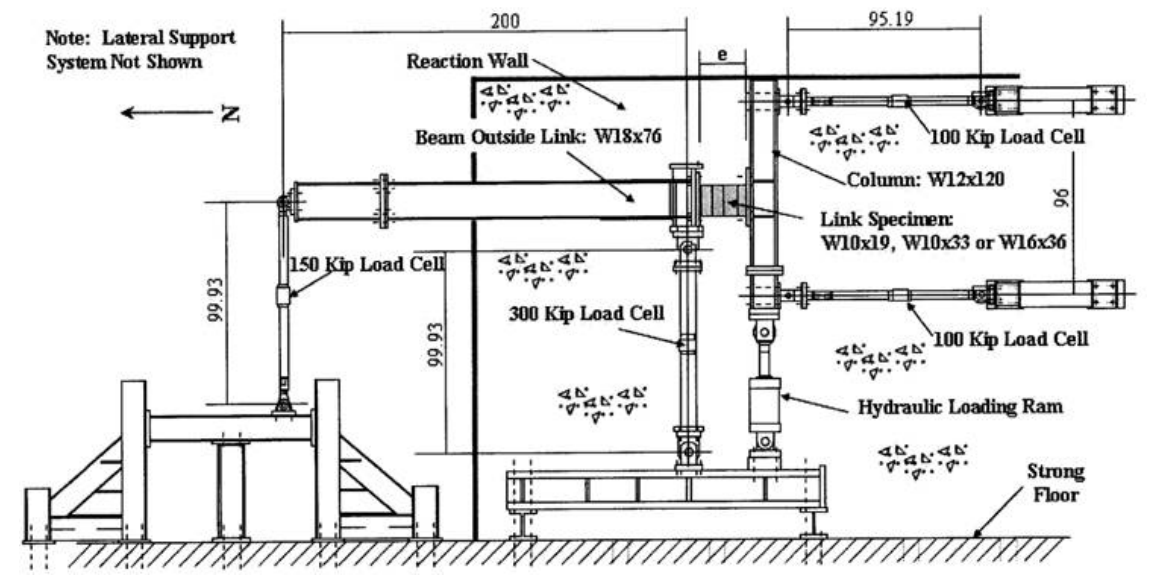

Figure 2.4: Experimental Set-up (Arce 2002)

Richards and Uang $(2002 ; 2004)$ performed finite element modeling of EBF links and EBF systems to address flange width-thickness limits stiffener spacing requirements and inelastic rotation demands. Nonlinear response history analyses were performed for nine eccentrically braced frames subjected to 20 earthquake records scaled to represent design events. Results were used to quantify the cumulative rotation demands on links in EBFs as a function of link length and system geometry and to develop a revised experimental loading 
that simulated the expected demands. Result of detailed finite element analysis, similar to these shown in Figure 2.5, of various link geometries were used to verify requirements of preventing web and flange local buckling.
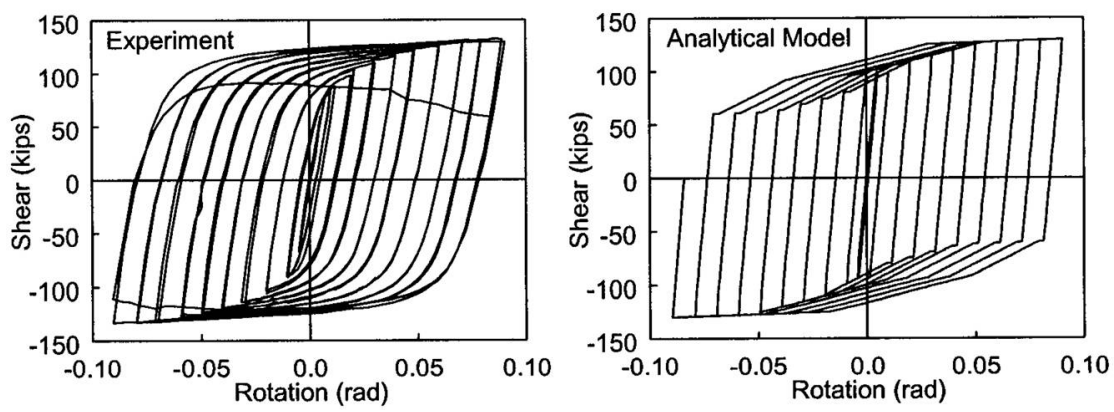

Figure 2.5: Comparison Between Experimental and Analytical Results (Richards 2004)

Ryu et al. (2004) duplicated and retested five of the shear link specimens tested by Arce (2002). Arce observed all five of these specimens to fail prematurely due to fracture of the link web. Ryu et al. used the same test setup and same testing procedures as Arce, except that the AISC loading protocol used by Arce was replaced with the revised protocol by Richards and Uang (2003). The revised loading protocol allowed the specimen to achieve significantly greater rotation (with the same failure mode: fracture of the web). The revised protocol was developed based on more rational basis, and is considered to be more adequate to represent seismic demands than the AISC protocol. Therefore, the concern raised by Arce (2002) that shear links my not be capable of achieving the required rotation is now largely resolved.

Okazaki (2004) performed an experimental and analytical investigation of the seismic performance of various types of link-to-column connections for eccentrically braced frames. The main objectives of this research were the following; to evaluate the performance of linkto-column connections used prior to the Northridge earthquake, to test moment resisting frame connections developed after the Northridge earthquake as link-to-column connections, to investigate the stress and strain environment at link-to-column connections, to check whether it is possible to predict the performance of these connections with finite el- 
ement simulations and to provide recommended design guidelines for EBF link-to-column connections. He performed a total of sixteen large-scale cyclic loading tests . Using the setup shown in Figure 2.6, these tests included four different connection types with four different link lengths. Two different loading protocols were used, namely, the protocol from the AISC 2002 and the protocol developed by Richards and Uang (2003). The four connection types were pre-Northridge, modified welding with access hole, free flange and no weld access hole connection. The pre-Northridge connection performed poorly and failed at nearly half of the target inelastic link rotation. Welding improvements were beneficial but not significant enough so that the link would reach the required rotation level. The free flange connections achieved considerably greater link rotations than the pre-Northridge connection, but still generally failed to reach the link rotation requirements. The results for the connection with no weld access hole depended strongly on the link length. Short links could achieve an inelastic rotation up to $49 \%$ greater than the target rotation, whereas longer links achieved an inelastic rotation of $17-37 \%$ less than the required target. The most common failure mode in these connections was fracture of the link fange initiating near the groove weld which connects the link to the column fange. The connection details that achieved desired ductilities in beam-to-column moment connections in MRFs were found to generally lack the desired ductility of EBF link-to-column connections. The local stresses and strains at link-to-column connection in EBFs are more severe than those in moment resisting connections. Detailed finite element analysis results for the stress and strain concentration correlated well to the fracture behavior of the specimens during testing. Generally, the fracture of the link flange near the groove weld was predicted by the analytical model. These results show that finite element simulation can be used to predict connection behavior even at the highly localized levels. Okazaki concluded that link-to-column connections should be avoided because of their limited ductility resulting from flange fracture which was found to be a major concern for links of all practical lengths.

\subsection{Structural Fuse Concept}

The LCF can be thought of as a system with a structural fuse (passive energy dissipation metallic dampers (PEDMD)), i.e. the link, which dissipates energy through inelastic defor- 


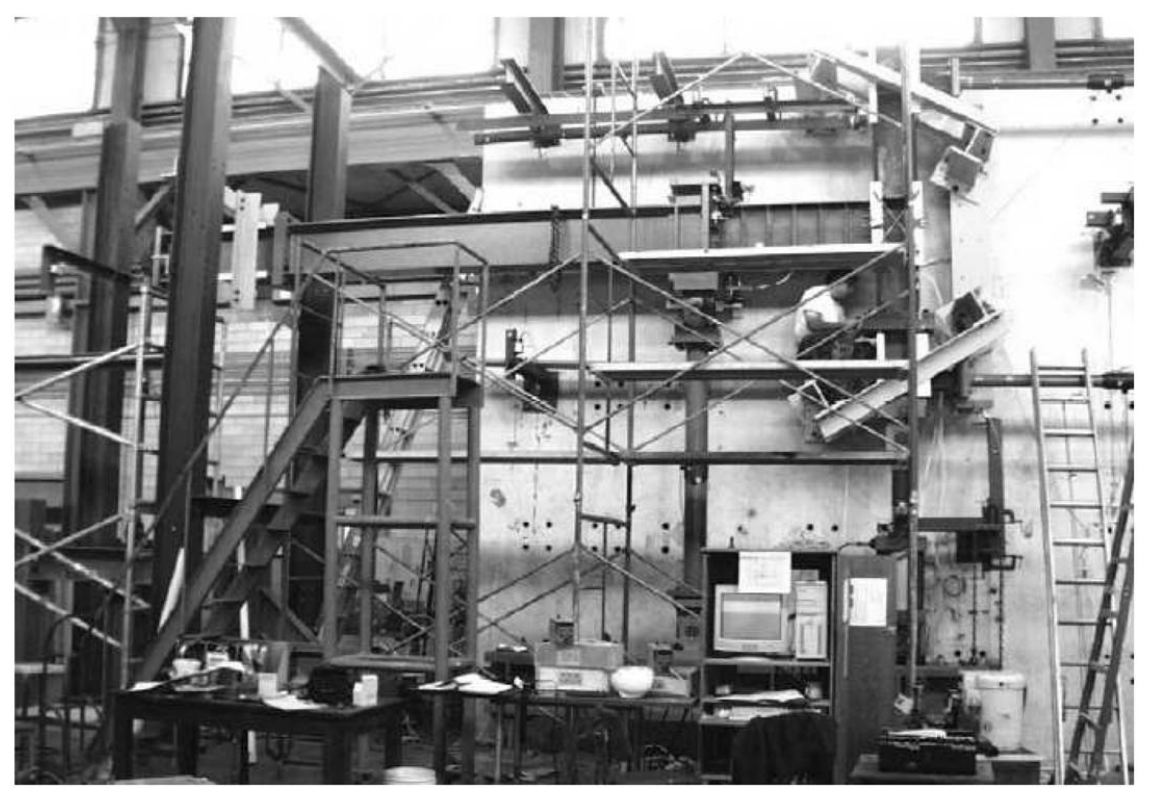

Figure 2.6: Details of the loading system (Okazaki 2004)

mation and limits the forces in the surrounding element. Here the structural fuse concept is briefly described along with references to other fuse concepts. PEDMD dissipate energy thorough hysteretic behavior and the amount of damping they provide is proportional to the magnitude of their plastic deformation. PEDMD are introduced as structural fuses such that all damage is concentrated on the PED devices (disposable and easy to repair structural elements), allowing the main structure to sustain only minor elastic deformations. The two main benefits are; first, following an earthquake only the dampers need to be replaced, making repairs/replace work easier and quicker (rapid return to occupancy or rapid repair) and second, self-recentering can be gained by removing the damaged ductile fuse, the main structure that remains elastic returns to its original place.

The "ductile fuse" concept has not been consistently defined in the past. Roeder and Popov (1977) introduced the eccentrically braced frame concept and the link in this system was called a ductile fuse because it was designed to dissipate energy via inelastic deformation. Fintel and Ghosh (1981) used the term structural fuse for the beam in moment resisting frames designed with strong columns and weak beams. However while these "fuses" have 
been introduced as components of the overall system that have well defined plastic yielding locations and help control the seismic behavior of the structures, they are not truly replaceable as a fuse (the fuse is a segment of main structures) and the cost of repairs can be significant. In other cases, some of which are reviewed here, structural fuses were used in a separate component from the primary structure and case of repair was considered (damage-controlled structures).

In systems where damage caused by the earthquake is concentrated within specific members that can be readily repaired, the primary structure can be protected from damage and can remain continuously used. Connor and Wada (1997) employed two independent structural systems: 1- a primary system that supports gravity loading and also provides some lateral stiffness; and 2- a bracing system that functions as the energy dissipation mechanism for lateral loading (Figure 2.7). Connor et al. (1997), demonstrated that in larger earthquakes the damage-controlled structures had decreased cost of repair related to conventional systems.

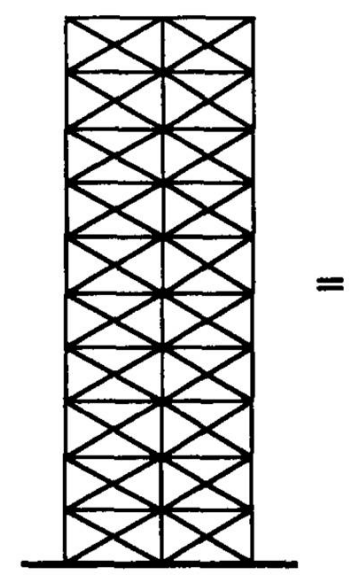

(a)

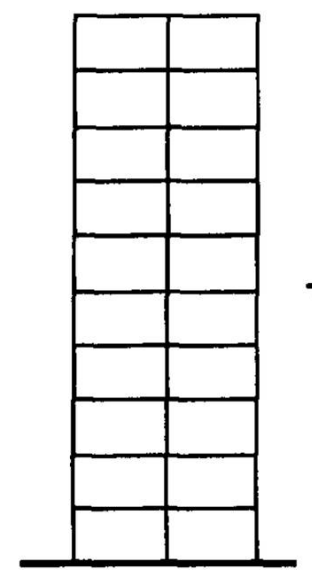

(b)

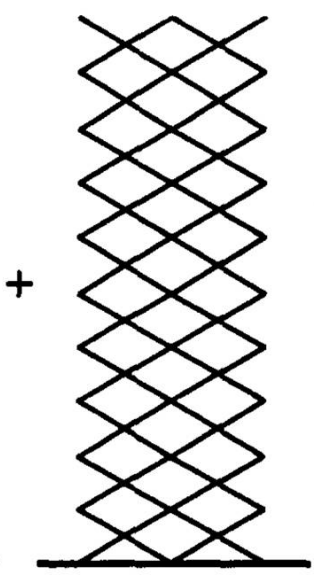

(c)

Figure 2.7: Concept of Damage-Controlled Structure: (a) Actual Structure; (b) Primary Structure (Gravity Structure); (c) Brace System (Seismic-Resistant Structure) (Connor et al., 1997)

One example of the use of primary structural system with elements added to dissipate seismic energy is the use of buckling-restrained braces (BRBs) (Figure 2.8) in Japan. Where 
in the United States BRBs are typically part of the primary structural system and only lateral load resisting elements are present when they are employed, in Japan BRBs are commonly employed within a primary moment resisting frame and are designed to control drift through hysteretic energy dissipation. Saeki et al. (1996), Iwata et al. (2000) and Sabelli et al. (2003) investigated the performance of BRBs system, and demonstrated the expected behavior of the basic structural framework remain elastic and all of the seismic damage occurs within the braces.
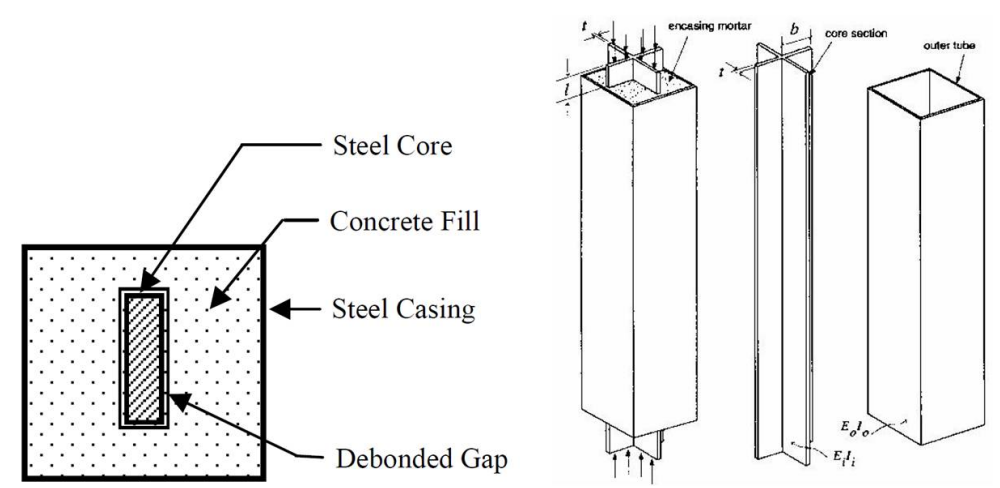

Figure 2.8: Schematic Details Used For Buckling Restrained Braces (Black et al., 2004)

Triangular added damping and stiffness (T-ADAS) devices are another example where secondary steel yielding elements are included for energy dissipation. As shown in Figure 2.9 a T-ADAS consists of triangular plates that, configured between braces and a story beam, can sustain a large number of yield reversals without strength degradation, thereby dissipating a significant amount of earthquake energy. T-ADAS was first used exclusively in nuclear installation by Kelly et al. (1972), and Whittaker et al. (1989) performed shake table tests with them in a 3-story building. Tsai et al (1993) proposed design procedure for T-ADAS system and compared their analytical characteristics with experimental results. Other studies such as Tena-Colunga (1997) and Alehashem et al. (2008) have investigated the mechanism and performance of T-ADAS devices and the performance of the systems that employ them.

A final example of a steel element employed to provide energy dissipation is the shear panel (SP) as shown in Figure 2.10. Nakashima (1995) proposed two analytical models 

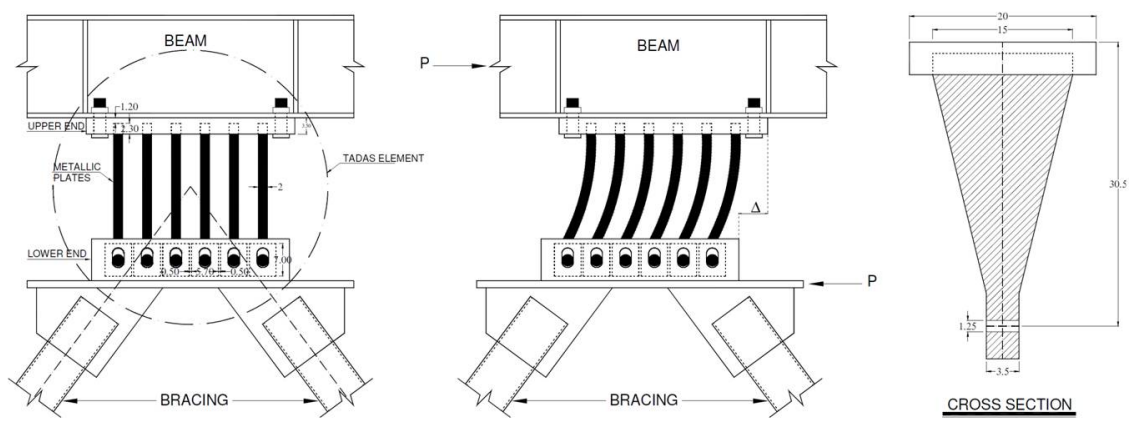

Figure 2.9: The Behavior of ADAS Damper During Earthquake (Alehashem et al., 2008)

of SPs. His models were well matched with the experimental result and enable prediction of the strain hardening behavior and stiffness degradation of the dampers. Tanaka et al (2000) verified the hysteretic performances of the damper of shear panel type with ultra low-yield- strength steel under static loading through cyclic loading tests. The hysteretic performances of the damper, maximum strength, allowable deformation and hysteretic rule are discussed and estimation formulae for the performances that contain the generalized width-thickness ratios are empirically obtained from the test results. Tsai et al. (2001) presented the results of analytical and experimental investigation on the effects of applying the shear panels, made from the low and high strength steels. His work showed shear panels possess significant energy dissipation characteristics, thereby reducing the inelastic deformation demand imposed on the beam-to-column connection in conventional moment frame. Chen et al. (2003) conducted cyclic analyses on different series of stiffened steal shear panel and investigated the hysteretic performance of the system focused on web buckling.Ge et al. (2008) investigated the deformation capacity of shear panel dampers and compared the results of a numerical analysis on developing high-performance stiffened steel shear panel dampers under cyclic shear with the experiment (Koike et al., 2008). It has been shown that the cyclic behavior and capacity of the SPDs with $\mathrm{Rw}$ below 0.20 can be predicted using the present analytical models with a good degree of accuracy. 


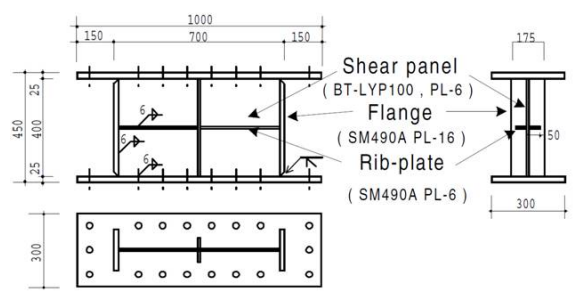

(a) Panel damper

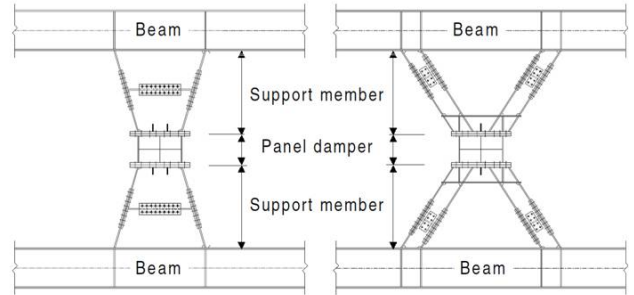

(b) Pillar type

(c) Bracing type

Figure 2.10: Example of Practically Applied Panel Damper and Its Arrangements in the Frame (Tanaka et al., 2000)

\subsection{Replaceable Links in Long-Span Bridges}

Replaceable links included for both stiffness and energy dissipation have recently been employed in the tower of long-span bridges. Some of the examples are the towers of RichmondSan Rafael bridge and the tower of the new East Spans of the San Francisco Oakland Bay Bridge. Shear links are used between the tower shafts and are designed to yield in the event of a major earthquake, to control drift and protect the tower and also incorporated details such that they may be replaced afterward if necessary.

The tower of the Richmond San Rafael bridges utilizes built-up shear links as part of the eccentric braced towers. The dimensions of these links are beyond the existing data of rolled shape link. Itani (1997) conducted two full scale experiments on the built-up shear links under severe cyclic deformation to determine their ultimate strength, plastic rotation, and failure mode. Figure 2.11 shows the test-up that was used for this investigation. The results of these experiments showed the over-strength factor for these links exceed 2.1 and their plastic rotation is $10 \%$ radians and that indicates significant ductile behavior since flange local buckling can be delayed until significant plastic rotation is achieved. The ultimate strength of the two tested links exceeded the code specified value by almost $31 \%$.

Nader et al.(2002) studied three alternative bridge configurations for retrofitting the new East Spans of the San Francisco Oakland Bay Bridge, each consisting of either single tower, dual portal towers or three-legged towers all having replaceable shear links connecting the main tower shafts. Each of these design alternatives was evaluated based on its seismic re- 


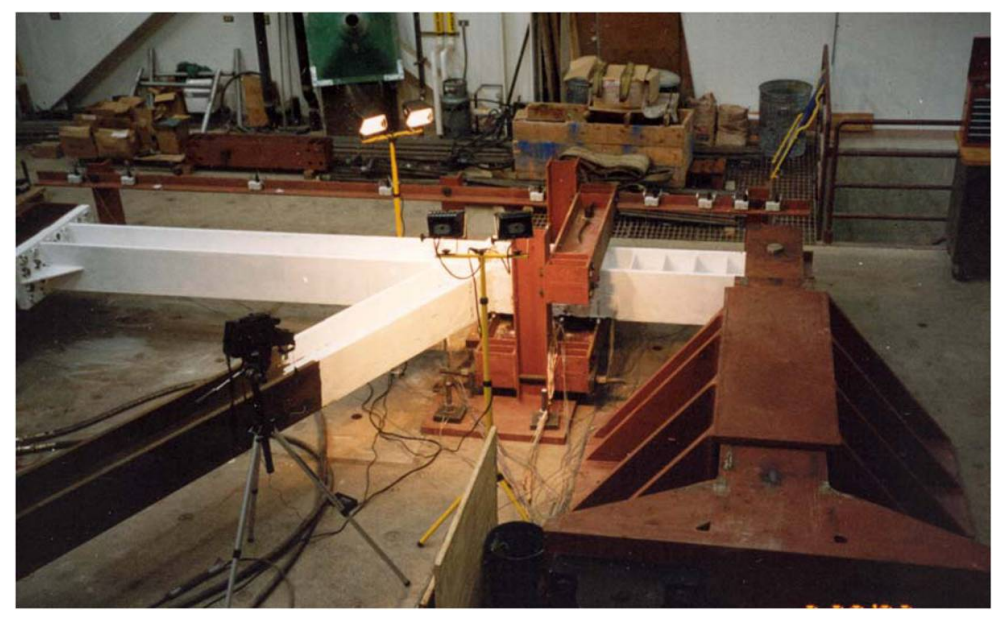

Figure 2.11: View of the test set-up used for Shear Link Experiments (Itani (1997))

sponse, construction cost and aesthetics. After evaluation of each system based on dynamic analysis, pushover analysis and various parametric studies to evaluate the lateral resisting system, a single tower as part of an asymmetric self-anchored suspension bridge was selected ((Figure 2.12)).

To provide a seismically reliable design, the selected alternative included: (1) shear links between the tower shafts which would yield in the event of a major earthquake; and may be replaced afterward if necessary (2) a floating deck isolated from the tower; and (3) a tie down / counter weight at the west pier to insure stability after the pier yields. They modeled the four tower shafts with elastic beam-column elements (Figure 2.13) and the shear link between the main tower shafts with inelastic moment-curvature beam elements. The inelastic beam element behavior was calibrated using results from a detailed local model where the yield moment of the inelastic beam elements were set to obtain the corresponding shear capacity of the shear link for the same yield vertical displacement. The rotation of the beam plastic hinges served as a measure of the shear deformations of the links.

Nader et al.(2002) showed the bridge was designed to provide a high level of seismic performance and to have a clearly defined plastic mechanism as shown in Figure 2.14 where the structure remains largely elastic with the exception of the east and west piers, and the tower shear links, which are designed to undergo inelastic deformation. The results show the 


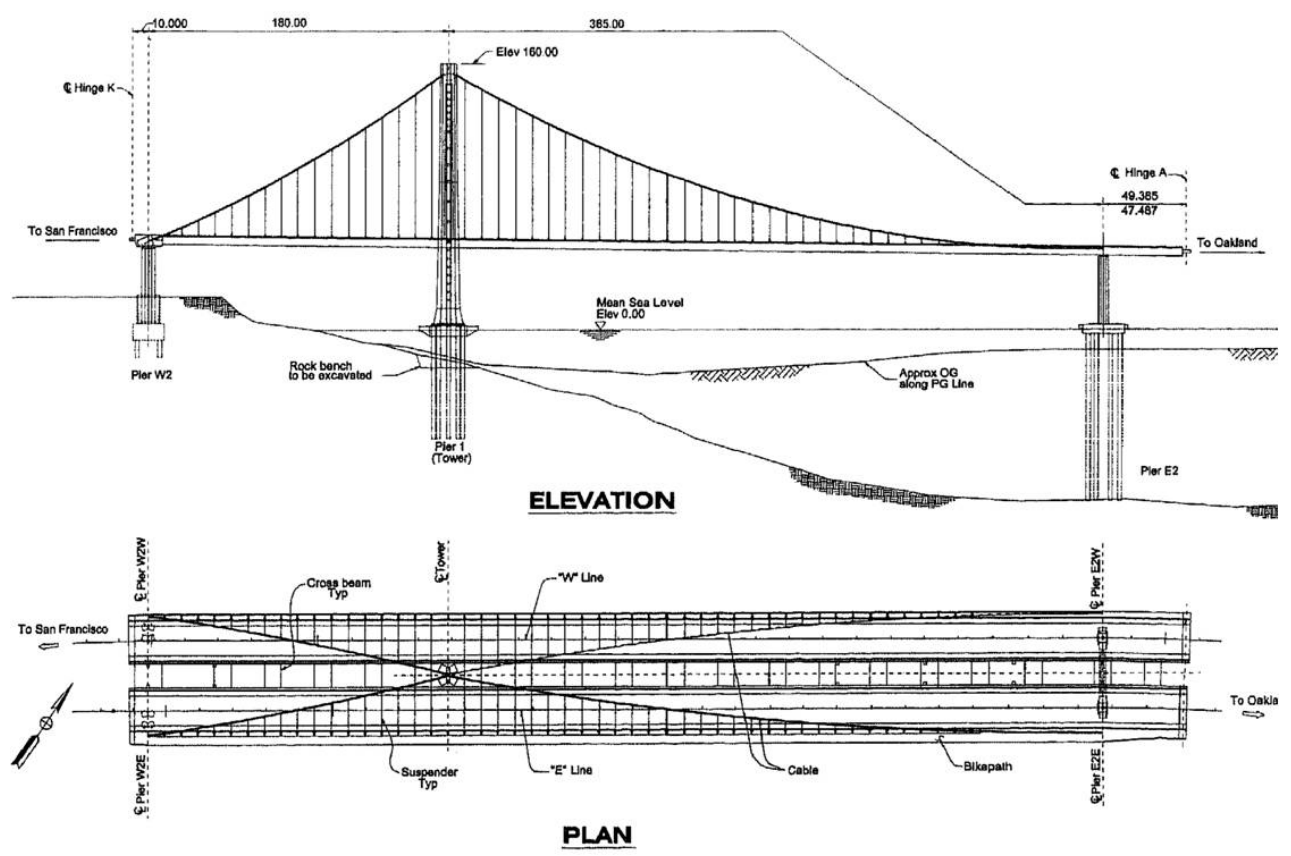

Figure 2.12: Elavetion and Plan of the Self Anchored Suspension Bridge (Nader et al.2002)

bridge provides full service almost immediately after an earthquake and sustains repairable damage.

The maximum shear link plastic rotation demand was found to be 0.05 radians compared with a maximum allowable plastic rotation of 0.08 radians. Figure 2.15 shows results of a longitudinal pushover analysis of the tower that indicates it has a stable behavior for displacements much larger than safety evaluation earthquake (SEE) displacement demand.

Goodyear and Sun (2003) described the preliminary design process for a state-of-theart single tower, cable-stayed solution for the signature span of the San Francisco-Oakland Bay Bridge East Span Seismic Safety Project. They described the shear links as sacrificial elements to dissipate earthquake energy by yielding in shear. At the functional evaluation earthquake (FEE), the links behave essentially elastically, adding significant stiffness to the towers to control displacement demands. At safety evaluation earthquake (SEE) events the shear links undergo significant shear yielding with higher shear ductility demands thereby limiting damage to the tower shafts while concrete columns remain elastic. The damaged 


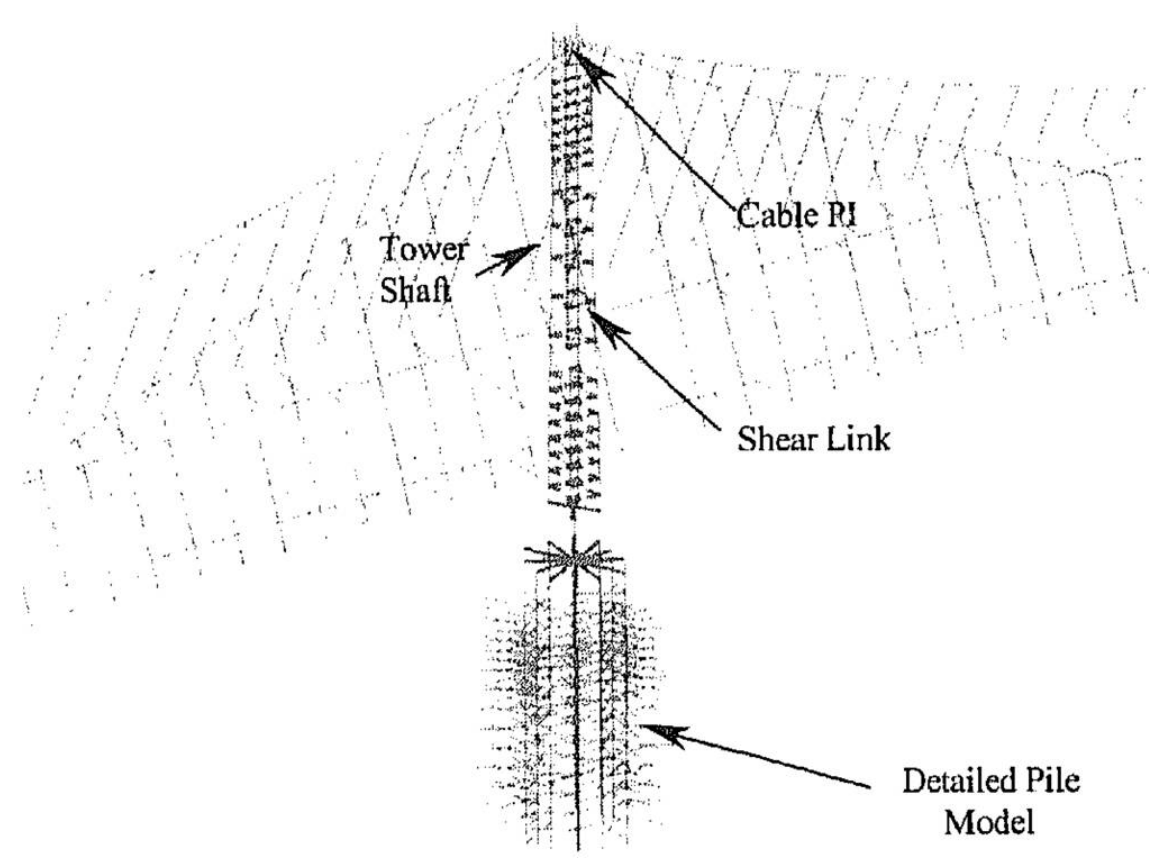

Figure 2.13: Main Tower Model Bridge (Nader et al. 2002)

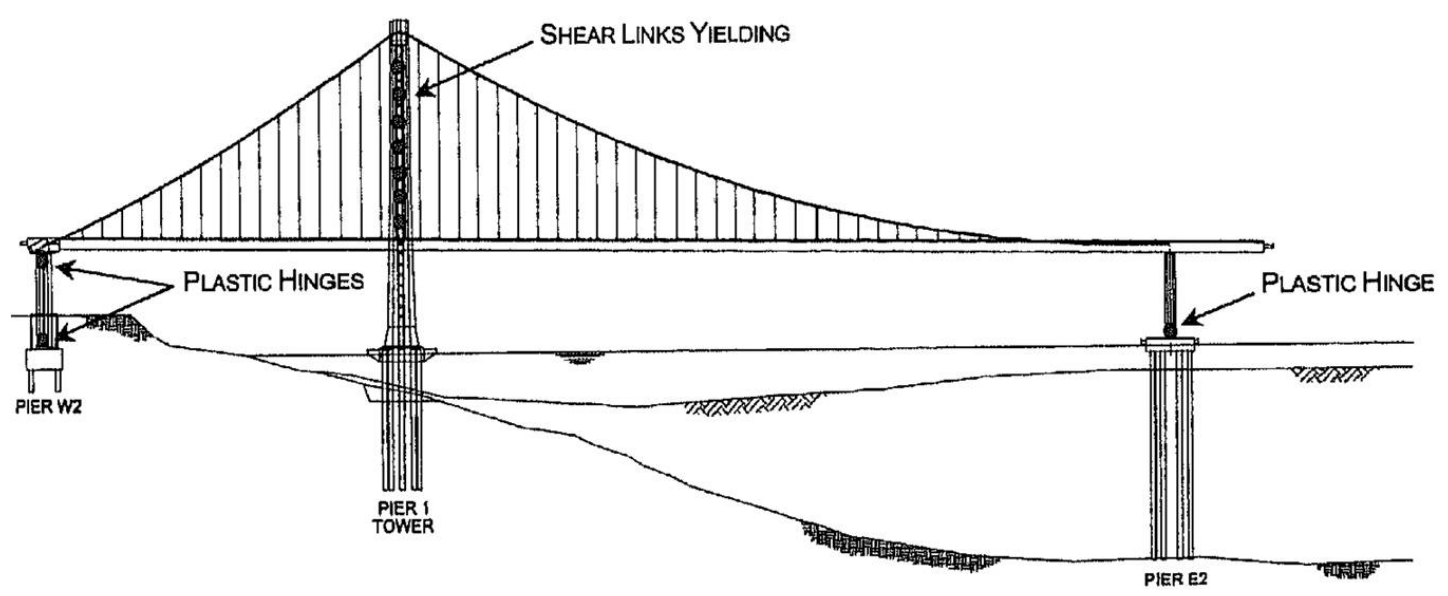

Figure 2.14: Seismic Displacement Demands (Nader et al. 2002)

links can be replaced after the event. To facilitate replacement, the links are connected to the tower with bolted connections. The resulting structural system improves performance and maintainability over traditional solutions, and provides a new method in bridge design for cable-stayed structures. Behavior of this system is described in Figure 2.16. 


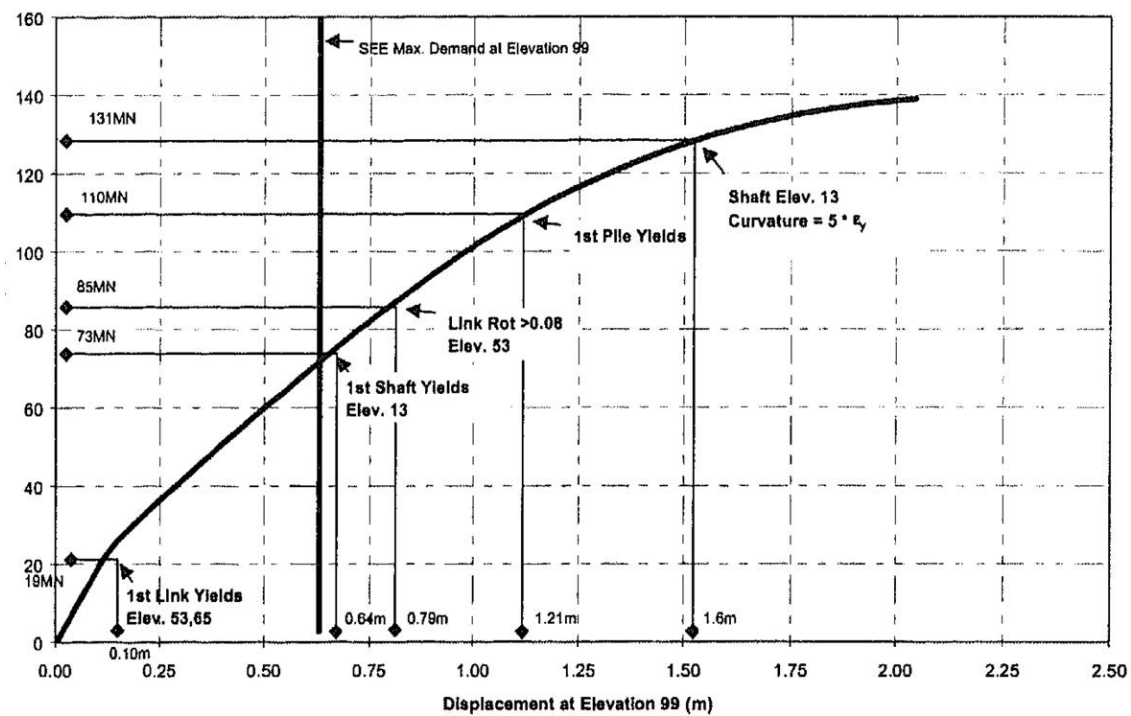

Figure 2.15: Pushover Analysis of the Single Tower (Nader et al. 2002)

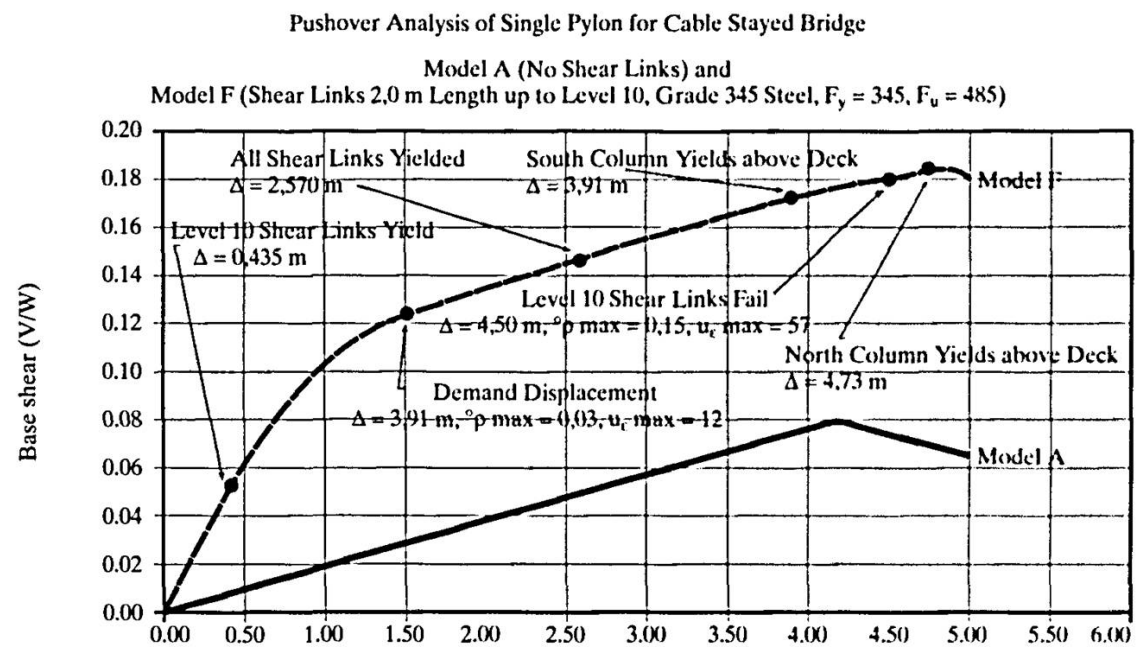

Figure 2.16: Lateral Load Displacement Ductility (Goodyear and Sun 2003)

\subsection{The Linked Column Frame System}

Dusicka and Iwai (2007) introduced link column frame system (LCF), a structural steel framing system free of diagonal bracing and intended to provide rapid return to occupancy following an earthquake. The LCF system is inspired by EBFs, and the bridge towers de- 
scribed previously. Dusicka and Iwai (2007) developed 3-story linked column frames for the building layout used by the SAC research project (FEMA-353, 2000). Each frame considered had different column base fixidity as shown in Figure 2.17. As shown in Figure 2.18, they compared the global pushover results for these models with the pushover results of a special moment resisting frame (SMRF) building developed as part of the SAC project as a post-Northridge design.

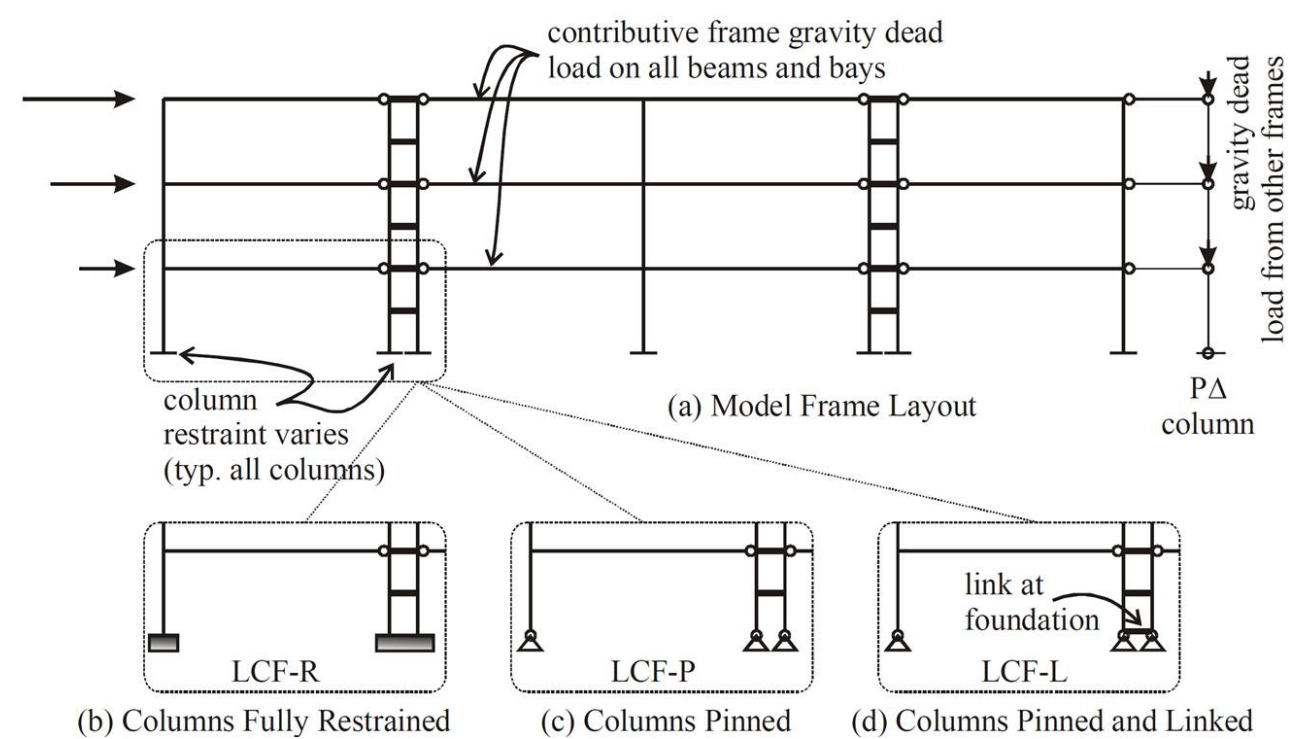

Figure 2.17: Numerical Model Layout with Different Column Boundary (Dusicka and Iwai 2007)

As shown, all LCFs had an elastic stiffness that was higher than the moment frame. Further, in all LCF's, columns were protected from yielding. Due to low stiffness of SMRFs its designs is controlled by satisfying maximum story drift requirements, resulting in the use of deep beams and columns. However the larger stiffness of LCF makes it possible to reduce the structural sections and the corresponding steel weight for the frame.The work described herein builds on this initial study of the LCF system.

The LCF system requires replaceable links and connections for these links that are effectively capable of providing sufficient inelastic deformation and ductility, as well as the ability to withstand the inelastic shear and moment demands of the link. The feasibility of 


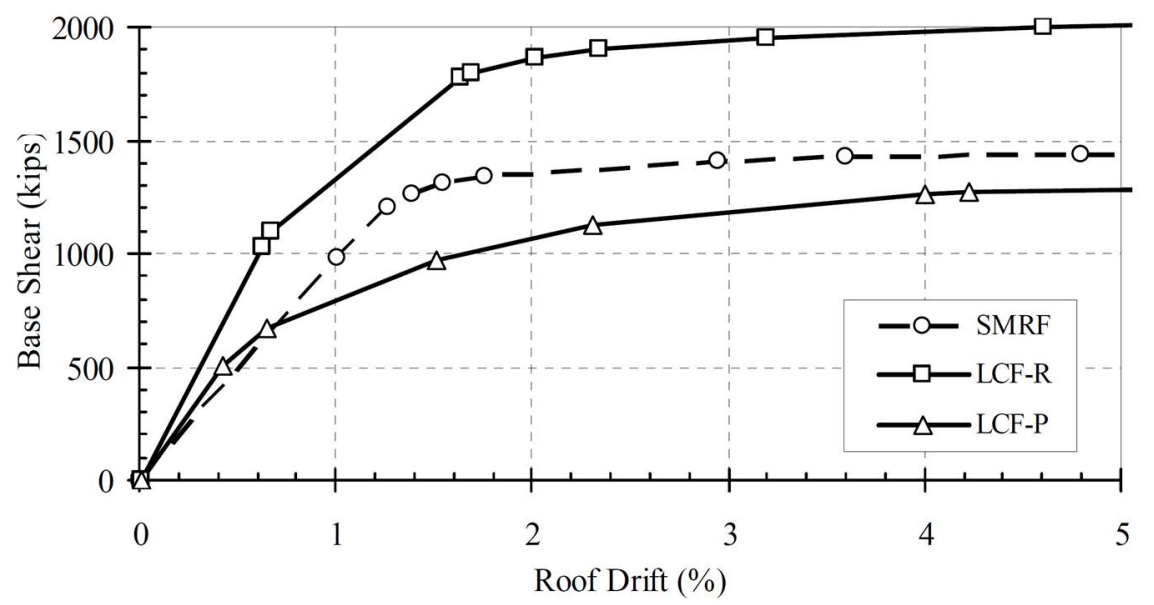

Figure 2.18: Pusheover Response of LCF in Comparison with SMRF (Dusicka and Iwai 2007)

links for use in the LCF utilizing end plate bolted connections was investigated analytically and experimentally by Dusicka and Lewis (2010). To improve the link performance they proposed a new method for stiffening the links using stiffeners parallel to the web near the end-plate connections. Their tests indicate that using this method improves the links' behavior by shifting the localized plastic strain demand away from the location of the flangeto-end plate welds for both shear and flexural links. More details on these new connection details are discussed in the next chapter.

\subsection{Summary}

The LCF system is a new earthquake resisting system that is adopted from EBFs system, in which seismic energy is dissipated primarily by inelastic action in the links prior to yielding of the MRF system, combined with a moment resisting frame system as a secondary seismic/gravity system. Also the LCF system uses the structural fuse concept in order to concentrate damage just in the links (easy to repair), allowing the MRF (gravity load carrying members) to sustain only minor elastic deformations under certain magnitude of earthquake. Most of the research on link behavior shows that by employing shear links, larger rotation capacity can be expected in comparison with flexural or intermediate links. 
This chapter discussed previous research on MRF, EBF, structural fuse concept and notably focused on the research of link behavior. 
Chapter 3

\section{LINKED COLUMN FRAME SYSTEM DESCRIPTION}

As shown in Figure 3.1 and described previously in Dusicka and Iwai (2007), the proposed LCF system consists of two components that work essentially in parallel to provide the desired seismic response. The primary lateral force resisting system, denoted the linked column (LC), is made up of two closely spaced columns connected with replaceable link beams. The secondary lateral force resisting system is a moment resisting frame (MF) that also acts as part of the gravity load system. The moment resisting frame is designed to be relatively flexible by utilizing beams with fully restrained connections at one end and simple connections at the other.

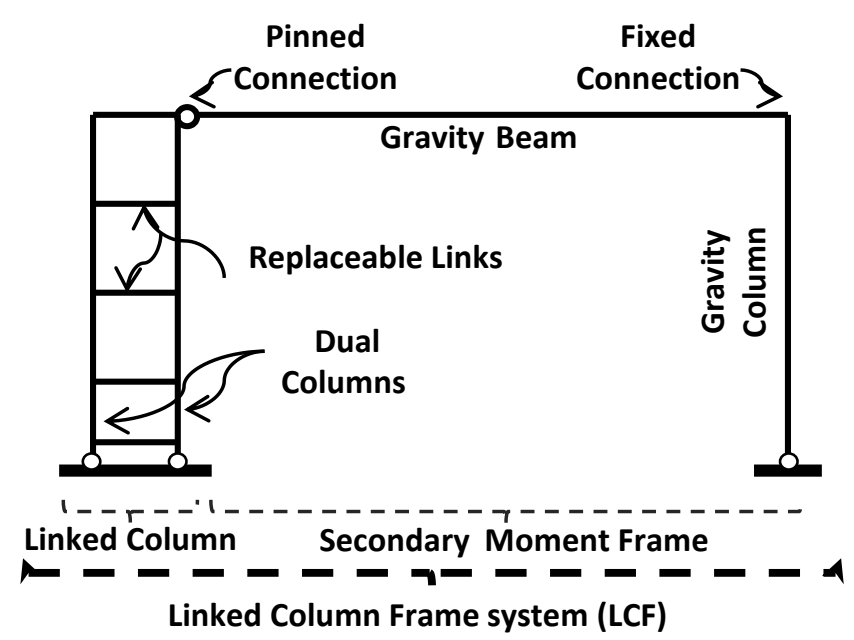

Figure 3.1: Plane Frame Elevation of a Building Bay with the Linked Column Frame System 
The pushover response of an idealized LCF system and the contribution of its components, i.e., the moment frame and the linked column, are shown in Figure 2. In this figure $\Delta_{Y L C}$ and $V_{Y L C}$ are the roof displacement and the base shear, respectively, corresponding to the development of the first plastic hinge in a link (this maybe a shear or flexural hinge depending on the link type). Similarly, $\Delta_{Y M F}$ and $V_{Y M F}$ represent the roof displacement and base shear corresponding to the development of the first plastic hinge in a MF beam. Finally, $\Delta_{Y L C F}$ and $V_{Y L C F}$ are the roof displacement and base shear of the LCF system at formation of the first link plastic hinge and $\Delta_{P L C F}$ and $V_{P L C F}$ are the roof displacement and base shear of the LCF system at formation of the first beam plastic hinge. When the response is idealized as that of two parallel systems, the displacements $\Delta_{Y L C}$ and $\Delta_{Y L C F}$ are equal, and $\Delta_{Y M F}$ and $\Delta_{P L C F}$ are equal, as shown in Figure 2. However, it should be noted that in taller LCFs there are interactions that are not accounted for in such an idealization.

In the proposed system, the links are designed to act as the yielding elements and provide a stable source of energy dissipation until large drifts are reached and plastic hinging occurs in the MF beam as well. If a link is placed at the bottom of the LC as shown in Figure 3.1. all columns are allowed to rotate at the foundation level, and if all columns are capacity designed, plastic hinging of the columns can be avoided. Thus, if in a given seismic event the MF stays in the elastic range, its stiffness may help the building re-center allowing a rapid repair to be achieved if the links are easily replaced. Further, in a larger seismic event both the links and beams of the MF may yield, enabling the system to have adequate ductility and energy dissipation to achieve collapse prevention. These two performance states, rapid repair and collapse prevention, are shown in Figure 3.2.

This figure make the simplifying assumption that development of plastic hinges in links or beams will result in damage requiring repair. This assumption is conservative for design but could be improved by incorporating seismic fragility data for these components for more severe damage states such as local buckling or fracture. However, that is beyond the scope of this research and is the subject of future investigation.

Additionally, it should be noted that non-structural and floor slab damage is not considered here; however, proper design of non-structural systems and floor systems would be 


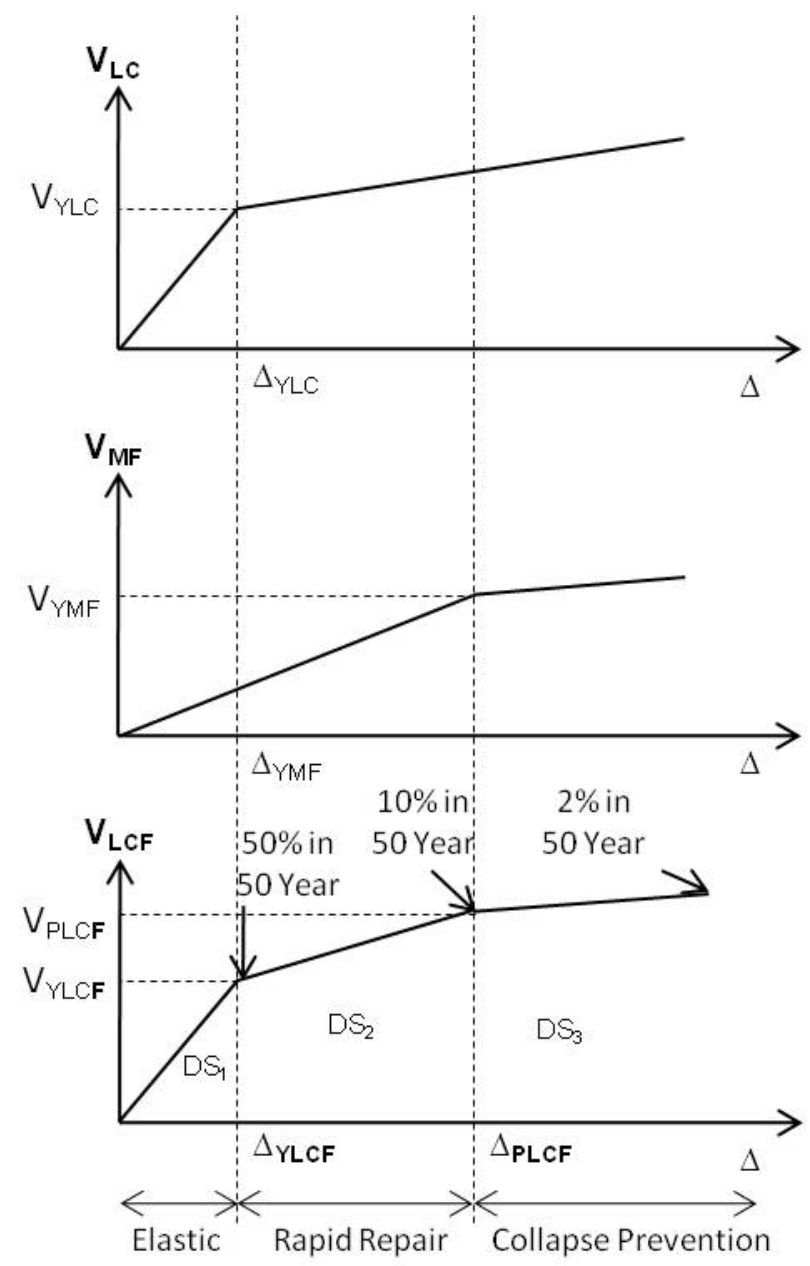

Figure 3.2: Idealized LCF and component Pushover Curves.

necessary to fully achieve rapid repair. Finally, to ensure the ease of link replacement, the LCF frames should ideally be located in accessible areas such as the building perimeter.

To ensure the links have adequate ductility and are easily replaceable, parallel research has developed details for the link-to-column connections similar to that shown in Figure 3.3 (Dusicka and Lewis, 2010).

That research, which has consisted of full-scale experiments and detailed finite element modeling, has developed welded end-plate details with stiffeners at the link ends that are parallel to the beam web and welded to the end plate and link flanges as shown in Figure 3.3 . 


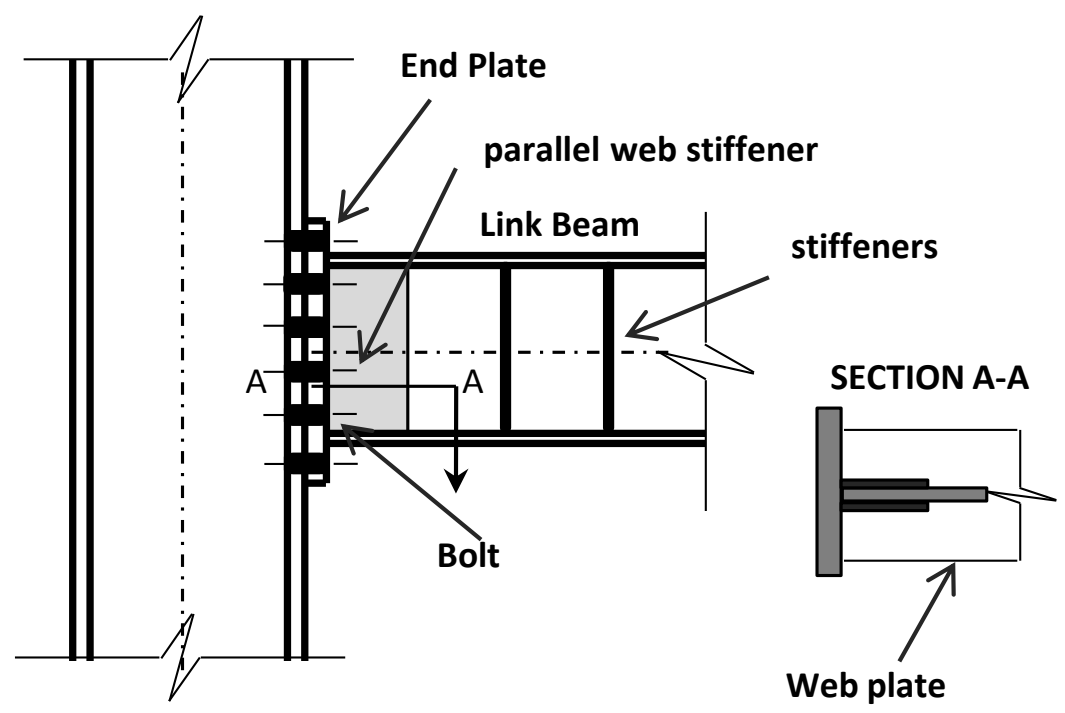

Figure 3.3: Link-to-Column Connection Detail with Bolted End-Plate and Parallel Web Stiffeners (adapted from Dusicka and Lewis (2010)).

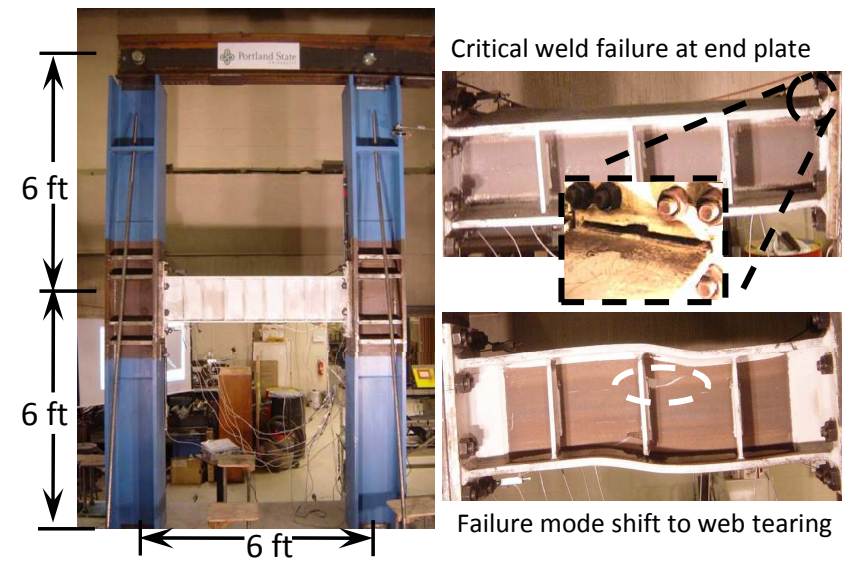

Figure 3.4: Test Set-Up and Link Failure Modes for Bolted End Plate Links with and without Parallel Web Stiffeners (Dusicka and Lewis, 2010).

Fillet welds are used for connecting the links and stiffeners to the end-plates. The end-plates can then be bolted to the columns ensuring relatively easy link replaceability. As shown 
in Dusicka and Lewis (2010), links utilizing these details have achieved large rotations in full-scale experiments, with flexural link achieving rotations of 0.07 rads and shear links achieving rotations of 0.10 rads. The parallel web stiffeners effectively reduce the flange and web strains at the link ends, preventing failure of the end-plate welds and ensuring yielding of the webs and flanges away from the end-plates. For comparison, similar links were tested with welded end-plates but lacking the parallel web stiffeners and achieved rotations of 0.04 rads and 0.055 rads before failure of the end-plate weld for flexural and shear links respectively. This demonstrates the effectiveness of adding the parallel web stiffeners and shifting the failure mode of the link (Figure 3.4 (Dusicka and Lewis, 2010)).

As described above and shown in Figure 3.2, plastic hinge formation in the MF beams is expected to happen at large drifts to help achieve collapse prevention performance in a large seismic event. However, it is desirable to have the MF be relatively flexible so that plastic hinge development in the beam can be avoided for seismic demand levels for which rapid repair is targeted. For steel moment resisting frames, story drift can be related to the beam rotation, $\theta_{b}$. For a beam fully restrained at each end (i.e. the case of rigid columns), $\theta_{b}$ may be calculated as $\frac{M L}{6 E I}$ and for a beam fully restrained at one end and pinned at the other, it may be calculated as:

$$
\theta_{b}=\frac{M L}{6 E I}
$$

where $E$ is Young's modulus, $I$ is moment of inertia, $L$ is the length of the beam and $M$ is the internal bending moment. By changing the boundary conditions of the beam from fully restrained at both ends to fully restrained at just one end of the beam and pinned at the other, the relationship between rotation and internal moment changes to:

$$
\theta_{b}=\frac{M L}{3 E I}
$$

Therefore, for the same span and plastic moment capacity $M_{p}$ of the beam, the rotation at development of $M_{p}$ essentially doubles when the boundary conditions are changed. To ensure that the onset of yielding in the beams occurs after significant link inelastic deformation, the beams in the LCF system are "pinned" at the connections to the LC as illustrated 


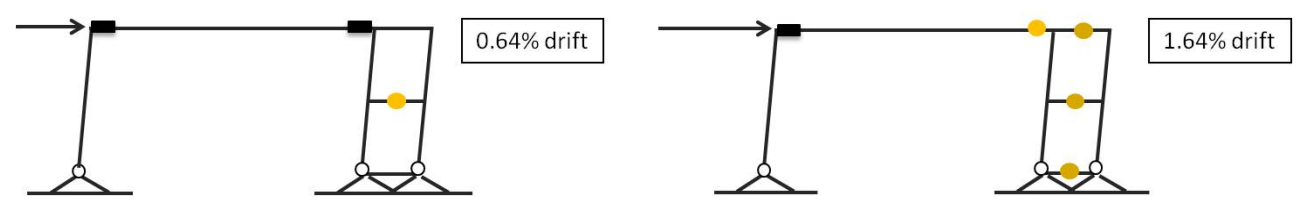

(a)

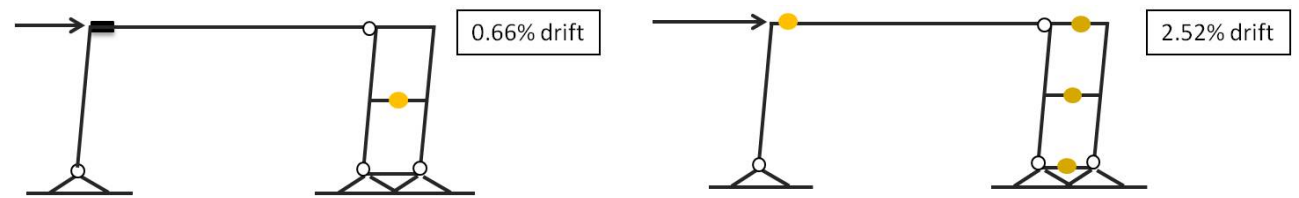

(b)

Figure 3.5: Pattern of Plastic Hinge Formation (a) MF with Beam Fully Restrained at Each End (b) MF with Beam Fully Restrained at One End and Pinned at the Other.

in Figure 3.1. Figure 3.5 shows the progression of hinge formation of the LCF systems with these two different boundary conditions for MF beam. As shown, link yielding begins approximately at the the same drift for both systems. However, beam yielding begins at a roof drift of $1.64 \%$ for fixed-fixed beam system, and at $2.52 \%$ drift for fixed-pinned beam system. The large difference between the story drifts at which the links and beams yield, in the second system, enables the structural designer to specifically design for the two different performance objectives of rapid repair and collapse prevention. It should be noted that the simple connections are typically ignored, with regards to lateral resistance of these structures, however, they have more lateral capacity than traditionally assumed. The simple connections contribution to LCF seismic response is addressed in later section.

Moreover, in order to prevent any column damage, all columns in the LCF system are pinned at the foundation while an additional link is added between the linked columns near the foundation to help control story drift demands at the bottom level (Dusicka and Iwai, 2007). This concept can be valid for low-rise LCFs and some mid-rise LCFs. For taller LCF, with very large axial force in the columns, the columns should be fully restrained at the foundation. In modeling the LCF system as discussed later, pinned column connections were assumed at the base to give conservative drift estimates. To investigate column rotation demands, fully restrained column base connections were also evaluated. 


\section{Chapter 4}

\section{DESIGN PROCEDURE}

The behavior of the LCF allows the system to be designed for a desired performance at a specific seismic hazard level. In this research, a specific pairing of performance and associated seismic hazard has been made that seems logical for certain applications. In practice, such decisions are the choice of the structural designer, owner and others involved in the design of a particular building. The objective of this research is to demonstrate the proposed system's capability of meeting particular performance objectives rather than advocating for particular sets of performance objectives at specific hazard level. Figure 4.1 shows base shear, $V_{L C F}$, versus roof displacement, $\Delta$, and identifies the base shear and roof displacement corresponding to the development of the first plastic hinge in a link, $V_{Y L C F}$ and $\Delta_{Y L C F}$, and corresponding to the development of the first plastic hinge in a MF beam, $V_{P L C F}$ and $\Delta_{P L C F}$. Figure 4.1 also displays the performance objectives used here, which include:

1. Immediate occupancy (IO) following an earthquake with a $50 \%$ probability of exceedance in 50 years (50\% in 50 year). This requires both the linked column and moment frame to remain elastic (Damage State $\left.1\left(D S_{1}\right)\right)$.

2. Rapid structural repair (RSR) following an earthquake with a $10 \%$ probability of exceedance in 50 years (10\% in 50 year) where the moment frame remains completely elastic but plastic hinges developed in the links, which may necessitate their repair or replacement (Damage State $\left.2\left(D S_{2}\right)\right)$.

3. Collapse prevention (CP) following an earthquake with a $2 \%$ probability of exceedance in 50 years ( $2 \%$ in 50 year) where significant yielding and plastification of the links and moment frame beams may occur (Damage State $3\left(D S_{3}\right)$ ). 


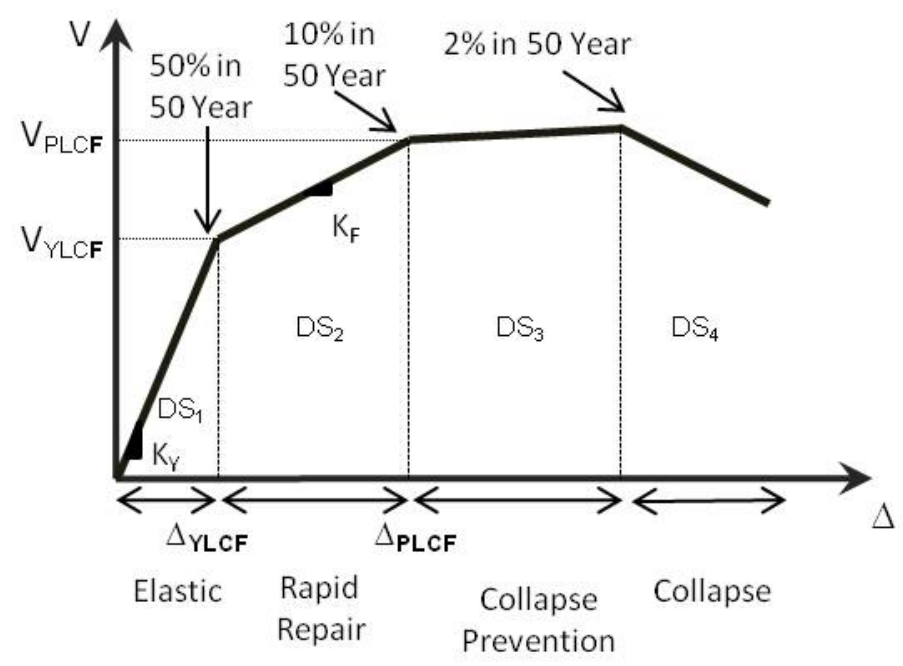

Figure 4.1: Damage States to Correlate Element Damage with Extent of Repair.

For the purposes of developing prototype LCF designs and evaluating their ability to achieve the performance objectives outlined above, two preliminary design procedures were developed. The first one is based on satisfying the drift requirements between linked column and moment frame. This preliminary procedure has key features that will be necessary in any future incarnations of the LCF design procedure. The second one is expected to produce designs that reflect differences in the seismic hazard at different return periods and will achieve the performance objectives across a wide range of seismic hazards associated with different hazard level and geographical locations. The preliminary procedures are as follows:

\subsection{Design Procedure Based on Story Drift Requirements}

1. Use standard practice, i.e., ASCE 7 (ASCE, 2005), to determine the design seismic loads and distributions for the building. In the prototype designs used in Chapters 5,6 , 7 and 8 the response modification factor, $R$, overstrength factor, $\Omega_{0}$, and displacement amplification factor, $C_{d}$, equal to those for eccentrically braced frames of 7,2 , and 4 respectively were used. In Chapter 9 , these values are determined using recent developed methods. 
2. Design the links and beams for the forces from elastic analysis of the system for the design base shear as calculated above. The links are designed similarly to links in eccentrically braced frames and their yielding behavior depends on their length and section properties. AISC Seismic Provisions (AISC, 2005b) divides links into three categories based on their link length, $e$, plastic shear capacity, $V_{p}$, and plastic moment capacity, $M_{p}$. $V_{p}$ and $M_{p}$, respectively, defined as follows:

$$
\begin{gathered}
V_{p}=0.6 F_{y}\left(d-2 t_{f}\right) t_{w} \\
M_{p}=F_{y} Z_{p}
\end{gathered}
$$

In the above equations, $F_{y}$ is the yield strength of the steel, $d$ is the link depth, $t_{w}$ is the web thickness, $t_{f}$ is the flange thickness, and $Z_{p}$ is the plastic modulus.

Shear links, which yield primarily in shear, have :

$$
e \leq 1.6 \frac{M_{p}}{V_{p}}
$$

flexural links, which yield primarily in flexure, have:

$$
e \geq 2.6 \frac{M_{p}}{V_{p}}
$$

and intermediate links, which may yield in a combination of shear and flexure, have:

$$
1.6 \frac{M_{p}}{V_{p}}<e<2.6 \frac{M_{p}}{V_{p}}
$$

In general yielding in shear is more desirable, since it involves uniform participation of the web panels along the entire length of the link. Flexural yielding restricts plastic deformation near the link ends, and consequently, leads to less ductile behavior. Because of strain hardening, shear-flexure interaction occurs over a wide range of link 
length. However, in the LCF system, the choice of link type depends on the building height and the desired moment frame to link strength ratio, as discussed in latter sections.

3. Capacity design all columns for simultaneous plastic hinge formation in all links and beams. Note that the axial load in the columns from link hinging is reduced by the shear at each ends of the beams.

4. Ensure that drift requirements are satisfied, which consists of two separate evaluations. First, the code-based drift limits are checked using elastic static analyses and the displacement amplification factor $C_{d}$. It should be noted that the LCF system may be drift controlled and all prototype LCF systems described below were found to be drift controlled. Second, the roof displacement at which the first plastic hinge develops in a beam of the moment frame, $\Delta_{Y M F}$, should be greater than the roof displacement at which the first plastic hinge develops in a link of the linked columns, $\Delta_{Y L C}$. In the prototype designs described below, the ratio of these displacements were within the range:

$$
1.2<\frac{\Delta_{Y M F}}{\Delta_{Y L C}}<3
$$

The effectiveness of this simple displacement constraint is evaluated below using the prototype designs and response history analysis. The $\Delta_{Y L C}$ and $\Delta_{Y M F}$ may be estimated via pushover analysis using common structural analysis software or by using separate plastic analyses of the linked columns and moment frames and their elastic stiffness.

5. Ensure that the columns satisfy capacity design requirements after any revision of link and beam sizes. 


\subsection{Design Procedure Based on Spectral Parameters}

A different, somewhat more refined design procedure is possible by generalizing design parameters of the LCF as functions of site specific spectral parameters like acceleration at certain periods. The goal is to relate the design parameters to spectral displacement at different hazard levels to ensure the achievement of multiple performance objectives, as discussed previously.

In the first design procedure, the key was to ensure the roof displacement, at which the first plastic hinge develops in a beam of the moment frame, $\Delta_{Y M F}$, is greater than the roof displacement at which the first plastic hinge develops in a link of the linked columns, $\Delta_{Y L C}$ by a fracture between 1.2 and 3.0. Here, using a similar concept, a design procedure is developed that relates $\Delta_{Y M F}$ to $S_{d 2 \% \text { in50year }}$ and $\Delta_{Y L C}$ to $S_{d 10 \% \text { in50year }}$ as shown in Figure 4.2 . $S_{d}$ is the site specific spectral displacement at different hazard levels and at the LCF's fundamental period. For this development the Capacity Spectrum concept will be used (Chopra and Goel, 1999) and (Lin et al., 2003).

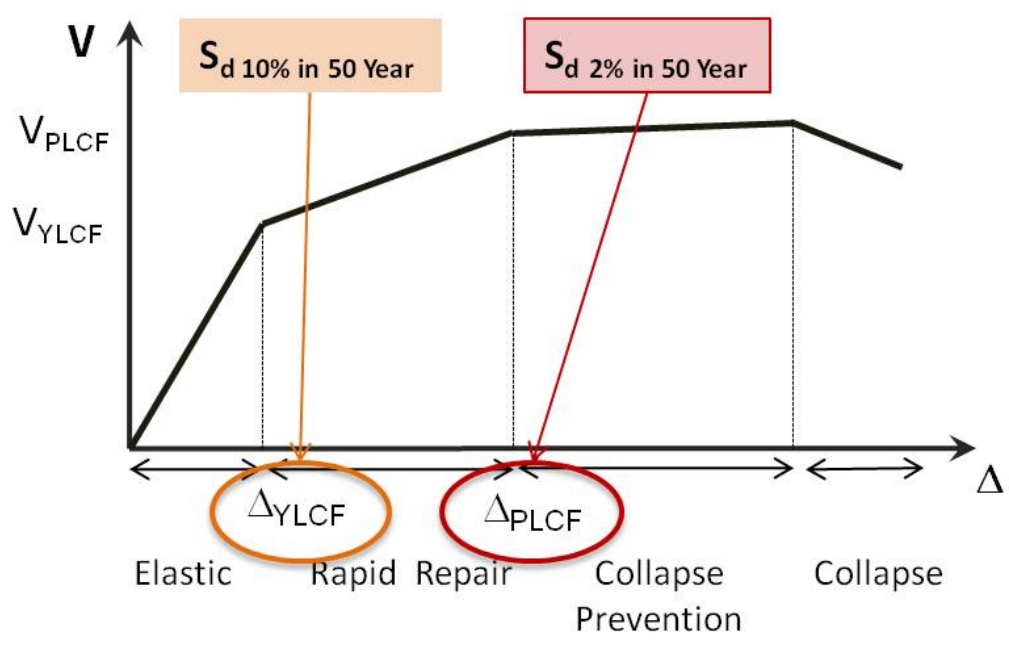

Figure 4.2: Idealized Pushover Curve for LCF. 


\subsubsection{Capacity Spectrum Method}

One appropriate approach to introduce nonlinear analysis into the seismic design methodology is a combination of the nonlinear static (pushover) analysis and the response spectrum approach. This method, named the capacity spectrum method, has been adopted by ATC-40 (1996) for evaluating nonlinear behavior and assessing the seismic vulnerability of buildings. The specific procedure compares the capacity of the structure in the form of a pushover curve (the resulting base shear versus roof displacement relationship) converted to equivalent spectral acceleration and spectral displacement, with demands on the structure in the form of an elastic response spectrum. The intersection of the two curves approximates the response of the structure and may estimate the performance of the structure.

Freeman (1998) introduced the procedure for this type of analysis; it can be summarized as follows:

1. Capacity Curve: calculate the capacity curve in terms of roof displacement, $\Delta_{R}$, and base shear, $V$.

2. Dynamic Characteristics: calculate modal vibrational characteristics such as periods of vibration, mode shapes, modal participation factors, and effective modal mass ratios. The conversion of the $V$ vs $\Delta_{R}$ capacity curve to the $S_{a}$ vs $S_{d}$ capacity spectrum can be accomplished by knowing the dynamic characteristics of the structure in terms of period $(T)$ mode shape $\left(\phi_{x}\right)$ and lumped floor mass $\left(m_{x}\right)$. A single degree of freedom (SDOF) system is used to represent a translational vibrational mode of the structure. This system has an effective mass equal to $\alpha M$, where $\alpha$ is the effective mass ratio and $M$ is the total mass of the structure. This system also has a roof participation factor $\left(P F \phi_{R}\right)$ that gives the ratio of the roof displacement $\left(\Delta_{R}\right)$ to the displacement of the mass $\left(S_{d}\right)$ of the SDOF system. The value of $\alpha$ can be calculated as follows:

$$
\alpha=\left(\Sigma m_{x} \phi_{x}\right)^{2} / \Sigma m_{x} \Sigma m_{x} \phi_{x}^{2}
$$

For most multi-story buildings this can be estimated as equal to 0.80 . Thus, $S_{a}=$ 
$V / \alpha M g$ can be estimated as:

$$
S_{a}=(V / W) / 0.80
$$

The value of $P F \phi_{R}=\left(\Sigma m \phi / \Sigma m \phi_{x}^{2}\right) \phi_{R}$. This can be estimated at 1.4, so:

$$
S_{d}=\Delta_{R} / 1.4
$$

3. Capacity Spectrum: Convert the $V$ vs $\Delta_{R}$ capacity curve to a $S_{a}$ vs $S_{d}$ capacity spectrum by use of dynamic characteristics.

4. Demand Curves - Response Spectra: The demand curve is represented by earthquake response spectra; typically, the 2 percent damped response spectrum that is generally used to represent the demand when the structure is responding linearly elastic.

5. Graphical Solution: When both the capacity spectrum and the demand response spectrum are defined with the same set of coordinates, they can be plotted together.

The Capacity Spectrum Method can be summarized as follows: If the capacity curve can extend through the envelope of the demand curve, the building survives the earthquake. The intersection of the capacity and appropriately damped demand curve represents the inelastic response of the structure. This method was utilized for evaluating LCF behavior and the new design procedure is based on this concept.

Figure 4.3 shows the Capacity Spectrum Method for the LCF3-SLC for two different hazard levels. The curve shows the median response spectra for the set of ground motions and a pushover curve, which is converted to equivalent spectral acceleration and spectral displacement. As shown, the intersection between the capacity spectrum and the response spectrum in Figure 4.3(b) for 2\% in 50 year events, is at a much larger spectral displacement than the intersection between the capacity spectrum and the response spectrum in Figure $4.3(\mathrm{a})$ for $10 \%$ in 50 year events. This difference shows the capability of the system 
to be designed for, and achieve, two seperate performance levels for different hazard level events.

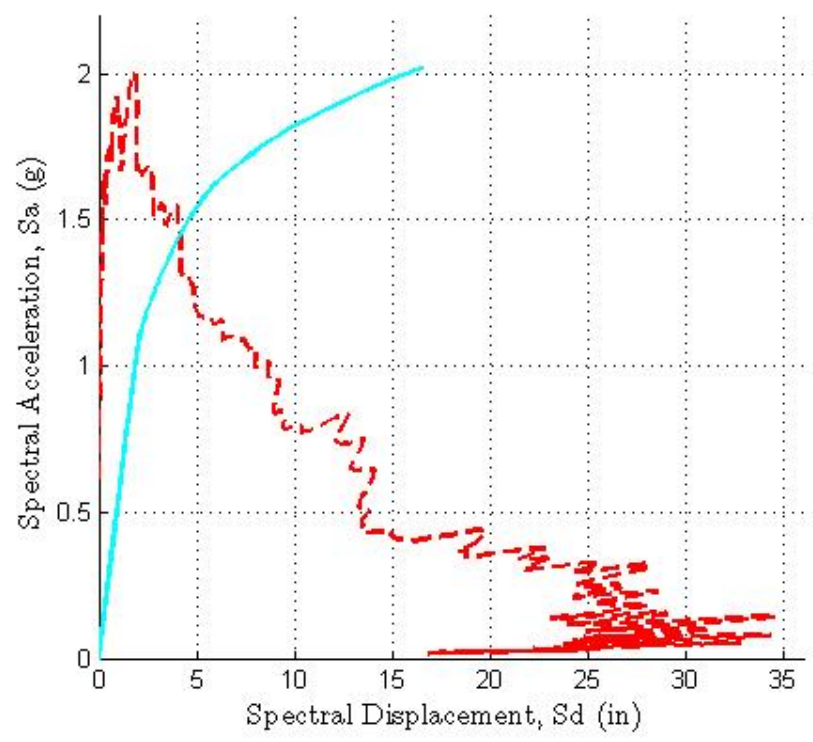

(a)

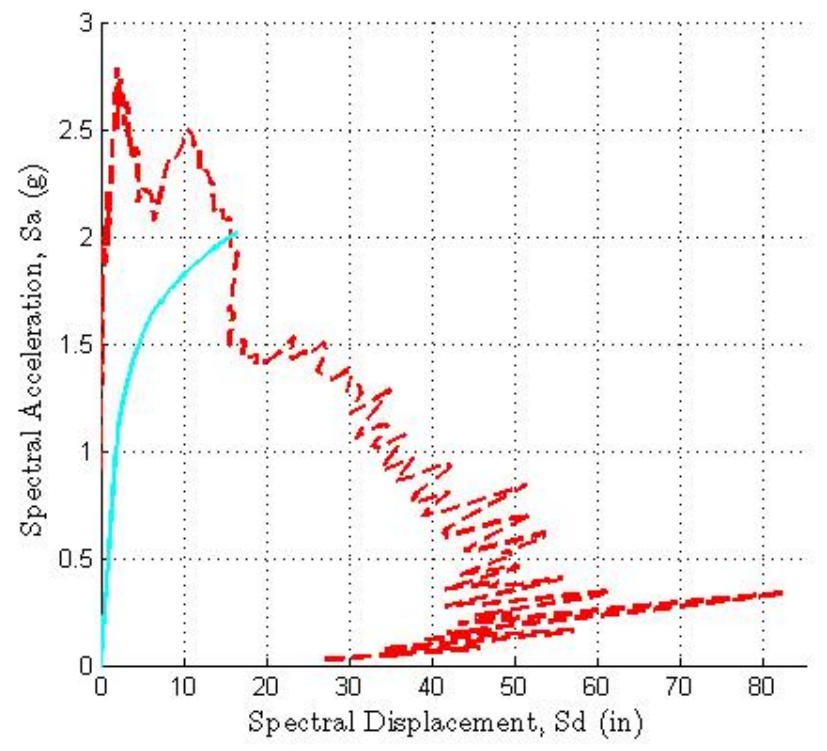

(b)

Figure 4.3: The Capacity Spectrum Method Applied on the LCF3-SLC. 
This concept leads to the new design procedure for LCF as outlined in following steps:

Step 1: As shown in Figure 3.2, for low and mid-rise LCFs the assumed idealized pushover response of LCF system and its components indicates the following equation:

$$
\frac{\Delta_{P L C F}}{\Delta_{Y L C F}}=\frac{\Delta_{Y M F}}{\Delta_{Y L C}}
$$

Step 2: By using Equation 4.8 and Equation 4.9 and as shown in Figure 4.4, the following equation can be obtained:

$$
\frac{\Delta_{P L C F}}{\Delta_{Y L C F}}=\frac{\Delta_{Y M F}}{\Delta_{Y L C}}=\frac{S_{d M F(2 \% i n 50)}}{S_{d L C(10 \% i n 50)}}=\frac{\frac{S_{a M F(2 \% i n 50)}}{K_{3}}}{\frac{S_{a L C(10 \% i n 50)}}{K_{1}}}
$$
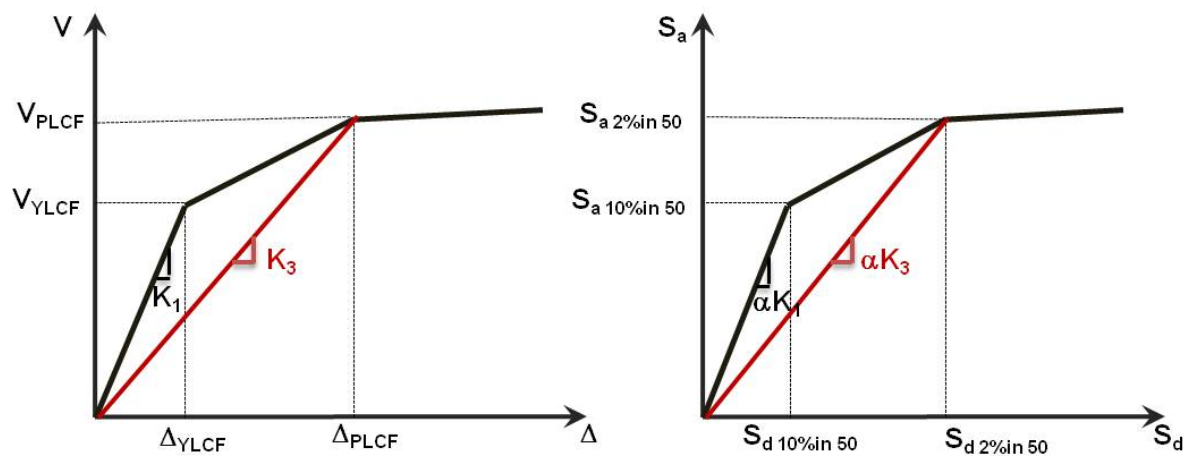

Figure 4.4: Idealized Pushover and Corresponding Capacity Spectrum Curve.

Step 3: The spectral response acceleration can be converted to the design response acceleration according to $S_{a}=\frac{S_{1}}{T}$, if the fundamental period of structure is between $T_{s}$ (short period) and $T_{L}$ (long-period transition period)(ASCE, 2005). The fundamental period for 3 , 6 and 9-story LCF is within this range. Plugging $S_{a}=\frac{S_{1}}{T}$ into the above equation produces the following results:

$$
\frac{\Delta_{P L C F}}{\Delta_{Y L C F}}=\frac{\frac{S_{a M F(2 \% i n 50)}}{K_{3}}}{\frac{S_{a L C(10 \% i n 50)}}{K_{1}}}=\frac{\frac{S_{1(2 \% i n 50)}}{T_{(2 \% i n 50)} K_{3}}}{\frac{S_{1(10 \% i n 50)}}{T_{(10 \% i n 50)} K_{1}}}
$$

Step 4: Also, the fundamental period of the structure can be found directly using: 


$$
T=2 \pi \sqrt{\frac{m}{K}}
$$

It is assumed that Equation 4.13 is valid for both the initial stiffness and to calculate an effective period when large displacement are present using $K_{3}$. Plugging Equation 4.13 into Equation 4.12 can create the following result:

$$
\frac{\Delta_{P L C F}}{\Delta_{Y L C F}}=\frac{\frac{S_{1(2 \% i n 50)}}{T_{(2 \% \text { in } 50) K_{3}}}}{\frac{S_{1}(10 \% \text { in } 50)}{T_{(10 \% i n 5)} K_{1}}}=\frac{K_{1}}{K_{3}} \frac{2 \pi \sqrt{\frac{m}{K_{(10 \% i n 50)}}}}{2 \pi \sqrt{\frac{m}{K_{(2 \% i n 50)}}}} \frac{S_{1(2 \% i n 50)}}{S_{1(10 \% i n 50)}}
$$

Step 5: By assuming $\alpha K_{3}=K_{(2 \% i n 50)}$ and $\alpha K_{1}=K_{(10 \% i n 50)}$ from Figure 4.4 , the above equation can be modified to:

$$
\frac{\Delta_{P L C F}}{\Delta_{Y L C F}}=\frac{K_{1}}{K_{3}} \frac{2 \pi \sqrt{\frac{m}{K_{(10 \% i n 50)}}}}{2 \pi \sqrt{\frac{m}{K_{(2 \% i n 50)}}}} \frac{S_{1(2 \% \text { in } 50)}}{S_{1(10 \% i n 50)}}=\sqrt{\frac{K_{1}}{K_{3}}} \frac{S_{1(2 \% \text { in } 50)}}{S_{1(10 \% i n 50)}}
$$

Step 6: As shown in Figure 4.4, $K_{3}=\frac{V_{P L C F}}{\triangle_{P L C F}}$ and $K_{1}=\frac{V_{Y L C F}}{\triangle_{Y L C F}}$. Plugging these into Equation 4.15, the general equation for design parameters as a function of site specific spectral parameters can be obtained:

$$
\sqrt{\frac{V_{P L C F} \Delta_{P L C F}}{V_{Y L C F} \Delta_{Y L C F}}} \geq \frac{S_{1(2 \% i n 50)}}{S_{1(10 \% i n 50)}}
$$

This equation makes the LCF design dependent upon the location for which the LCF is being designed. This should ensure that the system satisfies the multiple performance objectives for sites with different seismic characteristics. For example, the target response spectra values for site class D were presented in FEMA-355 C (2001) in Table A-1 (Figure 4.5 for different location (Los Angeles, Seattle, Boston). Table 4.1 shows the new design equation limits for these different sites:

\subsubsection{Design Procedure}

An approach similar to the first design procedure can be employed while making use of the above site-specific recommendations for achieving the multiple performance objectives 


\begin{tabular}{|c|c|r|r|r|r|}
\hline \multirow{2}{*}{ Location } & Hazard Level & \multicolumn{4}{|c|}{ Period } \\
\cline { 2 - 5 } & & $\mathbf{0 . 3}$ & $\mathbf{1 . 0}$ & $\mathbf{2 . 0}$ & $\mathbf{4 . 0}$ \\
\hline \multirow{3}{*}{ Los Angeles } & $2 / 50$ & 1.610 & 1.190 & 0.540 & 0.190 \\
\cline { 2 - 5 } & $10 / 50$ & 1.070 & 0.680 & 0.330 & 0.123 \\
\cline { 2 - 5 } & $50 / 50$ & 0.514 & 0.288 & 0.149 & 0.069 \\
\hline \multirow{2}{*}{ Seattle } & $2 / 50$ & 1.455 & 1.000 & 0.410 & 0.164 \\
\cline { 2 - 6 } & $10 / 50$ & 0.710 & 0.390 & 0.180 & 0.072 \\
\hline \multirow{2}{*}{ Boston } & $2 / 50$ & 0.340 & 0.160 & 0.077 & 0.030 \\
\cline { 2 - 5 } & $10 / 50$ & 0.120 & 0.052 & 0.028 & 0.0108 \\
\hline
\end{tabular}

Figure 4.5: Target Response Spectra Values for Site Class D for 5\% Damping Level (FEMA$355 \mathrm{C}, 2001$ ).

Table 4.1: Response Spectra Values for LCF Design

\begin{tabular}{cccc}
\hline Location & Hazard Level & $S_{1}$ & $\frac{S_{1(2 \% \text { in } 50)}}{S_{1(10 \% \text { in } 50)}}$ \\
\hline \multirow{2}{*}{ Los Angeles } & $2 \%$ in 50 year & 1.19 & 1.75 \\
& $10 \%$ in 50 year & 0.68 & \\
\hline \multirow{2}{*}{ Seattle } & $2 \%$ in 50 year & 1.00 & 2.54 \\
& $10 \%$ in 50 year & 0.39 & \\
\hline \multirow{2}{*}{ Boston } & $2 \%$ in 50 year & 0.16 & 3.07 \\
& $10 \%$ in 50 year & 0.052 & \\
\hline
\end{tabular}

through the following method:

1. Use standard practice, i.e., ASCE 7 (ASCE, 2005), to determine the design seismic loads and distributions for the building. Here, values of the response modification factor, $R$, overstrength factor, $\Omega_{0}$, and displacement amplification factor, $C_{d}$, equal to those for eccentrically braced frames of 7, 2, and 4 respectively were used. Note that different values are found in Chapter 9, but these above are used for initial designs discussed in Chapter 5 .

2. Design the links and beams for the forces from elastic analysis of the system for the design base shear as calculated above. The links are designed similarly to links in 
eccentrically braced frames and their yielding behavior depends on their length and section properties.

3. Capacity design all columns for simultaneous plastic hinge formation in all links and beams. Note that the axial load in the columns from link hinging is reduced by the shear at the ends of the beams.

4. Ensure that drift requirements are satisfied, which consists of two separate evaluations. First, the code-based drift limits are checked using elastic static analyses and the displacement amplification factor $C_{d}$. It should be noted that the LCF system may be drift controlled and all prototype LCF systems described below were found to

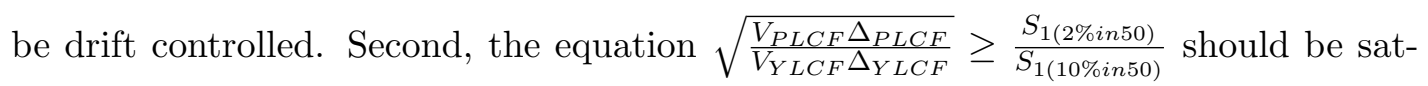
isfied, where $\Delta_{P L C F}$ and $\Delta_{Y L C F}$ are the roof displacement at which the first plastic hinge develops in a beam of the moment frame and in a link of the linked columns, respectively. $V_{P L C F}$ and $V_{Y L C F}$ are corresponding base shear of LCF for these roof displacements.

5. Ensure that the columns satisfy capacity design requirements after any revision of link and beam sizes. 


\section{Chapter 5}

\section{OVERVIEW OF PROTOTYPE DESIGNS}

Prototype LCF systems were designed for modified versions of the SAC buildings Gupta and Krawinkler, 1999). The buildings considered were 3, 6, and 9 stories tall with uniform $3.96 \mathrm{~m}$ (13 ft) tall stories with uniform $3.96 \mathrm{~m}(13 \mathrm{ft})$ story height. Story masses, plan dimensions, and dead and live loads were consistent with the SAC buildings with the 6story building being similar to the 3 story building in those respects. The SAC moment frame buildings were designed for site class D soil and the NEHRP'94 (FEMA222A, 1995) design spectra with $S_{D S}$ and $S_{D 1}$, equal $1.07 \mathrm{~g}$ and $0.68 \mathrm{~g}$, respectively. It is noted that the median response spectrum for the 10/50 hazard level ground motions reasonably match that design spectrum. Similarly the LCF systems were designed for a site class D soil and adjusted maximum considered earthquake spectral response parameters at 0.2 sec. and 1 sec. periods, $S_{M S}$ and $S_{M 1}$, were $1.61 \mathrm{~g}$ and $1.19 \mathrm{~g}$ respectively. Resulting design spectral acceleration parameters at $0.2 \mathrm{sec}$. and $1 \mathrm{sec}$., $S_{D S}$ and $S_{D 1}$, were $1.07 \mathrm{~g}$ and $0.79 \mathrm{~g}$, respectively, per ASCE 7 (ASCE, 2005).

Moreover, the SAC moment frame were designed to satisfy drift requirements based on UBC 1994 (1994). For structures under 65 feet in height, story drift was limited to $0.04 / R_{w}$ or 0.005 times the story height. The LCF systems were designed to satisfy drift requirements based on ASCE 7 (ASCE, 2005), that is $0.02 \%$ of story height for EBF system with $C_{d}=$ 4. Both systems then have an equal elastic interstory drift limit of 0.78 .

Also, In order to maintain the overall plan dimensions of the SAC buildings shown in Figure 5.1(a), beam lengths had to be decreased due to the introduction of the linked column. As shown in Figure 5.1(b), two bays of LC were used for the 3 and 6-story LCFs; however, two bays and three bays of LC were used for the 9-story building designs as shown in Figure 5.2. In all cases it was assumed that two lines of LCF framing were present to resist the lateral seismic loads in the direction of the building under consideration. 


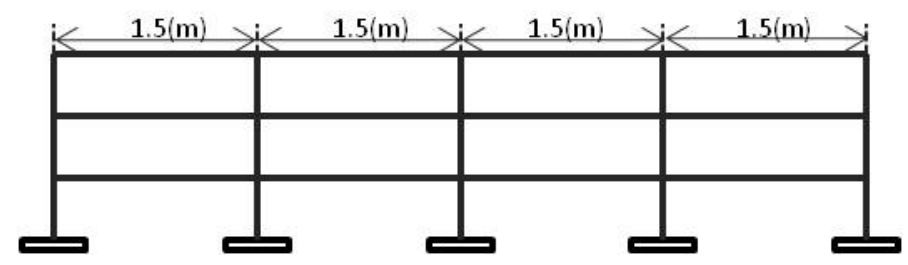

(a)

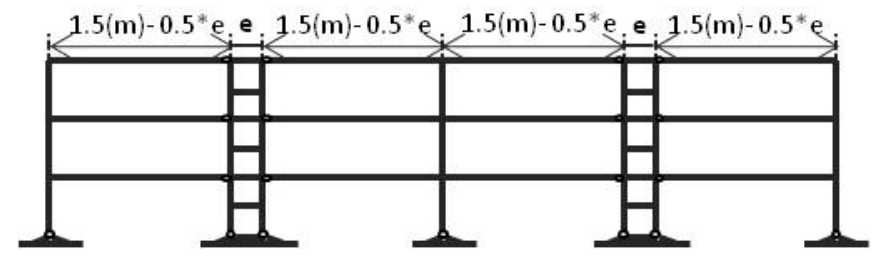

(b)

Figure 5.1: Frame Model of 3 Story. (a) SAC Model Special Moment Resisting Frame, (b) LCF Model Based on SAC Model.

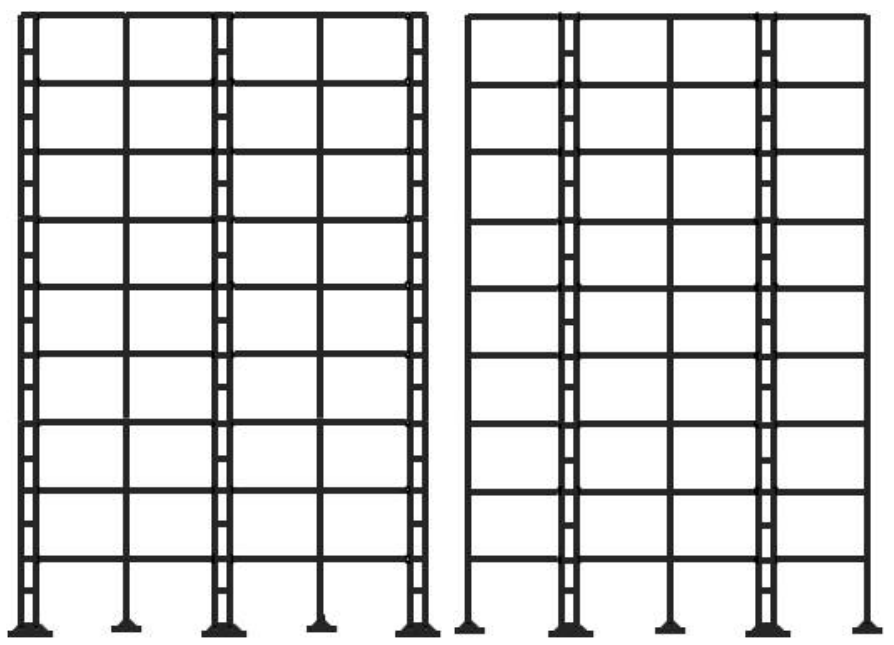

(a)

(b)

Figure 5.2: 9 Story LCF Elevations: (a) LCF with 3 Bays of Linked Columns, (b) LCF with 2 Bays of Linked Columns. 
In total, nine different LCF systems were designed. Their overall designs are discussed here and their fundamental behaviors are contrasted after the analytical model development section below. Table 5.1 shows the primary characteristics of the different designs, including: the number of stories (3, 6 and 9), the overall LCF layout (the number of LC in one line of framing), the spacing between the columns of the LC and the yielding behavior of the links (shear, flexural or intermediate links). The 3 and 6-story LCFs also include, designs with LC having different strengths and stiffnesses relative to the MF, as discussed after the analytical model development section below. In the 6- and 9-story designs it was necessary to increase the spacing of the $\mathrm{LC}$ to meet the drift requirements and still utilize standard steel wide flange shapes for the links.

The naming convention for the prototype variations in Table 5.1 starts with the number of stories. For 3-story LCFs this is followed by a descriptor to show the relative strength of the LC with respect to the MF(SLC for strong LC, SMF for strong MF and SS for the same strength of LC and MF). For the 6-story LCFs, the number of stories is followed by a descriptor for the type of links that have been used ( $\mathrm{S}$ for shear link, I for intermediate link and F for flexure link) followed by the LC column spacing. For the 9-story LCFs, the number of stories is followed by the number of LC in one frame line which is either 2 or 3 . Table 5.3, Table 5.4, Table 5.5 and Table 5.6 show the link, beam and column sections for each of the nine prototype buildings. 
Table 5.1: Design Characteristics of LCF Buildings

\begin{tabular}{|c|c|c|c|c|}
\hline Name & $\begin{array}{l}\text { No. of } \\
\text { Stories }\end{array}$ & $\begin{array}{c}\text { No. of LCF } \\
\text { Bays }\end{array}$ & $\begin{array}{c}\text { LCF } \\
\text { Column } \\
\text { Spacing } \\
(\mathrm{m})\end{array}$ & Link Classification \\
\hline 3-SLC & 3 & 2 & 1.52 & Shear \\
\hline $3-\mathrm{SMF}$ & 3 & 2 & 1.52 & Flexure \\
\hline 3-SS & 3 & 2 & 1.52 & Shear, Intermediate, Flexure \\
\hline $6-\mathrm{S}-80$ & 6 & 2 & 2.03 & Shear \\
\hline $6-\mathrm{I}-100$ & 6 & 2 & 2.55 & Intermediate \\
\hline $6-\mathrm{I}-120$ & 6 & 2 & 3.05 & Intermediate \\
\hline $6-\mathrm{F}-120$ & 6 & 2 & 3.05 & Flexure \\
\hline $9-2 b$ & 9 & 2 & 3.05 & Shear, Intermediate, Flexure \\
\hline $9-3 b$ & 9 & 3 & 3.05 & Shear, Intermediate, Flexure \\
\hline
\end{tabular}


Table 5.2: Design Details; Beam and Column section for LCF Model Buildings

\begin{tabular}{|c|c|c|c|c|c|c|c|}
\hline \multirow[b]{3}{*}{ Model } & \multirow[b]{3}{*}{ Story } & \multicolumn{2}{|c|}{ Link Column } & \multicolumn{4}{|c|}{ Moment Frame } \\
\hline & & \multirow[b]{2}{*}{ Column } & \multirow[b]{2}{*}{ Link } & \multicolumn{2}{|c|}{ Column } & \multicolumn{2}{|c|}{ Beam } \\
\hline & & & & Exterior & Interior & Exterior & Interior \\
\hline \multirow{2}{*}{ 3-SLC } & 1 & $\mathrm{~W} 14 \times 257$ & W24x176 & $\mathrm{W} 14 \times 257$ & $\mathrm{~W} 14 \times 257$ & W30x99 & W30x99 \\
\hline & 3 & W14x257 & W16x100 & W14x257 & W14x257 & W21x68 & W21x68 \\
\hline \multirow{2}{*}{ 3-SMF } & 1 & $\mathrm{~W} 14 \mathrm{x} 311$ & W24x62 & $\mathrm{W} 14 \mathrm{x} 311$ & $\mathrm{~W} 14 \mathrm{x} 311$ & W36x135 & W36x135 \\
\hline & 3 & W14x311 & W12x22 & W14x311 & W14x311 & W27x94 & W27x94 \\
\hline \multirow{2}{*}{ 3-SS } & 1 & $\mathrm{~W} 14 \times 257$ & $\mathrm{~W} 24 \times 117$ & $\mathrm{~W} 14 \times 257$ & $\mathrm{~W} 14 \times 257$ & W30x116 & W36x116 \\
\hline & 3 & $\mathrm{~W} 14 \times 257$ & W14x26 & $\mathrm{W} 14 \times 257$ & W14x257 & W21x93 & W21x93 \\
\hline \multirow{3}{*}{$6-\mathrm{S}-80$} & 1 & W14x730 & W24x131 & $\mathrm{W} 14 \mathrm{x} 426$ & $\mathrm{~W} 14 \times 500$ & W33x141 & W30x108 \\
\hline & 3 & W14x665 & $\mathrm{W} 24 \mathrm{x} 162$ & $\mathrm{~W} 14 \mathrm{x} 426$ & $\mathrm{~W} 14 \times 500$ & W36x150 & W33x118 \\
\hline & 6 & W14x342 & W24x131 & $\mathrm{W} 14 \times 370$ & W14x398 & W33x141 & W30x108 \\
\hline \multirow{3}{*}{$6-\mathrm{I}-100$} & 1 & W14x665 & W24x131 & $14 \times 455$ & $\mathrm{~W} 14 \times 455$ & W27x114 & W27x94 \\
\hline & 3 & $\mathrm{~W} 14 \times 605$ & $\mathrm{~W} 24 \mathrm{x} 146$ & $\mathrm{~W} 14 \mathrm{x} 455$ & $\mathrm{~W} 14 \mathrm{x} 455$ & W33x141 & W27x102 \\
\hline & 6 & $\mathrm{~W} 14 \times 342$ & W21x111 & $\mathrm{W} 14 \times 342$ & $\mathrm{~W} 14 \times 370$ & W27x114 & W27x94 \\
\hline \multirow{3}{*}{$6-\mathrm{I}-120$} & 1 & W14x665 & $\mathrm{W} 24 \mathrm{x} 131$ & $\mathrm{~W} 14 \times 370$ & W14x398 & W27x114 & W24x62 \\
\hline & 3 & W14x605 & $\mathrm{W} 24 \mathrm{x} 146$ & $\mathrm{~W} 14 \times 370$ & W14x398 & W30x116 & W24x68 \\
\hline & 6 & $\mathrm{~W} 14 \times 342$ & W21x111 & $\mathrm{W} 14 \times 257$ & $\mathrm{~W} 14 \times 283$ & W24x68 & W24x62 \\
\hline \multirow{3}{*}{$6-\mathrm{F}-120$} & 1 & W14x665 & W27x114 & $\mathrm{W} 14 \mathrm{x} 455$ & W14x398 & $\mathrm{W} 27 \times 114$ & W24x62 \\
\hline & 3 & W14x605 & $\mathrm{W} 24 \mathrm{x} 103$ & $\mathrm{~W} 14 \mathrm{x} 455$ & W14x398 & W33x141 & W24x68 \\
\hline & 6 & W14x342 & W24x62 & W14x342 & W14x283 & W27x114 & W24x62 \\
\hline \multirow{4}{*}{$9-2 b$} & 1 & $\mathrm{~W} 14 \times 730$ & W24x192 & W14x665 & W14x665 & W36x210 & W36x170 \\
\hline & 3 & $\mathrm{~W} 14 \times 730$ & W24x192 & W14x665 & W14x665 & W36x247 & W36x170 \\
\hline & 6 & W14x665 & $\mathrm{W} 24 \mathrm{x} 176$ & W14x605 & W14x605 & W36x247 & W36x170 \\
\hline & 9 & W14x500 & W24x62 & W14x455 & W14x455 & W30x108 & W30x108 \\
\hline \multirow{4}{*}{$9-3 b$} & 1 & W14x730 & W24x176 & \multicolumn{2}{|c|}{ W14x55 } & \multicolumn{2}{|c|}{ W36x150 } \\
\hline & 3 & $\mathrm{~W} 14 \mathrm{x} 730$ & $\mathrm{~W} 24 \mathrm{x} 176$ & \multicolumn{2}{|c|}{$\mathrm{W} 14 \times 550$} & \multicolumn{2}{|c|}{ W36x182 } \\
\hline & 6 & W14x730 & $\mathrm{W} 24 \mathrm{x} 117$ & \multicolumn{2}{|c|}{$\mathrm{W} 14 \times 550$} & \multicolumn{2}{|c|}{ W36x150 } \\
\hline & 9 & $\mathrm{~W} 14 \mathrm{x} 730$ & W24x62 & \multicolumn{2}{|c|}{$\mathrm{W} 14 \mathrm{x} 426$} & \multicolumn{2}{|c|}{$\mathrm{W} 27 \times 94$} \\
\hline
\end{tabular}


Table 5.3: Design Details; Beam and Column section for 3-story Model Buildings

\begin{tabular}{|c|c|c|c|c|c|c|c|}
\hline \multirow[b]{3}{*}{ Model } & \multirow[b]{3}{*}{ Story } & \multicolumn{2}{|c|}{ Link Column } & \multicolumn{4}{|c|}{ Moment Frame } \\
\hline & & \multirow[b]{2}{*}{ Column } & \multirow[b]{2}{*}{ Beam } & \multicolumn{2}{|c|}{ Column } & \multicolumn{2}{|c|}{ Beam } \\
\hline & & & & Exterior & Interior & Exterior & Interior \\
\hline \multirow{3}{*}{ 3-SLC } & $\begin{array}{c}\text { Base } \\
\text { Int } 1 / 2 \\
1 / 2\end{array}$ & $\mathrm{~W} 14 \times 257$ & $\begin{array}{l}\text { W24x176 } \\
\text { W24x176 } \\
\text { W24x176 }\end{array}$ & $\mathrm{W} 14 \mathrm{x} 257$ & $\mathrm{~W} 14 \times 257$ & W30x99 & W30x99 \\
\hline & $\begin{array}{c}\text { Int } 2 / 3 \\
2 / 3\end{array}$ & $\mathrm{~W} 14 \times 257$ & $\begin{array}{l}\text { W24x101 } \\
\text { W24x101 }\end{array}$ & $\mathrm{W} 14 \times 257$ & $\mathrm{~W} 14 \times 257$ & W30x90 & W30x90 \\
\hline & $\begin{array}{c}\text { Int } 3 / \text { R00f } \\
\text { 3/Roof }\end{array}$ & $\mathrm{W} 14 \times 257$ & $\begin{array}{l}\text { W16x100 } \\
\text { W16x100 }\end{array}$ & $\mathrm{W} 14 \times 257$ & $\mathrm{~W} 14 \times 257$ & W21x68 & W21x68 \\
\hline \multirow{3}{*}{ 3-SMF } & $\begin{array}{c}\text { Base } \\
\text { Int } 1 / 2 \\
1 / 2\end{array}$ & W14x311 & $\begin{array}{l}\text { W24x62 } \\
\text { W24x62 } \\
\text { W24x62 }\end{array}$ & $\mathrm{W} 14 \times 311$ & W14x311 & W36x135 & W36x135 \\
\hline & $\begin{array}{c}\text { Int } 2 / 3 \\
2 / 3\end{array}$ & W14x311 & $\begin{array}{l}\text { W16x31 } \\
\text { W16x31 }\end{array}$ & $\mathrm{W} 14 \times 311$ & W14x311 & W36x90 & W30x90 \\
\hline & $\begin{array}{c}\text { Int 3/R00f } \\
\text { 3/Roof }\end{array}$ & $\mathrm{W} 14 \times 311$ & $\begin{array}{l}\text { W12x22 } \\
\text { W12x22 }\end{array}$ & $\mathrm{W} 14 \times 311$ & W14x311 & W27x94 & W27x94 \\
\hline \multirow{3}{*}{3 -SS } & $\begin{array}{c}\text { Base } \\
\text { Int } 1 / 2 \\
1 / 2\end{array}$ & $\mathrm{~W} 14 \times 257$ & $\begin{array}{l}\text { W24x117 } \\
\text { W24x117 } \\
\text { W24x117 }\end{array}$ & $\mathrm{W} 14 \times 257$ & $\mathrm{~W} 14 \times 257$ & W30x116 & W30x116 \\
\hline & $\begin{array}{c}\text { Int } 2 / 3 \\
2 / 3\end{array}$ & $\mathrm{~W} 14 \times 257$ & $\begin{array}{l}\text { W18x86 } \\
\text { W18x86 }\end{array}$ & $\mathrm{W} 14 \times 257$ & $\mathrm{~W} 14 \times 257$ & W30x116 & W30x116 \\
\hline & $\begin{array}{c}\text { Int } 3 / \text { R00f } \\
3 / \text { Roof }\end{array}$ & $\mathrm{W} 14 \times 257$ & $\begin{array}{l}\text { W14x26 } \\
\text { W14x26 }\end{array}$ & $\mathrm{W} 14 \times 257$ & $\mathrm{~W} 14 \times 257$ & W21x93 & W21x93 \\
\hline
\end{tabular}


Table 5.4: Design Details; Beam and Column section for 6-story Model Buildings

\begin{tabular}{|c|c|c|c|c|c|c|c|}
\hline \multirow[b]{3}{*}{ Model } & \multirow[b]{3}{*}{ Story } & \multicolumn{2}{|c|}{ Link Column } & \multicolumn{4}{|c|}{ Moment Frame } \\
\hline & & \multirow[b]{2}{*}{ Column } & \multirow[b]{2}{*}{ Beam } & \multicolumn{2}{|c|}{ Column } & \multicolumn{2}{|c|}{ Beam } \\
\hline & & & & Exterior & Interior & Exterior & Interior \\
\hline \multirow{6}{*}{$6-\mathrm{S}-80$} & $\begin{array}{c}\text { Base } \\
\text { Int } 1 / 2 \\
1 / 2\end{array}$ & W14x730 & $\begin{array}{l}\text { W24x131 } \\
\text { W24x131 } \\
\text { W24x131 }\end{array}$ & W14x455 & $\mathrm{W} 14 \times 500$ & W33x141 & W30x108 \\
\hline & $\begin{array}{c}\text { Int } 2 / 3 \\
2 / 3\end{array}$ & W14x665 & $\begin{array}{l}\text { W24x131 } \\
\text { W24x62 }\end{array}$ & $\mathrm{W} 14 \times 455$ & $\mathrm{~W} 14 \times 500$ & W36x150 & W30x108 \\
\hline & $\begin{array}{c}\text { Int } 3 / 4 \\
3 / 4\end{array}$ & W14x665 & $\begin{array}{l}\text { W24x162 } \\
\text { W24x162 }\end{array}$ & W14x455 & $\mathrm{W} 14 \times 500$ & W36x150 & W30x108 \\
\hline & $\begin{array}{c}\text { Int } 4 / 5 \\
4 / 5\end{array}$ & W14x665 & $\begin{array}{l}\text { W24x162 } \\
\text { W24x146 }\end{array}$ & $\mathrm{W} 14 \times 455$ & $\mathrm{~W} 14 \times 500$ & W36x150 & W30x118 \\
\hline & $\begin{array}{c}\text { Int } 5 / 6 \\
5 / 6\end{array}$ & W14x550 & $\begin{array}{l}\text { W24x146 } \\
\text { W24x146 }\end{array}$ & $\mathrm{W} 14 \times 455$ & $\mathrm{~W} 14 \times 500$ & W36x150 & W30x118 \\
\hline & $\begin{array}{c}\text { Int 6/R0of } \\
6 / \text { Roof }\end{array}$ & W14x342 & $\begin{array}{l}\text { W24x131 } \\
\text { W24x131 }\end{array}$ & $\mathrm{W} 14 \times 370$ & W14x398 & W33x141 & W30x108 \\
\hline \multirow{6}{*}{$6-\mathrm{I}-100$} & $\begin{array}{c}\text { Base } \\
\text { Int } 1 / 2 \\
1 / 2\end{array}$ & W14x665 & $\begin{array}{l}\text { W24x131 } \\
\text { W24x131 } \\
\text { W24x131 }\end{array}$ & W14x455 & $\mathrm{W} 14 \times 455$ & W27x114 & W27x94 \\
\hline & $\begin{array}{c}\text { Int } 2 / 3 \\
2 / 3 \\
\end{array}$ & W14x605 & $\begin{array}{l}\text { W24x131 } \\
\text { W24x146 }\end{array}$ & $\mathrm{W} 14 \times 455$ & $\mathrm{~W} 14 \mathrm{x} 455$ & W33x141 & W27x102 \\
\hline & $\begin{array}{c}\text { Int } 3 / 4 \\
3 / 4\end{array}$ & W14x605 & $\begin{array}{l}\text { W24x146 } \\
\text { W24x146 }\end{array}$ & W14x455 & $\mathrm{W} 14 \times 455$ & W33x141 & W27x102 \\
\hline & $\begin{array}{c}\text { Int } 4 / 5 \\
4 / 5\end{array}$ & W14x550 & $\begin{array}{l}\text { W24x146 } \\
\text { W24x1131 }\end{array}$ & $\mathrm{W} 14 \times 455$ & $\mathrm{~W} 14 \mathrm{x} 455$ & W33x141 & W27x102 \\
\hline & $\begin{array}{c}\text { Int } 5 / 6 \\
5 / 6\end{array}$ & $\mathrm{~W} 14 \mathrm{x} 426$ & $\begin{array}{l}\text { W24x131 } \\
\text { W24x131 }\end{array}$ & W14x455 & $\mathrm{W} 14 \times 455$ & W33x130 & W27x102 \\
\hline & $\begin{array}{c}\text { Int 6/R00f } \\
\text { 6/Roof }\end{array}$ & W14x342 & $\begin{array}{l}\text { W24x111 } \\
\text { W24x111 }\end{array}$ & W14x342 & $\mathrm{W} 14 \times 370$ & W27x114 & W27x94 \\
\hline
\end{tabular}


Table 5.5: Design Details; Beam and Column section for 6-story Model Buildings

\begin{tabular}{|c|c|c|c|c|c|c|c|}
\hline \multirow[b]{3}{*}{ Model } & \multirow[b]{3}{*}{ Story } & \multicolumn{2}{|c|}{ Link Column } & \multicolumn{4}{|c|}{ Moment Frame } \\
\hline & & \multirow[b]{2}{*}{ Column } & \multirow[b]{2}{*}{ Beam } & \multicolumn{2}{|c|}{ Column } & \multicolumn{2}{|c|}{ Beam } \\
\hline & & & & Exterior & Interior & Exterior & Interior \\
\hline \multirow{6}{*}{$6-\mathrm{I}-120$} & $\begin{array}{c}\text { Base } \\
\text { Int } 1 / 2 \\
1 / 2\end{array}$ & W14x665 & $\begin{array}{l}\text { W24x131 } \\
\text { W24x131 } \\
\text { W24x131 }\end{array}$ & $\mathrm{W} 14 \times 370$ & W14x398 & W27x114 & W24x62 \\
\hline & $\begin{array}{c}\text { Int } 2 / 3 \\
2 / 3\end{array}$ & W14x605 & $\begin{array}{l}\text { W24x131 } \\
\text { W24x131 }\end{array}$ & $\mathrm{W} 14 \times 370$ & W14x398 & W30x116 & W24x68 \\
\hline & $\begin{array}{c}\text { Int } 3 / 4 \\
3 / 4\end{array}$ & W14x605 & $\begin{array}{l}\text { W24x146 } \\
\text { W24x146 }\end{array}$ & $\mathrm{W} 14 \times 370$ & W14x398 & W30x116 & W24x68 \\
\hline & $\begin{array}{c}\text { Int } 4 / 5 \\
4 / 5\end{array}$ & $\mathrm{~W} 14 \times 550$ & $\begin{array}{l}\text { W24x146 } \\
\text { W24x146 }\end{array}$ & $\mathrm{W} 14 \times 370$ & W14x398 & W30x116 & W24x68 \\
\hline & $\begin{array}{c}\text { Int } 5 / 6 \\
5 / 6\end{array}$ & $\mathrm{~W} 14 \mathrm{x} 426$ & $\begin{array}{l}\text { W24x131 } \\
\text { W24x131 }\end{array}$ & $\mathrm{W} 14 \times 370$ & W14x398 & W30x108 & W24x68 \\
\hline & $\begin{array}{c}\text { Int } 6 / \text { Roof } \\
6 / \text { Roof }\end{array}$ & $\mathrm{W} 14 \times 342$ & $\begin{array}{l}\text { W21x111 } \\
\text { W21x111 }\end{array}$ & $\mathrm{W} 14 \times 257$ & $\mathrm{~W} 14 \times 283$ & W24x162 & W24x68 \\
\hline \multirow{6}{*}{$6-\mathrm{F}-120$} & $\begin{array}{c}\text { Base } \\
\text { Int } 1 / 2 \\
1 / 2\end{array}$ & W14x665 & $\begin{array}{l}\text { W27x114 } \\
\text { W27x114 } \\
\text { W27x114 }\end{array}$ & $\mathrm{W} 14 \times 455$ & W14x398 & W24x68 & W24x62 \\
\hline & $\begin{array}{c}\text { Int } 2 / 3 \\
2 / 3\end{array}$ & W14x605 & $\begin{array}{l}\text { W27x114 } \\
\text { W27x114 }\end{array}$ & $\mathrm{W} 14 \mathrm{x} 455$ & W14x398 & W33x141 & W24x68 \\
\hline & $\begin{array}{c}\text { Int } 3 / 4 \\
3 / 4\end{array}$ & W14x605 & $\begin{array}{l}\text { W27x114 } \\
\text { W27x114 }\end{array}$ & $\mathrm{W} 14 \mathrm{x} 455$ & W14x398 & W33x141 & W24x68 \\
\hline & $\begin{array}{c}\text { Int } 4 / 5 \\
4 / 5\end{array}$ & $\mathrm{~W} 14 \times 500$ & $\begin{array}{l}\text { W24x103 } \\
\text { W24x103 }\end{array}$ & $\mathrm{W} 14 \mathrm{x} 455$ & W14x398 & W33x141 & W24x68 \\
\hline & $\begin{array}{c}\text { Int } 5 / 6 \\
5 / 6\end{array}$ & $\mathrm{~W} 14 \times 426$ & $\begin{array}{l}\text { W24x103 } \\
\text { W24x103 }\end{array}$ & W14x455 & W14x398 & W33x130 & W24x68 \\
\hline & $\begin{array}{c}\text { Int 6/R00f } \\
6 / \text { Roof }\end{array}$ & $\mathrm{W} 14 \times 342$ & $\begin{array}{l}\text { W24x62 } \\
\text { W24x62 }\end{array}$ & W14x342 & $\mathrm{W} 14 \times 283$ & W27x114 & W24x62 \\
\hline
\end{tabular}


Table 5.6: Design Details; Beam and Column section for 9-story Model Buildings

\begin{tabular}{|c|c|c|c|c|c|c|c|}
\hline \multirow[b]{3}{*}{ Model } & \multirow[b]{3}{*}{ Story } & \multicolumn{2}{|c|}{ Link Column } & \multicolumn{4}{|c|}{ Moment Frame } \\
\hline & & \multirow[b]{2}{*}{ Column } & \multirow[b]{2}{*}{ Beam } & \multicolumn{2}{|c|}{ Column } & \multicolumn{2}{|c|}{ Beam } \\
\hline & & & & Exterior & Interior & Exterior & Interior \\
\hline \multirow{9}{*}{$9-2 b$} & $\begin{array}{c}\text { Base } \\
\text { Int } 1 / 2 \\
1 / 2\end{array}$ & W14x730 & $\begin{array}{l}\text { W24x176 } \\
\text { W24x192 } \\
\text { W24x192 }\end{array}$ & $\mathrm{W} 14 \times 665$ & W14x665 & W36x210 & W36x170 \\
\hline & $\begin{array}{c}\text { Int } 2 / 3 \\
2 / 3\end{array}$ & $\mathrm{~W} 14 \times 730$ & $\begin{array}{l}\text { W24x192 } \\
\text { W24x192 }\end{array}$ & W14x665 & W14x665 & W36x 210 & W36x 170 \\
\hline & $\begin{array}{c}\text { Int } 3 / 4 \\
3 / 4\end{array}$ & $\mathrm{~W} 14 \times 730$ & $\begin{array}{l}\text { W24x192 } \\
\text { W24x192 }\end{array}$ & $\mathrm{W} 14 \times 665$ & $\mathrm{~W} 14 \times 665$ & W36x 247 & W36x170 \\
\hline & $\begin{array}{c}\text { Int } 4 / 5 \\
4 / 5\end{array}$ & W14x730 & $\begin{array}{l}\text { W24x192 } \\
\text { W24x192 }\end{array}$ & W14x665 & W14x665 & W36x247 & W36x170 \\
\hline & $\begin{array}{c}\text { Int } 5 / 6 \\
5 / 6\end{array}$ & $\mathrm{~W} 14 \times 730$ & $\begin{array}{l}\text { W16x176 } \\
\text { W16x176 }\end{array}$ & $\mathrm{W} 14 \times 665$ & W14x665 & W36x247 & W36x170 \\
\hline & $\begin{array}{c}\text { Int } 6 / 7 \\
6 / 7\end{array}$ & W14x665 & $\begin{array}{l}\text { W24x176 } \\
\text { W24x176 }\end{array}$ & W14x605 & W14x605 & W36x247 & W36x170 \\
\hline & $\begin{array}{c}\text { Int } 7 / 8 \\
7 / 8\end{array}$ & W14x665 & $\begin{array}{l}\text { W24x176 } \\
\text { W24x117 }\end{array}$ & $\mathrm{W} 14 \times 605$ & W14x605 & W36x210 & W36x170 \\
\hline & $\begin{array}{c}\text { Int } 8 / 9 \\
8 / 9\end{array}$ & $\mathrm{~W} 14 \times 550$ & $\begin{array}{l}\text { W24x117 } \\
\text { W16x62 }\end{array}$ & $\mathrm{W} 14 \times 550$ & $\mathrm{~W} 14 \times 550$ & W33x141 & W33x141 \\
\hline & $\begin{array}{c}\text { Int 9/Roof } \\
\text { 9/Roof }\end{array}$ & $\mathrm{W} 14 \times 550$ & $\begin{array}{l}\text { W24x62 } \\
\text { W24x62 }\end{array}$ & $\mathrm{W} 14 \times 455$ & $\mathrm{~W} 14 \mathrm{x} 455$ & W30x108 & W30x108 \\
\hline \multirow{9}{*}{$9-3 b$} & $\begin{array}{c}\text { Base } \\
\text { Int } 1 / 2 \\
1 / 2\end{array}$ & W14x730 & $\begin{array}{l}\text { W24x117 } \\
\text { W24x176 } \\
\text { W24x176 }\end{array}$ & $\mathrm{W} 14 \times 550$ & $\mathrm{~W} 14 \times 550$ & W36x150 & W36x150 \\
\hline & $\begin{array}{c}\text { Int } 2 / 3 \\
2 / 3\end{array}$ & $\mathrm{~W} 14 \times 730$ & $\begin{array}{l}\text { W24x176 } \\
\text { W24x176 }\end{array}$ & $\mathrm{W} 14 \times 550$ & $\mathrm{~W} 14 \times 550$ & W36x182 & W36x182 \\
\hline & $\begin{array}{c}\text { Int } 3 / 4 \\
3 / 4\end{array}$ & $\mathrm{~W} 14 \times 730$ & $\begin{array}{l}\text { W24x176 } \\
\text { W24x176 }\end{array}$ & $\mathrm{W} 14 \times 550$ & $\mathrm{~W} 14 \times 550$ & W36x182 & W36x182 \\
\hline & $\begin{array}{c}\text { Int } 4 / 5 \\
4 / 5\end{array}$ & W14x730 & $\begin{array}{l}\text { W24x176 } \\
\text { W24x176 }\end{array}$ & $\mathrm{W} 14 \times 550$ & $\mathrm{~W} 14 \times 550$ & W36x182 & W36x182 \\
\hline & $\begin{array}{c}\text { Int } 5 / 6 \\
5 / 6\end{array}$ & $\mathrm{~W} 14 \times 730$ & $\begin{array}{l}\text { W16x176 } \\
\text { W16x176 }\end{array}$ & $\mathrm{W} 14 \times 550$ & $\mathrm{~W} 14 \times 550$ & W36x150 & W36x150 \\
\hline & $\begin{array}{c}\text { Int } 6 / 7 \\
6 / 7\end{array}$ & $\mathrm{~W} 14 \times 730$ & $\begin{array}{l}\text { W24x176 } \\
\text { W24x117 }\end{array}$ & $\mathrm{W} 14 \times 550$ & $\mathrm{~W} 14 \times 550$ & W36x150 & W36x150 \\
\hline & $\begin{array}{c}\text { Int } 7 / 8 \\
7 / 8\end{array}$ & $\mathrm{~W} 14 \times 730$ & $\begin{array}{l}\text { W24x117 } \\
\text { W24x84 }\end{array}$ & $\mathrm{W} 14 \times 550$ & $\mathrm{~W} 14 \times 550$ & W36x150 & W36x150 \\
\hline & $\begin{array}{c}\text { Int } 8 / 9 \\
8 / 9\end{array}$ & W14x730 & $\begin{array}{l}\text { W24x84 } \\
\text { W16x62 }\end{array}$ & $\mathrm{W} 14 \times 550$ & $\mathrm{~W} 14 \times 550$ & W30x108 & W30x108 \\
\hline & $\begin{array}{c}\text { Int 9/R00f } \\
\text { 9/Roof }\end{array}$ & $\mathrm{W} 14 \times 730$ & $\begin{array}{l}\text { W24x62 } \\
\text { W24x62 }\end{array}$ & $\mathrm{W} 14 \mathrm{x} 426$ & $\mathrm{~W} 14 \mathrm{x} 426$ & W27x94 & W27x94 \\
\hline
\end{tabular}




\section{Chapter 6}

\section{ANALYTICAL MODELS}

The structural analysis software OpenSees (Mazzoni et al., 2009) was used to develop analytical models of the prototype LCF systems. The models are an assembly of beam-column elements with cyclic load-deformation behaviors calibrated to represent the behaviors of the links, beams and columns. Research presented in this chapter shows that complete cyclic response of link, beam and column responding in flexure, including loss of capacity, can be simulated using beam-column elements in which nonlinear flexural and axial response is predicted by a fiber cross-sectional model. Fiber cross sections were employed, which enable the creation of the various steel cross sections with the assumption of plane strain compatibility. In shear links, which dissipate energy primarily through shear yielding, an independent nonlinear shear force versus shear deformation section were combined to this fiber cross-section. Also, simple connection was modeled in OpenSees using zero length nonlinear spring element.

Steel material response was modeled using hysteretic material for links, beams and connections. However, the columns were modeled using the steel02 material available in OpenSees. The fatigue and $\mathrm{min} / \max$ material were combined with the hysteretic material and assigned to distributed-plasticity fiber sections to capture different types of degradation for different elements.

In this chapter, a detailed description of the proposed models are provided and the accuracy of the these proposed models are verified by comparing to the results of the past experimental programs.

\subsection{Link Models}

The models for the link elements were developed and calibrated using a methodical process that involved the following steps: (i) gathering experimental data from tests on links with 
different yielding mechanisms (i.e., shear, flexural and combined yielding); (ii) selecting appropriate material models, section behavior, and element type to model the links; and (iii) calibrating a link element in OpenSees to the experimental data; considering all possible link behavior modes.

Experimental data was gathered from tests performed by Kasai (1985), Engelhardt (1989), Arce (2002) and Dusicka and Lewis (2010). Kasai (1985) tested 30 isolated links of various lengths and cross-sections and from the results proposed a simple criterion for web stiffener spacing to prevent premature cyclic web buckling. Engelhardt (1989) performed 14 tests on 2/3-scale EBF subassemblages subject to cyclic loads. The subassemblages modeled a portion of a single diagonal EBF with the links attached to the columns. Arce $(2002)$ tested isolated links composed of A992 steel under cyclic loading. Dusicka and Lewis (2010) performed experiments on links welded to end-plates and having parallel web stiffeners as described above. From this data set, a range of links from short shear yielding to long flexurally yielding were selected for calibrating the OpenSees link models. The experimental shear force vs. link rotation curves were digitized in the cases where electronic data files were not available so that the data could be directly compared with analytical results.

In OpenSees, a series of alternatives for modeling the link were considered. Ultimately, the shear and flexural responses of the links were assumed to be uncoupled, which is adequate for links having cross-sections that are not overly deep. The selected method for modeling the link behavior uses a distributed plasticity beam-column element with a fiber crosssection that controls the axial and flexural response and is aggregated with an independent nonlinear shear force versus shear deformation section. This approach is illustrated in Figure 6.1. For axial and flexural response, the material stress-strain behavior is specified and applied to the fibers. For shear response, a shear stress-strain behavior is specified and simply multiplied by the shear area, which for wide-flange sections is the web area.

Distributed plasticity beam-column elements use multiple fiber sections at pre-assigned locations along the element length, with total element response determined by numerically integrating the fiber section responses. There are two classes of distributed plasticity beam-column elements, displacement-based distributed plasticity beam column elements and force-based distributed plasticity beam column elements. The force-based beam col- 

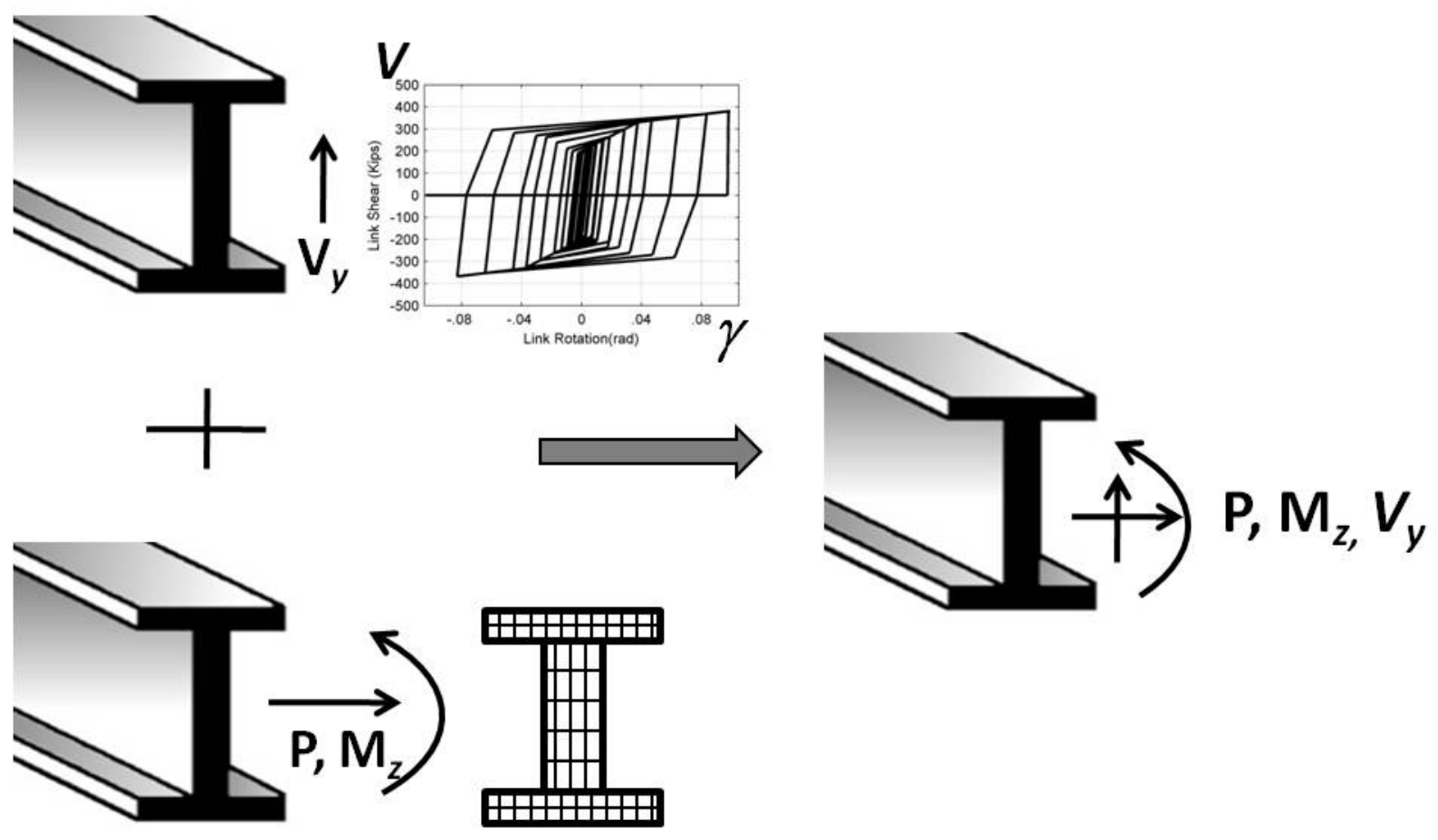

Figure 6.1: The Aggregate Procedure in OpenSees (Mazzoni et al., 2009).

umn element formulation was used, and is based on assumed internal force distributions of constant axial load and linearly varying bending moment within the element. The use of this element capable of automatically satisfying modeled load patterns and boundary conditions allows for significant computational savings compared relative to displacement-based formulations.

Elastic material properties for the fiber section and shear section are based on typical values for structural steel while the nonlinear hardening parameters for the material models were calibrated to fit the collected experimental data. The material models were developed to achieve the goal of direct simulation of the nonlinear behavior as well as to demonstrate any significant stiffness and strength deterioration observed in the cyclic response of links. Data from shear link experiments was used for calibrating the shear material properties. Data from flexural link experiments was used for calibrating the material properties applied to the fiber cross-section. The response of intermediate links was used as verification after 


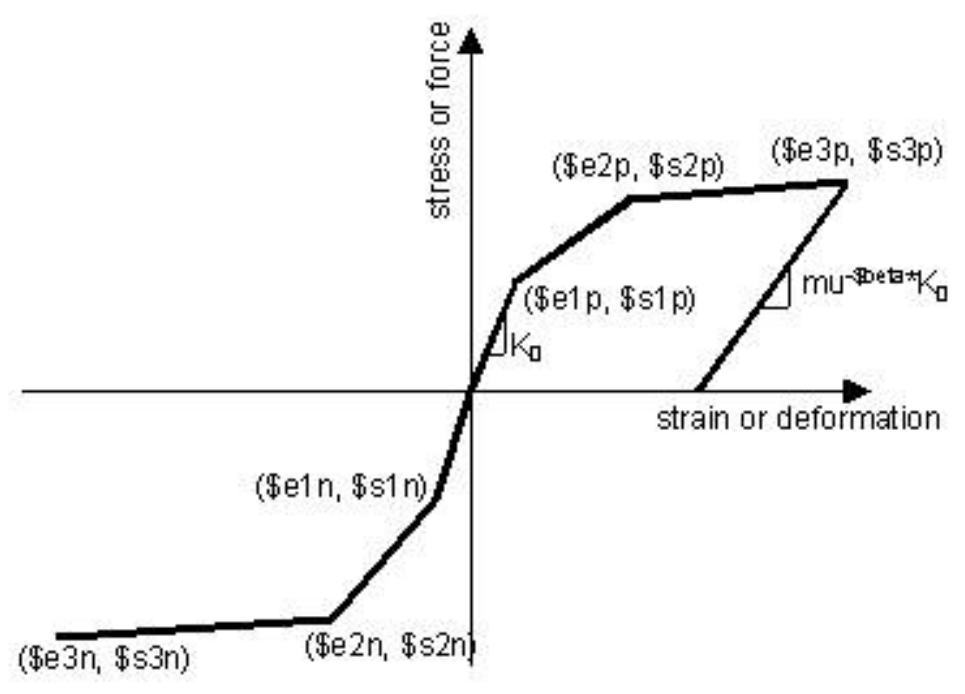

Figure 6.2: Hysteretic Material, OpenSees (Mazzoni et al. 2009).

aggregating the section described above.

After considering several different uniaxial material models available in OpenSees, the hysteretic material (Figure 6.2) model was found to be the most capable of simulating the individual shear and flexural response. The stresses and strains were selected based on the A992 steel behavior. After the second slope, perfectly plastic behavior was assumed until reaching the ultimate strain value of 0.2 .

Degradation of response was modeled using additional uniaxial materials combined with hysteretic material. Two different models for deterioration were chosen because of the difference in the observed degradation of shear and flexural links. As shown in Figure 6.3. in the shear link specimens, minimal degradation typically occurred before failure and the failure was generally abrupt, while flexural links typically degraded slowly relative to the rate of degradation observed in shear dominated links through the development of inelastic local buckling of the flanges. This is a generalization, but adequate for the purposes of evaluating frame response here. These two methods for capturing degradation for shear and flexural links are as follows: 


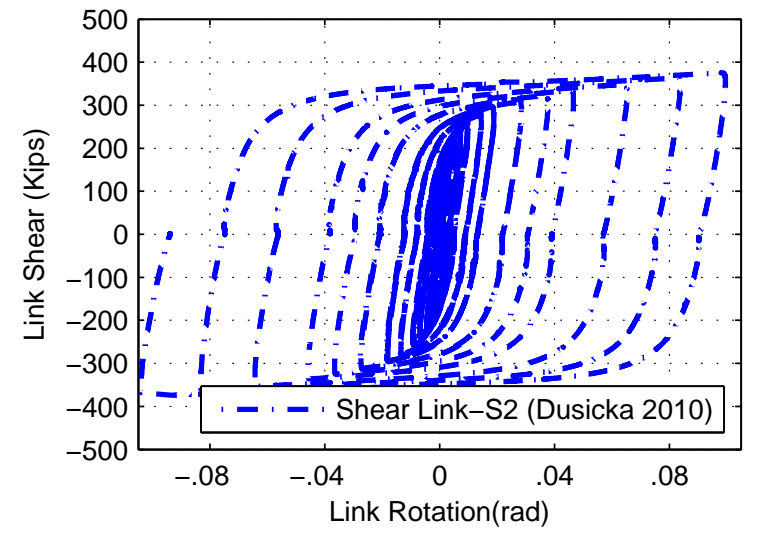

(a)

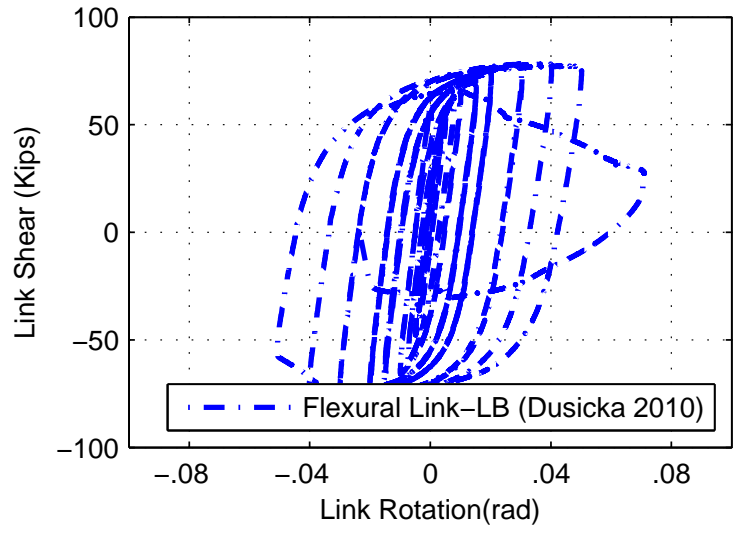

(b)

Figure 6.3: Experimental Link Shear vs. Link Rotation Results (a) Shear Link (b) Flexural Link.

\subsubsection{Shear Links}

In the shear links, a maximum shear strain of 0.1 was specified using the minmax material wrapper in OpenSees. After reaching this strain, the shear stress was assumed to go to a value of zero. When applied to the section behavior, this shear strain corresponds to a shear rotation angle of approximately 0.1 rads, which is the average rotation at which strength dropped to $80 \%$ histeretic of maximum strength in lab tests of shear links with web stiffeners (Dusicka and Lewis, 2010).

\subsubsection{Flexural Links}

For simulation of the degradation of the flexural response, the fatigue material model developed by Uriz (2005) was combined with the hysteretic material for application to the fiber cross-section. The fatigue material consists of a plastic strain-based low cycle fatigue model that uses a Coffin-Manson low cycle fatigue curve and a Miner damage accumulation index. As individual fibers reach their low cycle fatigue limit, the section's flexural strength degrades relatively slowly, simulating the more gradual link strength and stiffness degradation observed in flexural link tests.

The Coffin-Manson relationship, which is the relationship between the logarithm of 
the number of constant amplitude cycles to failure, $N_{f}$, and the logarithm of the strain amplitude, $\epsilon_{i}$, experienced in each cycle, is assumed to be linear and is represented below through Equation 6.1(ASTM 2003, Fisher et al. 1997). However, the empirical parameters determined for Equation 6.1 differ for low cycle fatigue where large inelastic deformations occur in each cycle. Ballio and Castiglioni (1995) conducted several constant amplitude, low cycle fatigue tests on cantilever columns with different cross-sections. They reported that the number of cycles to failure seemed to follow the Coffin-Manson relationship shown above, regardless of the amplitude of the cycles. Subsequently, variable amplitude histories were applied to the specimens, from which it was reported that a linear accumulation of damage (Miners rule) served as a good estimation tool to predict the start of fracture in test with different amplitudes. Miners rule is a form of damage accumulation, as shown in Equation 6.2. Damage for each amplitude of cycling is estimated by dividing the number of cycles at that amplitude $\left(n_{i}\right)$ by the number of constant amplitude cycles $\left(N_{f i}\right)$ necessary to cause failure at that amplitude, and overall damage due to low cycle fatigue is estimated by linearly summing the damage for all the amplitudes of deformation cycles considered $\left(\epsilon_{i}\right)$. It carries the important implication that the sequence of each cycle during the overall response has no effect on the fatigue life (Uriz, 2005). In Equation 6.2 DI is a parameter that varies from 0 , at the undamaged state, to 1 , at failure, representing an accumulated damage index.

$$
\begin{gathered}
\epsilon_{i}=\epsilon_{0}\left(N_{f}\right)^{m} \\
D I=\sum \frac{n_{i}}{N_{f i}}
\end{gathered}
$$

As an example, considering one cycle at strain amplitude of $\epsilon_{i}$, the equivalent damage resulting from this complete cycle would be:

$$
D I=\frac{n_{i}}{N_{f} i}=\frac{1}{10^{m^{-1} \log \left(\frac{\epsilon_{i}}{\epsilon_{0}}\right)}}
$$

In this equation, $\epsilon_{0}$ is a material parameter that roughly indicates the strain amplitude at 
which one complete cycle on a virgin material will cause failure, and $m$ is another material parameter which describes the sensitivity of the log of the total strain amplitude to the log of the number of cycles to failure. In this model, a cycle is simply a strain history which begins at a trough, continues to a peak, and returns to another trough. In OpenSees and for calibration flexure links, the coefficient $m$ is -0.458 and relates the sensitivity of the total strain to the number of cycles to failure. The corresponding value of the coefficient $\left(\epsilon_{0}\right)$ was determined to be 0.409 , and represents approximately the strain range at which one complete cycle will cause low cycle fatigue failure.

\subsubsection{Mesh Sensitivity Analysis}

The effect of using a different number of fiber sections along the element length and a different number of integration points were investigated. The results indicate that mesh dependency exists for the distributed-plasticity element model for simulation of links behavior. The number of fiber element across the horizontal length of the flanges and vertical length of the web, the number of fiber element across the thickness of the flanges and web, as well as the mumbler of integration points were selected based on experimental behavior. Through this calibration, it was determined that one fiber section per inch across the height and width of the section, two fiber sections across the thickness of the web and flanges and five integration points were adequate to capture the experimental behavior. Thus, these parameters were used to define the mesh requirements in modeling the links and beams for the remaining models.

\subsubsection{Link Simulation Results}

Using the modeling recommendations developed above, link model simulations were performed, calibrated and compared with experimental results. Table 6.1 shows the list of specimens that were used for calibrating the OpenSees models. As mentioned earlier, data for the first two specimens $(\mathrm{S} 2, \mathrm{LB})$ was gathered from the recent test program at Portland State University (Dusicka and Lewis, 2010), where the test setup used is shown in Figure 6.4. The OpenSees model was calibrated to these two data sets. The Arce (2002) tests (4c, 7, 
Table 6.1: Links Used for Calibration of OpenSees Model

\begin{tabular}{lllll}
\hline Specimen & Type & Section & e(in) & $\frac{e}{\left(M_{p} / V_{p}\right)}$ \\
\hline \hline S2 & Shear Link & W12X96 & 53.0625 & 1.3 \\
LB & Flexural Link & W12X22 & 53.0625 & 3.2 \\
\hline $4 \mathrm{c}$ & Shear Link & W10X33 & 23 & 0.9 \\
7 & Flexural Link & W10X33 & 73 & 2.9 \\
8 & Shear Link & W16X36 & 36.6 & 1.5 \\
3 & Flexural Link & W10X19 & 48 & 3.8 \\
$6 \mathrm{a}$ & Intermediate Link & W10X33 & 48 & 1.9 \\
9 & Intermediate Link & W16X36 & 48 & 2 \\
\hline
\end{tabular}

$8,3,6 \mathrm{a}, 9)$ were used for validation of this model.

The slight difference between the experimental link stiffness in the test by Arce (2002) and the OpenSees model indicated that the connection in the test setup rotated slightly, leading to flexibility in the experimental result. However, in the OpenSees analytical model, it was assumed that the connection was perfectly rigid. Finite element modeling by Richard and Uang $(2002 ; 2004)$ confirmed the same issue of connection flexibility in the Arce (2002) test set-up.

Figure 6.5 shows the cyclic shear force vs. total link rotation response of the link element with calibrated material properties, along with the cyclic shear force vs. total link rotation response of selected link test specimens. As shown, the link model reasonably represents the behavior of these tests, which include a flexural, an intermediate and a shear link.

\subsection{Beam and Column Models}

The beams and columns were modeled using force-based distributed plasticity beam-column elements with fiber cross-sections and using five integration points. These types of element and material models have been used by others to model the nonlinear response of steel 


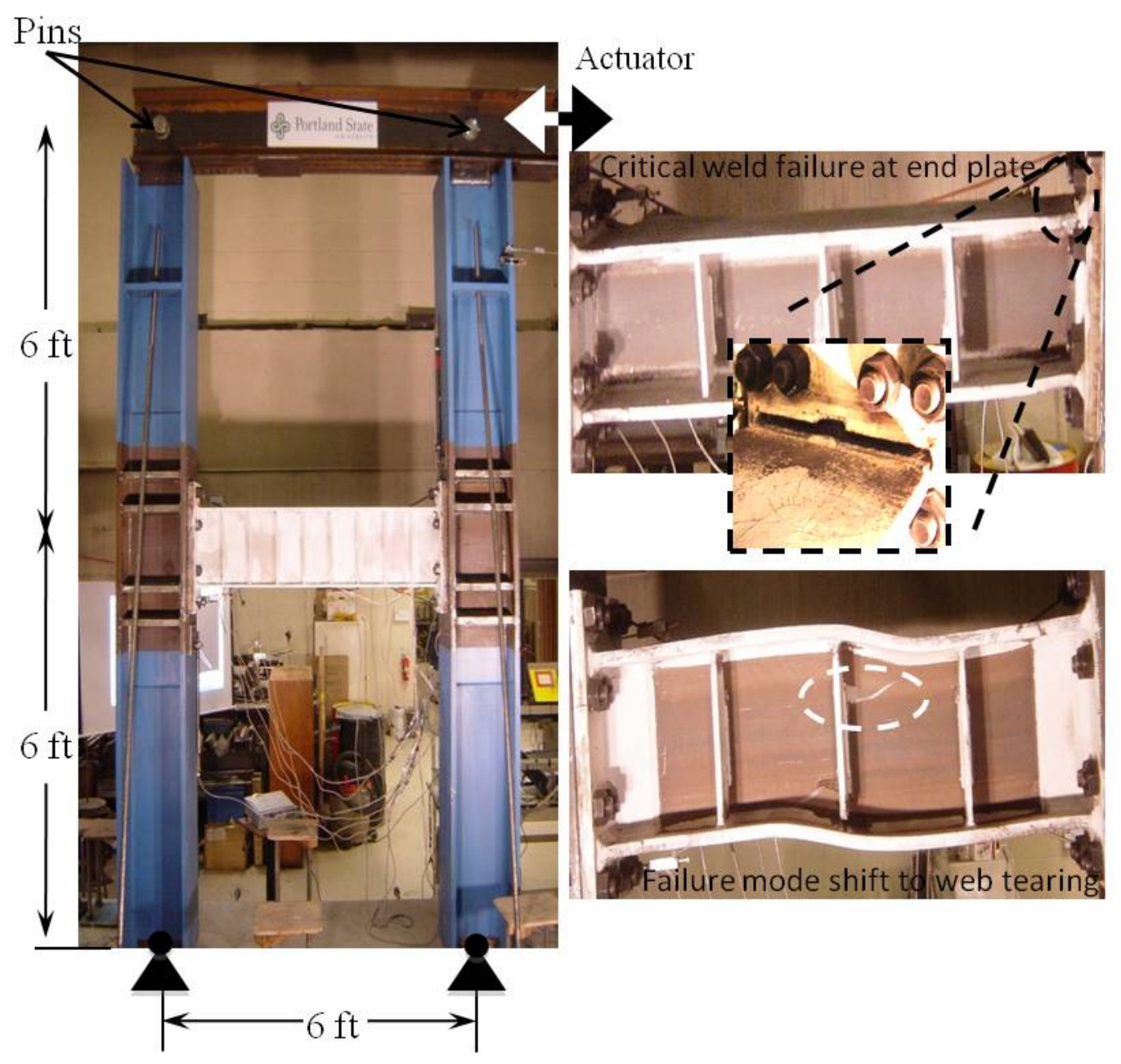

Figure 6.4: Test Set-Up and Link Failure Modes for Bolted End-Plate Links with and without Parallel Web Stiffeners (Dusicka and Lewis, 2010). 

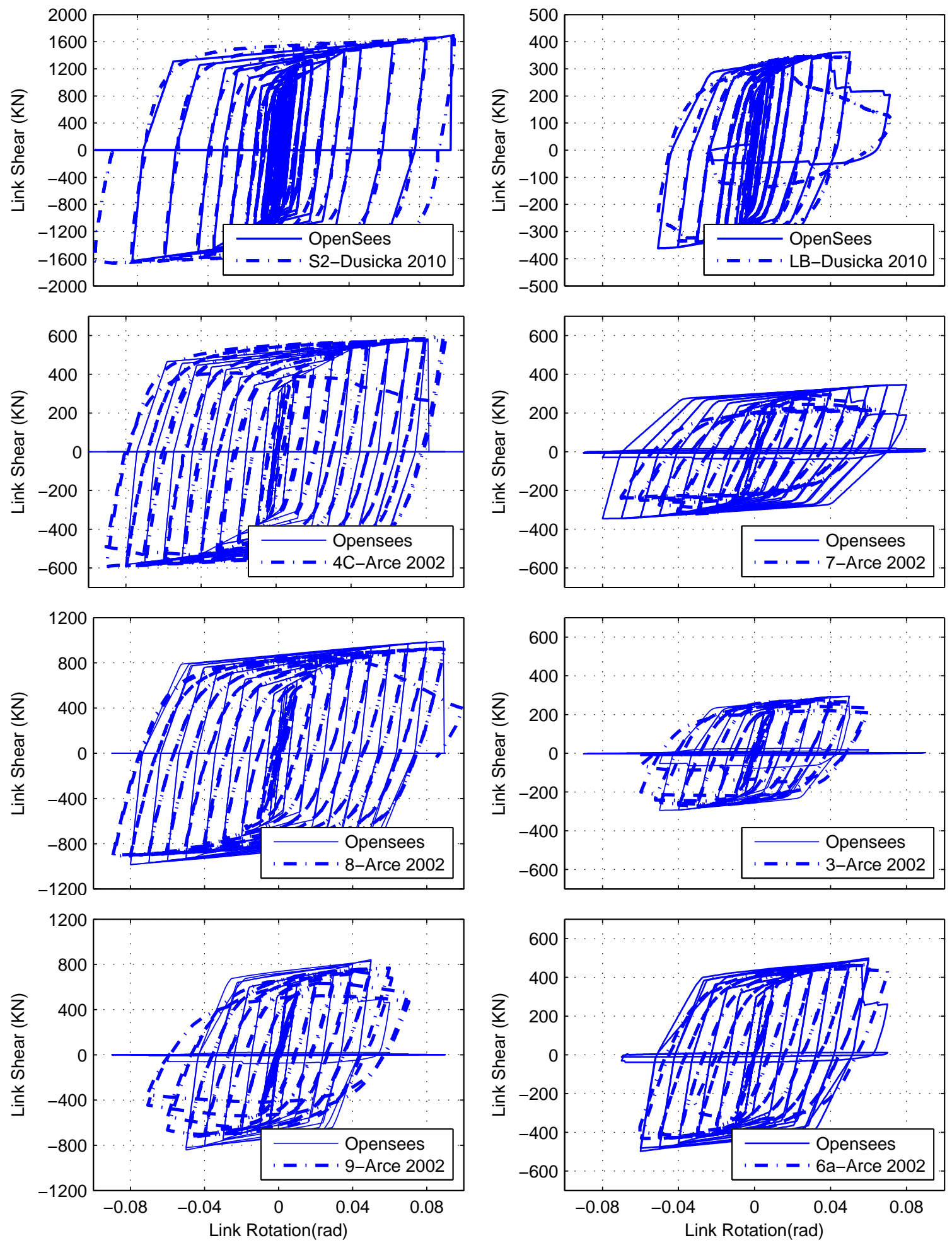

Figure 6.5: Comparison of Experimental Link Shear vs. Link Rotation Results with the Developed OpenSees Model. 
moment resisting frames prior to strength depredation with success (Xuewei et al., 2008, Kolkan, 2006; Kolkan and Kunnath, 2007; Mathur, 2011; Chen, 2011; Lu and MacRae, 2011).

The steel material for the columns was modeled using the Steel02 Material available in OpenSees, which is a Giuffr-Menegotto-Pinto model. The model approximated a yield stress of $345 \mathrm{MPa}(50 \mathrm{ksi})$ and strain hardening of $2 \%$ was used. These are typical values for steel used for rolled wide flange shapes. The value of $R_{0}$, which is the value for controlling the transition from the elastic to plastic branches, is 20. Strength degradation of the columns was not modeled because the columns are capacity designed and should remain mostly elastic.

The steel material for the beams were modeled using the hysteretic material available in OpenSees with typical values for structural steel for elastic material properties. Strength degradation of the beams was modeled, although, the beam rotations are small relative to those typical in traditional moment resisting frames as they are in single curvature rather than double curvature. Simulation of the degradation of the beam response was modeled similarly to the degradation of the flexural links where the fatigue material model developed by Uriz (2005) was combined with the hysteretic material for application to the fiber crosssection. The nonlinear hardening parameters for the material models were calibrated to fit collected experimental data for beams with prequalified connection types for use in connecting beams to column flanges in intermediate moment frames (IMFs).

As mentioned earlier, one of the advantages of the LCF system rather than special moment frames (SMFs) is avoiding complex detailing for the moment frame connections since the rotation demands are considerably smaller. Thus, connections for IMFs are modeled. The two main prequalified connections for IMFs are the bolted unstiffened extended end plate (BUEEP) connection and the welded unreinforced flange-welded web (WUFW) connection (ANSI/AISC 358-05, 2005). These connection behaviors were simulated by modifying the beam cross-section fiber material model at the beam-to-column connections. 


\subsubsection{Bolted Unstiffened Extended End-Plate Moment Connection}

Bolted end-plate connections are made by welding the beam to an end-plate and bolting the end-plate to a column flange. The behavior of this type of connection can be controlled by a number of different limit states including flexural yielding of the beam section, flexural yielding of the end-plates, yielding of the column panel zone, tension failure of the end-plate bolts, shear failure of the end-plate bolts, or failure of various welded connections.

The desired seismic behavior for the MF of the LCF is to have flexural yielding of the beam section. This can be achieved by providing sufficient strength in the elements of the connections to ensure that the inelastic deformation of the MF achieved by beam yielding. As part of the SAC Steel Project (Gupta and Krawinkler, 1999), a research program to investigate the design and behavior of extended end-plate moment connections under cyclic loading and a validation study utilizing the finite element method were conducted at Virginia Polytechnic Institute and State University (Sumner and Murray, 2002).

Eleven cyclic beam-to-column connection tests were performed as a part of their study. The results showed that the four bolt extended unstiffened (4E-1.25-1.5-24) and the eight bolt extended stiffened (8ES-1 1/4-1 3/4-30) end-plate moment connections (Figure 6.6) with strong plate connection ( $110 \%$ of the beam strength) provided the needed strength, stiffness and ductility required for use in seismic regions by having failure in the beam from local flange and web buckling. The four bolt extended unstiffened connection has been used in IMF buildings.

A four bolt extended unstiffened end-plate connection consists of two rows of two bolts for each flange. One row is outside the flange on the extended part of the end-plate and the other is inside the flange. This configuration exhibited good ductility and energy dissipation capacity. Beam flange local buckling, the primary failure mode, is a predictable limit state that provides a ductile failure mechanism. No yielding or other distress of the connection region was observed during the tests, indicating that the strong plate connection remained elastic throughout the duration of the test. The total interstory drift rotations that were sustained for at least one complete cycle exceeded $0.05 \mathrm{rad}$, which is adequate for IMF connections (FEMA-350, 2000). 

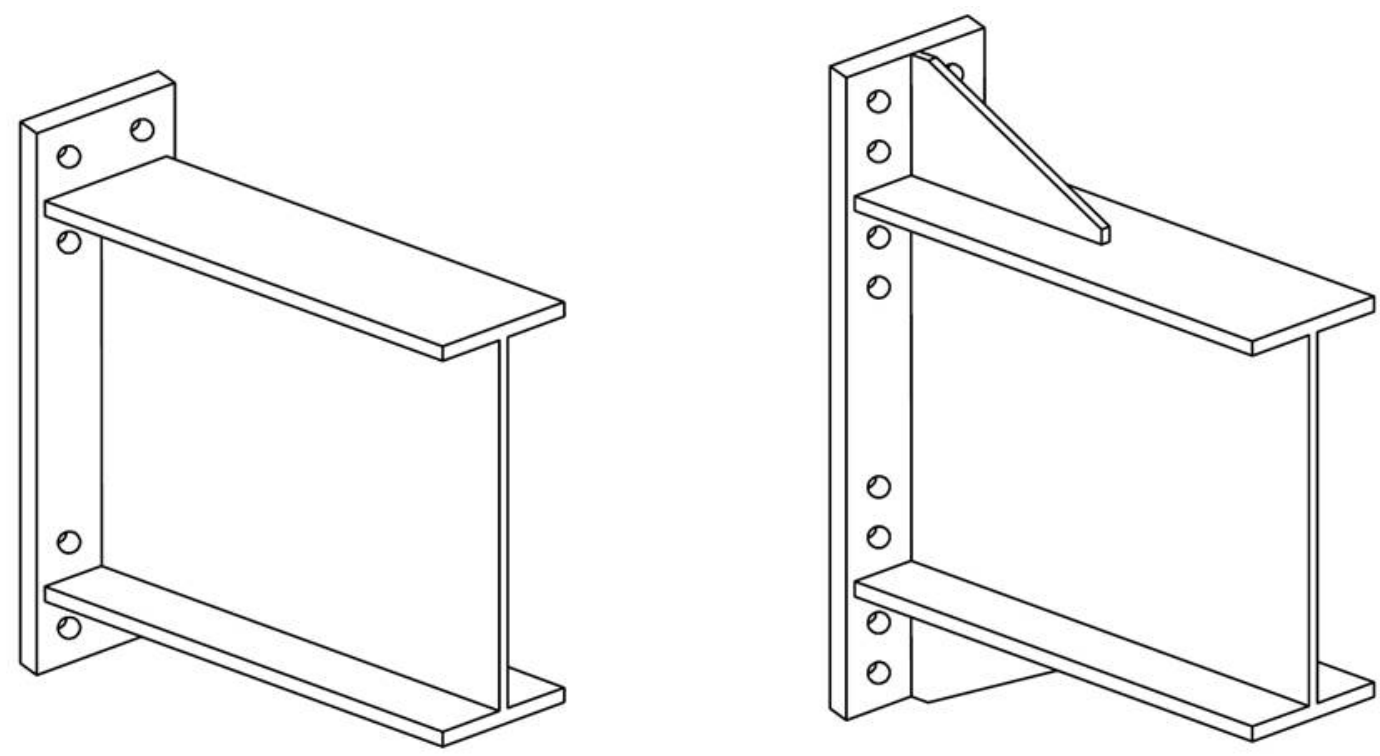

Figure 6.6: Four Bolt Unstiffened and Eight Bolt Stiffened Extended End-plate Connection Configurations.

The fiber cross-section beam-column element in OpenSees was employed to model the MF beams with bolt extended unstiffened end-plate connections at one end. As discussed, hysteretic material model in parallel with a low cycle fatigue model was used to represent the degrading response. The material model parameters were the same as those used for the fibers of the link cross-sections. However, for calibration the degradation, the coefficient $m$ equals -0.458 (relates the sensitivity of the total strain to the number of cycles to failure) and the coefficient $\left(\epsilon_{0}\right)$ equals 0.168 (represents approximately the strain range at which one complete cycle will cause low cycle fatigue failure) were determined. Figure 6.8(a) shows the cyclic moment vs. total plastic rotation response of the beam with calibrated material properties, along with the cyclic moment vs. total plastic rotation response of selected beam test specimen 4E, from Sumner and Murray (2002).

\subsubsection{Welded Unreinforced Flange-welded Web Moment Connection}

Figure 6.7 shows the view of the welded unreinforced flangewelded web (WUFW) moment connection. In this connection, inelastic rotation is developed primarily by yielding of the 
beam in the region adjacent to the face of the column. Connection fracture is controlled through special detailing requirements associated with the welds joining the beam flanges to the column flange, the welds joining the beam web to the column flange, and the shape and finish of the weld access holes (ANSI/AISC 358-05, 2005).

As a part of the SAC Steel Project phase 2, a research program to investigate the design and behavior of WUF-W connections under cyclic loading and a validation study utilizing the finite element method were conducted at Lehigh University (Ricles et al., 2002).

Again, eleven cyclic beam-to-column connection tests were performed as a part of their study. The conclusion shows that specimens T1 and T5 with groove welded web and supplement fillet weld attachment detail achieved an inelastic story drift greater than 0.035 radians in at least one complete cycle, prior to when either fracture occurred or specimen strength had deteriorated to $80 \%$ of the nominal flexural beam strength. The benefit of the supplemental fillet weld can be seen by comparing the results for Specimen T1 with T2, where in the latter, the supplemental fillet weld was omitted and the inelastic story drift was consequently reduced to 0.025 radians. Specimen T5 was similar to specimen T1 except that specimen T5 had a stronger panel zone. Therefore, the inelastic panel zone deformations were reduced in specimen $\mathrm{T} 5$ compared to specimen $\mathrm{T} 1$, resulting in an increase of the overall ductility in the former.

Similar to MF beams with bolt extended unstiffened end-plate connections at one end, the fiber cross-section beam-column element in OpenSees was employed to model the MF beams with welded unreinforced flange welded web at one end. The only difference is using the value of 0.241 instead of 0.168 for the coefficient $\left(\epsilon_{0}\right)$. Figure 6.8(b) shows the cyclic normalized moment vs. total plastic rotation response of the beam with calibrated material properties along with the cyclic normalized moment vs. total plastic rotation response of selected beam test specimen $\mathrm{T} 1$.

\subsection{Connection Models}

As shown in Figure 1.1, two different connection types have been used in the LCF system.

- Fully restrained connections for link-to-column connections and beam-to-columns con- 


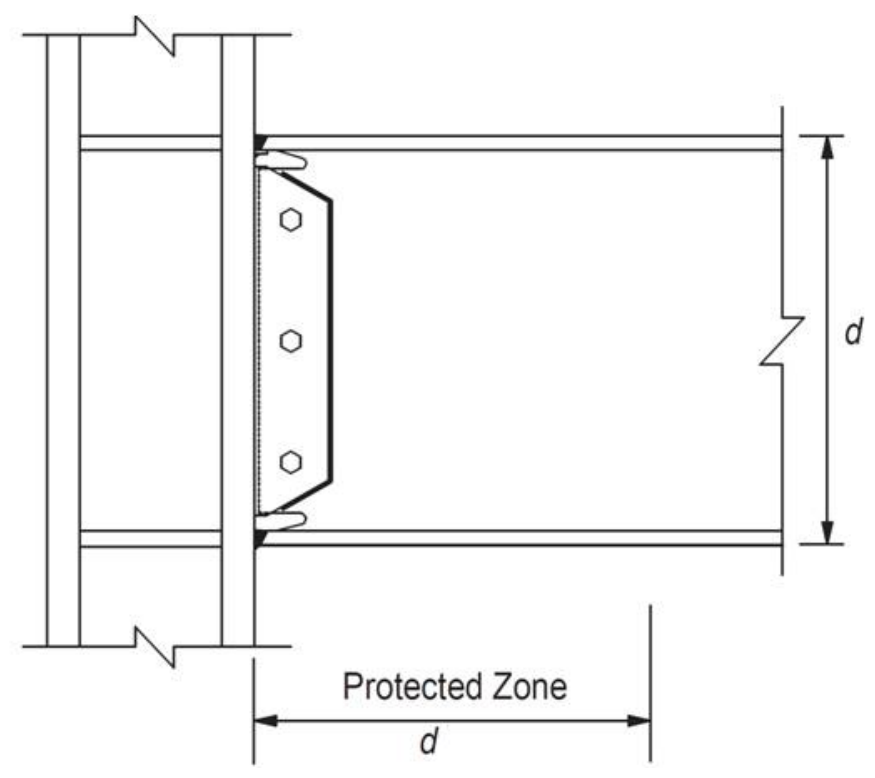

Figure 6.7: WUF-W Moment Connection.

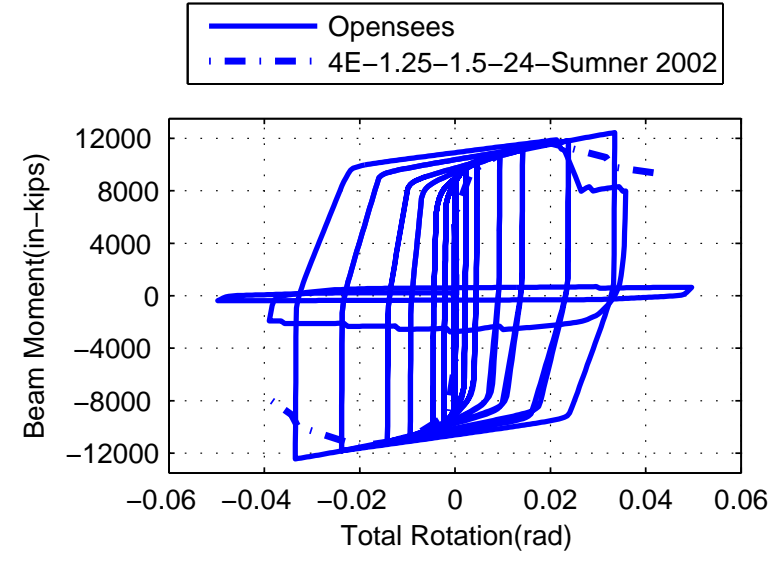

(a)

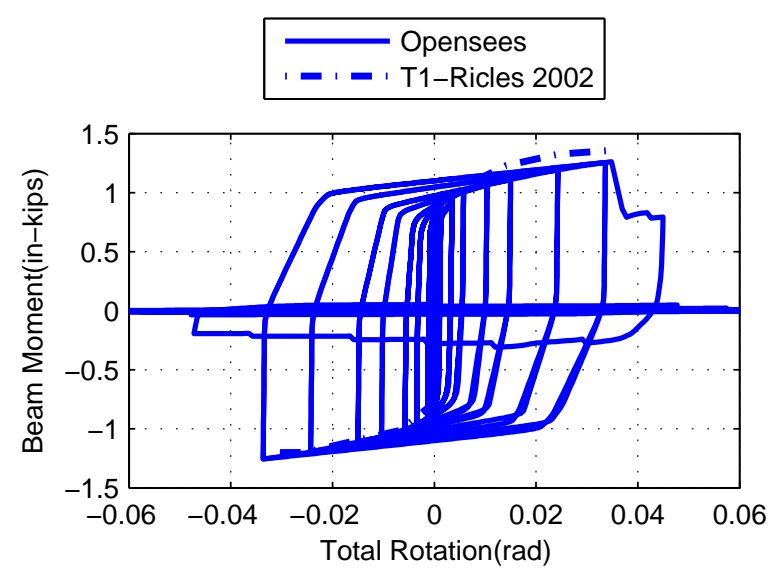

(b)

Figure 6.8: Comparison of Experimental Results with the Developed OpenSees Model (a) Four Bolt Extended Unstiffened Moment Rotation (b) Welded Unreinforced Flange Welded Web. 
nections at the beam end a way from the LCs.

- Simple connections for beam-to-column connections, at the connections to the LCs.

\subsubsection{Fully Restrained Connections}

In the previous section, the fully restrained connection behavior was simulated through the beam response and the model was calibrated to the prequalified connection types for use in connecting beams to columns in Intermediate Moment Frames (IMF).

Here, three methods of representing the beam-to-column and link-to-column fully restrained connections were considered, as shown in Figure 6.9. The responses of these models were compared to select the most appropriate method. The three models considered were:

- Centerline Model: In this model the centerline dimensions of the structural members are used and the flexibility of the connections is represented by the stiffness of the structural elements.

- Rigid End Offset Model: In this model, rigid offsets are used such that only the clear span of each structural member is modeled as being flexible. In the linked column portion of the $\mathrm{LCF}$, the connection region may represent a considerable percentage of the link's length, resulting in an overestimation of the linked column's flexibility if a centerline model is used. This model assumes the joint deformation is negligible.

- Panel Zone Model: In this model, the shear flexibility of the joint panel zones is modeled explicitly via a combination of springs and rigid links. Although, if the panel zones are capacity designed (this assumes that panel zones would be detailed to remain mostly elastic) their shear deformations will be small and can be reasonably neglected. More details are explained below.

When the centerline dimension is used, the length of the beams and columns in the joint region, which is half the beam or column depth, compensates for the effect of the joint. For most purposes, this is a reasonable assumption. However, in the linked column portion of the LCF the connection region may represent a considerable percentage of the 

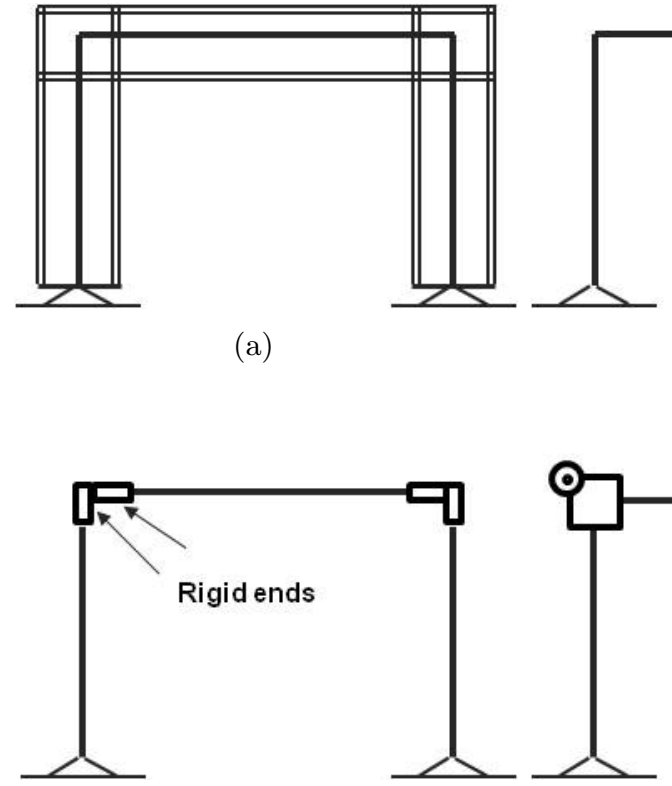

(a)

(c) (b)

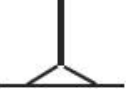

Rotational Spring

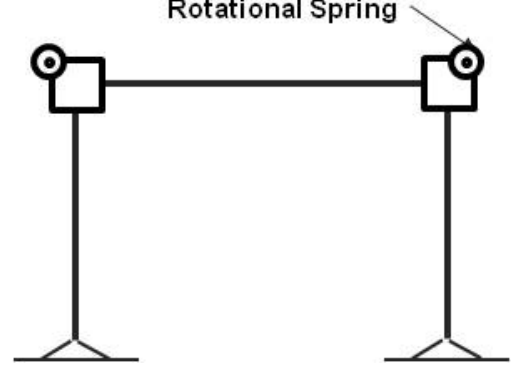

(d)

Figure 6.9: Different Methods of Modeling Beam-to-Column Connections (a) Actual Structure (b) Centerline Model (c) Rigid End Offset Model (d) Panel Zone Model.

link's length, resulting in an over estimation of the linked column's flexibility. Further, if the panel zones are capacity designed, their shear deformations will be small and the joint deformations may be further over estimated by using a centerline model. Alternatively, rigid end offsets represent the other extreme, with the deformation of the connection region neglected completely, which is more appropriate for the LCF system. In OpenSees, the rigid link beam element was used to represent the rigid offset end zone.

There may be cases where panel zone deformation is significant and should be accounted for. Models for the behavior of the panel zone in terms of shear force-shear distortion relationships have been developed by others (Krawinkler, (2000) and Foutch and Yun, (2002)) using a rotational spring with stiffness $k_{\theta}$ to tie the beam and column together, as demonstrated in Figure 6.10. This model is adopted here to investigate the impact of these various modeling assumptions on the system response. The elastic stiffness of the panel zone is given by: 


$$
K_{\theta}=\frac{M_{y}}{\theta_{y}}
$$

where $M_{y}$ is the moment in the connection at shear yield and $\theta_{y}$ is the yield rotation in panel zone. The equations for determining the stiffness of the panel zone spring are based on the yield properties of the panel zone. The yielding property of the panel zone is:

$$
\begin{gathered}
M_{y}=V_{y} \cdot d_{b}=0.55 \cdot F_{y} \cdot d_{c} \cdot t \cdot d_{b} \\
\gamma_{y}=\frac{F_{y}}{\sqrt{3} \cdot G}=\theta_{y}
\end{gathered}
$$

where $F_{y}$ is the yield strength of the panel zone, $G$ is the shear modulus, $d_{c}$ is the depth of column, $t$ is the thickness of panel zone, which is the thickness of the web of the column plus the thickness of the doubler plates if they are utilized, $d_{b}$ is the depth of beam and $\gamma_{y}$ is the yield shear strain of the panel zone.

Figure 6.11 shows the results of pushover analyses of a 3-story LCF with the three different connection models. As shown, the panel zone building model is stiffer than the centerline model and will therefore help in satisfying the drift design criteria. However, as

illustrated in Figure 6.11, there is only a slight difference between the panel zone model and the rigid offset model in the pushover response of this three story LCF (3SL). Therefore, since the rigid offset model is simpler and produces similar results, it is selected for use in modeling all prototype LCFs described herein. Note that in the 3-story LCF used in Figure 6.11 and in other prototype LCFs the column panel zone are assumed to be capacity designed.

\subsubsection{Simple Connections}

As mentioned earlier, one effective way to decrease the beam rotation demand and delay the onset of yielding/plastification in the LCF beams is to change their boundary conditions from fully restrained at both ends to fully restrained at just one end of the beam and simply connected at the other. The increase in beam flexibility results in an increase in drift at 


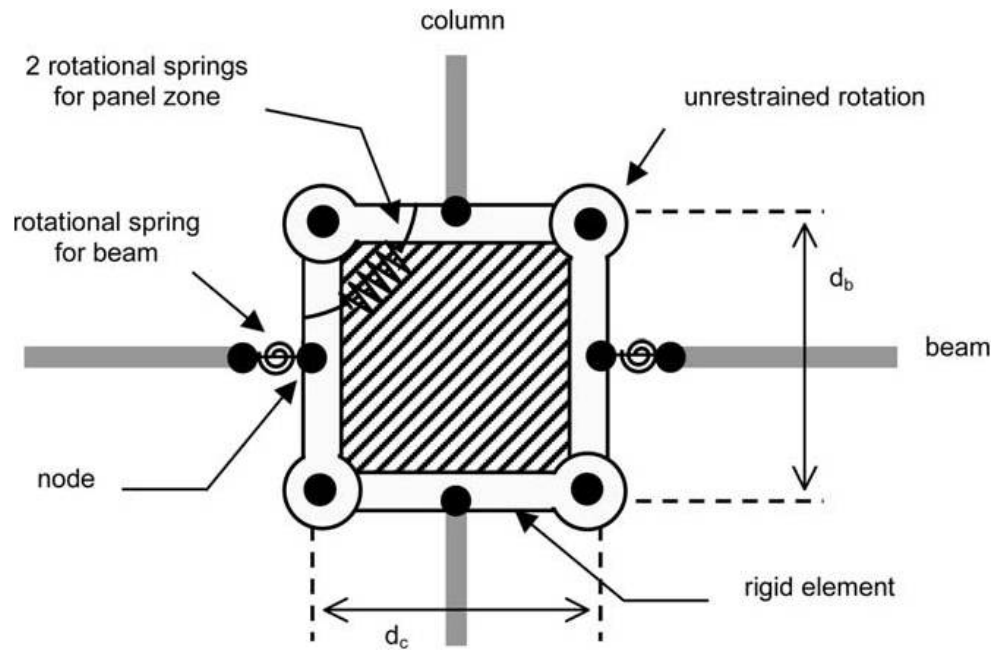

Figure 6.10: Plan and Elevation View of Post-Northridge Buildings (Lee and Foutch 2002)

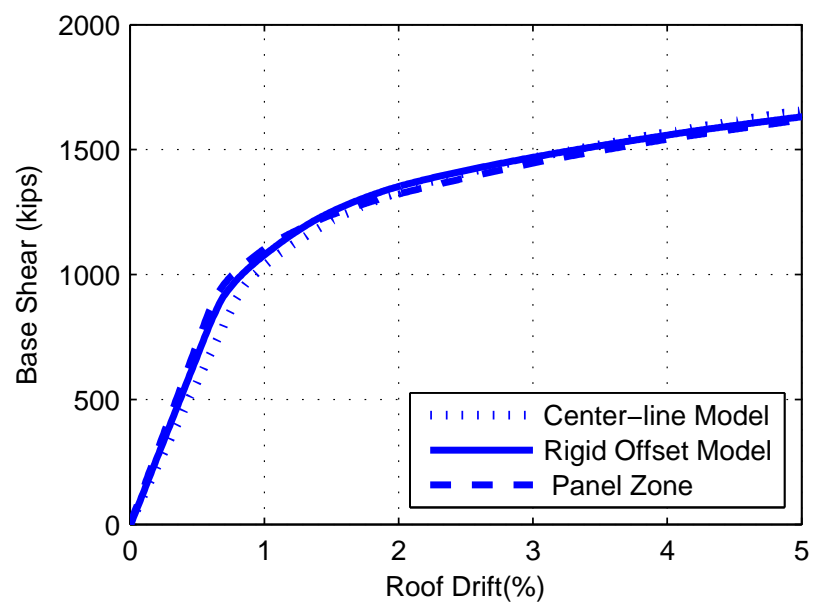

Figure 6.11: Comparison of the Pushover Response of Three Methods of Modeling Beamto-Column Connections for LCF3-SLC. 


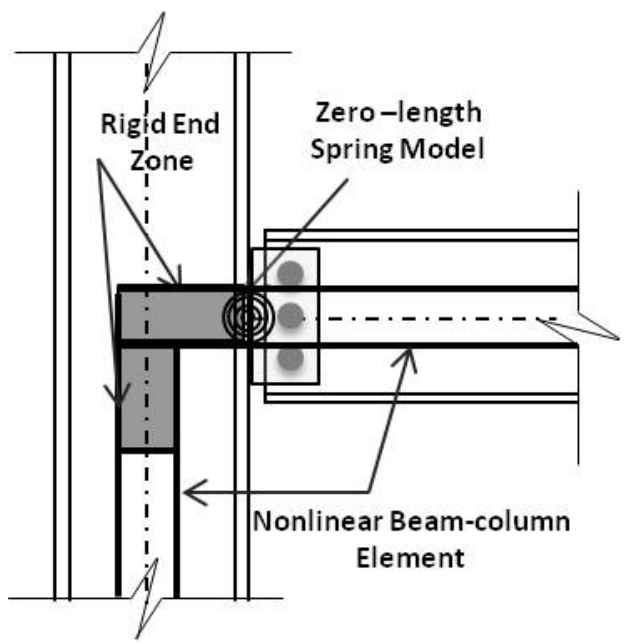

Figure 6.12: Shear-tab Connection Model in OpenSees.

which the beam plastic hinge starts to form.

While simple connections, such as single plate shear or web angle connections, have low rotational stiffness, it is still important to examine their impact on achieving the LCF performance objectives, including delaying beam yielding. For capturing the contribution of simple connections to LCF seismic response, these connections were modeled in OpenSees.

Sixteen full-scaled simple connections models were tested at University of California at Berkeley by Liu and Astaneh-Asl (2000). Based on those tests and the moment-rotational model developed by Liu and Astaneh-Asl (2004), the simple connections were simulated.

The model shown in Figure 6.12 is a combination of the zero length nonlinear spring element with hysteretic material with pinching capability which simulates degradation of strength and stiffness.

The moment-rotation model developed by Liu and Astaneh-Asl (2004) was used to estimate the initial rotational stiffness and the maximum positive and negative moment capacities for the shear-tab connections without slabs. All of the parameters of the bending moment and rotation capacity in the figures were based upon Liu and Astaneh-Asl (2000). Figure 6.13 shows the the backbone moment-rotation models for bare-steel shear-tab connections based on the cyclic behavior of the shear-tab connection. 


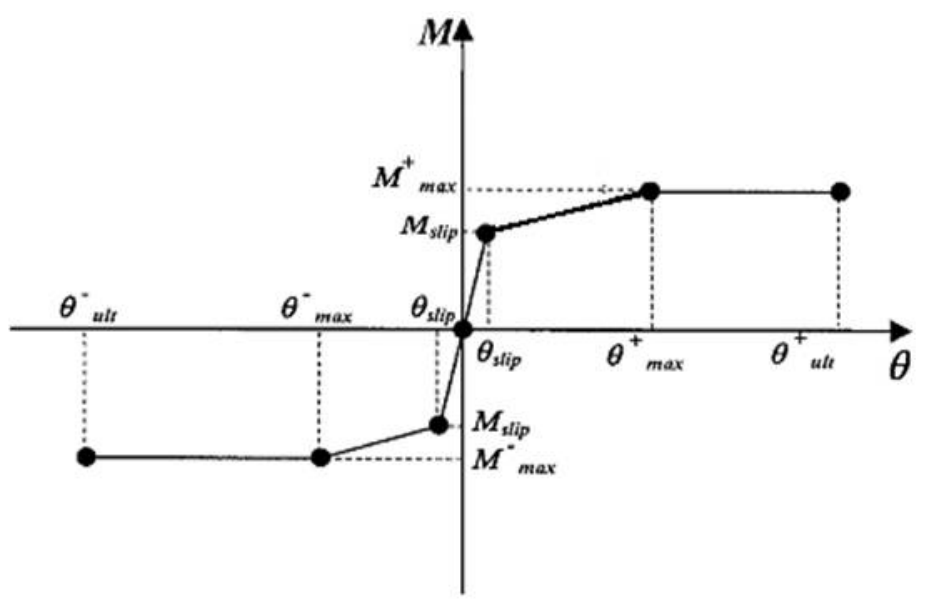

Figure 6.13: Bare-steel Shear-tab Moment-rotation Model (Liu and Astaneh-Asl, 2004).

The ultimate rotation capacity for positive and negative bending, $\theta_{u l t}^{+}$and $\theta_{u l t}^{-}$, are calculated according to the dimension of the shear tab and the gap between the beam web and column flange. The equation for rotation capacity, $\theta_{u l t}$, is therefore defined as follows:

$$
\theta_{u l t}=g / d_{f}
$$

where $\mathrm{g}=$ gap between the beam flange and the column; and $d_{f}=$ distance from the midheight of the shear tab to the furthest beam flange. The average value for both $\theta_{u l t}^{+}$and $\theta_{u l t}^{-}$ for shear-tab connection without slab is 0.05 rad.

$M_{\max }^{+}$and $M_{\text {max }}^{-}$, maximum positive and negative moment capacity, are calculated based on the design shear load of the connection and geometric properties of the shear-tab and composite slab.

The moment at which the connection slips, $M_{\text {Slip }}$, was estimated based on a trend observed in the momentrotation backbone curves. The curves indicated that the slip moment, and therefore initial rotational stiffness, was related to the maximum positive moment. According to the experimental results from Liu and Astaneh-Asl (2004), $M_{\text {Slip }}$, was $50-60 \%$ of $M_{\text {max }}^{+}$for bare-steel shear-tab connections and the corresponding rotation, $\theta_{\text {Slip }}$, was 0.005 rad on average for all specimens without slab. The values for $\theta_{\max }$, based on averaging of 
backbone curves of moment-rotation for typical shear tab connections tested, was 0.03 rad.

For the LCF frame models described below, the composite slab is simulated as well. An additional fiber section was constructed on the top of the $\mathrm{W}$ section. This fiber section was developed using a uniaxial material Concrete02 model in OpenSees with concrete compressive strength $4 \mathrm{ksi}$ and very small tensile strength, which has the young's modulus of concrete, through the beam cross-section.

Figure 6.14(b) shows the OpenSees model for the shear-tab connections was simulated using the moment-rotation model without slab proposed by Liu and Astaneh-Asl (2004) (specimen 2A, four-bolt specimen), as described previously. The assumption is installation foam board on top of the connection instead of the slab and composite slab on the rest of the beam. The OpenSees model (Figure 6.14(b) is in near similar agreement with the experimental model (Figure 6.14(a) . It should be noted that when it is applied to LCF system, the behavior of this connection is scaled up to the design strength of the LCF's connections.

Figure 6.15 shows the pushover comparison of the LCF 3-story model: one without modeling a simple connection and composite slab; the other modeling both factors. This Figure demonstrates that modeling simple connection and composite concrete slab increases the stiffness and strength of the building as expected, however, it does not effect the drift difference between first story link yielding and beam yielding.

\subsection{Frame Models}

After modeling the links, the beams, the columns and the connections as described above, the prototype LCF design's Models were developed in OpenSees. A model of one of the 3-story prototypes, namely LCF 3-SLC, was used to explore various aspects of the frame models and select appropriate modeling methods by examining the cyclic pushover response. After the modeling methods were selected, they were applied to all prototype LCFs to investigate the impact of parameters such as link stiffness, link yield mode, linked column and moment frame stiffnesses and LCF height (i.e., number of stories) on system performance.

The model incorporated P-delta effects via a P-Delta column that was linked to the LCF with axially rigid pin-ended members. Horizontal constraints were imposed to ensure 


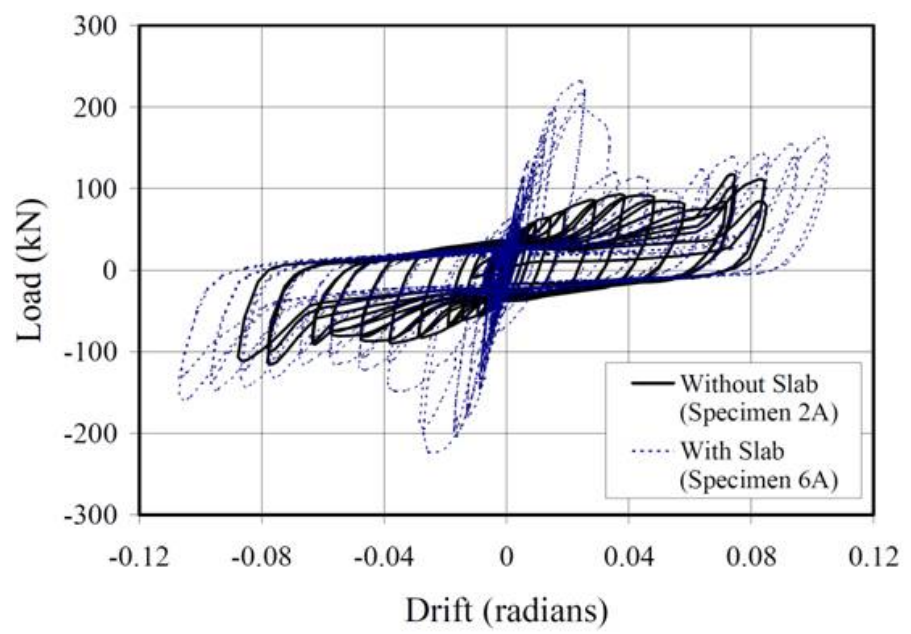

(a)

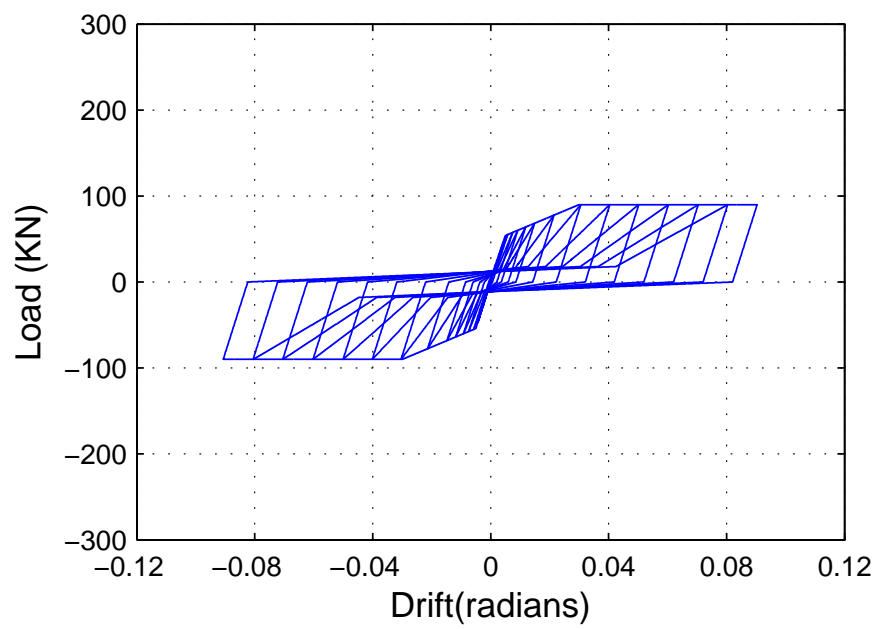

(b)

Figure 6.14: a) Load-drift Response for Specimens with and without the Floor Slab (Liu and Astaneh-Asl, 2004) b) Developed OpenSees Model for Shear-tab Connection. 


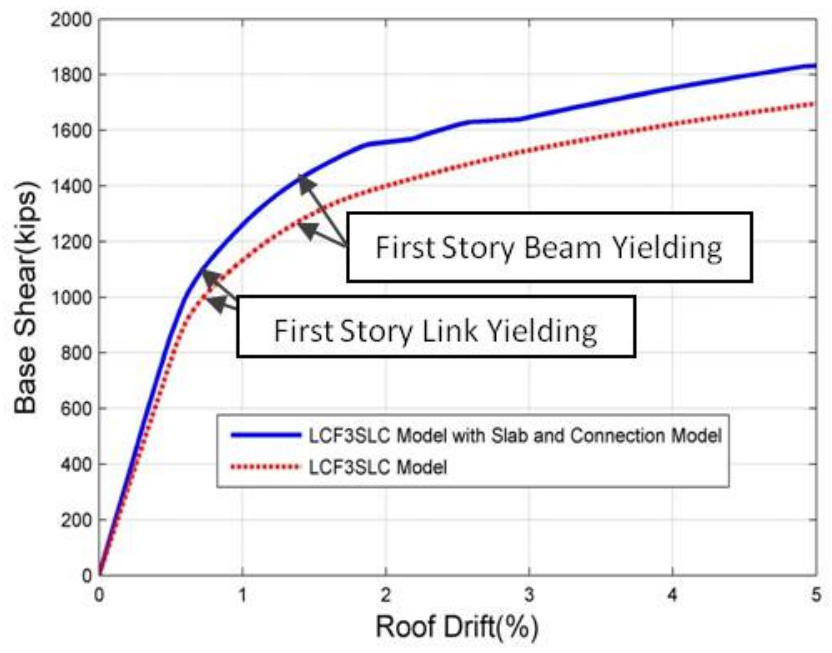

Figure 6.15: Comparison of the Pushover Response of LCF3-SLC with/without Modeling Slab and Connection.

a rigid diaphragm, which also resulted in near zero axial loads in the beams.

As discussed earlier, rigid end offsets were used at all beam-to-column and link-to-column intersections such that the deformable regions of the links, beams and columns were representing only the clear span of each structural member. This is necessary because in the linked column portion of the LCF, the connection region may represent a considerable percentage of the link's length, resulting in an overestimation of the linked column's flexibility, if a centerline model is used. Further, if the panel zones are capacity designed (this assumes that panel zones would be detailed to remain mostly elastic) their shear deformations will be small and can be reasonably neglected.

Gravity loads were assigned to the beams as distributed loads and tributary seismic mass was applied at the nodes at the centerline of the beam-to column connections at each story. Rayleigh damping of $2 \%$ in the first and third modes was used in the models.

Monotonic and cyclic pushover analyses were performed on the model of LCF 3SLC using a lateral load distribution determined by the code-prescribed equivalent lateral forces applied at the floor levels to explore the system behavior prior to developing models of the other LCF designs and running nonlinear response analyses. 


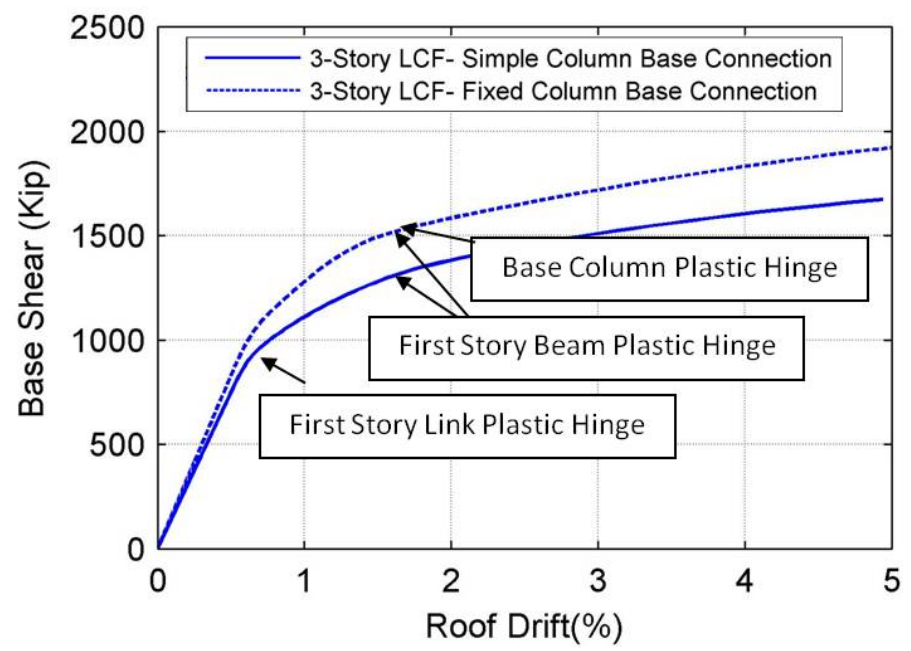

Figure 6.16: Pushover Response of 3-story LCF .

The progression of yielding is shown in Figures 6.16 and 6.17 which show the static and cyclic pushover response of the system as well as the link shear force and beam moment vs. roof drift. The pushover response demonstrates the system's ability to limit yielding to only the links until large drifts, for both system. One system with columns fully restrained at foundation and the other with simple connection at base, as shown in Figure 6.16. Figure 6.18 shows the progression of hinge formation of the LCF 3SLC system. As shown, link yielding begins at a roof drift of $0.69 \%$, beam yielding begins at a roof drift of $1.59 \%$, and at $5 \%$ drift there is extensive link and beam yielding. The large difference between the story drifts at which the links and beams yield enables the structural designer to specifically design for the two different performance objectives of rapid repair and collapse prevention.

In the case that all columns restrained at the foundation, the elastic stiffness and strength was higher than LCF with pinned connection at the base, due to the addition of the linked columns as shown in Figures 6.16. However, the sequence of yielding is very similar. The first story links became plastic at $0.72 \%$ drift, the beams yielded at $1.64 \%$ drift and were followed closely by the columns ( $1.69 \%$ drift). 


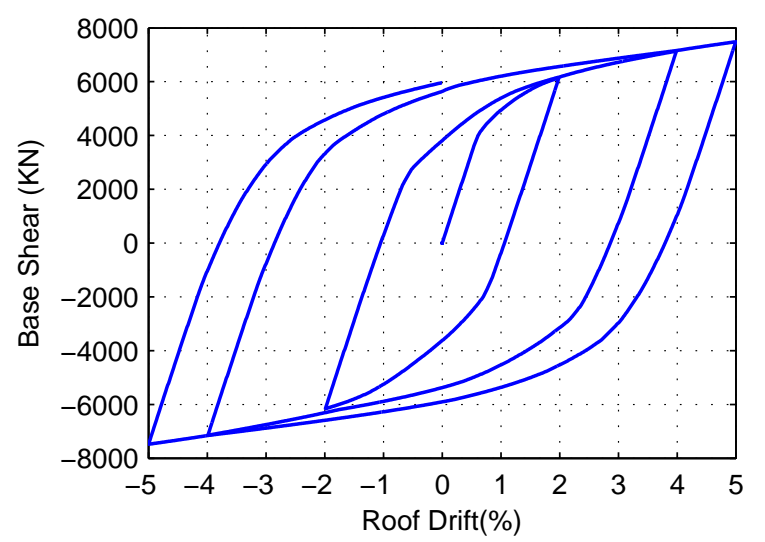

(a)

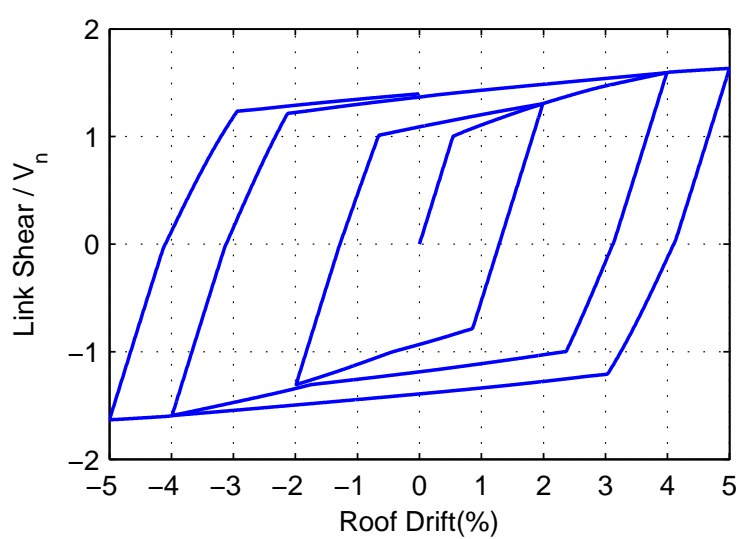

(b)

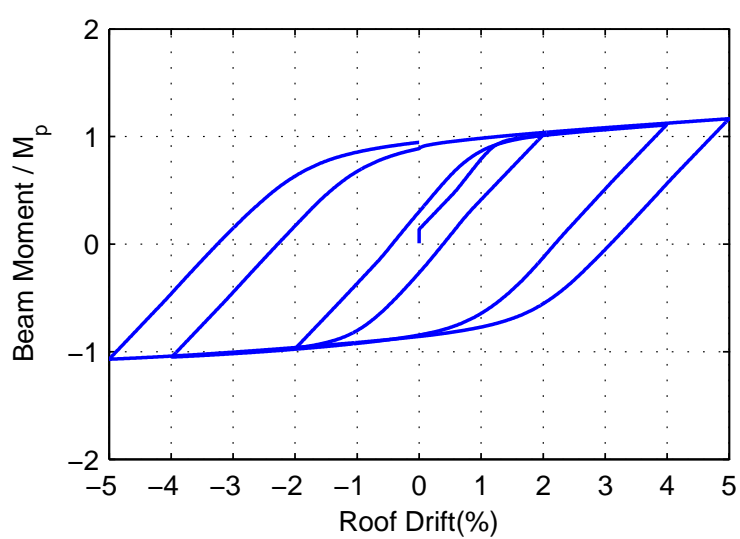

(c)

Figure 6.17: Pushover Response of LCF (a) Cyclic Analysis (b) The First Link Yielding (c) The First Beam Yielding. 


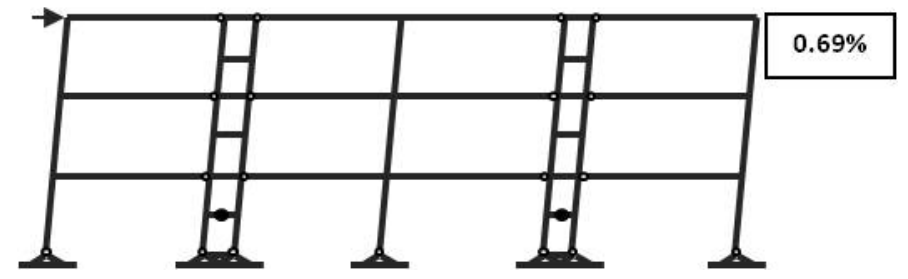

(a)

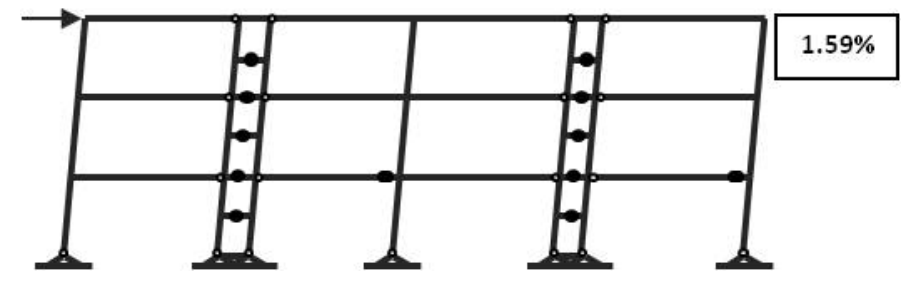

(b)

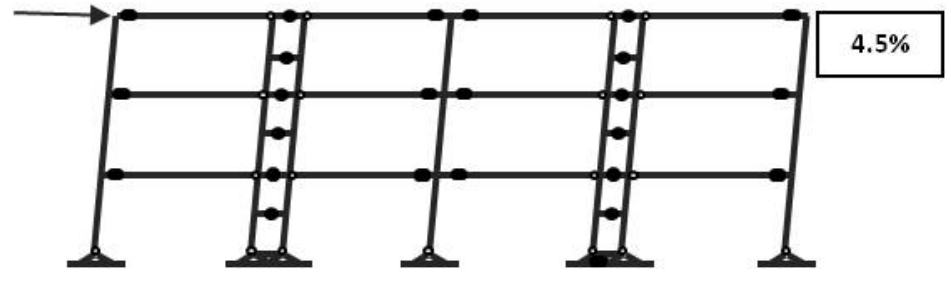

(c)

Figure 6.18: Pattern of Plastic Hinge Formation (a) The First Link Yield (b) The First Beam yield (c) Extensive Link and Beam Yield 
Chapter 7

\section{NONLINEAR ANALYSIS}

\subsection{Nonlinear Static (Pushover) Analysis}

\subsubsection{Fundamental Characteristics of the Prototype LCF Systems}

As described previously and shown in Table 5.1, several LCF systems were designed at 3, 6 and 9 stories. These systems have different characteristics that are observed largely from pushover analyses and described here. The characteristics of interest include yielding mode of the links, initial stiffness, lateral strength and roof displacement at the onset of link yielding and at the onset of beam yielding, and the fundamental period vibration. For each system, 3 different pushover analyses were done: pushover of the system with hinges at the beam ends; pushover of the system with the hinges at the link ends; and pushover of the complete system. These analyses enable approximation of the contributions of the LC and MF to the total response. The resulting system characteristics values are shown for all LCF designs in Table 7.1. Note that the fundamental period, T, shown in the table was obtained from modal analysis using OpenSees.

Three different 3-story LCF systems were designed for this study. These systems were designed such that each has a similar overall behavior including the total strength, $V_{p}$ and the fundamental period. The 3-story systems also all have values for the ratio of the yield displacement of moment frame to the yield displacement of link column that are greater than $1.8\left(\frac{\Delta_{Y M F}}{\Delta_{Y L C}} \geq 1.8\right)$. However, each 3 -story system has a different type of link (shear, flexural or intermediate), and therefore, different relative strengths of the linked column with respect to the moment frame. LCF 3-SLC has all shear links which results in linked columns that are considerably stronger and stiffer $\left(\frac{V_{Y M F}}{V_{Y L C}}=0.52\right)$ than LCF 3-SMF, which has all flexural links $\left(\frac{V_{Y M F}}{V_{Y L C}}=2.07\right)$. LCF 3-SS has a mix of shear, flexural and intermediate links and the linked columns and moment frame in that system have similar strengths $\left(\frac{V_{Y M F}}{V_{Y L C}}=0.96\right)$ while the linked column is still considerably stiffer $\left(\frac{\Delta_{Y M F}}{\Delta_{Y L C}} \geq 2.46\right)$. 
Table 7.1: Fundamental Characteristic of 3, 6 and 9-story LCF

\begin{tabular}{|c|c|c|c|c|c|c|c|c|c|c|}
\hline Name & System & $\Delta_{Y_{(m m)}}$ & $\Delta_{P_{(m m)}}$ & $V_{Y_{(K N)}}$ & $V_{P_{(K N)}}$ & $K_{\left(\frac{K N}{m}\right)}$ & $T_{s e c}$ & $\frac{\Delta_{Y M F}}{\Delta_{Y L C}}$ & $\sqrt{\frac{V_{P L C F} \Delta_{P L C F}}{V_{Y L C F} \Delta_{Y L C F}}}$ & $\frac{V_{Y M F}}{V_{Y L C}}$ \\
\hline \multirow{3}{*}{ 3-SLC } & $\mathrm{LC}$ & 103.4 & - & 2833 & - & 27391 & - & & & \\
\hline & $\mathrm{MF}$ & 190.2 & - & 1468 & - & 7707 & - & 1.84 & 2.08 & 0.52 \\
\hline & $\mathrm{LCF}$ & 82.1 & 189.1 & 3280 & 5228 & 37541 & 0.81 & & & \\
\hline \multirow{3}{*}{ 3-SMF } & $\mathrm{LC}$ & 67.3 & - & 1230 & - & 18269 & - & & & \\
\hline & $\mathrm{MF}$ & 175.2 & - & 2544 & - & 13737 & - & 2.75 & 2.45 & 2.07 \\
\hline & $\mathrm{LCF}$ & 71.4 & 222.8 & 2641 & 5060 & 37009 & 0.85 & & & \\
\hline \multirow{3}{*}{ 3-SS } & $\mathrm{LC}$ & 83.1 & - & 1980 & - & 23844 & - & & & \\
\hline & MF & 204.1 & - & 1903 & - & 9332 & - & 2.46 & 1.94 & 0.96 \\
\hline & $\mathrm{LCF}$ & 91.7 & 230.4 & 3431 & 5125 & 37415 & 0.84 & & & \\
\hline \multirow{3}{*}{ 6-S-80 } & $\mathrm{LC}$ & 176.3 & - & 4103 & - & 23275 & - & & & \\
\hline & MF & 283.7 & - & 2570 & - & 9058 & - & 1.61 & 2.15 & 0.63 \\
\hline & $\mathrm{LCF}$ & 126.2 & 341.4 & 4830 & 8279 & 38259 & 1.29 & & & \\
\hline \multirow{3}{*}{ 6-I-100 } & $\mathrm{LC}$ & 200.7 & - & 5400 & - & 26913 & - & & & \\
\hline & MF & 304.3 & - & 2121 & - & 6969 & - & 1.52 & 1.81 & 0.39 \\
\hline & LCF & 155.2 & 347.2 & 5950 & 8747 & 38340 & 1.24 & & & \\
\hline \multirow{3}{*}{$6-\mathrm{I}-120$} & $\mathrm{LC}$ & 194.6 & - & 6072 & - & 31210 & - & & & \\
\hline & MF & 333.5 & - & 1573 & - & 4716 & - & 1.71 & 1.80 & 0.26 \\
\hline & $\mathrm{LCF}$ & 172.5 & 391.2 & 6603 & 9483 & 38283 & 1.23 & & & \\
\hline \multirow{3}{*}{$6-\mathrm{F}-120$} & $\mathrm{LC}$ & 183.9 & - & 5708 & - & 31042 & - & & & \\
\hline & MF & 297.2 & - & 1801 & - & 6060 & - & 1.62 & 1.79 & 0.32 \\
\hline & LCF & 158.1 & 341.6 & 6099 & 9020 & 38607 & 1.23 & & & \\
\hline \multirow{3}{*}{$9-2 b$} & $\mathrm{LC}$ & 297.3 & - & 7040 & - & 23677 & - & & & \\
\hline & $\mathrm{MF}$ & 354.3 & - & 3980 & - & 11231 & - & 1.19 & 1.53 & 0.57 \\
\hline & $\mathrm{LCF}$ & 280.9 & 457.9 & 9202 & 13286 & 32755 & 1.44 & & & \\
\hline \multirow{3}{*}{$9-3 b$} & $\mathrm{LC}$ & 302.6 & - & 8940 & - & 29549 & - & & & \\
\hline & MF & 388.6 & - & 3614 & - & 9300 & - & 1.28 & 1.61 & 0.41 \\
\hline & LCF & 289.6 & 502.2 & 10471 & 15742 & 36162 & 1.61 & & & \\
\hline
\end{tabular}


Four different 6-story LCF systems were investigated. They again were designed to have similar overall behavior; however, these systems not only differ in link type, but also in linked column spacing and corresponding link lengths. Various link lengths were employed to examine the impact of overturning moment on LCF behavior. For example, increasing the linked column spacing decreases the axial load in the columns caused by overturning moment and increases the total stiffness of LCF, thus reducing story drifts. Table 7.1 also shows relative strengths of the linked column and moment frame. As shown, the 6-story LCF with the shortest links, LCF 6-S80 has the largest relative linked column strength.

In the 9-story designs, two different layouts were chosen as discussed previously, one with two sets of linked columns (LCF 9-2b) and the other with three sets of linked columns (LCF 9-3b). However, the link lengths were the same. As shown in Table 7.1, LCF 9-3b is a stiffer system $\left(k_{e}=36162 \frac{K N}{m}\right)$ and has higher overall strength $\left(V_{p}=15742 \mathrm{KN}\right)$ than the LCF 9-2b $\left(k_{e}=32755 \frac{K N}{m}\right.$ and $\left.V_{P}=13286 \mathrm{KN}\right)$.

It should be noted, except the 9-stories LCF, all other frames have the value larger than

1.75 ( Table 4.1 for Los Angeles location) for $\sqrt{\frac{V_{P L C F} \Delta_{P L C F}}{V_{Y L C F} \Delta_{Y L C F}}}$. This can be a validation of the key equation (Equations 4.16) of second design procedure, that was discussed in Chapter 4.

\subsubsection{Comparison of LCF and SMRF Pushover Curves}

As shown in Figure 7.1, the LCF (3-SLC) design has a lower overstrength relative to a comparable SAC moment frame which results in lower foundation demand for LCF building. Both systems were approximately designed to the similar code requirements and both satisfy the drift limit while LCF is a more efficient system. Although the short spans of the links create large axial load demands on the columns of the LCs, the system can be effectively designed with much lower overstrength than moment resisting frames, as shown in Figure 7.1 via the comparison with SAC moment frame building. Thus, there is a trade off in selecting an LCF that requires the foundation to be designed for smaller base shear but larger localized overturning demands under the linked columns. 


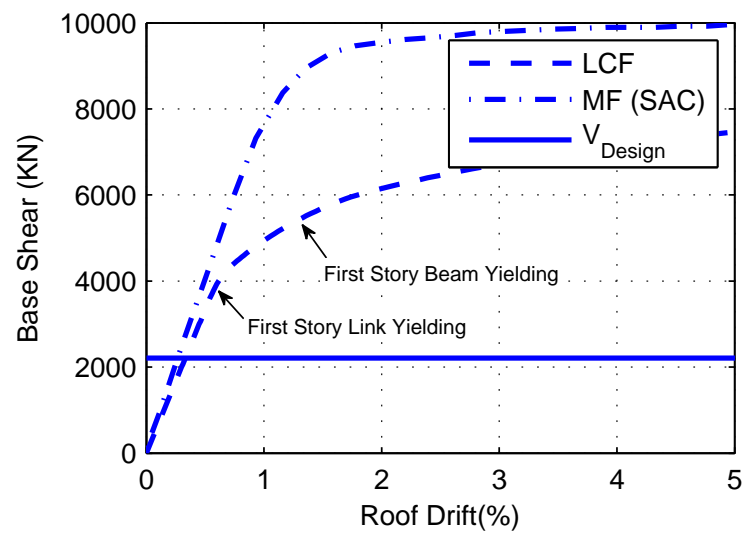

Figure 7.1: Pushover Analysis of LCF in Comparison with SAC Moment Frame.

\subsection{Nonlinear Dynamic (Response History) Analysis}

After establishing the basic characteristics of the LCF systems considered, nonlinear response history analysis was performed on each. Three suites of 20 earthquake ground motion records were used in the nonlinear analyses. The ground motions were those developed in the SAC project for the Los Angeles site by Somerville et al. (1997) for soil type D. (The target response spectra values for various earthquake hazard levels for soil type D are shown in Table 7.2(FEMA-355 C, 2001)). These three suites of ground motions represent three seismic hazard levels: $50 \%$ in 50 year, $10 \%$ in 50 year, and $2 \%$ in 50 year earthquakes scaled to target spectral acceleration values at four periods by Somerville et al. (1997). The target spectral acceleration values used for scaling the $2 \%$ in 50 year ground motions were the same as the maximum credible earthquake values used here for LCF design. The spectral acceleration for the $10 \%$ in 50 year hazard level are approximately $2 / 3$ of those for the $2 \%$ in 50 year ground motions and thus approximate the design basis earthquake. Results of the analyses will inform recommendations regarding LCF design and demonstrate system performance. As shown below, the results of this chapter indicate that in general, the LCF designs were able to achieve the performance objectives of:

1. Primarily elastic behavior in frequent earthquakes (50\% in 50 year) 
Table 7.2: Response Spectra Values (in units of g) for Site Class D for 5\% Damping Level in Los Angeles area

\begin{tabular}{ccc}
\hline & \multicolumn{2}{c}{ Period (sec) } \\
\cline { 2 - 3 } Hazard Level & 0.3 & 1.0 \\
\hline $2 \%$ in 50 year & 1.610 & 1.190 \\
$10 \%$ in 50 year & 1.070 & 0.680 \\
$50 \%$ in 50 year & 0.510 & 0.288 \\
\hline
\end{tabular}

2. Only link yielding in the design earthquake (10\% in 50 year)

3. Collapse prevention in the maximum earthquake ( $2 \%$ in 50 year)

\subsubsection{Story Drift}

Figure 7.2.1 shows the statistical results for the maximum story drift for the ground motions for each LCF (i.e., the median and 84th percentile values for the maximum story drift obtained for the ground motions for each hazard level). As shown, the LCF is capable of meeting drift limits as the story drifts for each hazard level are within ranges that would be considered acceptable for most applications, i.e., less than $1 \%$ for the $50 \%$ in 50 year hazard, less than $2 \%$ for the $10 \%$ in 50 year hazard and less than $5 \%$ for the $2 \%$ in 50 year hazard. Further, the story drifts are comparable to or less than drifts in post-Northridge moment resisting frame designs per Gupta and Krawinkler (1999).

Examining the story drift results for the 3-story LCFs, it appears that the shear link design, LCF 3-SL, has smaller story drifts relative to the other two designs and the flexural link design (LCF 3-SMF) has 84th percentile story drifts higher than $5 \%$ in the $2 \%$ in 50 year hazard. In this case the majority of the stiffness and strength of the LCF system is provided by the MF rather than the $\mathrm{LC}$ as shown in Table 7.1. This seems to indicate frames with larger contributions from LC will have more desirable performance. 
In the 6-story LCFs, the story drift distributions are similar to each other even though links with different yielding modes were used. The change in the length of links and impact on overturning stiffness may compensate for the effect of different link stiffness. In the $2 \%$ in 50 year ground motions the 6-story LCFs show some concentration of story drifts at the lower level, which is discussed further below.

LCF 9-3b, which has 3 LCs, is stiffer than LCF 9-2b resulting in considerably lower story drifts. Although both designs have story drifts that are acceptable in magnitude, again there is a concentration of drifts at the lower stories which is discussed below.

Most LCF buildings were able to meet the $2 \%$ code-base drift limit at the $10 \%$ in 50 year hazard level; however, first story drift in some cases was only able to meet the $2 \%$ code-based drift limit at the median level.

\subsubsection{Link Rotation}

Figure 7.2 .2 shows link rotation for all three hazard levels. The link yield rotation $\theta_{y}$ is shown by vertical solid lines for reference and was obtained using Timoschenko beam theory and is the average for all links for each particular design. As shown, the links are predominantly elastic for the $50 \%$ in 50 year hazard and should not require repair. LCF 3-SMF and LCF 3-SS, in which the flexure and intermediate links were used, do have a moderate amount of link yielding but are unlikely to require repair. However, median values of link rotations are less than the yield rotation for the $50 \%$ in 50 year hazard level for LCF 3-SMF and LCF 3-SS, which demonstrates that these buildings have at least a $50 \%$ probability of meeting the no repair performance objective in the $50 \%$ in 50 year hazard level.

In the $10 \%$ in 50 year hazard, links in all frames have rotations larger than yield and some may have damage that warrants link replacement. In the $2 \%$ in 50 year hazard level the links have larger inelastic demand and are more likely to require replacement. It is notable that none of the links in any of the LCFs considered failed under any ground motions using the failure criteria established from tests by Dusicka and Lewis (2010) and incorporated in the link model. In the $2 \%$ in 50 year hazard level the 84 th percentile link rotation in LCF 3-SMF, which uses flexural links, exceeds 0.06 rad at the bottom story. 


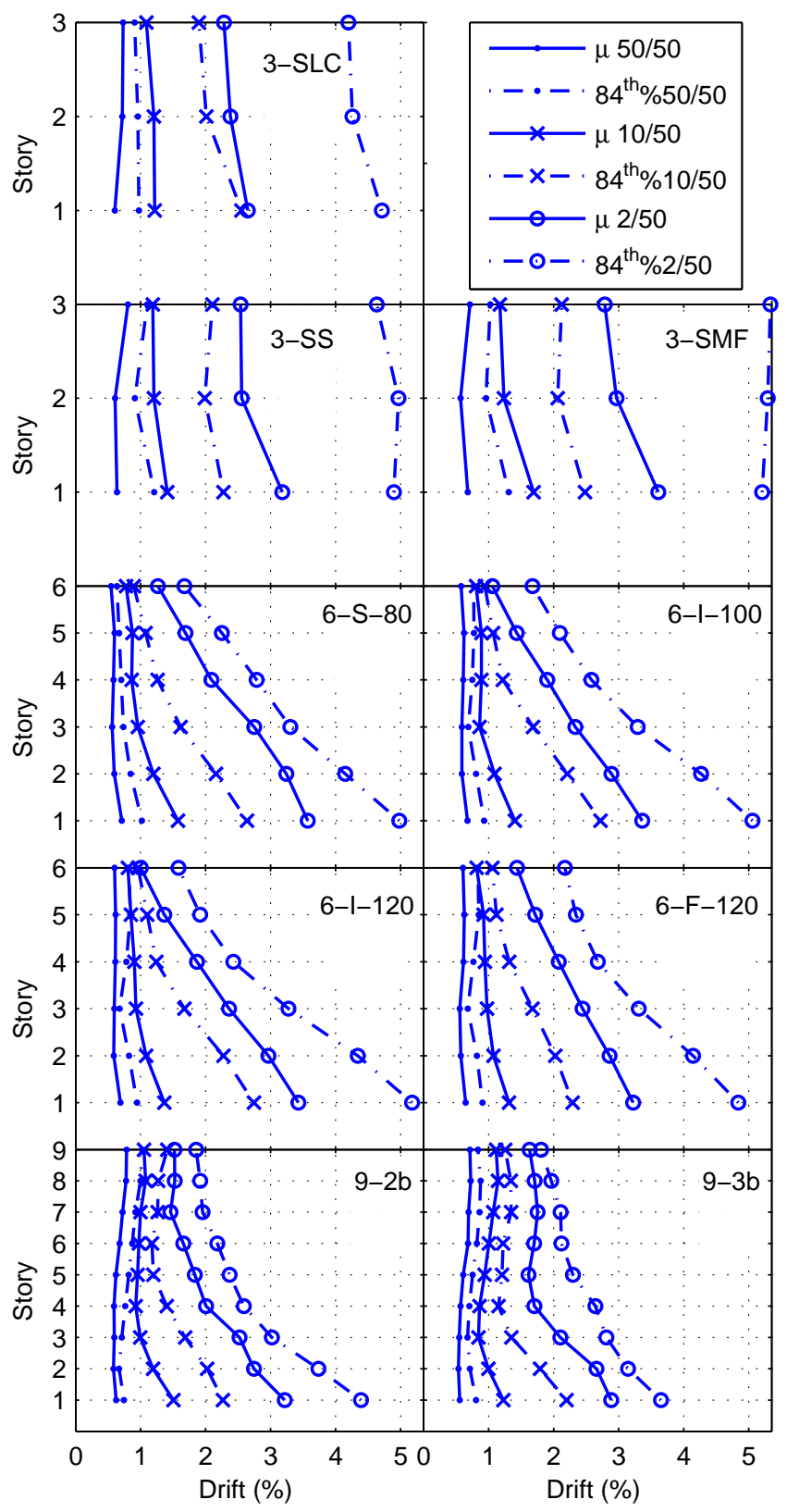

Figure 7.2: Median and 84th percentile Story Drift Results for a 3, 6 and 9-Story LCF Buildings.

This is considerabley larger than the $0.04 \mathrm{rad}$ link rotaion for LCF 3-SLC, which has shear links. The 84th percentile values of link rotation for the 6 and 9-story LCFs are large in 
the lower stories which is discussed further below. LCF 6-I-100 and LCF 6-I-120, which have intermediate links, have smaller link rotations (the $\theta_{\max }$ is $0.06 \mathrm{rad}$ ) than the other 6-story LCFs having shear or flexure links. Additionally, LCF 6-I-120 is more economical than LCF 6-I-100 because the longer length of the links increases the overturning stiffness of the building and leads to the smaller beam and column sizes. The link rotation demands in LCF 9-2b and LCF 9-3b are similar to each other, with larger demands on the lower stories in $2 \%$ in 50 year event but not large enough to cause link failure.

\subsubsection{Beam Rotation}

Figure 7.2 .3 shows the beam rotation demands for the three hazard levels with $\theta_{y}$, the approximate yield rotation, also shown for reference. As shown, in most cases beam yielding does not occur until the $2 \%$ in 50 year hazard level. This ensures that no repairs would be necessary following the design basis earthquake, which achieves the performance objectives and will help to minimize post event repair costs and downtime. In some cases, the 84th percentile values for the $10 \%$ in 50 year event in the first and second stories exceed the yield rotation but the median values are less than the yield line in all cases for the $10 \%$ in 50 year hazard. Moreover, the 84th percentile values of beam rotation demand are less than 0.05 rad in all cases, indicating that none of the beams are likely to fail at that hazard level if special moment frame detailing is used.

\subsubsection{Residual Story Drift}

Further, analytical studies was performed to show that self-recentering may be attained by removing the damaged links so the main structure that remains elastic returns to its original place. In other words, if the gravity system (secondary moment frame) remains elastic during the earthquake, the stored elastic rebound forces in moment frames are capable of self-recentering the LCF after removing the damage links. In evaluating whether a system has achieved recentering, a residual drift limit of less than $0.2 \%$ is imposed, as this corresponds to out-of-plumb limits in construction (ATC, 2009).

Table 7.3 shows the statistical results, median and 84th percentile, for the three hazard 


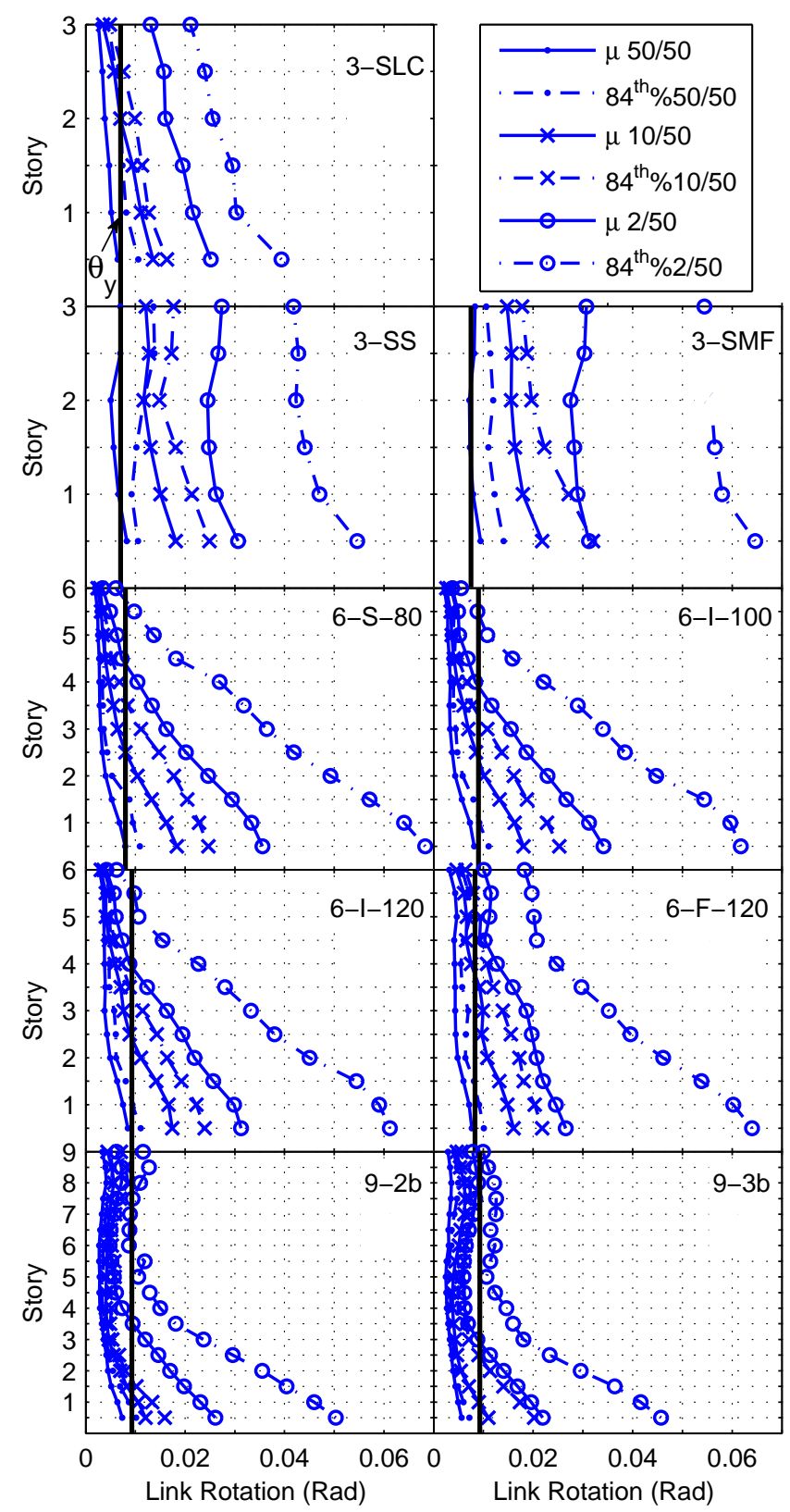

Figure 7.3: Median and 84th percentile Link Rotation Demand Results For a 3, 6 and 9-Story LCF.

levels for the maximum residual story drift values, $\theta_{\text {MaxResid }}$.

As previously mentioned, a residual story drift limit of $0.2 \%$ was used to assess recen- 


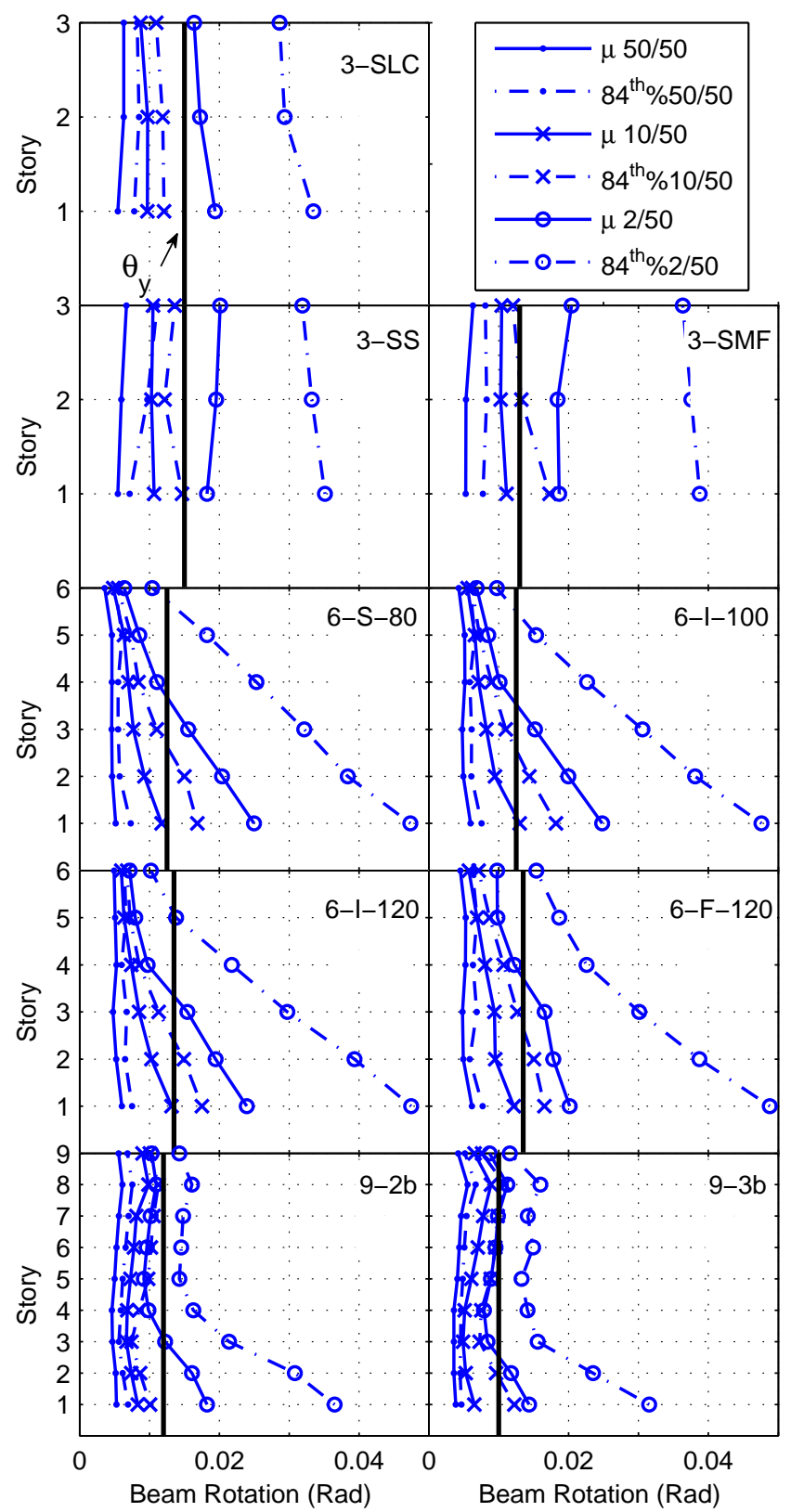

Figure 7.4: Median and 84th percentile Beam Rotation Demand Results For a 3, 6 and 9-Story LCF. 
Table 7.3: Residual Story Drift (\%) Median and 84th Percentile Response From Nonlinear Analyses.

\begin{tabular}{|c|c|c|c|c|c|c|}
\hline \multirow[b]{2}{*}{ Name } & \multicolumn{2}{|c|}{$50 \%$ in 50 year Ground Motion } & \multicolumn{2}{|c|}{$10 \%$ in 50 year Ground Motion } & \multicolumn{2}{|c|}{$2 \%$ in 50 year Ground Motion } \\
\hline & Median & $84 t h \%$ tile & Median & $84 t h \%$ tile & Median & $84 t h \%$ tile \\
\hline 3-SLC & 0.007 & 0.047 & 0.045 & 0.607 & 0.174 & 1.397 \\
\hline 3-SMF & 0.003 & 0.027 & 0.014 & 0.465 & 0.309 & 1.595 \\
\hline 3-SS & 0.005 & 0.044 & 0.069 & 0.375 & 0.194 & 1.372 \\
\hline $6-\mathrm{S}-80$ & 0.009 & 0.058 & 0.011 & 0.191 & 0.391 & 0.856 \\
\hline 6-I-100 & 0.003 & 0.036 & 0.007 & 0.320 & 0.345 & 1.141 \\
\hline 6-I-120 & 0.001 & 0.029 & 0.005 & 0.397 & 0.474 & 1.239 \\
\hline $6-\mathrm{F}-120$ & 0.001 & 0.043 & 0.016 & 0.253 & 0.452 & 1.001 \\
\hline $9-2 b$ & 0.001 & 0.032 & 0.112 & 0.323 & 0.362 & 0.882 \\
\hline $9-3 b$ & 0.001 & 0.015 & 0.064 & 0.213 & 0.216 & 0.821 \\
\hline
\end{tabular}

tering. Based on this, recentering was only able to achieved at the $10 \%$ in 50 year ground motion at the median level.

\subsubsection{Other Response Quantities}

Other response parameters are compared in Table 7.4 to evaluate building performance for the $2 \%$ in 50 year hazard level. Rotation ductility demand for links and beams ( $\mu_{\theta L}$ and $\mu_{\theta B}$ respectively), which is obtained by dividing the median and the 84 th percentile rotation by the yield rotation in each case, and a measure of maximum column demand in the buildings denoted $D_{C 0 l}$ are shown in Table 7.4 . The column demand parameter is maximum value of the interaction equation per AISC Specifications Eqn. H1-1 (AISC, 2005b) over the history of the ground motion. Statistics for these parameters are calculated similarly to the story drift and rotations. A value of $D_{C 0 l}$ of 1.0 or greater indicates the combined axial 
and flexure demands are causing inelastic response; values approaching 1.0 indicate some yielding may be occurring in the section.

As shown in Table 7.4 the 3-story LCF with flexural links have more ductility demand than these with shear links. In the 6-story LCFs, those with intermediate links, the links have lower ductility demands, indicating there may be a range of building heights for which shear, intermediate or flexural links are preferred, at least in terms of ductility demand.

The columns in all cases behave elastically at 50\% and $10 \%$ in 50 year hazard levels, although those values are not shown for brevity. Also, the median values for $D_{C 0 l}$ are significantly less than 1.0 for all hazard levels, indicating no yielding on average in even the $2 \%$ in 50 year event. However, some yielding is observed in the columns in some of the ground motions for the models at this hazard level, particularly for the 3-story LCF. This result is likely due to larger strain hardening in the links than what was accounted for in capacity design, in addition to the fact that in the 3-story LCFs simultaneous link yielding at all stories is likely. For the 6 and 9-story LCFs, Table 7.4 shows that the 84 th percentile values for $D_{C 0 l}$ are less than 1.0 for all cases.

\subsection{Response of Lower Stories in 6 and 9-story LCF}

Story drifts, link rotations and beam rotations were all observed to be larger on the lower stories of the 6-story and 9-story LCFs relative to other stories of those frames. Even with overall performance objectives achieved this is not ideal, as shown in Figure 7.5. The columns in these lower stories are, for the most part, not yielding and remain elastic so the solution to reduce and ensure more uniform story drifts and rotation demands must focus on adding stiffness. The stiffness at the lower stories is further limited by the lack of a fixed column base. As the bottom link yields, the lower story stiffness decreases substantially.

Several solutions are possible, such as:

- Embedding the column base and dealing with the consequences of larger column flexural demands

- Adding additional links at the lower stories to increase the story stiffness 
Table 7.4: Tabulated Response Parameters From Nonlinear Analyses (2\% in 50 years)

\begin{tabular}{|c|c|c|c|c|c|c|}
\hline \multirow[b]{2}{*}{ Name } & \multicolumn{2}{|c|}{$\mu_{\theta L}$} & \multicolumn{2}{|c|}{$\mu_{\theta B}$} & \multicolumn{2}{|c|}{$D_{C o l}$} \\
\hline & Median & $84 t h \%$ tile & Median & 84th\%tile & Median & $84 t h \%$ tile \\
\hline 3-SLC & 3.60 & 5.57 & 1.29 & 2.20 & 0.49 & 1.11 \\
\hline 3-SMF & 4.17 & 8.53 & 1.57 & 2.92 & 0.44 & 0.67 \\
\hline 3-SS & 4.38 & 7.71 & 1.31 & 2.33 & 0.50 & 1.07 \\
\hline $6-\mathrm{S}-80$ & 4.44 & 8.50 & 2.00 & 3.76 & 0.38 & 0.56 \\
\hline $6-\mathrm{I}-100$ & 3.80 & 6.88 & 1.98 & 3.84 & 0.33 & 0.64 \\
\hline $6-\mathrm{I}-120$ & 3.65 & 6.56 & 1.77 & 3.48 & 0.34 & 0.62 \\
\hline $6-\mathrm{F}-120$ & 3.21 & 7.71 & 1.49 & 3.63 & 0.27 & 0.57 \\
\hline $9-2 b$ & 2.80 & 5.37 & 1.52 & 3.00 & 0.50 & 0.88 \\
\hline $9-3 b$ & 2.35 & 4.84 & 1.48 & 3.10 & 0.58 & 0.94 \\
\hline
\end{tabular}

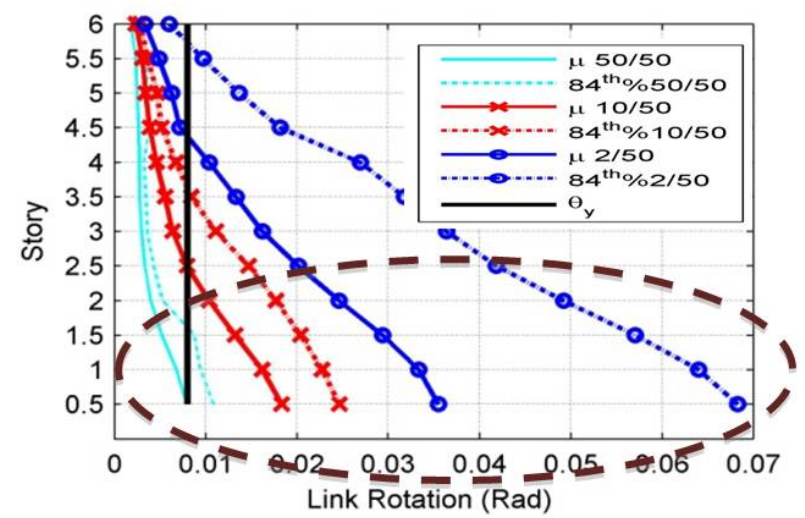

Figure 7.5: Median and 84th Percentile Link Rotation Demand Results For a 6-Story LCF.

- Using alternative geometries by leveraging two side-by-side LCs to increase the overturning resistance

- Using built-up link sections to increase their stiffness without proportionally increasing 
their strength

- Using built-up column sections or concrete-filled steel tube (CFT) columns leveraging the column stiffness to help increase story stiffness and column strength; it is acknowledged that connection design may be difficult. Connection concepts will be proposed but will likely need additional research outside the scope of this work. In addition to its high stiffness, the CFT column system has many advantages when compared to the ordinary steel system. One of the main advantages is the interaction between the steel tube and concrete; local buckling of the steel tube is delayed by the restraint of the concrete, and the strength of concrete is increased by the confining effect of the steel tube. Moreover, the steel ratio in the CFT cross section is much larger than in steel columns. The steel of the CFT section is well plastified under bending because it is located mostly outside the section. However, the connection details and the difficulties encountered when trying to ensure proper construction methods may need more thorough research.

- Using outrigger frames; drift controlled designs result in large distances between link columns (120"). The potential solution, in addition to the previously mentioned improvements, may be to change the boundary conditions of link column by using outrigger frames. The outrigger concept is in widespread use today in the design of tall buildings; in this concept, outrigger trusses (or, occasionally, girders) extend from a lateral load-resisting core to columns at the exterior of the building. The core may consist of either shear walls or braced frames but in LCF system the core is link column. Outrigger systems can lead to very efficient use of structural materials by mobilizing the axial strength and stiffness of exterior columns of moment frame to resist part of the overturning moment produced by lateral loading in link column. The outriggers in LCF connect the link column to columns of secondary moment frame of the structure. This way the horizontally applied load will force the link column to behave compositely with the moment frame by introducing axial forces in the columns of moment frame. These forces form a restraining moment which is in the opposite 
direction to the bending moment from the horizontal load. This effect will decrease the bending moments in the link column from outrigger level down to the base and will reduce the horizontal deflections of the structure. There are, however, some important space-planning limitations and certain structural complications associated with the use of outriggers in the tall LCF.

These solutions may improve the behavior of the 6-story and 9-story LCFs to ensure more uniform distribution of story drifts, link rotations and beam rotations to achieve better performance. In this study, three methods were investigated and the rest will be topics for future work.

The first method investigated is one which involves fixing the foundation in OpenSees model. For 6- and 9-story LCF, due to large axial force in columns, embedding the columns in concrete foundation is the only feasible solution. As mentioned earlier, the simple connections at base were assumed for these models, due to the fixed based connection providing more stiffness and less drift demands. The second method requires adding additional links at the lower stories to increase the story stiffness. The new design LCFs with columns embedded at base and additional links added were analyzed using OpenSees and the response of the system was investigated for LA ground motions. The results of nonlinear response history analyses are presented in section 7.3 .1 .

The third method uses built-up link sections. The complete study of this case and the effect of utilizing the build-up link section on overall LCF behavior is presented in chapter 8 , section 8.2 .

\subsubsection{Improving LCF Performance by Embedding the Column Base or by Adding Addi- tional Link at the Lower Level}

As mentioned earlier, the solution to ensure more uniform story drifts and rotation demands focuses on adding stiffness at lower stories in taller LCFs. Two methods, embedding the column base and adding additional links at the first floor, were investigated (Figure 7.6).

For this instance the LCF6-S-80 was selected form previous models. LCF6-S-80-Fixed model was developed assuming the column connections are fixed at the base while LCF6- 
S-80-Add model was developed by adding additional links per each LC at first level. In LCF6-S-80-Add model, the first pair of links was located at elevation 52" above the base and the second pair of links was located at elevation 156" above the base. Nonlinear response history analysis was performed and the results in comparison with LCF6-S-80 are presented in Figure 7.7 .

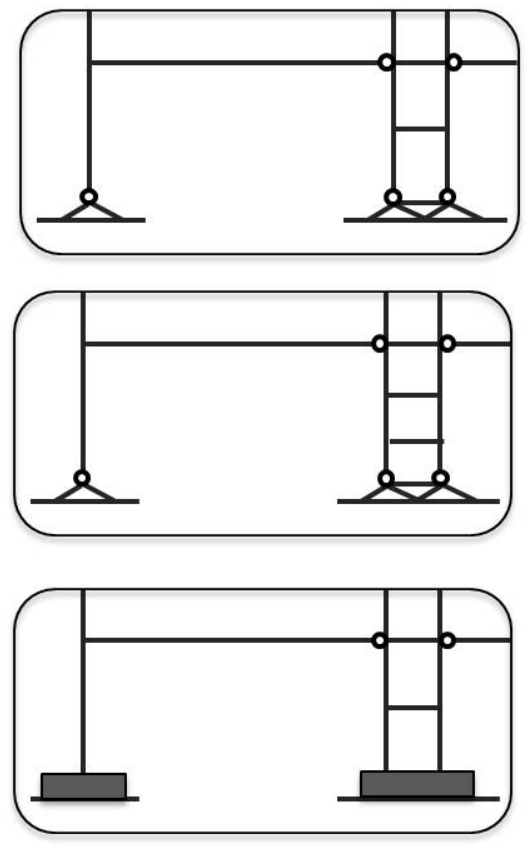

Figure 7.6: Different Column Boundary Condition for LCF, Additional Link at the First Floor and Fully Restrained Column Connections.

Figure 7.7 shows the the statistical results for the maximum story drift, link rotation and beam rotation demands for all three hazard levels for LCF6-S-80, LCF6-S-80-Add and LCF6-S-80-Fixed, with vertical solid lines that represent the onset of plastification of links and beams. As shown, all three systems are capable of meeting drift limits, as the story drifts for each hazard level are within ranges that would be considered acceptable for most applications; i.e., less than $1 \%$ for the $50 \%$ in 50 year hazard, less than $2 \%$ for the $10 \%$ in 50 year hazard and less than $5 \%$ for the $2 \%$ in 50 year hazard. It is also appears that adding the additional links at the first floor or fixing the column connections at the base, decreases the story drift by approximately $15 \%$ at that level, which may yield ideal results. 

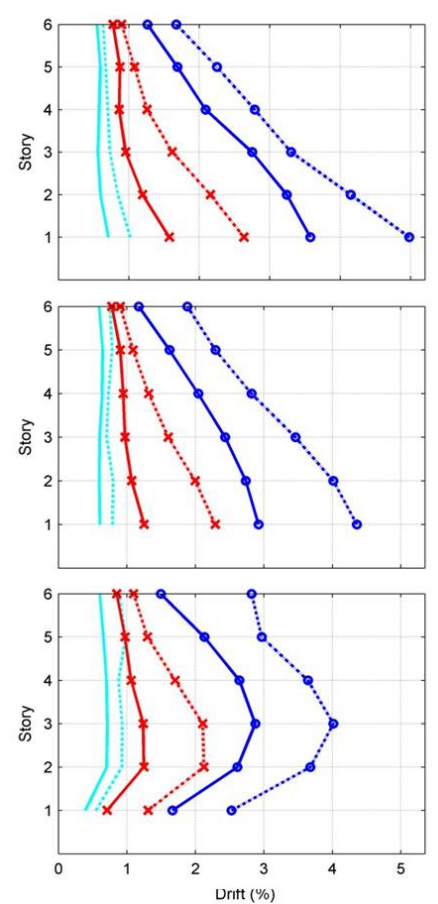
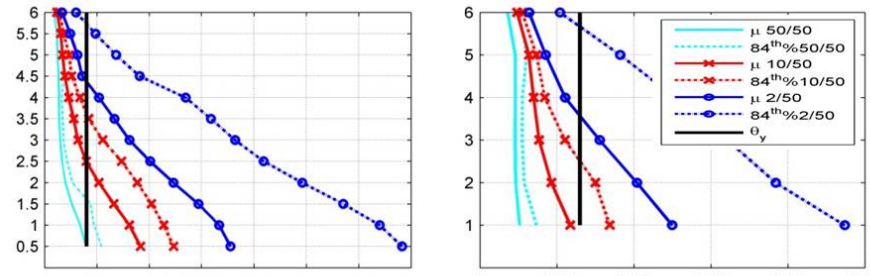

LCF6-S-80
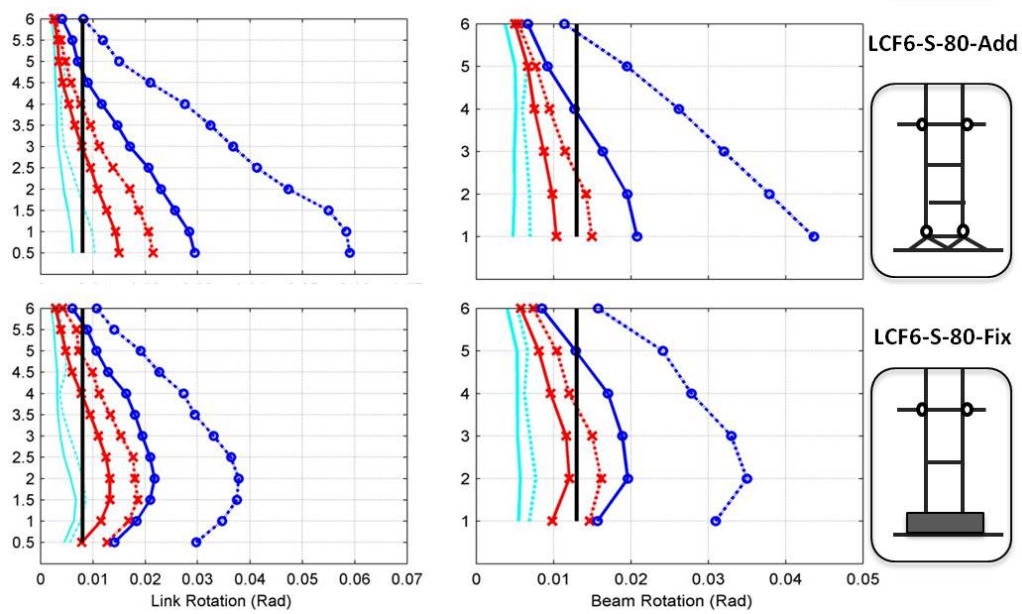

Figure 7.7: Median and 84th Percentile Story Drift, Link Rotation and Beam Rotation Results for LCF6-S-80, LCF 6-S-80-Add and LCF6-S-80-Fixed .

Furthermore, the links in all cases are predominantly elastic for the $50 \%$ in 50 year hazard and should not require repair; in the $10 \%$ in 50 year hazard, links in all frames have rotations larger than yield and some may have damage that warrants link replacement; and finally in the $2 \%$ in 50 year hazard level, the links have larger inelastic demand and are more likely to require replacement. Moreover, the same improvement occurs in link rotation demands. In LCF-S-80-Add model, for both the 84 th percentile level in $2 \%$ in 50 year event, $0.01 \mathrm{Rad}$ and at median level in $2 \%$ in 50 year event, $0.005 \mathrm{Rad}$, reductions were observed at lower levels. This reduction in link rotaion demands is more significant in LCF-S-80-Fixed model. Also, more unifrom link rotation demands (more link yielding in upper floors) were observed in this model.

Finally, as shown, beam yielding does not occur until the $2 \%$ in 50 year hazard level in all cases, which ensures that the purpose of rapid repair is fulfilled. Reducing the beam rotation demand from $0.026 \mathrm{Rad}$ to almost $0.02 \mathrm{Rad}$ at the median level ( $2 \%$ in 50 year event) 
indicates more uniform beam rotation distribution for each of the new designs. Again more uniform beam rotation demands were observed in the fully restrained column at foundation system.

It should be noted the columns' rotations at foundation level in $2 \%$ in 50 year event at 84th percentile level, are within acceptable range corresponding to the target building performance levels of collapse prevention, based on FEMA-356 (2000) acceptance criteria.

In conclusion, adding stiffness at lower levels by implementing an additional link at the first floor or embedding column connections at base, improves LCF performance through the delivery of more uniform demand distribution.

\subsection{Evaluation of the Robustness of the Design Procedure for Different Seismic Regions}

To evaluate the robustness of the design procedure, the performance of an LCF designed for various seismic regions was evaluated. In previous sections, three suites of 20 SAC ground motions for the Los Angeles site were used for nonlinear dynamic analyses. The Los Angeles acceleration spectra and ground motions at the hazard levels considered have particular characteristics that may differ from other regions in the U.S., so the performance in other regions with different ground motion characteristics may differ as well (Table 4.1). Thus, LCFs in geographies with other seismic hazard characteristics should be evaluated to ensure that the design procedure results in performance as intended for the levels of seismic hazard considered. For this reason, two suites of $20 \mathrm{SAC}$ ground motions for the Seattle site developed by Somerville et al. (1997) for soil type D were selected to use for additional LCF dynamic analyses. The Seattle area is considered a medium to high seismic design category within the United States. The target response spectra values for various earthquake hazard levels for soil type D for the Seattle site are shown in Table 7.5 (FEMA-355 C, 2001). The ground motions were scaled on average to those spectral values.

In total, 6 LCF buildings were designed (all 6 designs were built by Arlindo Lopez, PhD candidate- Portland State University (Lopez et al. 2012a) ) for the Seattle location; three 3-story and three 6-story. As outlined before, the previously developed SAC joint venture (FEMA 355-C) prototype building layout was used as a basis for the building geometry as 
Table 7.5: Response Spectra Values (in units of g) for Site Class D for 5\% Damping Level in Seattle area

\begin{tabular}{ccc}
\hline & \multicolumn{2}{c}{ Period $(\mathrm{sec})$} \\
\cline { 2 - 3 } Hazard Level & 0.3 & 1.0 \\
\hline $2 \%$ in 50 year & 1.455 & 1.00 \\
$10 \%$ in 50 year & 0.71 & 0.39 \\
\hline
\end{tabular}

prototype for the the LCF building designs. The LCF buildings followed similar layout, except that two of the columns were replaced by linked columns and beam lengths were adjusted accordingly, so that the building had the same overall plan dimensions. The links connecting the LCs were designed as shear links. Link designs utilized built-up sections for additional design freedom and additional designs were also developed using wide flange beams.

The initial member sizes of the LCFs were obtained using gravity load analyses along with equivalent seismic lateral loads using building code prescribed forces similar to those for the Los Angeles buildings. In this study, instead of eccentric braced frame values, seismic design coefficients for special moment frame of $R=8, \Omega=3$ and $C_{d}=5.5$ were used as specific LCF system coefficients. Strong column weak beam capacity design principles were applied for all columns, including LCs. Similar to the Los Angeles buildings, the initial LCF structure subjected to equivalent seismic lateral loads resulted in interstory drifts exceeding code maxima. Two different design approaches were undertaken to determine the section sizes of LCF systems meeting the design intent of $2.5 \%$ interstory drift limits; 1 ) increasing MF beam sizes first and, 2) increasing LC links and column sizes first.

This resulted in LCF-L and LCF-M designs corresponding to the approach of controlling drift primarily using LC and MF respectively. Also, additional designs were completed using wide flange sections for shear links based on second design approach; the latter are denoted LCF-WF design systems. Rolled wide flange sections were used for columns and MF beams. Built-up sections from plates as well as rolled wide flange alternatives were developed for 
the links.

The resulting LCF 3- and 6-story systems are summarized in Table 7.6 and 7.7 for both approaches. The link properties were summarized in Table 7.8 .

These six models have different pushover characteristics which are described here. For the LCF systems, individual contributions from LC and MF were calculated with separate pushover analyses of a modified model where the member connections in MF and LC, respectively, were pinned. The resulting values of the system characteristics are shown for all Seattle LCF designs in Table 7.9. In this table, the yield drift, stiffness and base shear ratio of linked column and moment frame were all compared.

In all cases, the displacement or drift ratio $\frac{\Delta_{Y M F}}{\Delta_{Y L C}}$ was within the range of 1.2-3, indicating that rapid repair performance level, in which only LC links are damaged and all gravity members remain elastic, can occur over a drift range that is at least twice the drift at first yield of the links.

Moreover, in all cases except 6-story LCF-M, the ratio of $\sqrt{\frac{V_{P L C F} \Delta_{P L C F}}{V_{Y L C F} \Delta_{Y L C F}}}$ was close enough to or greater than $\frac{S_{1(2 \% i n 50)}}{S_{1(10 \% \text { in } 50)}}$ ratio, which for the Seattle location is 2.54 . In the case of 6story LCF-M design, where the MF beams were primarily used to achieve the prescribed drift criteria, the $\sqrt{\frac{V_{P L C F} \Delta_{P L C F}}{V_{Y L C F} \Delta_{Y L C F}}}$ ratio is much lesser than 2.54, suggesting that using LC links and columns first to meet drift requirements results in a system that is more likely to achieve the target performance objectives.

Structural steel weight was also calculated for each of the frames as an indicator of the structural cost, as summarized in Table 7.9. For the 3-story LCF systems, those where the LC links and columns were used as the primary means of achieving the drift requirements were found to be significantly lighter frames than those in which MF beams were used as means to control drift. These lighter LCF designs had comparable weights to special moment resisting frame (SMRF) designs (3- and 6-story SAC SMRF models that were designed at Portland State University were used here), indicating that comparable cost effectiveness is possible, considering the steel costs only.

In the 6-story LCF, again the system in which the LC links and columns were used as the primary means of achieving drift criteria resulted in lighter frames than those in which MF beams were used as means to control drift (Lopez et al., 2012a). 
Table 7.6: Design Details; Beam and Column Section for 3-story Seattle Buildings

\begin{tabular}{|c|c|c|c|c|c|c|c|}
\hline \multirow[b]{3}{*}{ Model } & \multirow[b]{3}{*}{ Story } & \multicolumn{2}{|c|}{ Link Column } & \multicolumn{4}{|c|}{ Moment Frame } \\
\hline & & \multirow[b]{2}{*}{ Column } & \multirow[b]{2}{*}{ Beam } & \multicolumn{2}{|c|}{ Column } & \multicolumn{2}{|c|}{ Beam } \\
\hline & & & & Exterior & Interior & Exterior & Interior \\
\hline \multirow{3}{*}{ 3-Story LCF-L } & $\begin{array}{c}\text { Base } \\
\text { Int } 1 / 2 \\
1 / 2\end{array}$ & $\mathrm{~W} 14 \times 257$ & $\begin{array}{l}\mathrm{B} 20.25 \mathrm{X} 10.5 \\
\mathrm{~B} 20.25 \mathrm{X} 10.5 \\
\mathrm{~B} 20.25 \mathrm{X} 10.5\end{array}$ & $\mathrm{~W} 14 \times 120$ & $\mathrm{~W} 14 \times 233$ & W24x84 & $\mathrm{W} 24 \times 84$ \\
\hline & $\begin{array}{c}\text { Int } 2 / 3 \\
2 / 3\end{array}$ & $\mathrm{~W} 14 \times 257$ & $\begin{array}{l}\mathrm{B} 20.25 \times 10.5 \\
\mathrm{~B} 20.25 \times 10.5\end{array}$ & $\mathrm{~W} 14 \times 120$ & $\mathrm{~W} 14 \times 233$ & W24x68 & W24x68 \\
\hline & $\begin{array}{c}\text { Int 3/R00f } \\
3 / \text { Roof }\end{array}$ & $\mathrm{W} 14 \times 257$ & $\begin{array}{l}\mathrm{B} 15.25 \mathrm{X} 10.5 \\
\mathrm{~B} 15.25 \mathrm{X} 10.5\end{array}$ & $\mathrm{~W} 14 \times 120$ & $\mathrm{~W} 14 \times 233$ & W21x55 & $\mathrm{W} 21 \times 55$ \\
\hline \multirow{3}{*}{ 3-Story LCF-M } & $\begin{array}{c}\text { Base } \\
\text { Int } 1 / 2 \\
1 / 2\end{array}$ & $\mathrm{~W} 14 \times 233$ & $\begin{array}{l}\mathrm{B} 20.25 \mathrm{X} 10.5 \\
\mathrm{~B} 20.25 \mathrm{X} 10.5 \\
\mathrm{~B} 20.25 \mathrm{X} 10.5\end{array}$ & $\mathrm{~W} 14 \times 211$ & $\mathrm{~W} 14 \times 370$ & W24x146 & W24x146 \\
\hline & $\begin{array}{c}\text { Int } 2 / 3 \\
2 / 3 \\
\end{array}$ & $\mathrm{~W} 14 \times 233$ & $\begin{array}{l}\mathrm{B} 20.25 \mathrm{X} 10.5 \\
\mathrm{~B} 20.25 \mathrm{X} 10.5\end{array}$ & $\mathrm{~W} 14 \times 211$ & $\mathrm{~W} 14 \times 370$ & W24x117 & $\mathrm{W} 24 \times 117$ \\
\hline & $\begin{array}{c}\text { Int 3/R00f } \\
\text { 3/Roof }\end{array}$ & $\mathrm{W} 14 \times 233$ & $\begin{array}{l}\mathrm{B} 15.25 \mathrm{X} 10.5 \\
\mathrm{~B} 15.25 \mathrm{X} 10.5\end{array}$ & W14x211 & $\mathrm{W} 14 \times 370$ & W21x55 & W21x55 \\
\hline \multirow{3}{*}{ 3-Story LCF-WF } & $\begin{array}{c}\text { Base } \\
\text { Int } 1 / 2 \\
1 / 2 \\
\end{array}$ & $\mathrm{~W} 14 \times 257$ & $\begin{array}{l}\text { W24X76 } \\
\text { W24X76 } \\
\text { W24X76 }\end{array}$ & $\mathrm{W} 14 \times 120$ & $\mathrm{~W} 14 \times 233$ & W24x84 & W24x84 \\
\hline & $\begin{array}{c}\text { Int } 2 / 3 \\
2 / 3\end{array}$ & $\mathrm{~W} 14 \times 257$ & $\begin{array}{l}\text { W24X76 } \\
\text { W18X40 }\end{array}$ & W14x120 & $\mathrm{W} 14 \times 233$ & W24x68 & W24x68 \\
\hline & $\begin{array}{c}\text { Int } 3 / \text { Roof } \\
3 / \text { Roof }\end{array}$ & $\mathrm{W} 14 \times 257$ & $\begin{array}{l}\mathrm{W} 18 \mathrm{X} 40 \\
\mathrm{~W} 18 \mathrm{X} 40\end{array}$ & $\mathrm{~W} 14 \times 120$ & $\mathrm{~W} 14 \times 233$ & W21x55 & W21x55 \\
\hline
\end{tabular}


Table 7.7: Design Details; Beam and Column Section for 6-story Seattle Buildings

\begin{tabular}{|c|c|c|c|c|c|c|c|}
\hline \multirow[b]{3}{*}{ Model } & \multirow[b]{3}{*}{ Story } & \multicolumn{2}{|c|}{ Link Column } & \multicolumn{4}{|c|}{ Moment Frame } \\
\hline & & \multirow[b]{2}{*}{ Column } & \multirow[b]{2}{*}{ Beam } & \multicolumn{2}{|c|}{ Column } & \multicolumn{2}{|c|}{ Beam } \\
\hline & & & & Exterior & Interior & Exterior & Interior \\
\hline \multirow{6}{*}{ 6-Story LCF-L } & $\begin{array}{c}\text { Base } \\
\text { Int } 1 / 2 \\
1 / 2\end{array}$ & $\mathrm{~W} 14 \times 730$ & $\begin{array}{l}\text { B22.75X10.5 } \\
\text { B22.75X10.5 } \\
\text { B36X17 }\end{array}$ & $\mathrm{W} 14 \times 283$ & W14x605 & W24x84 & W24x84 \\
\hline & $\begin{array}{c}\text { Int } 2 / 3 \\
2 / 3\end{array}$ & $\mathrm{~W} 14 \times 730$ & $\begin{array}{l}\text { B36X17 } \\
\text { B36X17 }\end{array}$ & $\mathrm{W} 14 \times 283$ & W14x605 & W24x84 & W24x84 \\
\hline & $\begin{array}{c}\text { Int } 3 / 4 \\
3 / 4\end{array}$ & $\mathrm{~W} 14 \times 730$ & $\begin{array}{l}\text { B36X17 } \\
\text { B36X17 }\end{array}$ & $\mathrm{W} 14 \times 283$ & W14x605 & W33x118 & W33x118 \\
\hline & $\begin{array}{c}\text { Int } 4 / 5 \\
4 / 5\end{array}$ & $\mathrm{~W} 14 \times 730$ & $\begin{array}{l}\text { B36X17 } \\
\text { B36X17 }\end{array}$ & $\mathrm{W} 14 \times 283$ & W14x605 & W33x118 & W33x118 \\
\hline & $\begin{array}{c}\text { Int } 5 / 6 \\
5 / 6\end{array}$ & W14x605 & $\begin{array}{l}\text { B36X17 } \\
\text { B22.75X10.5 }\end{array}$ & W14x283 & W14x605 & W33x118 & W33x118 \\
\hline & $\begin{array}{c}\text { Int 6/Roof } \\
6 / \text { Roof }\end{array}$ & W14x605 & $\begin{array}{l}\text { B22.75X10.5 } \\
\text { B36X17 }\end{array}$ & $\mathrm{W} 14 \times 283$ & W14x605 & W24x84 & W24x84 \\
\hline \multirow{6}{*}{ 6-Story LCF-M } & $\begin{array}{c}\text { Base } \\
\text { Int } 1 / 2 \\
1 / 2\end{array}$ & W14x605 & $\begin{array}{l}\mathrm{B} 31.25 \times 10.5 \\
\mathrm{~B} 22.75 \times 10.5 \\
\mathrm{~B} 31.25 \times 10.5\end{array}$ & W14x398 & $\mathrm{W} 14 \times 730$ & W30x90 & W30x90 \\
\hline & $\begin{array}{c}\text { Int } 2 / 3 \\
2 / 3\end{array}$ & W14x605 & $\begin{array}{l}\mathrm{B} 31.25 \times 10.5 \\
\mathrm{~B} 31.25 \times 10.5\end{array}$ & W14x398 & W16x730 & W30x108 & W30x108 \\
\hline & $\begin{array}{c}\text { Int } 3 / 4 \\
3 / 4\end{array}$ & W14x605 & $\begin{array}{l}\text { B31.25X10.5 } \\
\text { B31.25X10.5 }\end{array}$ & W14x398 & $\mathrm{W} 16 \times 730$ & W36x182 & W36x182 \\
\hline & $\begin{array}{c}\text { Int } 4 / 5 \\
4 / 5\end{array}$ & W14x605 & $\begin{array}{l}\mathrm{B} 22.75 \times 10.5 \\
\mathrm{~B} 22.75 \times 10.5\end{array}$ & W14x398 & W16x730 & W36x182 & W36x182 \\
\hline & $\begin{array}{c}\text { Int } 5 / 6 \\
5 / 6\end{array}$ & $\mathrm{~W} 14 \times 550$ & $\begin{array}{l}\mathrm{B} 22.75 \times 10.5 \\
\mathrm{~B} 22.75 \times 10.5\end{array}$ & W14x311 & $\mathrm{W} 14 \times 550$ & W30x90 & W30x90 \\
\hline & $\begin{array}{c}\text { Int 6/Roof } \\
\text { 6/Roof }\end{array}$ & $\mathrm{W} 14 \times 550$ & $\begin{array}{l}\mathrm{B} 22.75 \times 10.5 \\
\mathrm{~B} 22.75 \times 10.5\end{array}$ & W14x311 & $\mathrm{W} 14 \times 550$ & W30x90 & W30x90 \\
\hline \multirow{6}{*}{ 6-Story LCF-WF } & $\begin{array}{c}\text { Base } \\
\text { Int } 1 / 2 \\
1 / 2\end{array}$ & $\mathrm{~W} 14 \times 730$ & $\begin{array}{l}\text { W24x103 } \\
\text { W24x103 } \\
\text { W24x103 }\end{array}$ & $\mathrm{W} 14 \times 283$ & W14x605 & W24x84 & W24x84 \\
\hline & $\begin{array}{c}\text { Int } 2 / 3 \\
2 / 3 \\
\end{array}$ & $\mathrm{~W} 14 \times 730$ & $\begin{array}{l}\text { W24x103 } \\
\text { W24x176 }\end{array}$ & $\mathrm{W} 14 \times 283$ & W16x605 & W33x130 & W33x130 \\
\hline & $\begin{array}{c}\text { Int } 3 / 4 \\
3 / 4\end{array}$ & $\mathrm{~W} 14 \times 730$ & $\begin{array}{l}\text { W24x176 } \\
\text { W24x176 }\end{array}$ & $\mathrm{W} 14 \times 283$ & W16x605 & W33x130 & W33x130 \\
\hline & $\begin{array}{c}\text { Int } 4 / 5 \\
4 / 5\end{array}$ & $\mathrm{~W} 14 \times 730$ & $\begin{array}{l}\text { W24x176 } \\
\text { W24x176 }\end{array}$ & $\mathrm{W} 14 \times 283$ & W16x605 & W33x118 & W33x118 \\
\hline & $\begin{array}{c}\text { Int } 5 / 6 \\
5 / 6\end{array}$ & W14x605 & $\begin{array}{l}\text { W24x176 } \\
\text { W24x103 }\end{array}$ & $\mathrm{W} 14 \times 283$ & W14x605 & W33x118 & W33x118 \\
\hline & $\begin{array}{c}\text { Int 6/R00f } \\
6 / \text { Roof }\end{array}$ & W14x605 & $\begin{array}{l}\text { W224x103 } \\
\text { W24x103 }\end{array}$ & $\mathrm{W} 14 \times 283$ & W14x605 & W24x84 & W24x84 \\
\hline
\end{tabular}


Table 7.8: Considered Link Sectional Properties

\begin{tabular}{|c|c|c|c|c|c|c|c|}
\hline Build-up Link & $d(i n)$ & $b_{f}(i n)$ & $t_{w}(i n)$ & $t_{f}(i n)$ & $V_{p}(K i p)$ & $M_{p}(K i p-i n)$ & $1.6 \frac{M_{p}}{V_{p}}(\mathrm{in})$ \\
\hline B36x17 & 36 & 17 & 0.60 & 1.00 & 612 & 39205 & 102 \\
\hline B31.25x10.5 & 31.25 & 10.5 & 0.5 & 0.625 & 450 & 15333 & 54 \\
\hline B22.75x10.5 & 22.75 & 10.5 & 0.375 & 0.625 & 241 & 9610 & 63 \\
\hline B22.25x10.5 & 22.25 & 10.5 & 0.375 & 0.625 & 213 & 8324 & 62 \\
\hline B15.25x10.5 & 15.25 & 10.5 & 0.375 & 0.625 & 158 & 5891 & 60 \\
\hline
\end{tabular}

Table 7.9: Fundamental Characteristic of 3- and 6-story Seattle LCF

\begin{tabular}{cccccc}
\hline Name & $\frac{k_{M F}}{k_{L C}}$ & $\frac{\Delta_{M F}}{\Delta_{L C}}$ & $\sqrt{\frac{V_{P L C F} V_{Y L C F} \Delta_{Y L C F}}{V_{Y L C}}}$ & $\frac{V_{M F}}{V_{L C}}$ & $W t .\left(10^{3}\right) K g$ \\
\hline 3-SMRF & - & - & - & - & 39.5 \\
\hline 3-Story LCF-M & 0.34 & 3.37 & 2.62 & 1.16 & 50.3 \\
\hline 3-Story LCF-L & 0.21 & 3.19 & 2.45 & 0.66 & 37.4 \\
\hline 3-Story LCF-WF & 0.18 & 3.01 & 2.08 & 0.56 & 38.9 \\
\hline \hline 6-SMRF & - & - & - & - & 178 \\
\hline 6-Story LCF-M & 0.61 & 1.28 & 1.89 & 0.79 & 176 \\
\hline 6-Story LCF-L & 0.32 & 2.43 & 2.63 & 0.79 & 170 \\
\hline 6-Story LCF-WF & 0.40 & 1.92 & 2.16 & 0.77 & 180 \\
\hline
\end{tabular}


Similar to the Los Angles site, the two suites of Seattle ground motions represent two seismic hazard levels: $10 \%$ in 50 year, and $2 \%$ in 50 year earthquakes; both scaled to target spectral acceleration values at four periods by Somerville et al. (1997). The target spectral acceleration values used for scaling the $2 \%$ in 50 year ground motions were the same as the maximum credible earthquake values used here for LCF design.

As shown below, and similar to Los Angeles ground motion, the results indicate that in general, each of the LCF systems exhibited three levels performance within the lateral response; elastic, just yielding of LC links and yielding of LC links as well as MF beams. Provided the links are replaceable, these correspond to three distinct performance levels; elastic, rapid structural repair via replaceable links and collapse prevention. It should be mentioned that for the Seattle location, there were not available ground motion records for the $50 \%$ in 50 years hazard level, but by applying engineering judgment and observing the result for $10 \%$ in 50 year event, the elastic performance objective can be assumed.

Figure 7.8 shows the the median and 84 th percentile values for the maximum story drift obtained for the ground motions for each hazard level for each LCF. As shown, the LCF is capable of meeting drift limits as the story drifts for each hazard level are within ranges that would be considered acceptable for most applications, i.e., less than $2 \%$ for the $10 \%$ in 50 year hazard and less than $5 \%$ for the $2 \%$ in 50 year hazard. Also, the story drifts are comparable to, or less than, drifts in post-Northridge moment resisting frame designs, per Gupta and Krawinkler (1999). In these LCFs, the story drift distributions are similar to each other, however, in the $2 \%$ in 50 year ground motions, the 6-story LCFs again show some concentration of story drifts at the lower level, which was discussed previously.

Figure 7.9 shows link rotation for the two hazard levels. The link yield rotation $\theta_{y}$ is shown by vertical solid lines for reference and was obtained using Timoschenko beam theory. This is the average of all links for each building. The links most likely are elastic for the $50 \%$ in 50 year hazard and should not require repair, since in $10 \%$ in 50 year event at median level, they are just barely larger than the yield line.

In the $10 \%$ in 50 year hazard, links in all frames have rotations larger than yield at 84th percentile level and some may have damage that warrants link replacement. In the $2 \%$ in 50 year hazard level, the links have larger inelastic demand and are more likely to require 


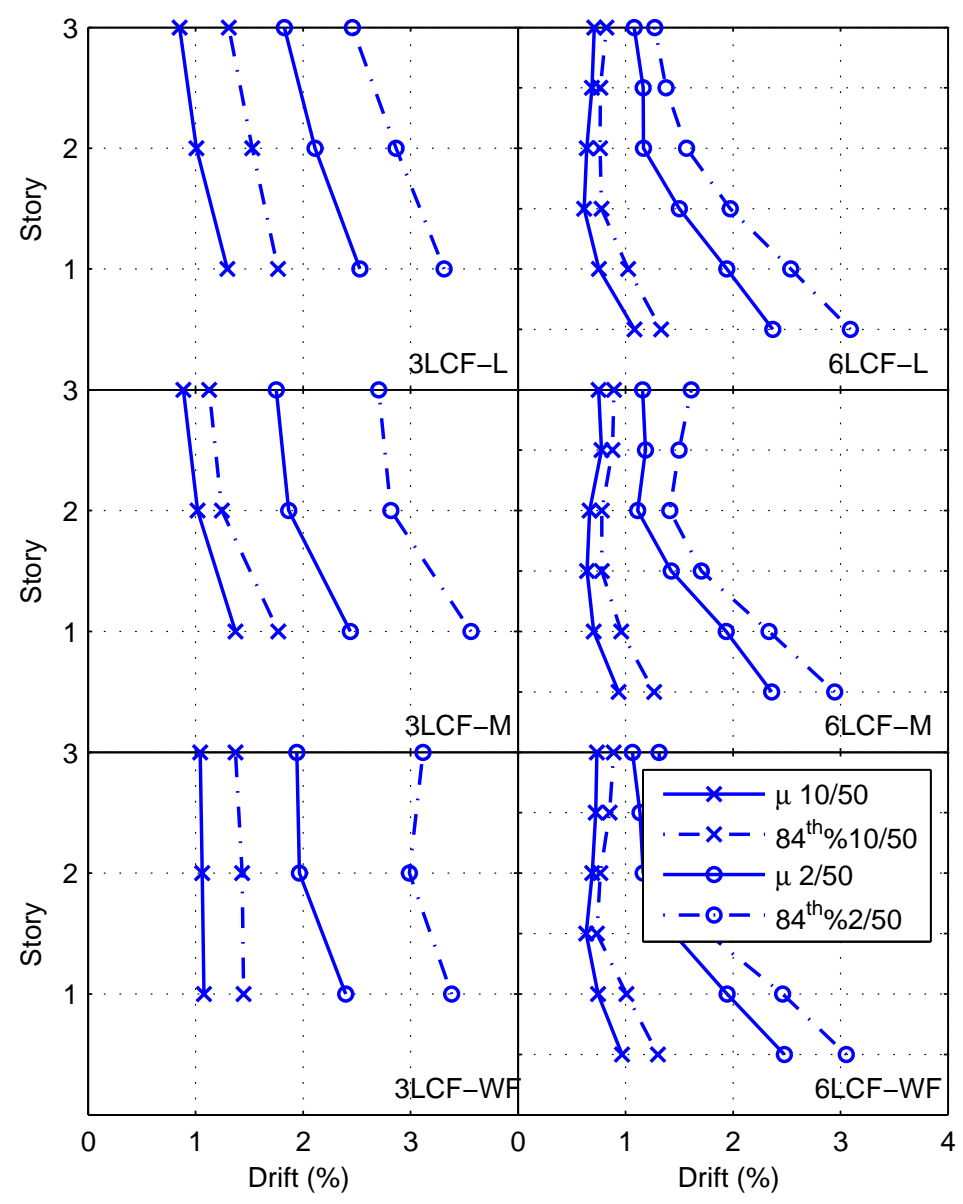

Figure 7.8: Median and 84th Percentile Story Drift Results for Seattle Models.

replacement. It is notable that none of the links in any of the LCFs considered failed under any ground motions using the failure criteria established from tests by Dusicka and Lewis (2010) and incorporated in the link model.

At the $2 \%$ in 50 year hazard level, the 84 th percentile link rotations do not exceed 0.05 rad. This is considerabley smaller than the limit failure criteria by Dusicka and Lewis (2010) (their studies show the failure for shear links with parallel web stiffener is $0.08 \mathrm{rad}$ ).

Figure 7.10 shows the beam rotation demands for two hazard levels with $\theta_{y}$, the approximate yield rotation, also shown for reference. As shown, in all cases beam yielding does not occur until the $2 \%$ in 50 year hazard level. This ensures that no repairs would be necessary 


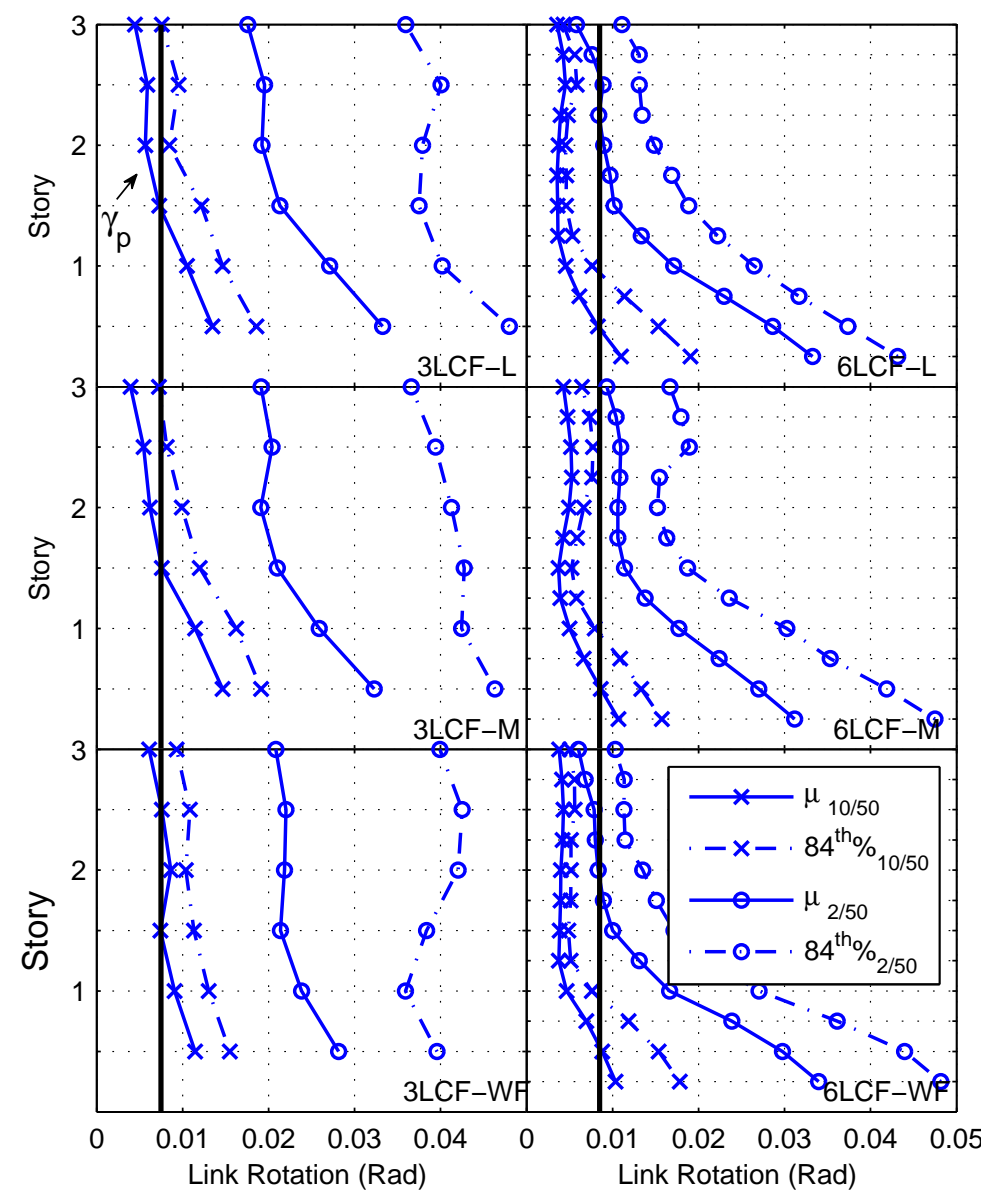

Figure 7.9: Median and 84th Percentile Link Rotation Demand for Seattle Models.

following the $10 \%$ in 50 year earthquake, which achieves the performance objectives and will help to minimize post event repair costs and downtime. Moreover, the 84th percentile values of beam rotation demand are less than $0.04 \mathrm{rad}$ in all cases, indicating that none of the beams are likely to fail at that hazard level if special moment frame detailing is used. 


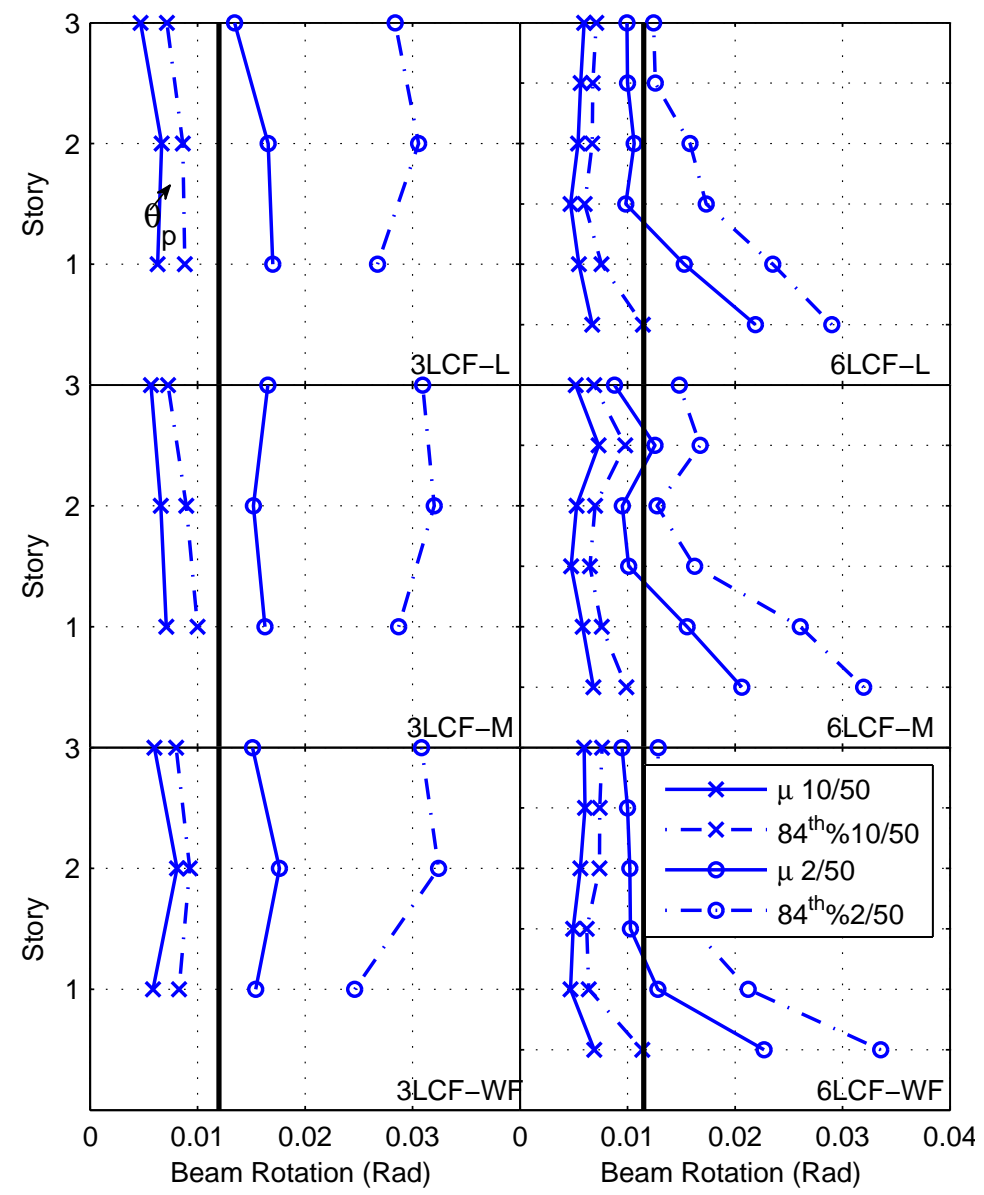

Figure 7.10: Median and 84th Percentile Beam Rotation Demand for Seattle Models. 


\section{Chapter 8}

\section{PARAMETERS AFFECTING LCF EFFICIENCY}

The LCF system has many individual components that contribute to the strength and stiffness of the overall system, and therefore impact the efficiency of an LCF design. This chapter presents the results of several parametric studies conducted to investigate the impacts of various design choices on the overall behavior and efficiency of the LCF. The studies used the 3-story and 6-story designs described in chapter five as the basis for modeling, and their components' strength and stiffness were modified to determine the impact on system responses and structural weight. For the links, variations in the web and flange area, moment of inertia and length were considered. Beam and column cross sections were also varied for each selected LCF. The information provides an enhanced understanding of the LCF system behavior, provides recommendations for improving the economic efficiency and performance of the LCF system and allows for development of improved design procedures.

\subsection{Developing Closed Form Equations for LCF Stiffness}

In this chapter, the impact of different components of an LCF on the overall LCF behavior, i.e. the stiffness and strength contributions of the LC and MF members, were studied using closed-form solutions for stiffness and strength derived from conventional methods. The closed-form equations can also be used for preliminary design to ensure the desired LCF behavior. The three main components that affect overall stiffness in the LCF are as follows:

- Shear and flexure stiffness of links in the LC

- Moment frame stiffness

- Overturning stiffness of the linked columns 
With the methods presented in this chapter, the contribution of each of these actions to the overall stiffness and strength can be estimated separately.

- Story stiffness due to shear of elements: The LCs with short links behave similarly to frames with closely spaced columns and deep beams, such as framed tube structures. In this type of frame the contribution to the lateral displacement of shearing deformations of beams and columns may be significant (Figure 8.1). Story stiffness due to shear of elements at each story, may be estimated as (Naeim, 2001):

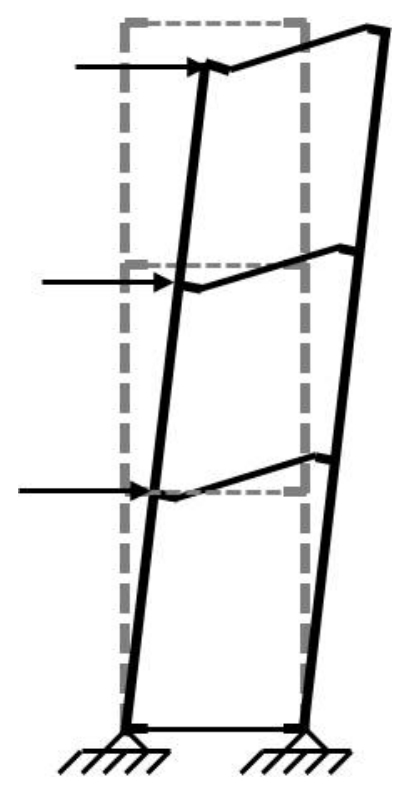

Figure 8.1: Frame Deformation Caused by the Shear Deformation of Links and Columns.

$$
K_{s}=\frac{G}{h_{i}^{2}} \frac{\left(\sum A_{l i} L_{l i}\right)\left(\sum A_{c i} L_{c i}\right)}{\left(\sum A_{l i} L_{l i}\right)+\left(\sum A_{c i} L_{c i}\right)}
$$

Where $h_{i}$ is the story hight, $G$ is the shear modulus and $A_{l i}$ and $A_{c i}$ are the shear areas of individual links and columns at level $i$. To determine the effective shear stiffness of a 3-story LC $\left(K_{s_{L C}}\right)$, the shear stiffness of the three stories are combined in series.

- Story stiffness due to flexure of elements: A significant portion of drift in buildings is caused by end rotations of beams and columns (Figure 8.2). For most typical 
low to mid-rise rigid frames, almost all of the drift is caused by this effect. However, for taller buildings other actions such as axial deformation of columns become more significant.

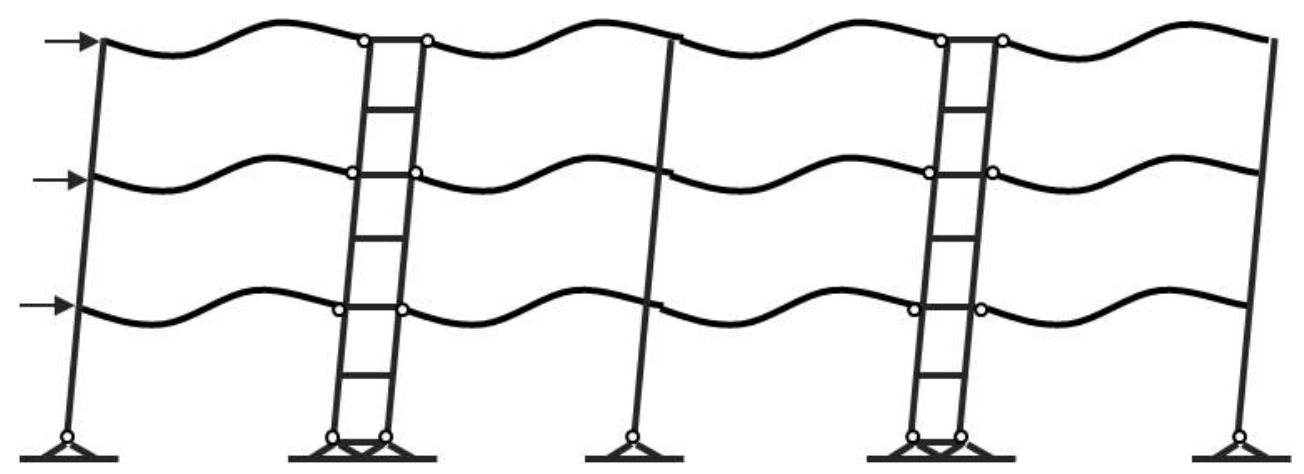

Figure 8.2: Frame Deformation Caused by the End Rotations of Beams and Columns.

Story stiffness due to flexure of elements at each story, may be estimated as Naeim, 2001):

$$
K_{b}=\frac{12 E}{h_{i}^{2}} \frac{\left(\sum K_{b / l}\right)_{i}\left(\sum K_{c}\right)_{i}}{\left(\sum K_{b / l}\right)_{i}+\left(\sum K_{c}\right)_{i}}
$$

where $h_{i}$ is the story hight, $\left(\sum K_{b / l}\right)_{i}$ is summation of $I_{i} / L_{i}$ for all beams or links, $\left(\sum K_{c}\right)_{i}$ is summation of $I_{i} / L_{i}$ for all columns, $I_{i}$ is individual beam, link or column moment of inertia and $L_{i}$ is individual bay length.

Again, to determine the effective flexural stiffness of a 3 -story LC $\left(K_{b_{L C}}\right)$ and MF $\left(K_{b_{M F}}\right)$, the flexural stiffness of the three stories are combined in series.

- Total lateral stiffness of an LCF: The total stiffness of an LC $\left(K_{T_{L C}}\right)$ can be found from a series combination of $K_{b_{L C}}$ and $K_{s_{L C}}$, i.e.:

$$
\frac{1}{K_{T_{L C}}}=\frac{1}{K_{b_{L C}}}+\frac{1}{K_{s_{L C}}}
$$

Then, the total stiffness of an LCF $\left(K_{L C F}\right)$ excluding overturning moments effect can be found from a parallel combination of $K_{T_{L C}}$ and $K_{b_{M F}}$, i.e.: 


$$
K_{L C F}=K_{T_{L C}}+K_{b_{M F}}
$$

- Story stiffness due to overturning moment: In tall buildings, there is significant axial deformation in the columns caused by the overturning moments. The distribution of axial forces among the columns due to the overturning moment is very similar to distribution of flexural stresses in a cantilever beam (Figure 8.3). The overturning moments cause larger axial forces and deformations on the columns which are farther from the center line of the frame. This action causes a lateral deformation that closely resembles the deformation of a cantilever beam.

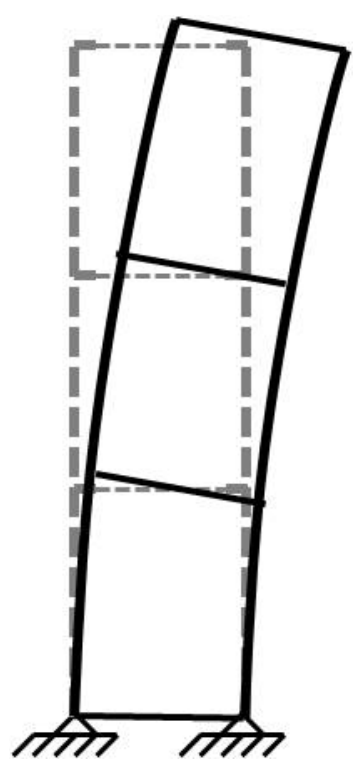

Figure 8.3: Frame Deformation Caused by the Overturning Moments.

The impact of overturning deformation on system stiffness of the LCF increases with increasing LC height, increasing link strength and decreasing the distance between link columns. The displacement caused by overturning moment may be estimated by simple application of the moment-area method. The moment of inertia for an equivalent beam is computed as: 


$$
I_{o i}=\sum\left(A_{c i} d_{i}^{2}\right)
$$

where $A_{c i}$ is a cross sectional area of an individual column and $d_{i}$ is its distance from the centerline of the frame. The summation is carried across all of the LC and MF columns. The computation of the displacement caused by overturning moment for each floor level can be summarized in the following steps:

- Step 1- Compute story moment of inertia $I_{o i}$.

- Step 2- Compute overturning moments $M_{i}$.

- Step 3- Compute area under the $M / E I_{o i}$ from:

$$
A_{i}=\frac{\left(M_{i}+M_{i+1}\right) h_{i}}{2 E I_{o i}}
$$

- Step 4- Compute $\overline{x_{i}}$ (Figure 8.4) from:

$$
\bar{x}_{i}=\frac{h_{i}}{3} \frac{M_{i}+2 M_{i+1}}{M_{i}+M_{i+1}}
$$

- Step 5- Compute story displacement from:

$$
\Delta_{c i}=A_{i}\left(h_{i}-\bar{x}_{i}\right)+\sum_{j=1}^{i-1} A_{j}\left(H_{i}-\overline{x_{j}}\right)
$$

The stiffness due to overturning moment $\left(K_{O}\right)$ for the entire frame can be calculated by dividing the top floor shear force by the displacement of the top floor. Finally, the total stiffness of LCF $\left(K_{T_{L C F}}\right)$ may be computed using a series combination of $K_{L C F}$ and $K_{O}$, i.e.:

$$
\frac{1}{K_{T_{L C F}}}=\frac{1}{K_{L C F}}+\frac{1}{K_{O}}
$$

As an example, Table 8.1 shows the stiffnesses of different components and the overall stiffness of LCF 6-I-120 based on the developed method and numerical analysis. As shown 

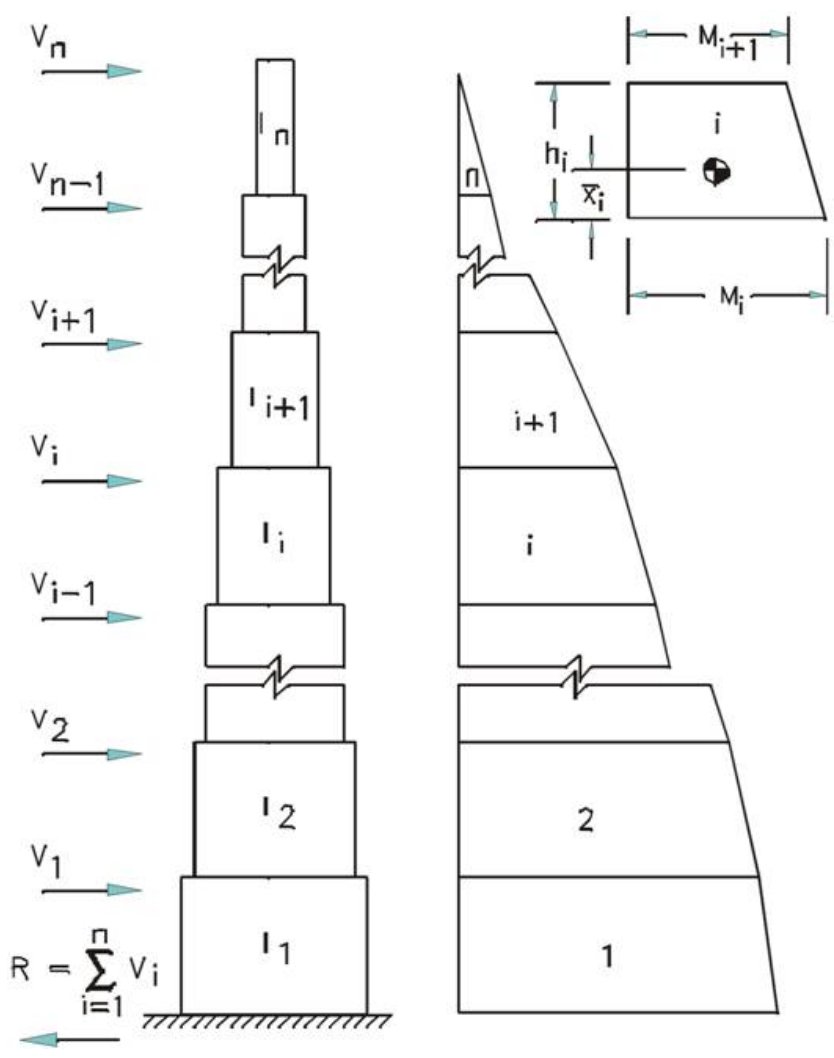

Figure 8.4: Estimating Displacements Cause by the Overturning Moments by the Moment Area Method (Naeim, 2001). 
Table 8.1: LCF 6-I-120 Overall and Components' Stiffnesses.

\begin{tabular}{cccccccc}
\hline Type of Analysis & $K_{s_{L C}}$ & $K_{b_{L C}}$ & $K_{T_{L C}}$ & $K_{b_{M F}}$ & $K_{L C F}$ & $K_{O}$ & $K_{T_{L C F}}$ \\
\hline Closed Form & 424 & 266 & 163 & 42 & 205 & 9984 & 202 \\
Numerical & - & - & 178 & 29 & - & - & 219 \\
\hline \hline
\end{tabular}

in this table, similar stiffnesses were determined using these two methods. It should be noted that numerical analysis results were obtained from three different pushover analyses: pushover of the system with hinges at the beam ends $\left(K_{T_{L C}}\right)$; pushover of the system with the hinges at the link ends $\left(K_{b_{M F}}\right)$; and pushover of the complete system $\left(K_{T_{L C F}}\right)$.

By having a closed form equation for total stiffness of an LCF based on the individual components stiffness, the investigation on the contribution of the individual components to the stiffness of the overall system can be achieved.

Figures 8.5 and 8.6 show each component's influence on the overall stiffness for a 3story and 6-story LCF using these closed form equations. These results were obtained after evaluating three 3-story and four 6-story LCF in Chapter 5.

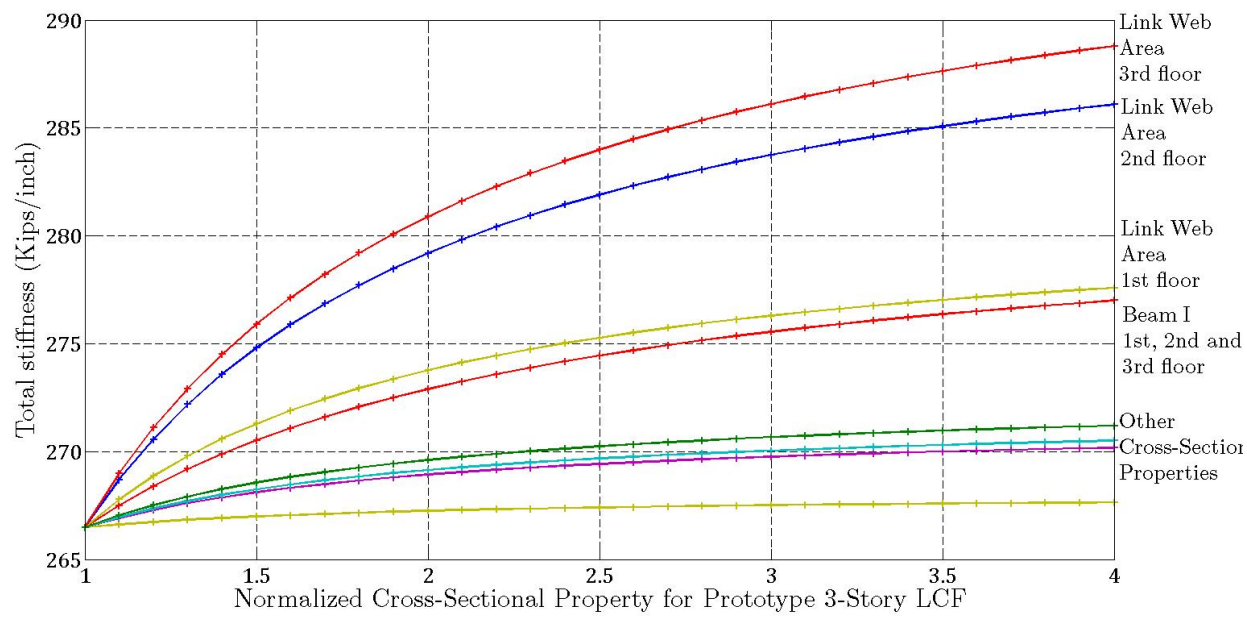

Figure 8.5: Structural Component Influence on the Overall Stiffness for 3-story LCF. 


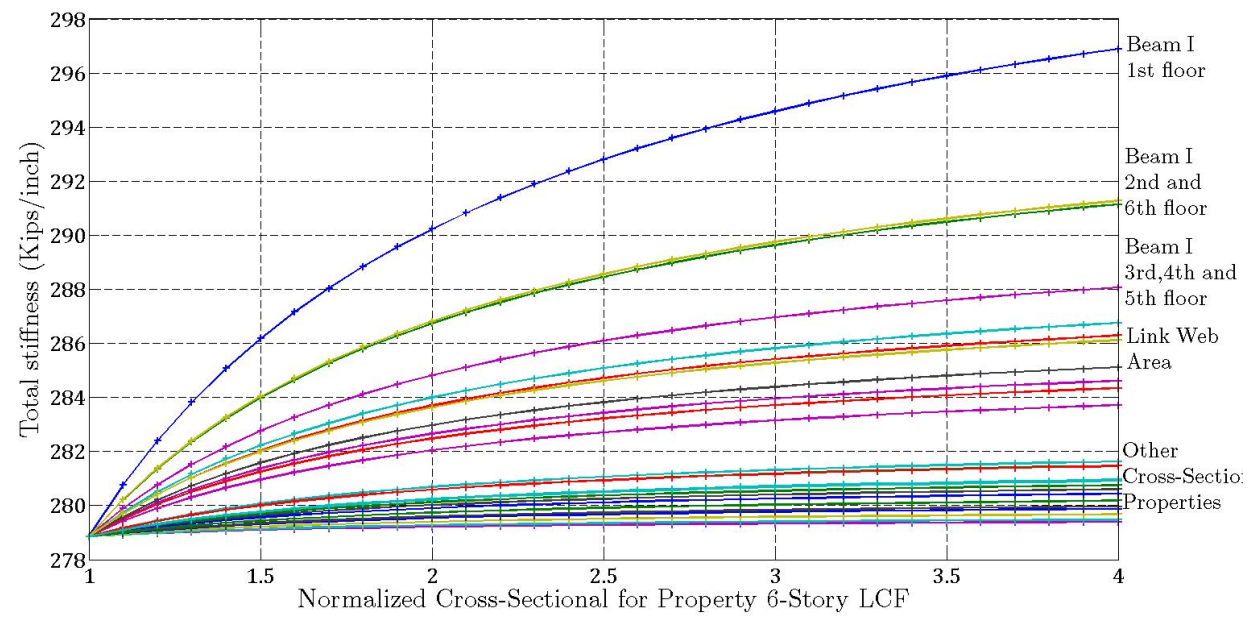

Figure 8.6: Structural Component Influence on the Overall Stiffness for 6-story LCF.

Figure 8.5 and Figure 8.6 both show how each section's properties impact the overall LCF initial stiffness. In these figures the initial stiffness is shown as a function of the normalized cross sectional property (i.e. the ratio of the varied property to the value of LCF). For example, in Figure 8.5 the total initial stiffness of 3-story LCF is 253 (kips/inch). Each of the normalized cross sectional properties increase individually from 1-4 to evaluate their impact on the initial stiffness.

As shown in the figures above for 3-story LCF, the stiffness varies more with area of the web of the links $\left(A_{w_{L}}\right)$ compared to the other component section properties. However in the 6-story LCF, the moment of inertia of moment frame beam $\left(I_{b}\right)$ has the main effect on the overall stiffness. In other words, in shorter LCF the link properties of link frame govern the behavior of LCF and in taller LCF the moment frame roll becomes more significant. Therefore, using different types of links other than rolled shape sections may result in a more efficient system.

\subsection{Improving LCF Efficiency Using Built-up Section}

Results from Section 8.1 demonstrated improved LCF efficiency could be achieved by varying the web area and moment of inertia of links independently. Using built-up links would 
allow this and correspondingly increase link stiffness without proportionally increasing link strength. Built-up sections offer the flexibility of being proportioned to any desired geometrical dimension, allowing the behavior and capacity of the section to be easily controlled.

The desired shear links built-up from plates for the LCF system should have relatively low shear capacity to reduce the axial demand in the column while still behaving as a shear link, which has larger rotational capacity compared to flexural or intermediate links. Well designed built-up shear links may be efficient energy dissipators with high tolerance for inelastic strain, exhibiting ductile hysteretic behavior with deformation capacities that surpass the AISC recommended deformation demand of 0.08 rad for EBF links, while reducing the axial demand in the columns.

The following list may be the advantages of built-up shear link section for LCF:

- Increase link stiffness without proportionally increasing link strength

- Decrease link size through reducing its flange size that does not affect the LCF overall stiffness

- Reduce column demands and column size by reducing link capacity

- Enable the use of more ductile shear links in taller building instead of intermediate or flexure links

- Decrease the size of beam and column of moment frame by slightly increasing links' web area

- Use less steel in LCF buildings

Three different 3-story LCFs are designed as per LCF design procedure described in chapter three to meet the inter story drift limit of $2.5 \%$ using both rolled shape and builtup links to compare behavior and effeciency. LCF3-W uses rolled shape for the links, whereas LCF3-BUS1 and LCF3-BUS2 use built-up sections for the links. As shown in the previous sections, the web area of the links has a significant impact on the overall stiffness 
Table 8.2: Design Details; Beam and Column Section for 3-story LCF Model Buildings

\begin{tabular}{|c|c|c|c|c|c|c|c|}
\hline \multirow[b]{3}{*}{ Model } & \multirow[b]{3}{*}{ Story } & \multicolumn{2}{|c|}{ Link Column } & \multicolumn{4}{|c|}{ Moment Frame } \\
\hline & & \multirow[b]{2}{*}{ Column } & \multirow[b]{2}{*}{ Link } & \multicolumn{2}{|c|}{ Column } & \multicolumn{2}{|c|}{ Beam } \\
\hline & & & & Exterior & Interior & Exterior & Interior \\
\hline \multirow{3}{*}{ 3LCF-W } & 1 & $\mathrm{~W} 14 \times 257$ & W24x176 & $\mathrm{W} 14 \times 257$ & $\mathrm{~W} 14 \times 257$ & W30x99 & W30x99 \\
\hline & 2 & $\mathrm{~W} 14 \times 257$ & W21x101 & $\mathrm{W} 14 \times 257$ & $\mathrm{~W} 14 \times 257$ & W30x90 & W30x90 \\
\hline & 3 & $\mathrm{~W} 14 \times 257$ & W16x100 & $\mathrm{W} 14 \times 257$ & $\mathrm{~W} 14 \times 257$ & W21x68 & W21x68 \\
\hline \multirow{3}{*}{ 3LCF-BUS1 } & 1 & $\mathrm{~W} 14 \times 257$ & BUS1-1 & $\mathrm{W} 14 \times 257$ & $\mathrm{~W} 14 \times 257$ & W30x99 & W30x99 \\
\hline & 2 & $\mathrm{~W} 14 \times 257$ & BUS1-2 & $\mathrm{W} 14 \times 257$ & $\mathrm{~W} 14 \times 257$ & W30x90 & W30x90 \\
\hline & 3 & $\mathrm{~W} 14 \times 257$ & BUS1-3 & $\mathrm{W} 14 \times 257$ & $\mathrm{~W} 14 \times 257$ & W21x68 & W21x68 \\
\hline \multirow{3}{*}{ 3LCF-BUS2 } & 1 & W14x311 & BUS2-1 & W14x193 & W14x211 & W27x84 & W27x84 \\
\hline & 2 & $\mathrm{~W} 14 \times 257$ & BUS2-2 & W14x193 & W14x211 & W24x68 & W24x68 \\
\hline & 3 & $\mathrm{~W} 14 \times 257$ & BUS2-3 & $\mathrm{W} 14 \times 193$ & $\mathrm{~W} 14 \times 211$ & W16x67 & W16x67 \\
\hline
\end{tabular}

of 3-story LCFs. Therefore, LCF3-BUS1 has links with the same web area as LCF3-W but with reduced flange sizes. In the LCF3-BUS2 design, the flange size of the links was decreased and the web area was increased, resulting in increased overall stiffness, allowing for a considerable reduction in the moment frame member.

Table 8.2 shows the link, beam and column sections for each of these three systems. All built-up links have been designed to behave as shear links. Also, Table 8.4 compares the components and the total weight of these LCFs.

Similar to chapter 7 , the characteristics of yielding mode of the links, initial stiffness and lateral strength and roof displacement at the onset of link yielding and at the onset 
Table 8.3: Link Sectional Properties for 3-story LCF Model Buildings

\begin{tabular}{lccccccc}
\hline Link & $\mathrm{d}(\mathrm{in})$ & $t_{w}($ in $)$ & $b_{f}($ in $)$ & $t_{f}($ in $)$ & $V_{p}($ Kip $)$ & $M_{p}($ Kip - in $)$ & $1.6 M_{p} / V_{p}($ in $)$ \\
\hline \hline W24x176 & 25.2 & 0.75 & 12.9 & 1.34 & 507 & 25550 & 80 \\
W21x101 & 21.4 & 0.5 & 12.3 & 0.8 & 297 & 12650 & 68 \\
W16x100 & 17 & 0.585 & 10.4 & 0.985 & 264 & 9900 & 60 \\
\hline BUS1-1 & 26 & 0.705 & 11.5 & 1 & 507 & 19500 & 62 \\
BUS1-2 & 22.1 & 0.48 & 10 & 0.8 & 297 & 11100 & 60 \\
BUS1-3 & 17.8 & 0.55 & 10.35 & 0.92 & 263 & 9800 & 60 \\
\hline BUS2-1 & 28.5 & 0.705 & 11.5 & 1 & 560 & 22050 & 63 \\
BUS2-2 & 25.5 & 0.48 & 10 & 0.8 & 346 & 13350 & 61 \\
BUS2-3 & 21 & 0.55 & 10.35 & 0.92 & 316 & 12100 & 61 \\
\hline
\end{tabular}

Table 8.4: Design Details; Weight (kips) for 3-story LCF Model Buildings

\begin{tabular}{lcccc}
\hline Model & Links & LC & MF & LCF \\
\hline 3LCF-W & 9.31 & 49.45 & 58.36 & 107.81 \\
\hline 3LCF-BUS1 & 7.73 & 47.86 & 58.36 & 106.22 \\
\hline 3LCF-BUS2 & 8.13 & 51.07 & 46.17 & 97.24 \\
\hline
\end{tabular}


Table 8.5: Fundamental Characteristic for 3-story LCF Model Buildings

\begin{tabular}{lcccccccc}
\hline Name & System & $\Delta_{Y}(i n)$ & $\Delta_{P}($ in $)$ & $V_{Y}($ Kip $)$ & $V_{P}($ Kip $)$ & $K_{e}\left(\frac{\text { Kip }}{i n}\right)$ & $\frac{\Delta_{Y M F}}{\Delta_{Y L C}}$ & $\frac{V_{Y M F}}{V_{Y L C}}$ \\
\hline \multirow{3}{*}{ 3LCF-W } & LC & 4.50 & - & 780 & - & 173 & & \\
& MF & 7.89 & - & 340 & - & 43 & 1.78 & 0.44 \\
& LCF & 4.39 & 7.83 & 1032 & 1325 & 235 & & \\
3 3LCF-BUS1 & LC & 4.56 & - & 775 & - & 170 & & \\
& MF & 7.89 & - & 347 & - & 44 & 1.78 & 0.45 \\
& LCF & 4.38 & 7.81 & 1011 & 1302 & 231 & & \\
3 3LCF-BUS2 & MF & 8.78 & - & 245 & - & 29 & 1.90 & 0.30 \\
& LCF & 4.37 & - & 858 & - & 196 & & \\
\hline
\end{tabular}

of beam yielding were obtained for each system. For each system, three different pushover analyses were performed: pushover of the system with hinges at the beam ends; pushover of the system with the hinges at the link ends; and pushover of the complete system. These analyses enable approximation of the contributions of the LC and MF to the total response. The resulting system characteristics' values are shown for all LCF designs in Table 8.5 .

As shown in Table 8.2, LCF3-W and LCF3-BUS1 have exactly the same MF and LC cross sections. The only difference is in their links. The built-up links of LCF3-BUS1 have the same web area but lower flange area in comparison with W section links of LCF3W (Table 8.3). Both systems have approximately the same overall behavior as shown in (Table 8.5), however, nearly $17 \%$ steel was saved in the links of LCF3-BUS1 system compared to the amount of steel required for LCF3-W (Table 8.4).

LCF3-BUS2 has links with 10-20\% larger web area than LCF3-BUS1 but still 12.5\% less steel in links when compared to LCF3-W. This larger web area provides $15 \%$ higher LC stiffness and 5\% higher overal stiffness and leads to reduction of MF size by $20 \%$ comapred to LCF3-W or LCF3-BUS1 to have the same overall behavior (Table 8.5 and Table 8.4). 


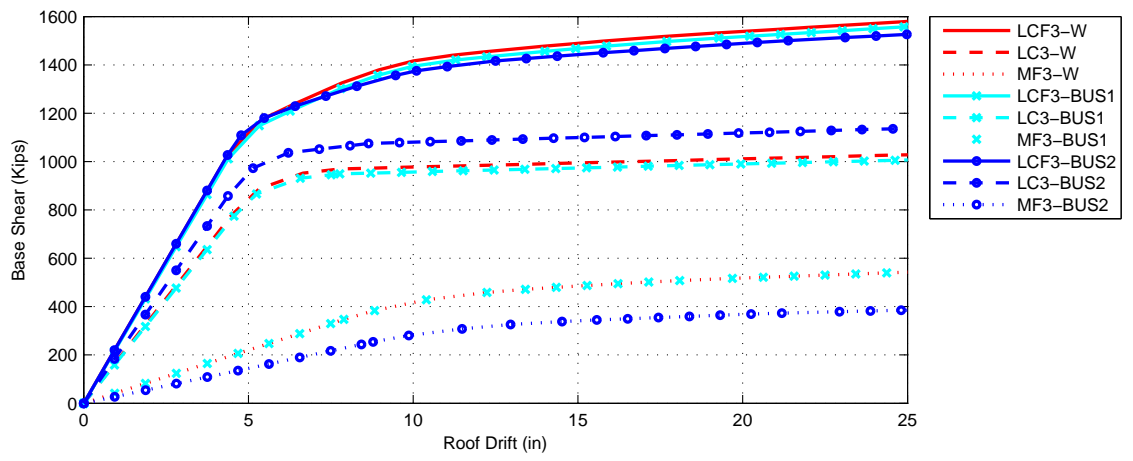

Figure 8.7: Pushover Response of LCFs and Their Components for 3-story LCF Model Buildings.

As shown in Figure 8.7, the contribution of LC3-BUS2 is higher than the other two systems and the contribution of MF3-BUS2 is lower, but all three systems have the same overall behavior.

The same design approach was used for 6-story LCF with link length of 60 in. Three different numerical 6-story models are designed as per LCF design procedure described in the previous section to determine the section sizes of LCF systems meeting the design intent of $2.5 \%$ inter-story drift limits. The beam, link and column sizes were provided in Table 8.6. LCF6-W is a system considering $\mathrm{W}$ sections for the links, whereas LCF6-BUS1 and LCF6-BUS2 are systems considering built-up sections for the links.

LCF6-BUS1 is designed based on reducing the flange size of the links, increasing the area of the link by less than $10 \%$ for satisfying drift requirments and the same moment frame, as shown in Table 8.7. In LCF6-BUS2 design, the flange size of the links was decreased and the web area of the links was increased by $25 \%$ in comparison with LCF6-W to investigate the impact of this increase on lowering the size of moment frame. As expected (as shown in Figure 8.6 the area of links web does not have significant impact on overall LCF stiffness) and shown in Table 8.8, very small reduction in moment frame sizes were gained, however, due to the increase in linked columns' size, the total weight of LCF6-BUS2 is more than the two other designs.

The fundamental characteristics of interest for each of the 6-story LCF systems are 
Table 8.6: Design Details; Beam and Column Section for 6-story LCF Model Buildings

\begin{tabular}{|c|c|c|c|c|c|c|c|}
\hline \multirow[b]{3}{*}{ Model } & \multirow[b]{3}{*}{ Story } & \multicolumn{2}{|c|}{ Link Column } & \multicolumn{4}{|c|}{ Moment Frame } \\
\hline & & \multirow[b]{2}{*}{ Column } & \multirow[b]{2}{*}{ Link } & \multicolumn{2}{|c|}{ Column } & \multicolumn{2}{|c|}{ Beam } \\
\hline & & & & Exterior & Interior & Exterior & Interior \\
\hline \multirow{3}{*}{$6 \mathrm{LCF}-\mathrm{W}$} & 1 & W14x730 & W24x207 & W14x605 & W14x605 & W33x152 & W30x108 \\
\hline & 3 & W14x665 & $\mathrm{W} 24 \times 176$ & $\mathrm{~W} 14 \times 605$ & $\mathrm{~W} 14 \times 605$ & W36x256 & W36x182 \\
\hline & 6 & W14x342 & W24x146 & $\mathrm{W} 14 \times 426$ & $\mathrm{~W} 14 \mathrm{x} 426$ & W33x201 & W33x118 \\
\hline \multirow{3}{*}{ 6LCF-BUS1 } & 1 & $\mathrm{~W} 14 \times 730$ & BUS1-4 & $\mathrm{W} 14 \times 605$ & $\mathrm{~W} 14 \times 605$ & W33x152 & W30x108 \\
\hline & 3 & W14x665 & BUS1-5 & $\mathrm{W} 14 \times 605$ & $\mathrm{~W} 14 \times 605$ & W36x256 & W36x182 \\
\hline & 6 & $\mathrm{~W} 14 \times 342$ & BUS1-6 & $\mathrm{W} 14 \times 426$ & $\mathrm{~W} 14 \mathrm{x} 426$ & W33x201 & W33x118 \\
\hline \multirow{3}{*}{ 6LCF-BUS2 } & 1 & $\mathrm{~W} 14 \times 730$ & BUS2-4 & $\mathrm{W} 14 \times 605$ & $\mathrm{~W} 14 \times 605$ & W33x152 & W30x108 \\
\hline & 3 & $\mathrm{~W} 14 \times 730$ & BUS2-5 & $\mathrm{W} 14 \times 605$ & W14x605 & $\mathrm{W} 36 \times 247$ & W36x135 \\
\hline & 6 & W14x342 & BUS2-6 & $\mathrm{W} 14 \times 426$ & $\mathrm{~W} 14 \mathrm{x} 426$ & W33x152 & W33x118 \\
\hline
\end{tabular}


Table 8.7: Link Sectional Properties for 6-story LCF Model Buildings

\begin{tabular}{lccccccc}
\hline Link & $\mathrm{d}(\mathrm{in})$ & $t_{w}($ in $)$ & $b_{f}($ in $)$ & $t_{f}($ in $)$ & $V_{p}($ Kip $)$ & $M_{p}($ Kip - in $)$ & $1.6 M_{p} / V_{p}($ in $)$ \\
\hline \hline W24x207 & 25.7 & 0.87 & 13 & 1.57 & 589 & 30300 & 82 \\
W24x176 & 25.2 & 0.75 & 12.9 & 1.34 & 507 & 25550 & 80 \\
W24x146 & 24.7 & 0.65 & 12.9 & 1.09 & 440 & 20900 & 76 \\
\hline BUS1-4 & 27.4 & 0.87 & 11.7 & 1.2 & 652 & 25200 & 62 \\
BUS1-5 & 26.5 & 0.75 & 11.2 & 1.1 & 547 & 21200 & 62 \\
BUS1-6 & 26 & 0.65 & 11.1 & 0.95 & 470 & 17950 & 61 \\
\hline BUS2-4 & 32 & 0.87 & 11.6 & 1.135 & 765 & 29950 & 63 \\
BUS2-5 & 30 & 0.75 & 11 & 1.05 & 628 & 24050 & 61 \\
BUS2-6 & 30 & 0.65 & 11 & 0.9 & 550 & 21000 & 61 \\
\hline
\end{tabular}

Table 8.8: Design Details; Weight (kips) for 6-story LCF Model Buildings

\begin{tabular}{lcccc}
\hline Model & Links & LC & MF & LCF \\
\hline 6LCF-W & 22.32 & 210.97 & 245.20 & 456.17 \\
\hline 6LCF-BUS1 & 18.68 & 207.33 & 245.20 & 452.53 \\
\hline 6LCF-BUS2 & 19.38 & 218.12 & 238.87 & 456.99 \\
\hline
\end{tabular}


Table 8.9: Fundamental Characteristic for 6-story LCF Model Buildings

\begin{tabular}{lcccccccc}
\hline Name & System & $\Delta_{Y}($ in $)$ & $\Delta_{P}($ in $)$ & $V_{Y}($ Kip $)$ & $V_{P}($ Kip $)$ & $K_{e}\left(\frac{\text { Kip }}{i n}\right)$ & $\frac{\Delta_{Y M F}}{\Delta_{Y L C}}$ & $\frac{V_{Y M F}}{V_{Y L C}}$ \\
\hline \multirow{6}{*}{6 LCF-W } & LC & 9.81 & - & 994 & - & 96 & & \\
& MF & 11.87 & - & 710 & - & 60 & 1.21 & 0.71 \\
& LCF & 5.34 & 13.87 & 1240 & 2130 & 233 & & \\
6 6LCF-BUS1 & MC & 9.93 & - & 1040 & - & 105 & & \\
& MF & 11.87 & - & 710 & - & 60 & 1.20 & 0.68 \\
& LCF & 5.63 & 14.30 & 1311 & 2213 & 233 & & \\
\hline \multirow{6}{*}{6 LCF-BUS2 } & MF & 11.10 & - & 1171 & - & 106 & & \\
& LCF & 6.53 & 15.11 & 1505 & 2388 & 231 & & \\
\hline
\end{tabular}

shown in Table 8.9 and the pushover responses of these systems are shown in Figure 8.8 . The initial stiffness of all three systems are the same, but LCF6-BUS2 has larger base shear. Also, LCF6-BUS2 does not pass the key design requirements $1.2<\frac{\Delta_{Y M F}}{\Delta_{Y L C}}<3$. Although link web area in LCF6-BUS2 increased significantly, because in 6-story LCF links web area does not govern the overall stiffness (the overall stiffness mainly governed by MF), only $4 \%$ less steel was used in the moment frame of LCF6-BUS2 compared to the other two systems. However, using built-up section saved $16 \%$ and $13 \%$ steel in the links for LCF6-BUS1 and LCF6-BUS2 respectively compared to LCF6-W. 


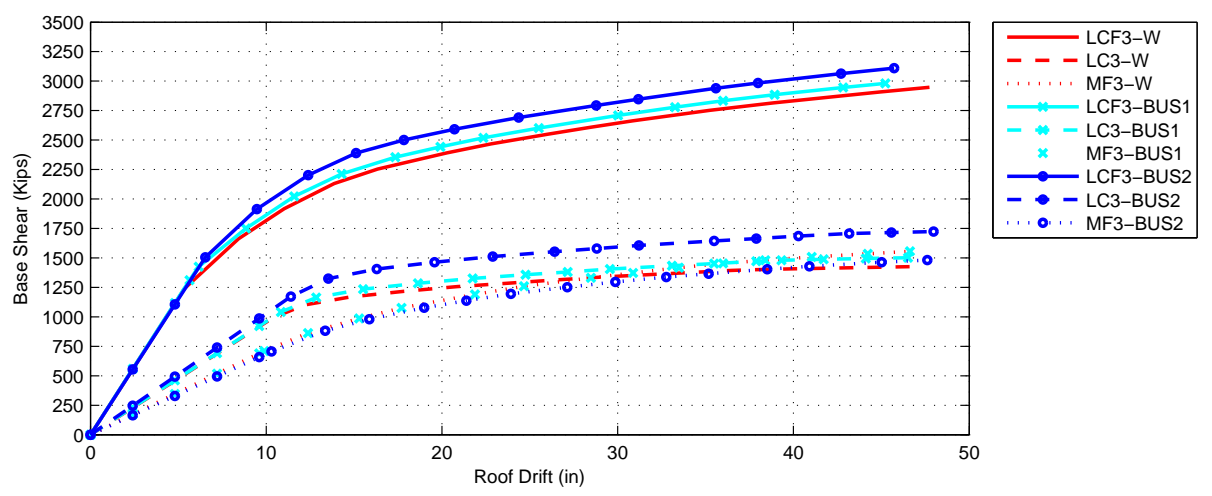

Figure 8.8: Pushover Response of LCFs and Their Components for 6-story LCF Model Buildings.

In conclusion, the stiffness of 3-story LCFs is most greatly impacted by the area of the links' webs compared to the other component section properties. The stiffness of 6 -story LCFs is most greatly impacted by the beam moment of inertia. Based of this, using built-up sections instead of W-shape sections for links in 3-story LCFs has considerable benefits for the overall efficiency because the web area can be controlled independent of the other cross section properties. 
Chapter 9

\section{QUANTIFICATION OF LCF SEISMIC PERFORMANCE FACTORS FOR USE IN SEISMIC DESIGN}

\subsection{Introduction}

The LCF is a recently defined seismic-force-resisting system that has never been subjected to any significant level of earthquake ground shaking. Both seismic response characteristics and the ability to meet seismic design performance objectives of this system are untested and unknown. As a result, there are no building system performance or seismic response parameters appropriate for use in seismic design of the LCF. Thus, there is a need to provide the response modification coefficient $(R)$, the system over-strength factor $\left(\Omega_{0}\right)$, and the deflection amplification factor $\left(C_{d}\right)$, for the LCF as a new seismic force resisting system proposed for inclusion in building codes.

These factors were initially introduced in the ATC-3-06 report, Tentative Provisions for the Development of Seismic Regulations for Buildings (ATC, 1978); the values of which are fundamentally critical in the specification of design seismic loading. The values were based largely on judgment and qualitative comparisons with the known response capabilities of relatively few seismic-force-resisting systems in widespread use at the time.

This chapter establishes seismic performance factors using Incremental Dynamic Analysis (IDA) and parametric study results based on the FEMA P695 (2009) (ATC-63) procedures (Methodology). The FEMA P695 (2009) Methodology was developed to determine building system performance and response parameters to ensure equivalent safety against collapse in earthquakes for buildings with different seismic-force-resisting systems. Based on the Methodology, the procedure employed involved developing detailed system design information, probabilistic assessment of collapse risk, comprehensive and advanced nonlinear test data on LCF components and assemblies; and explicit consideration of uncertainties in ground motion, modeling, design, and test data; all for the purpose of determining the 
collapse potential and seismic performance factors.

The Methodology recommended in FEMA P695 uses some key principles and terms, summarized as follows:

\subsubsection{General Assumptions}

- For new proposed LCF systems, the Methodology requires identification and use of applicable structural design and detailing requirements in ASCE (2005) and also calls for development and use of new requirements as needed to describe LCF limitations and enable the prediction of seismic component behaviors.

- The Methodology is concerned only with developing seismic response factors for achieving life safety performance, which is the objective of seismic regulations in model building codes.

- In general, life safety risk is difficult to predict and measure due to uncertainties in casualty rates and falling hazards effects. Therefore, the Methodology provides approximate uniform protection requirements against system collapse (when subjected to Maximum Considered Earthquake (MCE) ground motions) as the way to achieve the primary performance objective of life safety, rather than trying to define uniform protection of life safety.

- The Methodology uses code-defined (ASCE, 2005) Maximum Considered Earthquake (MCE) ground motions for various levels of ground motion hazard as the basis for evaluating structural collapse. It should be noted that seismic performance factors apply to the design response spectrum, which is two-thirds of the MCE spectrum.

\subsubsection{Seismic Performance Factors}

The seismic performance factors to be determined for LCF system are $R, \Omega_{0}$ and $C_{d}$. $R$ is used in current building codes to estimate strength demands for seismic force resisting systems designed using linear methods but responding beyond the linear range. It is the 
ratio of the base shear that would be developed in the system for the design earthquake ground motion if the system remained entirely linearly elastic to the design base shear.

$\Omega_{0}$ factor is the ratio of the maximum strength of the fully-yielded system to the design base shear, and $C_{d}$ is some fraction of the $R$ factor $\left(C_{d}=\frac{\delta}{\delta_{E}} R\right)$.

In terms of evaluating seismic response factors of LCF system, the following provides an overview of procedure following P695 Methodology:

Figure 9.1 illustrates seismic performance factors and their fundamental relations used in the methodology. Figure 9.1(a) explains these factors based on idealized pushover curve of the system, base shear vs roof displacement. In this figure, $V_{E}$ is the force level that would be developed if the system remained entirely linearly elastic for design earthquake ground motions, $V_{\text {Max }}$ is the maximum strength of the fully-yielded system and $V$ is the seismic design base shear. The term $\delta_{E} / R$, is roof drift of the system corresponding to design base shear, $V$, assuming the system remains elastic and $\delta$ is the roof drift of the yielded system corresponding to design earthquake ground motions. Seismic factors are defined by the following equations:

$$
\begin{gathered}
R=\frac{V_{E}}{V} \\
\Omega_{0}=\frac{V_{M a x}}{V} \\
C_{d}=\frac{\delta}{\delta_{E}} R
\end{gathered}
$$

The Methodology develops seismic performance factors consistent with the basic pushover concept but converted to spectral coordinates. This conversion, assumes that entire structural seismic weight, $W$, participates in basic mode of the system with a period of $T$.

Figure 9.1(b) shows the the seismic response factors defined by the Methodology. In this Figure $S_{\text {Max }}$ is the maximum strength of the fully-yielded system normalized by the effective seismic weight, $W$, of the structure; $S_{M T}$ is the Maximum Considered Earthquake (MCE) spectral acceleration at the period of the system, T; $\hat{S}_{C T}$ is the median $5 \%$ damped 


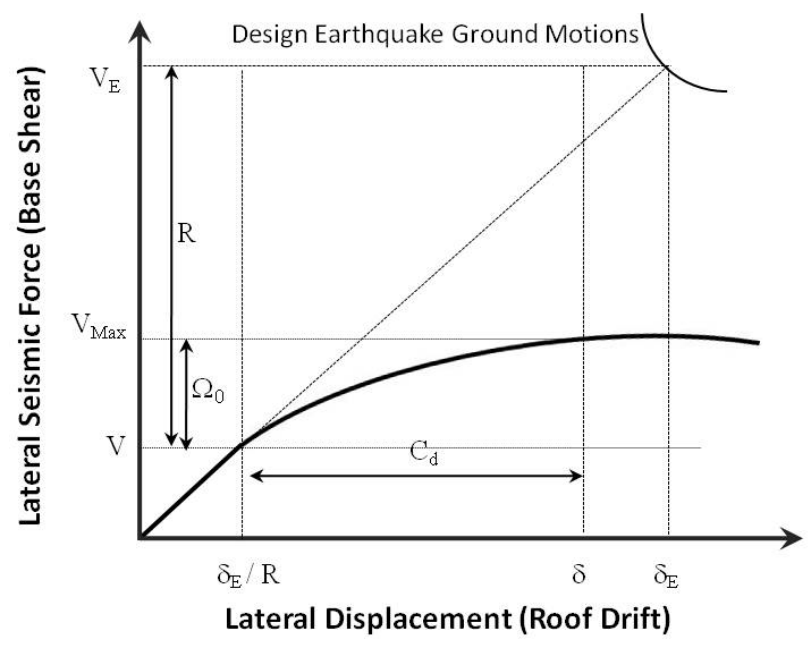

(a)

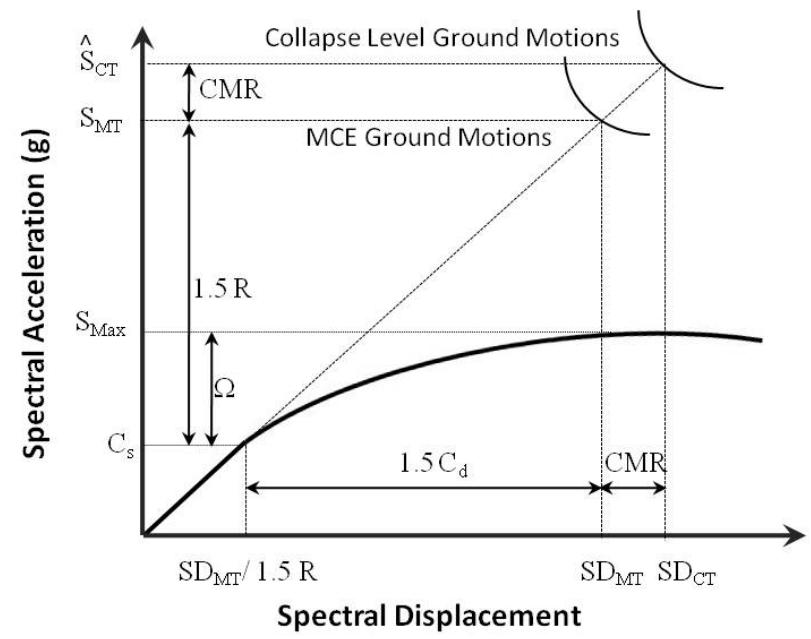

(b)

Figure 9.1: Illustration of Seismic Performance Factors, R, $\Omega$ and $C_{d}$ a) as Defined by the Commentary to the NEHRP Recommended Provisions (FEMA 2004b) b) as Defined by the FEMA P695 Methodology (2008). 
spectral acceleration of the collapse level ground motions at the period of the system; and $C_{s}$ is the seismic response coefficient $(V / W$, the ratio of the design base shear and the weight of the structure).

For defining $\hat{S}_{C T}$ the ground motion spectral acceleration causing median collapse is used. Median collapse is when $50 \%$ of the structures analyzed would have some form of collapse when subjected to this intensity of ground motion. Also shown in Figure 9.1(b), it is assumed that the ratio of the mean spectra acceleration corresponding to the MCE, $S_{M T}$, to the seismic response coefficient, $C_{S}$, is equal to 1.5 times the $R$ value. The 1.5 factor accounts for the definition of design earthquake ground motions as two-thirds of MCE ground motions. The other assumption is that the $C_{d}$ factor is equal to the $R$ factor. This assumption is reasonable for most conventional systems with effective damping approximately equal to the nominal $5 \%$ level used to define response spectral acceleration and displacement. Based on the Methodolgy, seismic factors are defined by following equations:

$$
\begin{gathered}
1.5 R=\frac{S_{M T}}{C_{s}} \\
\Omega=\frac{S_{M a x}}{C_{s}} \\
C_{d}=R
\end{gathered}
$$

\subsubsection{Collapse Margin Ratio}

As defined in FEMA P695, the Collapse Margin Ratio (CMR) is the ratio of the median 5\% damped spectral acceleration of the collapse level ground motions to the $5 \%$ damped spectral acceleration of the MCE ground motions, at the fundamental period of the structure, as shown in Figure 9.1(b) and given by:

$$
C M R=\frac{\hat{S}_{C T}}{S_{M T}}
$$




\subsubsection{Archetypes}

For determining the seismic response factors of LCF, and to represent the system thoroughly, there is a need for a set of LCF models that can capture all aspects and variability of the performance characteristics of the system such as building heights, structural framing configurations, framing bay sizes, magnitude of gravity loads, member and connection design and detailing requirements. Each of these models have been named an archetype in this Methodology. The Methodology requires detailed modeling of the nonlinear behavior of all archetypes, based on representative test data sufficient to capture collapse failure modes.

\subsubsection{Incremental Dynamic Analysis (IDA)}

The Methodology uses Incremental Dynamic Analysis (IDA) as an approach for nonlinear dynamic analysis. IDA is an emerging analysis method that offers thorough seismic demand and capacity prediction capability to estimate overal structure performance by using a series of nonlinear dynamic analyses under a multi scaled suite of ground motion records. This method involves subjecting a structure model to one ground motion record(s), each scaled to multiple levels of intensity, thus producing one curve(s) of response parameterized versus intensity level.

The Intensity Measure (IM) is the structural response that the designer chooses to monitor during an IDA. Possible IMs include: Peak Ground Acceleration (PGA), Peak Ground Velocity and the 5\% damped Spectral Acceleration at the structures first-mode period $(\mathrm{Sa}(\mathrm{T} 1,5 \%))$. On the other hand, the Damage Measure (DM) is a non-negative scalar value that characterizes the response of the structural model to a prescribed seismic loading. Similar to IM, there are many possible choices that can be utilized as a DM including maximum base shear, node rotations, peak story ductilities, peak roof drift, and the maximum peak interstory drift angle.

Once a proper nonlinear structural model, ground motion records, scale factors, IM and DM are all selected, the nonlinear time history analyses can be conducted. Each nonlinear time history analysis results in a discrete point consisting of an IM and DM scalar value that can provide the snapshots of the system response as ground motion records are incrementally 
increased, providing an ability to trace when, where, and at what demand-level elements begin to yield.

The Methodology utilizes an IDA method to estimate the collapse potential of an archetype through dynamic simulation and increasing the intensity of ground motions until the maximum roof displacement response increases. This implies a softening of the system. In the relationship of intensity of the ground motion (spectral acceleration at the period of the structure) versus the maximum dynamic responses (roof displacement of the system), the ground motion intensity corresponding to system collapse is based on having a gradually straightening acceleration-displacement response curve. The $\hat{S}_{C T}$ is defined as the median value of the resulting spectral acceleration capacities over the ground motion record set.

\subsubsection{Overall Process of the Methodology}

The key steps and general framework of the Methodology for finding seismic performance factors for the LCF system are explained briefly in following steps.

1. Develop the LCF Concept: A well-defined concept for the LCF, which can describe the system and characterize LCF components comprehensively.

2. Obtain Required Information: Information includes prototype designs, description of the LCF, such as geometric configurations, intended applications and behavioral characteristics, detailed design requirements and test results on the material, component, and system levels.

3. Archetype Development: Development of LCF system archetypes that characterize permissible configurations and other significant features of the LCF system.

4. Nonlinear Model Development: Development of nonlinear models of the archetypes that include explicit simulation of all significant deterioration mechanisms that could lead to LCF collapse.

5. Analyze Models: Nonlinear analysis of the archetypes using nonlinear static and nonlinear dynamic analysis procedure to examine the behavior of the LCF models 


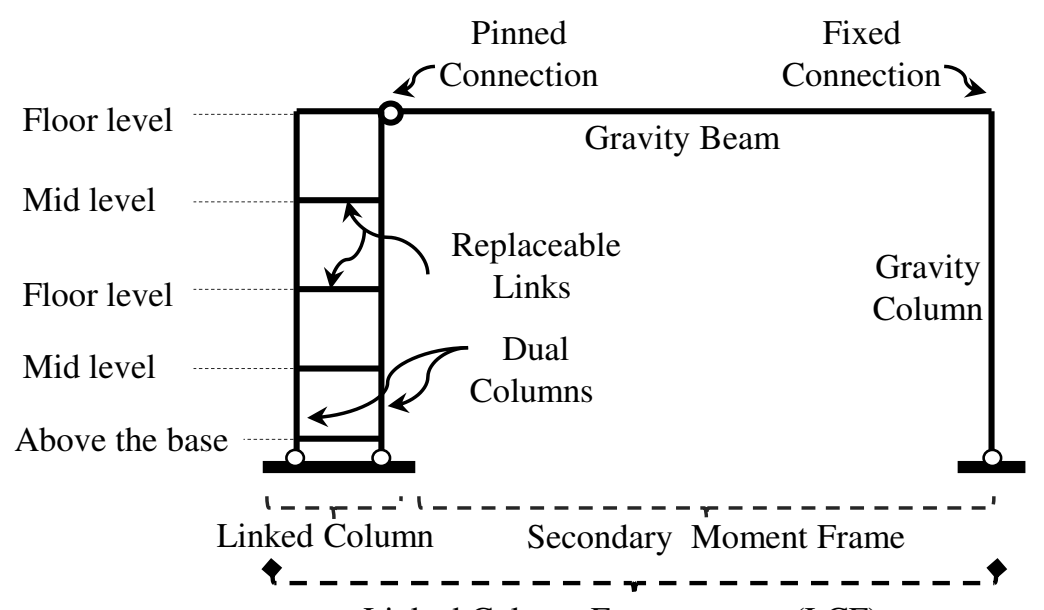

Linked Column Frame system (LCF)

Figure 9.2: Schematic of a Building Bay with the Linked Column Frame System.

and to provide statistical data on LCF parameters such as overstrength and ductility capacity.

6. Evaluate Performance: Performance evaluation utilizes the results from nonlinear static and nonlinear dynamic analysis to determine appropriate values for the response modification coefficient ( $\mathrm{R}$ factor), the LCF over-strength factor $(\Omega)$, and deflection amplification factor $\left(C_{d}\right)$. The trial initial value of $R$ is evaluated in terms of the acceptability of a calculated CMR.

\subsection{Development of the LCF Concept and Obtaining Required Information}

\subsubsection{Description of $L C F$}

In Chapter 3 of this research, the LCF system was introduced as a steel lateral system consisting of dual columns interconnected with replaceable link beams [Linked Column (LCs)] and flexible secondary moment frames (MF). The basic configuration is shown in Figure 9.2 and the summary of the LCF description and behavior is as follows:

The pushover response of an idealized LCF system and the contribution of its components, i.e., the moment frame and the linked column, are shown in Figure 9.3. A detailed 


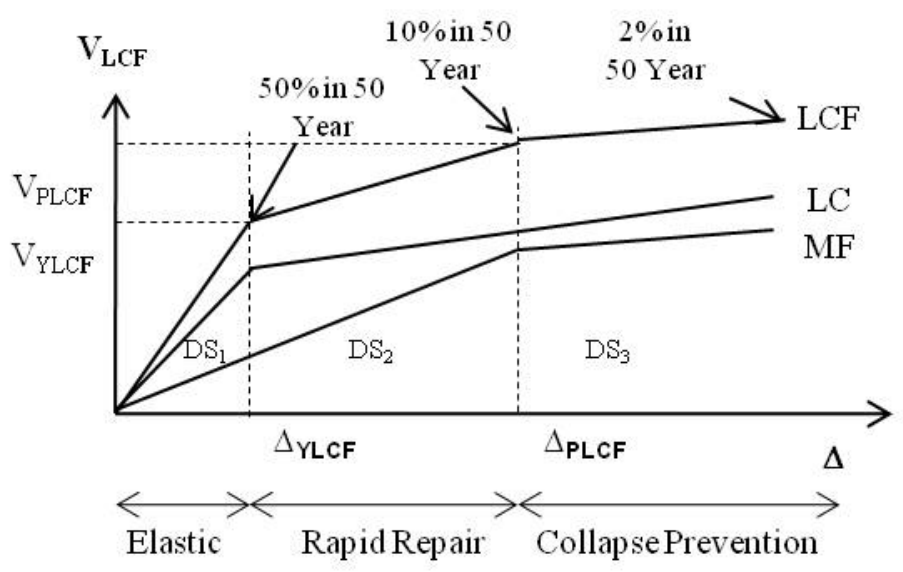

Figure 9.3: Idealized LCF and Component Pushover Curves.

description of this figure can be referenced in Chapter 3 .

Moreover, the inelastic dissipation mechanism was introduced by the link beams' yield in shear or flexural during certain earthquakes and they can be replaced after the event. The impact of this mechanism has been taken into account to develop an archetype index through the use of different types of links that influence the inelastic deformation capacity of the links. For larger earthquakes, plastic hinges also form in the beam of moment frame.

Column plastic hinging is prevented via capacity design and by using flexible connections to the foundation (shown as pins in Figure 9.2). As shown in Figure 9.2, the links are at mid-height and at the story level of each story. To provide additional stiffness to the system, additional links are added to the foundation just above the column connections. These links are connected to the columns with fully restrained connections and the columns are capacity designed for the links' plastic capacity.

In a given seismic event where plastic hinges develop only in the links, a rapid repair may be achieved if the links can be easily replaced. In a larger seismic event plastic hinges may develop in both the links and beams, providing the system adequate ductility and energy dissipation to achieve collapse prevention. These two performance states, rapid repair and collapse prevention, are shown in Figure 9.3 .

To ensure the links have adequate ductility and are easily replaceable, welded end-plate 
details with stiffeners at the link ends that are parallel to the beam web and welded to the end-plate and link flanges have been developed for the link-to-column connections by Dusicka and Lewis (2010).

It should be noted for delaying the onset of beam plastification, the beam has a simple connection to the LC and has a fixed connection at the other end.

\subsubsection{Intended Applications}

The LCF system can be used for any building application such as residential, commercial, schools or institutional buildings, offices and hospitals. However in this research, the buildings were to be designed as standard office buildings with floor dead load, roof dead load and reduced live load per floor, and for roof equal to 96 Psf, 83 Psf and 20 Psf respectively.

The seismic mass for the structure is as follows: for 3- and 6-story LCF, 70.90 Kips $\mathrm{sec}^{2} / \mathrm{ft}$ for roof and $65.53 \mathrm{Kips}-\mathrm{sec}^{2} / \mathrm{ft}$ for all the other floors; for 9-story LCF, 73.10

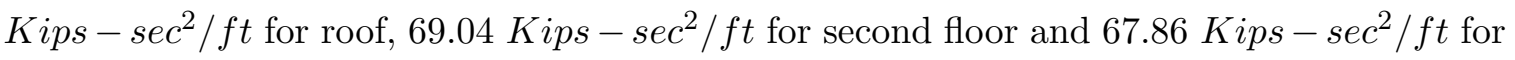
all other floors.

\subsubsection{Detailed Design requirements}

All aspects of the design and detailing of the LCF system are based on standard design provisions of ASCE 7 (ASCE, 2005), Minimum Design Loads for Buildings and Other Structures and the AISC Seismic Provisions for Structural Steel Buildings (AISC, 2005b). Following is a key point summary of design requirements for links, beams and columns. Links should be designed per AISC (2005b) to include all detailing of eccentric braced frame links such as stiffened detailing, different types of yielding and more. Link end-plates welded to the link ends and bolted to the columns are part of the design parameters, as are bolts capacity designed considering link overstrength. Additional welded detailing following the recommendation of Dusicka and Lewis (2010) considering end stiffness is also required. Recommended beam design considers the intermediate moment frame detailing for less complicated detailing compared to special moment frame. Columns should all be capacity designed for link and beam demands and overstrength considerations. 


\subsubsection{Prototype Design and Configuration}

In this study, the design requirements for LCF systems were obtained from SAC buildings (Gupta and Krawinkler, 1999). The buildings considered were 3-, 6-, and 9-stories tall with uniform story height of $3.96 \mathrm{~m}$ (13 ft). In order to maintain the overall plan dimensions of the SAC buildings shown in Figure 9.4(a) and Figure 9.4(b), beam lengths had to be decreased due to the introduction of the linked column. Two bays of LCs were used for the 3- and 6-story LCFs as shown in Figure 9.4(b), For the 9-story building designs, two bays and three bays of LCs were used with an LC at each end. An LC was also inserted into the middle of the frame in the case with 3 LC's, as shown in Figure 5.2 .

It can be assumed that two or three lines of LCF framing are present depending on location and hazard level; one at each end of the buildings, and one in middle in the case of three lines. The LCF framing lines serve the purpose of resisting the lateral seismic loads in the direction of the building under consideration.

\subsubsection{Data From Experiments}

For the new LCF system, analytical modeling alone can not predict all nonlinear behavior. There is also a need for comprehensive experimental investigations to validate material properties and component behavior, calibrate nonlinear analysis models and establish performance acceptance criteria.

Test data gathered is provided on three levels: 1) material, for characterizing the strength, stiffness, ductility and deformation properties of the materials and members; 2) component and connection, for calibrating analytical models of cyclic load-deformation characteristics for components and connections; 3) system, for quantifying interactions between structural components and connections of the LCF.

In Chapter 6 of this research, a comprehensive investigation has been done on this issue. The models for link, beam, column, slab and connection were developed and calibrated by using experimental test data on links, beams to column moment resisting and shear connections; all of which have been gathered from several published studies.

Link experimental data was gathered from tests performed by Kasai (1985), Engelhardt 


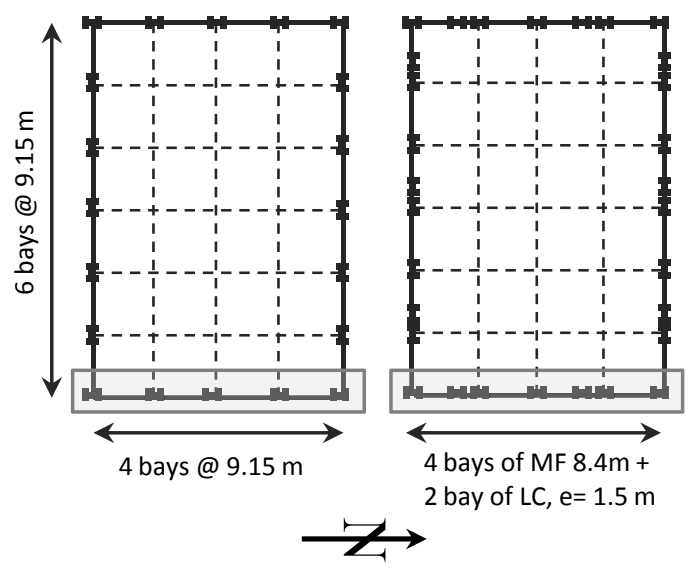

(a)

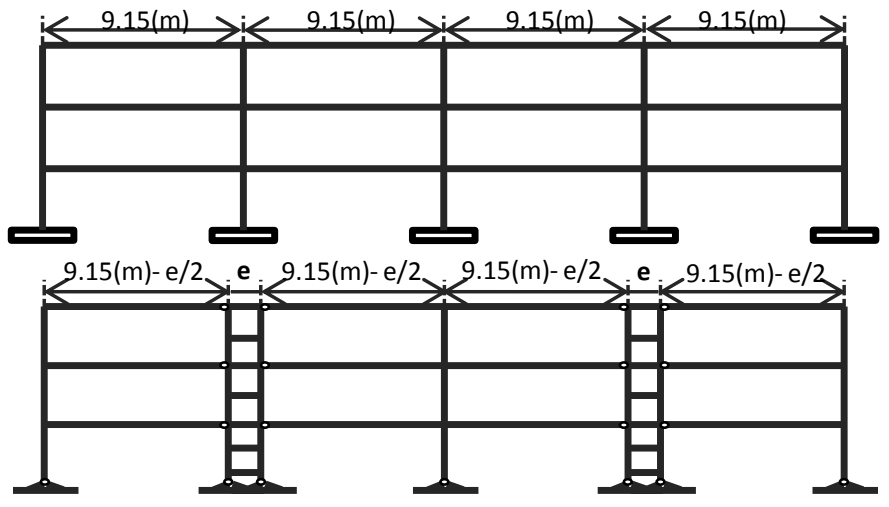

(b)

Figure 9.4: Frame Model of 3-Story. (a) Floor Plan for SAC Model Special Moment Resisting Frame and LCF Model (Based on SAC Model) (b) Elevations for SAC Model Special Moment Resisting Frame and LCF Model (Based on SAC Model). 
(1989), Arce (2002) and Dusicka and Lewis (2010).

Beam experimental data was gathered from tests conducted by Sumner and Murray (2002) for bolted unstiffened extended end-plate moment connections, and from Ricles et al. (2002) for welded unreinforced flange-welded web moment connections.

The types of element and material models used for the beam and column members have been used by others to model the nonlinear response of steel moment resisting frames prior to strength depredation with success by Xuewei et al. (2008); Kolkan (2006); Kolkan and Kunnath (2007); Mathur (2011); Chen (2011); Lu and MacRae (2011). In the LCF design, all columns are capacity designed and protected from significant yielding, therefore using their model without having to gather additional test results is reasonable.

For simple shear connections, experimental data was gathered from full-scale simple connection tests conducted by Liu and Astaneh-Asl (2000).

Thorough testing of a complete LCF system should be performed and used as a validation tool for the proposed analytical and performance-based design methodology. A hybrid testing program for the LCF system is underway, which will allow for full scale evaluation of the system performance and will account for the uncertainties via the experimental component and model more conventional behavior through numerical simulation. The system experiments led by collaborators at Portland State University are scheduled at NEES@Berkeley and construction has been in progress since summer 2012. The experiments utilize the hybrid simulation capabilities and include a full-scale 2-story and 1-bay experimental LCF subsystem. More information on hybrid testing and the OpenSees modeling conducted to support those tests is discussed in Chapter 10.

\subsection{Archetype Development}

After the development of a well-defined concept for the LCF and required information including detailed design requirements and results from material, component, and system testing is obtained, LCF behavior is characterized through the use of structural system archetypes.

Archetypes are representative of expected and permissible building configurations for newly developed LCF and they reflect the range of design parameters and system attributes 
that have a significant impact on LCF response. To assess the LCF archetype, the range of parameters and attributes is narrowed to the fewest and simplest possible, while still being reasonably representative of the variations that would be permitted in actual structures. The following characteristics are used to define LCF archetypes (Figure 9.5):

- Ground motion intensity (Seismic Design Category (SDC))

- Building heights

- Plan configuration

- Column Boundary conditions

- Structural framing configurations

- Beam and link spans

- Number of framing bays

- Member and connection design and detailing requirements

- Link type and corresponding failure modes

A matrix of index archetype configuration is developed based on the above characteristics in Table 9.1

In this Table, index archetype configurations include three building heights of 3-, 6- and 9-stories, two numbers of LCF bays (2 and 3), two different column boundary conditions (fixed and pinned), two LC column spacing (60 and 80 in.), two different link types (WF section and built-up section), two different numbers of LCF in the building's lateral direction (2 and 3), two design lateral load intensities $\left(D_{\max }\right.$ and $D_{\min }$ for Seismic Design Category D) and LCF containing links that have different yield mechanisms; shear links only or a combination of links that are shear, flexural or intermediate (defined in Table 9.1 as mix for link failure mode). WF section is a rolled wide flange beam section and built-up section is 
Table 9.1: Matrix of Index Archetype Configurations for LCF Buildings

\begin{tabular}{|c|c|c|c|c|c|c|c|c|c|}
\hline Index Archetype & $\begin{array}{l}\text { No. of } \\
\text { Stories }\end{array}$ & $\begin{array}{c}\text { No. of } \\
\text { LCF } \\
\text { Bays }\end{array}$ & $\begin{array}{c}\text { Base } \\
\text { Detailing }\end{array}$ & $\begin{array}{l}\text { Beam } \\
\text { Bay } \\
\text { Width } \\
\text { (inch) }\end{array}$ & $\begin{array}{l}\text { Linked } \\
\text { Column } \\
\text { Spacing } \\
\text { (inch) }\end{array}$ & $\begin{array}{c}\text { Cross } \\
\text { Section }\end{array}$ & $\begin{array}{c}\text { No. of } \\
\text { LCF in } \\
\text { Lateral } \\
\text { Direction }\end{array}$ & $\begin{array}{c}\text { Seismic } \\
\text { Design } \\
\text { Category }\end{array}$ & $\begin{array}{c}\text { Link } \\
\text { Failure } \\
\text { Mode }\end{array}$ \\
\hline 1 & 3 & 2 & Pinned & 330 & 60 & $\mathrm{~W}$ section & 2 & $D_{\max }$ & Shear \\
\hline 2 & 3 & 2 & Pinned & 330 & 60 & W section & 2 & $D_{\max }$ & Int/Flex \\
\hline 3 & 3 & 2 & Pinned & 330 & 60 & Built-up & 2 & $D_{\max }$ & Shear \\
\hline 4 & 6 & 2 & Pinned & 330 & 60 & W section & 2 & $D_{\max }$ & Shear \\
\hline 5 & 6 & 2 & Pinned & 330 & 60 & Built-up & 2 & $D_{\max }$ & Shear \\
\hline 6 & 6 & 2 & Fixed & 330 & 60 & Built-up & 2 & $D_{\max }$ & Shear \\
\hline 7 & 6 & 2 & Pinned & 320 & 80 & $\mathrm{~W}$ section & 2 & $D_{\max }$ & Shear \\
\hline 8 & 6 & 2 & Pinned & 320 & 80 & $\mathrm{~W}$ section & 2 & $D_{\max }$ & Int/Flex \\
\hline 9 & 6 & 2 & Pinned & 320 & 80 & $\begin{array}{l}\text { W sec- } \\
\text { tion(NL) }\end{array}$ & 2 & $D_{\max }$ & Shear \\
\hline 10 & 9 & 2 & Pinned & 320 & 80 & $\mathrm{~W}$ section & 2 & $D_{\max }$ & Mix \\
\hline 11 & 9 & 2 & Pinned & 320 & 80 & Built-up & 2 & $D_{\max }$ & Mix \\
\hline 12 & 9 & 2 & Fixed & 320 & 80 & W section & 3 & $D_{\max }$ & Mix \\
\hline 13 & 9 & 2 & Pinned & 320 & 80 & $\mathrm{~W}$ section & 3 & $D_{\max }$ & Mix \\
\hline 14 & 9 & 2 & Pinned & 320 & 80 & W section & 2 & $D_{\min }$ & Mix \\
\hline 15 & 9 & 2 & Pinned & 330 & 60 & W section & 2 & $D_{\min }$ & Mix \\
\hline 16 & 9 & 3 & Pinned & 320 & 80 & W section & 2 & $D_{\max }$ & Mix \\
\hline 17 & 9 & 3 & Pinned & 320 & 80 & Built-up & 2 & $D_{\max }$ & Mix \\
\hline
\end{tabular}




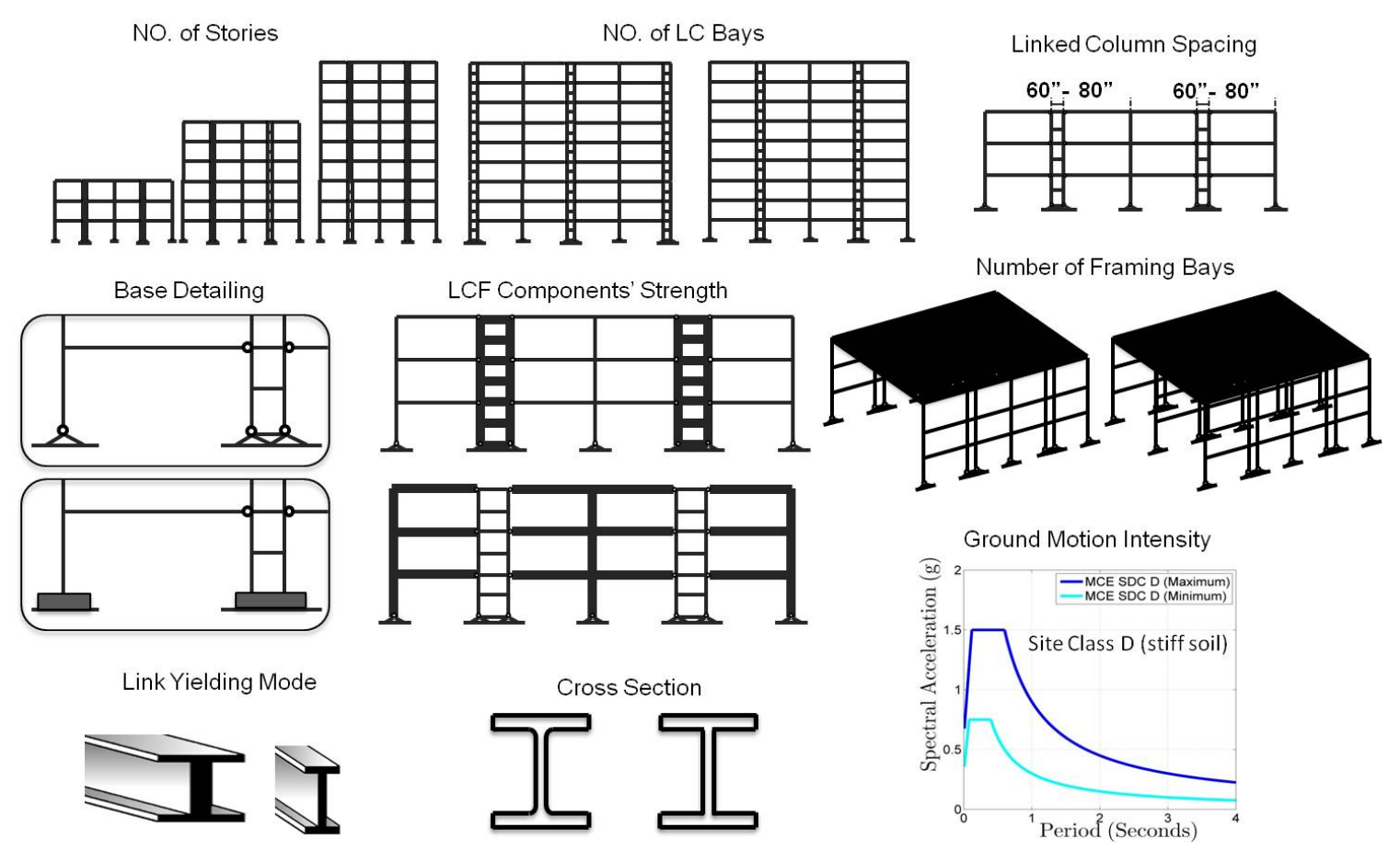

Figure 9.5: Different Characteristics Used to Define LCF Archetypes .

a section of plates welded together. More explanation for each LCF archetype is presented in the following section.

It should be noted that components not designated as part of the LCF system and also overstrength due to wind or other controlling load cases that are not attributed to earthquake and gravity load effects are not considered in the development of index archetype configurations

\subsection{Nonlinear Model Development}

After developing index archetype configurations considering all above mentioned features (Table 9.1), by applying proposed LCF design requirements and procedures, utilizing and applying test data, developing and calibrating LCF member properties, establishing connection details and simulating collapse in nonlinear static and dynamic analysis, index archetype models are developed. 


\subsubsection{Index Archetype Designs}

An explanation of the comprehensive design procedure can be found in Chapter 4 . Key design requirements were also reviewed in Section 9.2.3. All aspects of the design and detailing of the index archetype designs are based on standard design provisions of ASCE 7 (ASCE, 2005), Minimum Design Loads for Buildings and Other Structures and the AISC Seismic Provisions for Structural Steel Buildings (AISC, 2005b). From this standard, the trial values of the response modification factor, $R$, overstrength factor, $\Omega_{0}$, and displacement amplification factor, $C_{d}$, equal to those for special steel moment resisting frames of 8,3 , and 5.5 are used, respectively.

Some additional modifications to the design procedure discussed in Chapter 4 were made for development of index archetype designs. A summary of the specific designs and those modifications are provided below.

The following gravity and seismic load combinations are considered in design of the LCF archetypes:

$$
1.2 D+1.0 E+0.5 L
$$

$$
0.9 D-1.0 E
$$

Here, $D$ is structural self weight and dead loads, $L$ is the live load and $E$ is the earthquake load. Because snow load varies with location, it is not considered in Equation 9.8, which is different from the equation given in ASCE (2005).

The archetype LCF buildings are designed for site class D soil. Index archetype designs are prepared for the maximum and minimum seismic criteria corresponding with the seismic design category $D$, as summarized in Table 9.2 and required by FEMA P695. It is noted that the the corresponding maximum considered earthquake spectral values are equal to 1.5 times the design spectral value.

All index archetype designs are designed to satisfy seismic drift requirements based on ASCE 7 (ASCE, 2005), that is $0.025 \%$ of story height with $C_{d}=5.5$. 
Table 9.2: Design Spectral Values for Seismic Design Category D

\begin{tabular}{ccc}
\hline Spectral Accelerations for Design & $D_{\min }$ & $D_{\max }$ \\
\hline$S_{D S}$ & $0.50 \mathrm{~g}$ & $1.00 \mathrm{~g}$ \\
$S_{D 1}$ & $0.20 \mathrm{~g}$ & $0.60 \mathrm{~g}$ \\
\hline
\end{tabular}

As discussed in Chapter 4, after the code-based drift limits are checked using elastic static analysis and the displacement amplification factor $C_{d}$, the key design constraint is to ensure the roof displacement at which the first plastic hinge develops in a beam of the moment frame, $\Delta_{Y M F}$, is greater than the roof displacement at which the first plastic hinge develops in a link of the linked columns, $\Delta_{Y L C}$. In the prototype designs described below, the ratio of these displacements were within the range:

$$
1.2<\frac{\Delta_{Y M F}}{\Delta_{Y L C}}<3
$$

Using the above design considerations in addition to those described in Chapter 4 and Section 9.3 , the index archetype design shown in Tables 9.3 9.9 were developed for the system parameters in Table 9.1 .

As shown in Table 9.3, three different 3-story LCF archetypes were designed. All three have linked column spacings of $60 \mathrm{in}$. The main difference amongst these three LCFs is the cross section type link and link yield mechanism. In index archetype 1, WF section links with shear yielding behavior were used. However, in index archetype 2, a mix of intermediate and flexural links with WF sections were used. As is clear in Table 9.3, when the links change from shear behavior to flexure or intermediate behavior (decreasing the size for a similar length), the moment frame beam and column sizes increase to satisfy drift. Thus, these archetypes cover a range of relative stiffnesses for the LCs and MFs. Index archetype 1, which uses shear links, has stiffer LC and more flexible MF relative to index archetype 2, uses flexural and intermediate links. This two represent reasonable bounds as theses relate stiffnesses for the LCF when WF links are used. Index archetype 3 is very 
similar to index archetype 1, except instead of WF section links, built-up sections were used; yet in both cases the links yield in shear. Three built-up link designs were used in index archetype 3 and their cross section dimensions are summarized in Table 9.10, where they are all shear links. These simple changes in design of the 3-story archetypes cover reasonable variations that have impact on LCF behavior.

Six 6-story archetype LCFs were also designed. Tables 9.4 and 9.5 show the six 6 -story LCF archetype designs. Index archetypes 4, 5 and 6 have similar sizes for the beams and columns and both have shear links with 60 in. linked column spacing. However, index archetype 4 uses WF sections, index archetype 5 uses built-up sections and index archetype 6 has fully restrained column connections at the foundation. In index archetypes 7, 8 and 9, the linked column spacing was increased to 80 in. instead of 60 in. and in order to maintain the overall plan dimensions for all designs, the MF beam lengths had to be decreased. As a result, the axial load in the linked columns caused by overturning moment decreased and the total stiffness of the LCF increased, thus the story drifts reduce. As shown in Table 9.4. due to the increase in the linked column spacing, all cross section sizes for beams, columns and links of index archetype 7, were reduced in comparison to index archetype 4 while both utilize shear yielding links. In index archetype 8, intermediate and flexural links were used (resulting in smaller link cross sections relative to the shear links), therefore, the linked columns had smaller capacity design demands and smaller section sizes when compared with index archetype 7. However, the effect of employing intermediate and flexural links is a more flexible linked column, so stiffer moment frames with larger beam and column sizes were needed to satisfy drift. Finally, index archetype 9 is very similar to index archetype 8, except for the link sizes. Due to possible architectural issues, the shear links in index archetype 8 were limited to section depths of 24 in., but in index archetype 9, there was depth limit used in designing shear links sizes. "NL" was referenced in Table 9.1, index archetype 9, representing cross section which is not limited to $24 \mathrm{in}$. depth.

Finally, eight 9-story LCF archetypes were designed. In all eight designed frames a mix of shear, intermediate and flexural links were utilized and all frames had linked column spacing of 80 in., except for index archetype 15 which had 60 in. spacing. As shown in Table 9.6, index archetypes 10, 11 and 12 have the same cross sections, except for the links 
where index archetypes 10 and 11, WF and built-up sections were used, respectively. Index archetype 12 is the same as index archetype 11, except index archetype 12 has fixed column connections instead of pinned column connections at base.

Index archetype 13 is similar to index archetype 10; the only difference being the number of LCF frames in lateral direction. In all other designs, two perimeter LCF frames were used, but in index archetype 13, this was increased to three LCF frames, one additional frame located in the middle of the building, thus dividing the total base shear by three instead of two. As illustrated in Table 9.7, by keeping the linked column sizes the same as index archetype 10, the moment frame sizes were reduced significantly.

As mentioned earlier, the LCF system should be evaluated for the maximum and minimum spectral acceleration of the highest Seismic Design Category, SDC $D_{\max }$ and SDC $D_{\min }$, respectively. In most cases, designs for SDC $D_{\max }$ controls the collapse performance of the system, however, it is recommended to evaluate the system also against SDC $D_{\text {min }}$ in case it controls performance. Index archetype designs within a Seismic Design Category should consider spectral intensities corresponding to the maximum and minimum values for SDC D. Therefore, index archetypes 14 and 15 were investigated for SDC $D_{\min }$. Index archetype 14 uses 80 in. linked column spacing and index archetype 15 uses 60 in. linked column spacing. The cross sections of both designs are shown in Tables 9.7 and 9.8 . Both moment frame and linked column sizes are reduced noticeably compared to the LCF archetypes designed for SDC $D_{\max }$. By decreasing the link length while maintaining the same link cross sections and LC column sizes in index archetype 15 compared to index archetype 14, the moment frame cross section sizes were increased as necessary for satisfying drift.

Finally, index archetypes 16 and 17 which have 3 LCs per frame (Figure 5.2(a) each, were designed to provide response data for an alternative geometry.

It should be noted, in 9-story LCFs, overturning generally controls the behavior of these taller LCFs compared to lower LCFs, which leads to similar column sizes despite attempting to modify behavior. This constraint limits 9-story LCFs to similar designs. As mentioned earlier, the practical maximum height for this system is 9-stories for high seismic hazard sites. 
Table 9.3: Design Details; Beam and Column Section for 3-story Index Archetype Designs

\begin{tabular}{|c|c|c|c|c|c|c|c|}
\hline \multirow[b]{3}{*}{ Model } & \multirow[b]{3}{*}{ Story } & \multicolumn{2}{|c|}{ Link Column } & \multicolumn{4}{|c|}{ Moment Frame } \\
\hline & & \multirow[b]{2}{*}{ Column } & \multirow[b]{2}{*}{ Beam } & \multicolumn{2}{|c|}{ Column } & \multicolumn{2}{|c|}{ Beam } \\
\hline & & & & Exterior & Interior & Exterior & Interior \\
\hline \multirow{3}{*}{1} & $\begin{array}{c}\text { Base } \\
\text { Int } 1 / 2 \\
1 / 2\end{array}$ & $\mathrm{~W} 14 \times 257$ & $\begin{array}{l}\text { W24x103 } \\
\text { W24x103 } \\
\text { W24x103 }\end{array}$ & $\mathrm{W} 14 \times 120$ & W14x193 & W24x68 & W24x68 \\
\hline & $\begin{array}{c}\text { Int } 2 / 3 \\
2 / 3\end{array}$ & W14x257 & $\begin{array}{l}\text { W18x97 } \\
\text { W18x97 }\end{array}$ & $\mathrm{W} 14 \times 120$ & W14x193 & W24x62 & W24x62 \\
\hline & $\begin{array}{c}\text { Int 3/R00f } \\
\text { 3/Roof }\end{array}$ & $\mathrm{W} 14 \times 257$ & $\begin{array}{l}\text { W16x100 } \\
\text { W16x100 }\end{array}$ & $\mathrm{W} 14 \times 120$ & W14x193 & W21x55 & W21x55 \\
\hline \multirow{3}{*}{2} & $\begin{array}{c}\text { Base } \\
\text { Int } 1 / 2 \\
1 / 2\end{array}$ & $\mathrm{~W} 14 \times 257$ & $\begin{array}{l}\text { W21x93 } \\
\text { W21x93 } \\
\text { W21x93 }\end{array}$ & $\mathrm{W} 14 \times 211$ & $\mathrm{~W} 14 \times 370$ & W24x117 & W24x117 \\
\hline & $\begin{array}{c}\text { Int } 2 / 3 \\
2 / 3\end{array}$ & $\mathrm{~W} 14 \times 257$ & $\begin{array}{l}\text { W16x31 } \\
\text { W16x31 }\end{array}$ & $\mathrm{W} 14 \times 211$ & $\mathrm{~W} 14 \times 370$ & W24x94 & W24x94 \\
\hline & $\begin{array}{c}\text { Int } 3 / \text { R00f } \\
3 / \text { Roof }\end{array}$ & $\mathrm{W} 14 \times 257$ & $\begin{array}{l}\text { W14x26 } \\
W 14 \times 26\end{array}$ & $\mathrm{~W} 14 \times 211$ & $\mathrm{~W} 14 \times 370$ & $\mathrm{~W} 24 \times 76$ & $\mathrm{~W} 24 \times 76$ \\
\hline \multirow{3}{*}{3} & $\begin{array}{c}\text { Base } \\
\text { Int } 1 / 2 \\
1 / 2\end{array}$ & W14x257 & $\begin{array}{l}\mathrm{B} 24.25 \times 10.5 \\
\mathrm{~B} 24.25 \times 10.5 \\
\mathrm{~B} 24.25 \times 10.5\end{array}$ & $\mathrm{~W} 14 \times 120$ & W14x193 & W24x68 & W24x68 \\
\hline & $\begin{array}{c}\text { Int } 2 / 3 \\
2 / 3 \\
\end{array}$ & $\mathrm{~W} 14 \times 257$ & $\begin{array}{l}\mathrm{B} 18.25 \times 10.5 \\
\mathrm{~B} 18.25 \times 10.5\end{array}$ & $\mathrm{~W} 14 \times 120$ & W14x193 & W24x68 & W24x68 \\
\hline & $\begin{array}{c}\text { Int } 3 / \text { R00f } \\
\text { 3/Roof }\end{array}$ & $\mathrm{W} 14 \times 257$ & $\begin{array}{l}\mathrm{B} 15.25 \times 10.5 \\
\mathrm{~B} 15.25 \times 10.5\end{array}$ & $\mathrm{~W} 14 \times 120$ & W14x193 & $\mathrm{W} 21 \times 55$ & $\mathrm{~W} 21 \times 55$ \\
\hline
\end{tabular}


Table 9.4: Design Details; Beam and Column Section for 6-story Index Archetype Designs

\begin{tabular}{|c|c|c|c|c|c|c|c|}
\hline \multirow[b]{3}{*}{ Model } & \multirow[b]{3}{*}{ Story } & \multicolumn{2}{|c|}{ Link Column } & \multicolumn{4}{|c|}{ Moment Frame } \\
\hline & & \multirow[b]{2}{*}{ Column } & \multirow[b]{2}{*}{ Beam } & \multicolumn{2}{|c|}{ Column } & \multicolumn{2}{|c|}{ Beam } \\
\hline & & & & Exterior & Interior & Exterior & Interior \\
\hline \multirow{6}{*}{4} & $\begin{array}{c}\text { Base } \\
\text { Int } 1 / 2 \\
1 / 2\end{array}$ & $\mathrm{~W} 14 \times 730$ & $\begin{array}{l}\text { W24x279 } \\
\text { W24x176 } \\
\text { W24x176 }\end{array}$ & W14x370 & W14x665 & W30x90 & W30x90 \\
\hline & $\begin{array}{c}\text { Int } 2 / 3 \\
2 / 3\end{array}$ & W14x730 & $\begin{array}{l}\text { W24x176 } \\
\text { W24x176 }\end{array}$ & W14x370 & W14x665 & W33x118 & W33x118 \\
\hline & $\begin{array}{c}\text { Int } 3 / 4 \\
3 / 4\end{array}$ & $\mathrm{~W} 14 \times 730$ & $\begin{array}{l}\text { W24x176 } \\
\text { W24x176 }\end{array}$ & W14x370 & W14x665 & W36x182 & W36x182 \\
\hline & $\begin{array}{c}\text { Int } 4 / 5 \\
4 / 5\end{array}$ & $\mathrm{~W} 14 \times 730$ & $\begin{array}{l}\text { W24x176 } \\
\text { W24x176 }\end{array}$ & $\mathrm{W} 14 \times 370$ & W14x665 & W36x182 & W36x182 \\
\hline & $\begin{array}{c}\text { Int } 5 / 6 \\
5 / 6\end{array}$ & W14x605 & $\begin{array}{l}\text { W24x131 } \\
\text { W24x131 }\end{array}$ & $\mathrm{W} 14 \times 370$ & W14x665 & W36x170 & W36x170 \\
\hline & $\begin{array}{c}\text { Int 6/R00f } \\
\text { 6/Roof }\end{array}$ & W14x605 & $\begin{array}{l}\text { W24x131 } \\
\text { W24x131 }\end{array}$ & W14x370 & W14x665 & W30x90 & W30x90 \\
\hline \multirow{6}{*}{5,6} & $\begin{array}{c}\text { Base } \\
\text { Int } 1 / 2 \\
1 / 2\end{array}$ & $\mathrm{~W} 14 \times 730$ & $\begin{array}{l}\text { B36x17 } \\
\text { B36x14 } \\
\text { B36x14 }\end{array}$ & $\mathrm{W} 14 \times 370$ & W14x665 & W30x90 & W30x90 \\
\hline & $\begin{array}{c}\text { Int } 2 / 3 \\
2 / 3\end{array}$ & $\mathrm{~W} 14 \times 730$ & $\begin{array}{l}\text { B36x14 } \\
\text { B36x14 }\end{array}$ & $\mathrm{W} 14 \times 370$ & W16x665 & W33x118 & W27x118 \\
\hline & $\begin{array}{c}\text { Int } 3 / 4 \\
3 / 4\end{array}$ & $\mathrm{~W} 14 \times 730$ & $\begin{array}{l}\text { B36x14 } \\
\text { B36x14 }\end{array}$ & W14x370 & W16x665 & W36x182 & W36x182 \\
\hline & $\begin{array}{c}\text { Int } 4 / 5 \\
4 / 5\end{array}$ & $\mathrm{~W} 14 \times 730$ & $\begin{array}{l}\text { B36x14 } \\
\text { B36x14 }\end{array}$ & W14x370 & W16x665 & W36x182 & W36x182 \\
\hline & $\begin{array}{c}\text { Int } 5 / 6 \\
5 / 6\end{array}$ & W14x605 & $\begin{array}{l}\text { B30x10.5 } \\
\text { B30x10.5 }\end{array}$ & W14x370 & W14x665 & W36x170 & W36x170 \\
\hline & $\begin{array}{c}\text { Int 6/R00f } \\
\text { 6/Roof }\end{array}$ & W14x605 & $\begin{array}{l}\mathrm{B} 22.85 \times 10.5 \\
\mathrm{~B} 22.85 \times 10.5\end{array}$ & $\mathrm{~W} 14 \times 370$ & W14x665 & W30x90 & W30x90 \\
\hline \multirow{6}{*}{7} & $\begin{array}{c}\text { Base } \\
\text { Int } 1 / 2 \\
1 / 2\end{array}$ & W14x665 & $\begin{array}{l}\text { W24x279 } \\
\text { W24x146 } \\
\text { W24x146 }\end{array}$ & W14x311 & W14x605 & W24x84 & W24x84 \\
\hline & $\begin{array}{c}\text { Int } 2 / 3 \\
2 / 3\end{array}$ & W14x665 & $\begin{array}{l}\text { W24x146 } \\
\text { W24x146 }\end{array}$ & W14x311 & W16x605 & W33x130 & W33x130 \\
\hline & $\begin{array}{c}\text { Int } 3 / 4 \\
3 / 4\end{array}$ & W14x665 & $\begin{array}{l}\text { W24x146 } \\
\text { W24x146 }\end{array}$ & W14x311 & W16x605 & W33x130 & W33x130 \\
\hline & $\begin{array}{c}\text { Int } 4 / 5 \\
4 / 5\end{array}$ & W14x605 & $\begin{array}{l}\text { W } 324 \times 146 \\
W 24 \times 146\end{array}$ & W14x311 & W16x605 & W33x130 & W33x130 \\
\hline & $\begin{array}{c}\text { Int } 5 / 6 \\
5 / 6\end{array}$ & $\mathrm{~W} 14 \times 550$ & $\begin{array}{l}\text { W24x131 } \\
\text { W24x131 }\end{array}$ & W14x311 & W14x605 & W33x130 & W33x130 \\
\hline & $\begin{array}{c}\text { Int 6/R00f } \\
\text { 6/Roof }\end{array}$ & W14x550 & $\begin{array}{l}\text { W224x131 } \\
\text { W24x131 }\end{array}$ & W14x311 & W14x605 & W24x84 & $\mathrm{W} 24 \times 84$ \\
\hline
\end{tabular}


Table 9.5: Design Details; Beam and Column Section for 6-story Index Archetype Designs Continued From Table 9.4

\begin{tabular}{|c|c|c|c|c|c|c|c|}
\hline \multirow[b]{3}{*}{ Model } & \multirow[b]{3}{*}{ Story } & \multicolumn{2}{|c|}{ Link Column } & \multicolumn{4}{|c|}{ Moment Frame } \\
\hline & & \multirow[b]{2}{*}{ Column } & \multirow[b]{2}{*}{ Beam } & \multicolumn{2}{|c|}{ Column } & \multicolumn{2}{|c|}{ Beam } \\
\hline & & & & Exterior & Interior & Exterior & Interior \\
\hline \multirow{13}{*}{8} & Base & & $\mathrm{W} 24 \times 279$ & & & & \\
\hline & Int $1 / 2$ & $\mathrm{~W} 14 \times 550$ & W27x94 & W14x370 & W14x665 & W30x90 & W30x90 \\
\hline & $1 / 2$ & & W27x94 & & & & \\
\hline & Int $2 / 3$ & W14x550 & W27x94 & W14x370 & W14x665 & W36x170 & W36x170 \\
\hline & $2 / 3$ & 年 & W27x94 & (1) & 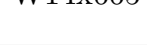 & (V) & 每 \\
\hline & Int $3 / 4$ & $\mathrm{~W} 14 \times 550$ & W24x94 & W14x370 & W14x665 & W36x170 & W36x170 \\
\hline & $3 / 4$ & & W24x94 & & & & \\
\hline & Int $4 / 5$ & $\mathrm{~W} 14 \times 550$ & W24x94 & W14 370 & W14 ×665 & 160 & W36x160 \\
\hline & $4 / 5$ & 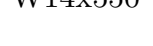 & W24x94 & V14X010 & $V 1+4000$ & V & $\operatorname{Vin} 50 \times 100$ \\
\hline & Int $5 / 6$ & W $14 \times 155$ & W24x94 & WN14 270 & WW14 ×665 & 120 & W $23 y 12$ \\
\hline & $5 / 6$ & $\sqrt{ } 14 \times 400$ & W24x94 & Vv14X010 & $\sqrt{14 x}$ & VV $50 \times 150$ & V $50 \times 100$ \\
\hline & Int $6 /$ R00f & & $\mathrm{W} 24 \times 55$ & & & & \\
\hline & 6/Roof & W $14 \times 455$ & W24x55 & W $14 \times 370$ & W14x665 & W $30 x 90$ & W30x90 \\
\hline \multirow{13}{*}{9} & Base & & $\mathrm{W} 24 \times 279$ & & & & \\
\hline & Int $1 / 2$ & W14x665 & W27x146 & W14x311 & W14x605 & W24x84 & W24x84 \\
\hline & $1 / 2$ & & W27x146 & & & & \\
\hline & Int $2 / 3$ & W14 & W27x146 & 11 & 5 & $20-20$ & 120 \\
\hline & $2 / 3$ & W $14 \times 000$ & W27x146 & W14X311 & W $10 \times 000$ & W $33 \times 130$ & W $33 \times 130$ \\
\hline & Int $3 / 4$ & W14 1065 & W27x146 & 11 & & & \\
\hline & $3 / 4$ & W $14 \times 005$ & W27x146 & W14x311 & W 10x605 & W33x 130 & W $33 \times 130$ \\
\hline & Int $4 / 5$ & W14x665 & W27x146 & W14×311 & W16x605 & W $33 \times 130$ & W $33 \times 130$ \\
\hline & $4 / 5$ & VVITSUOO & W27x146 & TISTI & 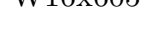 & 列 & 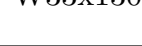 \\
\hline & Int $5 / 6$ & $\mathrm{~W} 14 \times 455$ & W24x131 & W14 3111 & W1 & W $33 \times 130$ & W $33 \times 130$ \\
\hline & $5 / 6$ & 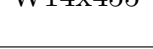 & W24x131 & $\sqrt{1+\lambda .11}$ & $V 1+\lambda v 00$ & 政 & V0. \\
\hline & Int $6 /$ R00f & $\mathrm{W} 14 \times 45.5$ & W24x131 & $W 14 \times 311$ & 05 & 84 & 130 \\
\hline & 6/Roof & 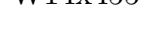 & W24x131 & TISUTL & WTAUDO & 共 & 年 \\
\hline
\end{tabular}


Table 9.6: Design Details; Beam and Column Section for 9-story Index Archetype Designs

\begin{tabular}{|c|c|c|c|c|c|c|c|}
\hline \multirow[b]{3}{*}{ Model } & \multirow[b]{3}{*}{ Story } & \multicolumn{2}{|c|}{ Link Column } & \multicolumn{4}{|c|}{ Moment Frame } \\
\hline & & \multirow[b]{2}{*}{ Column } & \multirow[b]{2}{*}{ Beam } & \multicolumn{2}{|c|}{ Column } & \multicolumn{2}{|c|}{ Beam } \\
\hline & & & & Exterior & Interior & Exterior & Interior \\
\hline \multirow{9}{*}{10} & $\begin{array}{c}\text { Base } \\
\text { Int } 1 / 2 \\
1 / 2\end{array}$ & $\mathrm{~W} 14 \times 730$ & $\begin{array}{l}\text { W24x279 } \\
\text { W27x146 } \\
\text { W27x146 }\end{array}$ & $\mathrm{W} 14 \times 730$ & $\mathrm{~W} 14 \times 730$ & W36x182 & W36x182 \\
\hline & $\begin{array}{c}\text { Int } 2 / 3 \\
2 / 3\end{array}$ & $\mathrm{~W} 14 \times 730$ & $\begin{array}{l}\text { W27x146 } \\
\text { W27x146 }\end{array}$ & $\mathrm{W} 14 \times 730$ & W14x730 & W36x182 & W36x182 \\
\hline & $\begin{array}{c}\text { Int } 3 / 4 \\
3 / 4\end{array}$ & $\mathrm{~W} 14 \times 730$ & $\begin{array}{l}\text { W27x194 } \\
\text { W27x194 }\end{array}$ & $\mathrm{W} 14 \times 730$ & $\mathrm{~W} 14 \times 730$ & W36x302 & W36x182 \\
\hline & $\begin{array}{c}\text { Int } 4 / 5 \\
4 / 5\end{array}$ & $\mathrm{~W} 14 \times 730$ & $\begin{array}{l}\text { W27x194 } \\
\text { W27x194 }\end{array}$ & $\mathrm{W} 14 \times 730$ & $\mathrm{~W} 14 \times 730$ & W36x302 & W36x182 \\
\hline & $\begin{array}{c}\text { Int } 5 / 6 \\
5 / 6\end{array}$ & $\mathrm{~W} 14 \times 730$ & $\begin{array}{l}\text { W27x194 } \\
\text { W27x194 }\end{array}$ & $\mathrm{W} 14 \times 730$ & $\mathrm{~W} 14 \times 730$ & W36x302 & W36x182 \\
\hline & $\begin{array}{c}\text { Int } 6 / 7 \\
6 / 7\end{array}$ & W14x665 & $\begin{array}{l}\text { W24x117 } \\
\text { W24x117 }\end{array}$ & $\mathrm{W} 14 \times 665$ & $\mathrm{~W} 14 \times 730$ & W36x302 & W36x182 \\
\hline & $\begin{array}{c}\text { Int } 7 / 8 \\
7 / 8\end{array}$ & W14x665 & $\begin{array}{l}\text { W24x117 } \\
\text { W24x117 }\end{array}$ & W14x665 & W14x730 & W36x302 & W36x182 \\
\hline & $\begin{array}{c}\text { Int } 8 / 9 \\
8 / 9\end{array}$ & $\mathrm{~W} 14 \times 550$ & $\begin{array}{l}\text { W24x117 } \\
\text { W24x62 }\end{array}$ & $\mathrm{W} 14 \times 550$ & $\mathrm{~W} 14 \times 550$ & W33x141 & W33x141 \\
\hline & $\begin{array}{c}\text { Int 9/R00f } \\
\text { 9/Roof }\end{array}$ & $\mathrm{W} 14 \times 550$ & $\begin{array}{l}\text { W24x62 } \\
W 24 \times 62\end{array}$ & $\mathrm{~W} 14 \times 550$ & $\mathrm{~W} 14 \times 550$ & W30x108 & W30x108 \\
\hline \multirow{9}{*}{11,12} & $\begin{array}{c}\text { Base } \\
\text { Int } 1 / 2 \\
1 / 2\end{array}$ & $\mathrm{~W} 14 \times 730$ & $\begin{array}{l}\text { B36x17 } \\
\text { B31.25x10.5 } \\
\text { B31.25x10.5 }\end{array}$ & $\mathrm{W} 14 \times 730$ & $\mathrm{~W} 14 \times 730$ & W36x256 & W36x182 \\
\hline & $\begin{array}{c}\text { Int } 2 / 3 \\
2 / 3\end{array}$ & $\mathrm{~W} 14 \times 730$ & $\begin{array}{l}\text { B36x17 } \\
\text { B36x17 }\end{array}$ & $\mathrm{W} 14 \times 730$ & W14x730 & W36x182 & W36x182 \\
\hline & $\begin{array}{c}\text { Int } 3 / 4 \\
3 / 4\end{array}$ & $\mathrm{~W} 14 \times 730$ & $\begin{array}{l}\text { B36x17 } \\
\text { B36x17 }\end{array}$ & $\mathrm{W} 14 \times 730$ & $\mathrm{~W} 14 \times 730$ & W36x302 & W36x182 \\
\hline & $\begin{array}{c}\text { Int } 4 / 5 \\
4 / 5\end{array}$ & $\mathrm{~W} 14 \times 730$ & $\begin{array}{l}\text { B36x17 } \\
\text { B36x17 }\end{array}$ & $\mathrm{W} 14 \times 730$ & $\mathrm{~W} 14 \times 730$ & W36x302 & W36x182 \\
\hline & $\begin{array}{c}\text { Int } 5 / 6 \\
5 / 6\end{array}$ & $\mathrm{~W} 14 \times 730$ & $\begin{array}{l}\text { B36x17 } \\
\text { B36x17 }\end{array}$ & $\mathrm{W} 14 \times 730$ & W14x730 & W36x302 & W36x182 \\
\hline & $\begin{array}{c}\text { Int } 6 / 7 \\
6 / 7\end{array}$ & W14x665 & $\begin{array}{l}\mathrm{B} 31.25 \times 10.5 \\
\mathrm{~B} 31.25 \times 10.5\end{array}$ & W14x665 & W14x730 & W36x302 & W36x182 \\
\hline & $\begin{array}{c}\text { Int } 7 / 8 \\
7 / 8 \\
\end{array}$ & W14x665 & $\begin{array}{l}\text { B22.875x10.5 } \\
\text { B22.875x10.5 }\end{array}$ & W14x665 & W14x730 & W36x302 & W36x182 \\
\hline & $\begin{array}{c}\text { Int } 8 / 9 \\
8 / 9\end{array}$ & $\mathrm{~W} 14 \times 550$ & $\begin{array}{l}\text { B22.875x10.5 } \\
\text { B15.25x10.5 }\end{array}$ & $\mathrm{W} 14 \times 550$ & $\mathrm{~W} 14 \times 550$ & W33x141 & W33x141 \\
\hline & $\begin{array}{c}\text { Int 9/Roof } \\
\text { 9/Roof }\end{array}$ & $\mathrm{W} 14 \times 550$ & $\begin{array}{l}\mathrm{B} 15.25 \times 10.5 \\
\mathrm{~B} 15.25 \times 10.5\end{array}$ & $\mathrm{~W} 14 \times 550$ & $\mathrm{~W} 14 \times 550$ & W30x108 & W30x108 \\
\hline
\end{tabular}


Table 9.7: Design Details; Beam and Column Section for 9-story Index Archetype Designs Continued From Table 9.6

\begin{tabular}{|c|c|c|c|c|c|c|c|}
\hline \multirow[b]{3}{*}{ Model } & \multirow[b]{3}{*}{ Story } & \multicolumn{2}{|c|}{ Link Column } & \multicolumn{4}{|c|}{ Moment Frame } \\
\hline & & \multirow[b]{2}{*}{ Column } & \multirow[b]{2}{*}{ Beam } & \multicolumn{2}{|c|}{ Column } & \multicolumn{2}{|c|}{ Beam } \\
\hline & & & & Exterior & Interior & Exterior & Interior \\
\hline \multirow{9}{*}{13} & $\begin{array}{c}\text { Base } \\
\text { Int } 1 / 2 \\
1 / 2 \\
\end{array}$ & $\mathrm{~W} 14 \times 730$ & $\begin{array}{l}\text { W24x279 } \\
\text { W27x146 } \\
\text { W27x146 }\end{array}$ & $\mathrm{W} 14 \times 550$ & $\mathrm{~W} 14 \times 605$ & W30x108 & W30x108 \\
\hline & $\begin{array}{c}\text { Int } 2 / 3 \\
2 / 3\end{array}$ & $\mathrm{~W} 14 \times 730$ & $\begin{array}{l}\text { W27x146 } \\
\text { W27x146 }\end{array}$ & $\mathrm{W} 14 \times 550$ & W14x605 & W30x108 & W30x108 \\
\hline & $\begin{array}{c}\text { Int } 3 / 4 \\
3 / 4\end{array}$ & W14x730 & $\begin{array}{l}\text { W27x178 } \\
\text { W27x178 }\end{array}$ & $\mathrm{W} 14 \times 550$ & $\mathrm{~W} 14 \times 605$ & W33x141 & W33x141 \\
\hline & $\begin{array}{c}\text { Int } 4 / 5 \\
4 / 5\end{array}$ & W14x730 & $\begin{array}{l}\text { W27x178 } \\
\text { W27x178 }\end{array}$ & $\mathrm{W} 14 \times 550$ & $\mathrm{~W} 14 \times 605$ & W33x201 & W33x141 \\
\hline & $\begin{array}{c}\text { Int } 5 / 6 \\
5 / 6\end{array}$ & $\mathrm{~W} 14 \times 730$ & $\begin{array}{l}\text { W27x178 } \\
\text { W27x178 }\end{array}$ & $\mathrm{W} 14 \times 550$ & $\mathrm{~W} 14 \times 605$ & W33x201 & W33x141 \\
\hline & $\begin{array}{c}\text { Int } 6 / 7 \\
6 / 7\end{array}$ & W14x665 & $\begin{array}{l}\text { W24x117 } \\
\text { W24x117 }\end{array}$ & $\mathrm{W} 14 \times 550$ & $\mathrm{~W} 14 \times 605$ & W33x201 & W33x141 \\
\hline & $\begin{array}{c}\text { Int } 7 / 8 \\
7 / 8\end{array}$ & W14x665 & $\begin{array}{l}\text { W24x117 } \\
\text { W24x117 }\end{array}$ & $\mathrm{W} 14 \times 550$ & W14x605 & W33x201 & W33x141 \\
\hline & $\begin{array}{c}\text { Int } 8 / 9 \\
8 / 9\end{array}$ & W14x550 & $\begin{array}{l}\text { W24x117 } \\
\text { W24x62 }\end{array}$ & W14x398 & W14x398 & W30x108 & W30x108 \\
\hline & $\begin{array}{c}\text { Int 9/Roof } \\
\text { 9/Roof }\end{array}$ & W14x550 & $\begin{array}{l}\text { W24x62 } \\
W 24 \times 62\end{array}$ & W14x398 & W14x398 & W24x94 & W24x94 \\
\hline \multirow{9}{*}{14} & $\begin{array}{c}\text { Base } \\
\text { Int } 1 / 2 \\
1 / 2\end{array}$ & W14x665 & $\begin{array}{l}\text { W24x279 } \\
\text { W24x117 } \\
\text { W24x117 }\end{array}$ & W14x145 & $\mathrm{W} 14 \times 211$ & W24x62 & W24x62 \\
\hline & $\begin{array}{c}\text { Int } 2 / 3 \\
2 / 3\end{array}$ & W14x665 & $\begin{array}{l}\text { W24x117 } \\
\text { W24x117 }\end{array}$ & W14x145 & $\mathrm{W} 14 \times 211$ & W24x62 & W24x62 \\
\hline & $\begin{array}{c}\text { Int } 3 / 4 \\
3 / 4\end{array}$ & W14x665 & $\begin{array}{l}\text { W24x117 } \\
\text { W24x117 }\end{array}$ & W14x145 & $\mathrm{W} 14 \times 211$ & W24x68 & W24x62 \\
\hline & $\begin{array}{c}\text { Int } 4 / 5 \\
4 / 5\end{array}$ & W14x665 & $\begin{array}{l}\text { W24x117 } \\
\text { W24x117 }\end{array}$ & W14x145 & $\mathrm{W} 14 \times 211$ & W27x94 & W24x68 \\
\hline & $\begin{array}{c}\text { Int } 5 / 6 \\
5 / 6\end{array}$ & W14x665 & $\begin{array}{l}\text { W24x117 } \\
\text { W24x117 }\end{array}$ & W14x145 & $\mathrm{W} 14 \times 211$ & W27x94 & W24x68 \\
\hline & $\begin{array}{c}\text { Int } 6 / 7 \\
6 / 7 \\
\end{array}$ & W14x550 & $\begin{array}{l}\text { W24x117 } \\
\text { W24x117 }\end{array}$ & W14x145 & $\mathrm{W} 14 \times 211$ & W27x94 & W24x68 \\
\hline & $\begin{array}{c}\text { Int } 7 / 8 \\
7 / 8\end{array}$ & W14x550 & $\begin{array}{l}\text { W24x117 } \\
\text { W24x117 }\end{array}$ & W14x145 & $\mathrm{W} 14 \times 211$ & W27x94 & W24x68 \\
\hline & $\begin{array}{c}\text { Int } 8 / 9 \\
8 / 9\end{array}$ & W14x550 & $\begin{array}{l}\text { W24x117 } \\
\text { W24x62 }\end{array}$ & $\mathrm{W} 14 \times 145$ & $\mathrm{~W} 14 \times 211$ & W24x68 & W24x68 \\
\hline & $\begin{array}{c}\text { Int 9/R00f } \\
\text { 9/Roof }\end{array}$ & W14x550 & $\begin{array}{l}\text { W24x62 } \\
\text { W24x62 }\end{array}$ & $\mathrm{W} 14 \times 145$ & $\mathrm{~W} 14 \times 211$ & W24x68 & W24x62 \\
\hline
\end{tabular}


Table 9.8: Design Details; Beam and Column Section for 9-story Index Archetype Designs Continued From Table 9.7

\begin{tabular}{|c|c|c|c|c|c|c|c|}
\hline \multirow[b]{3}{*}{ Model } & \multirow[b]{3}{*}{ Story } & \multicolumn{2}{|c|}{ Link Column } & \multicolumn{4}{|c|}{ Moment Frame } \\
\hline & & \multirow[b]{2}{*}{ Column } & \multirow[b]{2}{*}{ Beam } & \multicolumn{2}{|c|}{ Column } & \multicolumn{2}{|c|}{ Beam } \\
\hline & & & & Exterior & Interior & Exterior & Interior \\
\hline \multirow{9}{*}{15} & $\begin{array}{c}\text { Base } \\
\text { Int } 1 / 2 \\
1 / 2 \\
\end{array}$ & $\mathrm{~W} 14 \times 665$ & $\begin{array}{l}\text { W24x279 } \\
\text { W24x117 } \\
\text { W24x117 }\end{array}$ & $\mathrm{W} 14 \times 257$ & $\mathrm{~W} 14 \times 283$ & W24x62 & W24x62 \\
\hline & $\begin{array}{c}\text { Int } 2 / 3 \\
2 / 3\end{array}$ & $\mathrm{~W} 14 \times 665$ & $\begin{array}{l}\text { W24x117 } \\
\text { W24x117 }\end{array}$ & $\mathrm{W} 14 \times 257$ & $\mathrm{~W} 14 \times 283$ & W24x68 & W24x68 \\
\hline & $\begin{array}{c}\text { Int } 3 / 4 \\
3 / 4\end{array}$ & W14x665 & $\begin{array}{l}\text { W24x117 } \\
\text { W24x117 }\end{array}$ & $\mathrm{W} 14 \times 257$ & $\mathrm{~W} 14 \times 283$ & W30x90 & W30x90 \\
\hline & $\begin{array}{c}\text { Int } 4 / 5 \\
4 / 5\end{array}$ & W14x665 & $\begin{array}{l}\text { W24x117 } \\
\text { W24x117 }\end{array}$ & $\mathrm{W} 14 \times 257$ & W14x283 & W33x130 & W30x90 \\
\hline & $\begin{array}{c}\text { Int } 5 / 6 \\
5 / 6 \\
\end{array}$ & W14x665 & $\begin{array}{l}\text { W24x117 } \\
\text { W24x117 }\end{array}$ & $\mathrm{W} 14 \times 257$ & $\mathrm{~W} 14 \times 283$ & W33x130 & W30x90 \\
\hline & $\begin{array}{c}\text { Int } 6 / 7 \\
6 / 7\end{array}$ & $\mathrm{~W} 14 \times 550$ & $\begin{array}{l}\text { W24x117 } \\
\text { W24x117 }\end{array}$ & $\mathrm{W} 14 \times 257$ & W14x283 & W33x130 & W30x90 \\
\hline & $\begin{array}{c}\text { Int } 7 / 8 \\
7 / 8\end{array}$ & $\mathrm{~W} 14 \times 550$ & $\begin{array}{l}\text { W24x117 } \\
\text { W24x117 }\end{array}$ & $\mathrm{W} 14 \times 257$ & $\mathrm{~W} 14 \times 283$ & W33x130 & W30x90 \\
\hline & $\begin{array}{c}\text { Int } 8 / 9 \\
8 / 9\end{array}$ & $\mathrm{~W} 14 \times 550$ & $\begin{array}{l}\text { W24x117 } \\
\text { W24x62 }\end{array}$ & $\mathrm{W} 14 \mathrm{x} 257$ & $\mathrm{~W} 14 \times 283$ & W30x90 & W24x68 \\
\hline & $\begin{array}{c}\text { Int 9/Roof } \\
\text { 9/Roof }\end{array}$ & $\mathrm{W} 14 \times 550$ & $\begin{array}{l}\text { W24x62 } \\
\text { W24x62 }\end{array}$ & $\mathrm{W} 14 \times 257$ & $\mathrm{~W} 14 \times 283$ & W30x90 & W24x68 \\
\hline \multirow{9}{*}{16} & $\begin{array}{c}\text { Base } \\
\text { Int } 1 / 2 \\
1 / 2\end{array}$ & $\mathrm{~W} 14 \times 730$ & $\begin{array}{l}\text { W24x279 } \\
\text { W24x84 } \\
\text { W24x84 }\end{array}$ & $\mathrm{W} 14 \times 730$ & $\mathrm{~W} 14 \times 730$ & W36x150 & W36x150 \\
\hline & $\begin{array}{c}\text { Int } 2 / 3 \\
2 / 3\end{array}$ & $\mathrm{~W} 14 \times 730$ & $\begin{array}{l}\text { W24x84 } \\
W 24 \times 84\end{array}$ & W14x730 & W14x730 & W36x150 & W36x150 \\
\hline & $\begin{array}{c}\text { Int } 3 / 4 \\
3 / 4\end{array}$ & $\mathrm{~W} 14 \times 730$ & $\begin{array}{l}\text { W24x84 } \\
\text { W27x146 }\end{array}$ & W14x730 & W14x730 & W36x210 & W36x 210 \\
\hline & $\begin{array}{c}\text { Int } 4 / 5 \\
4 / 5\end{array}$ & $\mathrm{~W} 14 \times 730$ & $\begin{array}{l}\text { W27x146 } \\
\text { W27x146 }\end{array}$ & W14x730 & W14x730 & W36x210 & W36x 210 \\
\hline & $\begin{array}{c}\text { Int } 5 / 6 \\
5 / 6\end{array}$ & $\mathrm{~W} 14 \times 730$ & $\begin{array}{l}\text { W27x146 } \\
\text { W27x146 }\end{array}$ & $\mathrm{W} 14 \times 730$ & $\mathrm{~W} 14 \times 730$ & W36x210 & W36x 210 \\
\hline & $\begin{array}{c}\text { Int } 6 / 7 \\
6 / 7 \\
\end{array}$ & $\mathrm{~W} 14 \times 730$ & $\begin{array}{l}\text { W27x146 } \\
\text { W27x146 }\end{array}$ & $\mathrm{W} 14 \times 730$ & $\mathrm{~W} 14 \times 730$ & W36x210 & W36x210 \\
\hline & $\begin{array}{c}\text { Int } 7 / 8 \\
7 / 8\end{array}$ & $\mathrm{~W} 14 \times 730$ & $\begin{array}{l}\text { W27x146 } \\
\text { W24x84 }\end{array}$ & $\mathrm{W} 14 \times 730$ & $\mathrm{~W} 14 \times 730$ & W36x150 & W36x150 \\
\hline & $\begin{array}{c}\text { Int } 8 / 9 \\
8 / 9 \\
\end{array}$ & $\mathrm{~W} 14 \times 550$ & $\begin{array}{l}\text { W24x84 } \\
\text { W24x62 }\end{array}$ & $\mathrm{W} 14 \times 550$ & $\mathrm{~W} 14 \times 550$ & W36x150 & W36x150 \\
\hline & $\begin{array}{c}\text { Int 9/R00f } \\
\text { 9/Roof }\end{array}$ & $\mathrm{W} 14 \times 550$ & $\begin{array}{l}\text { W24x62 } \\
\text { W24x62 }\end{array}$ & $\mathrm{W} 14 \times 550$ & $\mathrm{~W} 14 \times 550$ & W30x90 & W30x90 \\
\hline
\end{tabular}


Table 9.9: Design Details; Beam and Column Section for 9-story Index Archetype Designs Continued From Table 9.8

\begin{tabular}{|c|c|c|c|c|c|c|c|}
\hline \multirow[b]{3}{*}{ Model } & \multirow[b]{3}{*}{ Story } & \multicolumn{2}{|c|}{ Link Column } & \multicolumn{4}{|c|}{ Moment Frame } \\
\hline & & \multirow[b]{2}{*}{ Column } & \multirow[b]{2}{*}{ Beam } & \multicolumn{2}{|c|}{ Column } & \multicolumn{2}{|c|}{ Beam } \\
\hline & & & & Exterior & Interior & Exterior & Interior \\
\hline \multirow{9}{*}{17} & $\begin{array}{c}\text { Base } \\
\text { Int } 1 / 2 \\
1 / 2\end{array}$ & $\mathrm{~W} 14 \times 730$ & 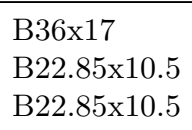 & $\mathrm{W} 14 \times 730$ & $\mathrm{~W} 14 \times 730$ & W36x150 & W36x150 \\
\hline & $\begin{array}{c}\text { Int } 2 / 3 \\
2 / 3\end{array}$ & $\mathrm{~W} 14 \times 730$ & $\begin{array}{l}\text { B22.85x10.5 } \\
\text { B22.85x } 10.5\end{array}$ & $\mathrm{~W} 14 \times 730$ & $\mathrm{~W} 14 \times 730$ & W36x150 & W36x150 \\
\hline & $\begin{array}{c}\text { Int } 3 / 4 \\
3 / 4\end{array}$ & $\mathrm{~W} 14 \times 730$ & $\begin{array}{l}\text { B31.25x10.5 } \\
\text { B31.25x10.5 }\end{array}$ & $\mathrm{W} 14 \times 730$ & $\mathrm{~W} 14 \times 730$ & W36x210 & W36x 210 \\
\hline & $\begin{array}{c}\text { Int } 4 / 5 \\
4 / 5\end{array}$ & $\mathrm{~W} 14 \times 730$ & $\begin{array}{l}\text { B31.25x10.5 } \\
\text { B31.25x10.5 }\end{array}$ & W14x730 & W14x730 & W36x210 & W36x 210 \\
\hline & $\begin{array}{c}\text { Int } 5 / 6 \\
5 / 6\end{array}$ & $\mathrm{~W} 14 \times 730$ & $\begin{array}{l}\text { B31.25x10.5 } \\
\text { B31.25x10.5 }\end{array}$ & $\mathrm{W} 14 \times 730$ & $\mathrm{~W} 14 \times 730$ & W36x210 & W36x210 \\
\hline & $\begin{array}{c}\text { Int } 6 / 7 \\
6 / 7\end{array}$ & $\mathrm{~W} 14 \times 730$ & $\begin{array}{l}\text { B31.25x10.5 } \\
\text { B22.85x10.5 }\end{array}$ & $\mathrm{W} 14 \times 730$ & $\mathrm{~W} 14 \times 730$ & W36x210 & W36x210 \\
\hline & $\begin{array}{c}\text { Int } 7 / 8 \\
7 / 8\end{array}$ & $\mathrm{~W} 14 \times 730$ & $\begin{array}{l}\text { B22.85x10.5 } \\
\text { B22.85x10.5 }\end{array}$ & W14x730 & W14x730 & W36x150 & W36x150 \\
\hline & $\begin{array}{c}\text { Int } 8 / 9 \\
8 / 9\end{array}$ & $\mathrm{~W} 14 \times 550$ & $\begin{array}{l}\mathrm{B} 22.85 \times 10.5 \\
\mathrm{~B} 15.25 \times 10.5\end{array}$ & $\mathrm{~W} 14 \times 550$ & $\mathrm{~W} 14 \times 550$ & W36x150 & W36x150 \\
\hline & $\begin{array}{c}\text { Int 9/Roof } \\
\text { 9/Roof }\end{array}$ & $\mathrm{W} 14 \times 550$ & $\begin{array}{l}\mathrm{B} 15.25 \times 10.5 \\
\mathrm{~B} 15.25 \times 10.5\end{array}$ & $\mathrm{~W} 14 \times 550$ & $\mathrm{~W} 14 \times 550$ & W30x90 & W30x90 \\
\hline
\end{tabular}




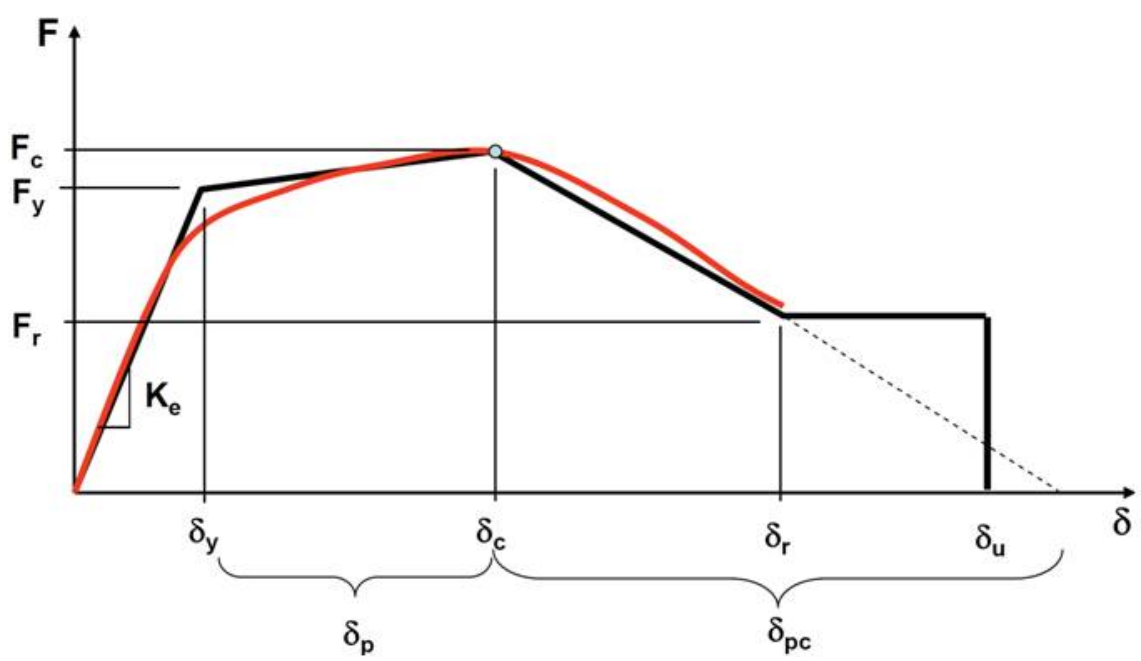

Figure 9.6: Parameters of an Idealized Component Backbone Curve (FEMA P695, 2009).

\subsubsection{Index Archetype Models}

Chapter 6 of this research comprehensively discussed how the LCF buildings were modeled to capture all significant nonlinear effects related to the collapse behavior of the system. A brief description is provided below with emphasis on items important to the implementation of the FEMA P695 procedure.

LCF component models were developed to simulate the stiffness, strength, and inelastic deformation under reverse cyclic loading. Ibarra et al. (2005) has demonstrated that the most significant factors influencing collapse response are the plastic deformation capacity, $\delta_{p}$, the post-capping tangent stiffness, $K_{p c}$, and the residual strength, $F r$. These parameters are used to define a component backbone curve, as shown in Figure 9.6, where $F_{y}$ and $\delta_{y}$ are effective yield strength and deformation, $K_{e}=F_{y} / \delta_{y}$ is effective elastic stiffness, $F_{c}$ and $\delta_{c}$ are capping strength and deformation for monotonic loading. $\delta_{p}$ is plastic deformation capacity for monotonic loading, $K_{p}=\left(F_{c}-F_{y}\right) / \delta_{p}$ is effective post-yield tangent stiffness, $\delta_{p c}$ is post-capping deformation capacity, $K_{p c}=F_{c} / \delta_{p c}, F_{r}$ is residual strength and $\delta_{u}$ is ultimate deformation capacity.

Degradation of both the backbone curve and the hysteretic response parameters influence collapse response in nonlinear dynamic analyses. 
As discussed in Chapter 6 and Section 9.2.5 all LCF components are rigorously modeled and calibrated to test data in OpenSees to simulate degradation at component levels that lead to adequate modeling of system degradation.

The beams were modeled using the hysteretic material available in OpenSees for application to the fiber cross-section. Strength degradation of the beams was modeled using the fatigue material model developed by Uriz (2005).

The links were modeled using beam-column element with a fiber cross-section that controls the axial and flexural response and is aggregated with an independent nonlinear shear force versus shear deformation section. The hysteretic material model, combined with fatigue material model developed by Uriz (2005) and OpenSees Min/Max material, was found to be the most capable of simulating the nonlinear response and strength degradation of links.

The simple connection and the slab impact were modeled in OpenSees based on test data performed by Liu and Astaneh-Asl (2000).

Examples of inelastic hysteretic response of LCF components with cyclic strength and stiffness degradation are shown in Figure 9.7 .

For the case in which there was no access to the electronic data files for the whole cyclic test results, the data of the backbone was gathered by digitizing the figures of tests (Figure 9.7(a) and Figure 9.7(d) . The Graph Digitizer Scout software was used for this matter.

As shown in Figure 9.7, the models are capable of simulating strength and stiffness degradation under reverse cyclic loading by employing appropriate history parameters to modify the backbone curve properties and cyclic response parameters

\subsection{Nonlinear Analysis}

In this section, the nonlinear analysis procedure for collapse assessment of the LCF archetypes will be described.

After using structural system archetypes as inputs and after applying design requirements and material test data to each index archetype configuration, the index archetype designs using trial values of $R, C_{d}$ and $\Omega_{0}$ equal to $8,5.5$ and 3 , respectively were developed. 


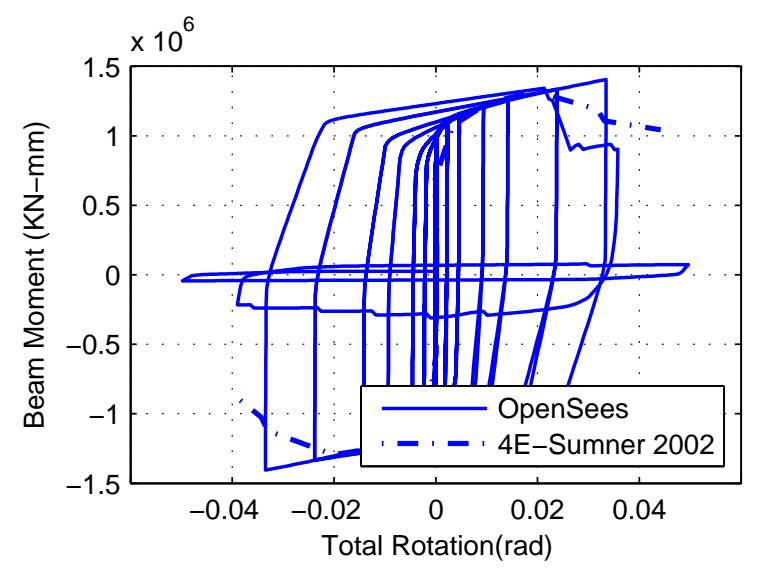

(a)

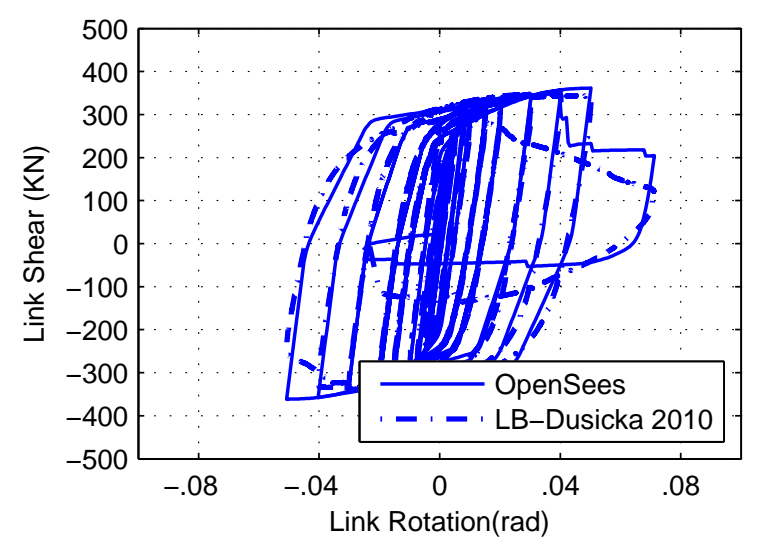

(c)

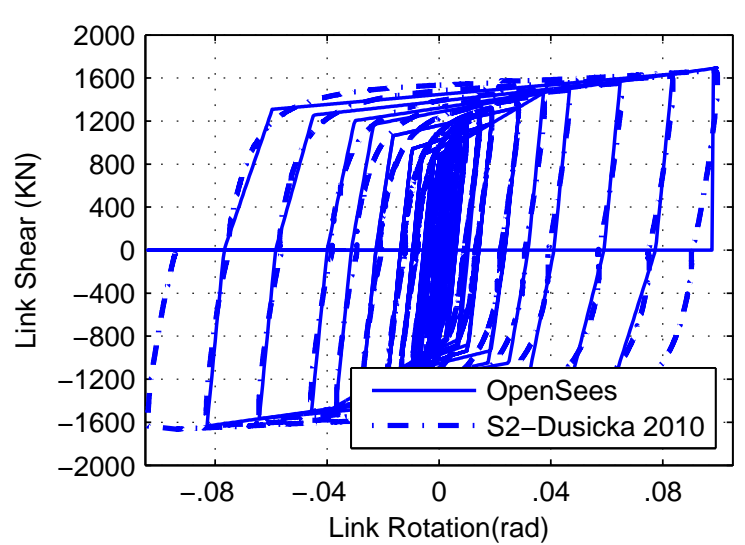

(b)

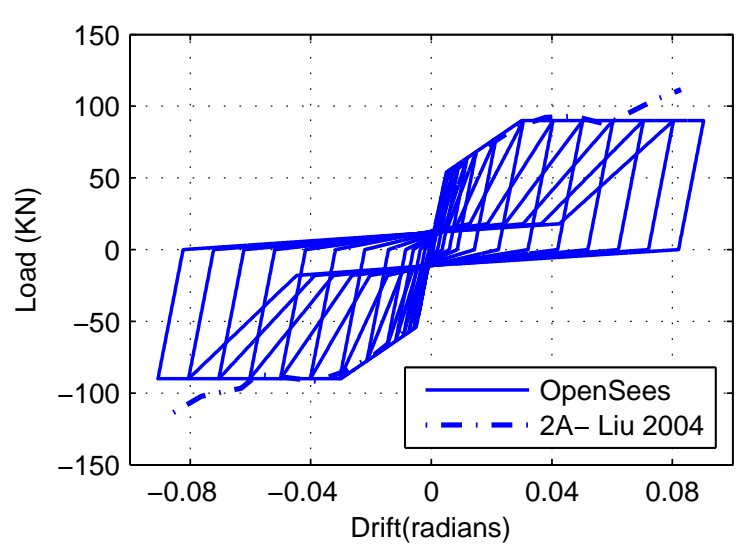

(d)

Figure 9.7: Comparison of Experimental Results with the Developed OpenSees Model (a) Beam Model with Four Bolt Extended Unstiffened Moment Rotation (b) Link Model (Shear Link) (C) Link Model (Flexural Link) (d) Shear-tab Connection. 
Now using data from components, connections, assembly and system tests, the calibrated models are used as inputs for nonlinear analysis in this section. The analysis procedure starts with identifying specified ground motions for use in nonlinear dynamic analyses. Nonlinear static analysis of all fifteen index archetype models was performed to obtain values for system overstrength, $\Omega_{0}$, and ductility capacity, $\mu_{c}$. Nonlinear dynamic analyses of all index archetype models were then performed using the Far-Field ground motion set to investigate median collapse capacities, $\hat{S}_{C T}$, and collapse margin ratios, CMR. As mentioned before, the median collapse capacity is defined as the ground motion intensity, where half of the ground motions in the Far-Field record set cause collapse of an index archetype model. It should be noted that the gravity loads for analysis are different from design gravity loads. The gravity load combination is given by the following equation:

$$
1.05 D+0.25 L
$$

where $\mathrm{D}$ is the nominal dead load of the structure and the superimposed dead load, and $\mathrm{L}$ is the nominal live load.

The structural analysis software OpenSees (Mazzoni et al. 2009) was used to develop analytical models of all the index archetype designs. OpenSees is not only capable of static and dynamic (response history) analyses but also capable of capturing strength and stiffness degradation in LCF components at large deformations.

\subsubsection{Ground Motion}

\section{Ground Motion Hazard}

As defined in ASCE/SEI 7-05 (ASCE 2006a), collapse safety is evaluated relative to ground motion intensity associated with Maximum Considered Earthquake (MCE) and defined in terms of spectral acceleration. For collapse assessment of LCF, ground motion levels corresponding to maximum and minimum seismic criteria of Seismic Design Category (SDC) D were used. Figure 9.8 shows maximum and minimum MCE ground motion spectral intensities for Seismic Design Categories D. In this case, site conditions are based on Site Class D that represent stiff soil. Table 9.11 provides specific values of short-period and 


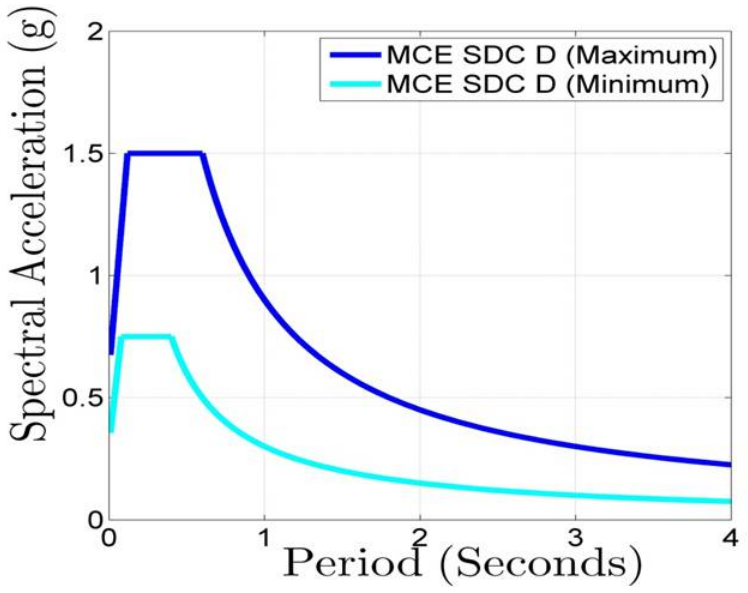

Figure 9.8: MCE Response Spectra for Collapse Evaluation of Structure Archetype for SSDC D.

1-second spectral accelerations, respectively, for these categories.

\section{Ground Motion Record Sets}

The input ground motion record set is defined by the P695 methodology and consists of 22 paired (44 total) horizontal acceleration time history records recorded at sites greater than or equal $10 \mathrm{~km}$ for the fault rupture site, referred to as the "Far-Field" record set. The ground motion record sets include records from all large-magnitude events in the PEER NGA database (PEER, 2006) (no more than two of the strongest records are taken from each earthquake). Also the ground motion set is consistent with ASCE/SEI 7-05 (ASCE, 2006a) for three-dimensional analysis of structures and they are applicable to collapse evaluation of a variety of structural system located at different sites.

\section{Ground Motion Record Scaling}

According to FEMA P695, record scaling involves two steps:

1. Individual records in each set are normalized by their respective peak ground velocities $(\mathrm{PGV})$. The reason for this scaling is to remove unwarranted variability between records due to inherent differences in event magnitude, distance to source, source type and site conditions, without eliminating record-to-record variability. 
Table 9.10: Considered Link Sectional Properties

\begin{tabular}{lccccccc}
\hline Built-up Link & $d($ in $)$ & $b_{f}($ in $)$ & $t_{w}($ in $)$ & $t_{f}($ in $)$ & $V_{p}($ Kip $)$ & $M_{p}($ Kip $-i n)$ & $1.6 \frac{M_{p}}{V_{p}}($ in $)$ \\
\hline B36x17 & 36 & 17 & 0.60 & 1.00 & 612 & 39205 & 102 \\
\hline B36x14 & 36 & 14 & 0.60 & 1.00 & 612 & 33385 & 87 \\
\hline B31.25x10.5 & 31.25 & 10.5 & 0.5 & 0.625 & 450 & 15674 & 55 \\
\hline B30x10.5 & 30 & 10.5 & 0.375 & 0.625 & 324 & 13583 & 67 \\
\hline B24.25x10.5 & 24.25 & 10.5 & 0.425 & 0.625 & 293 & 10637 & 58 \\
\hline B22.875x10.5 & 22.875 & 10.5 & 0.375 & 0.625 & 243 & 9672 & 63 \\
\hline B18.25x10.5 & 18.25 & 10.5 & 0.415 & 0.625 & 212 & 7431 & 56 \\
\hline B15.25x10.5 & 15.25 & 10.5 & 0.375 & 0.625 & 158 & 5891 & 60 \\
\hline
\end{tabular}

Table 9.11: Short-Period and 1-second Spectral Acceleration, Site Coefficients and Design Parameters Used for Collapse Evaluation of Seismic Design Category D

\begin{tabular}{|c|c|c|c|c|c|c|c|c|}
\hline \multirow[b]{2}{*}{ Seismic Design Category } & \multicolumn{7}{|c|}{ Maximum Considered Earthquake } & \multirow{2}{*}{$\begin{array}{l}\text { Design } \\
S_{D 1}(g)\end{array}$} \\
\hline & $S_{s}(g)$ & $F_{a}$ & $S_{M S}(g)$ & $S_{1}(g)$ & $F_{v}$ & $S_{M 1}(g)$ & $S_{D S}(g)$ & \\
\hline$D_{\max }$ & 1.5 & 1 & 1.5 & 0.6 & 1.5 & 0.9 & 1.0 & 0.6 \\
\hline$D_{\min }$ & 0.55 & 1.36 & 0.75 & 0.132 & 2.28 & 0.3 & 1.0 & 0.2 \\
\hline
\end{tabular}


2. Normalized ground motions are collectively scaled (anchored) to a specific ground motion intensity in a way that the median spectral acceleration of the record set matches spectral acceleration at the fundamental period of the structure being analyzed. In FEMA P695 method, the median value of the scaled record set needs only to match the MCE demand at the fundamental period, T, rather than over the range of periods required by ASCE/SEI 7-05.

The record sets that were obtained from Appendix A of FEMA P695 have already been normalized, but scaling to the MCE demand at each index archetype's fundamental period was performed as part of analysis.

The fundamental period of the structure, $T$, was computed using the Equation 9.12 from FEMA P695:

$$
T=C_{u} C_{t} h_{n}^{x}>0.25
$$

Where $h_{n}$ is the height, in feet, of the building above the base to the highest level of the structure, and values of the coefficient, $C_{u}$, are given in Table 12.8-1 and values of period parameters, $C_{t}$ and $x$, are given in Table 12.8-2 of ASCE/SEI 7-05.

$T$ is the code-defined period, and not the period computed using eigenvalue analysis of the structural model, $T_{n}$. However, the values of both are close to each other (Table 9.12). It should be noted that in taller LCFs the second mode potentially has more impact on the structural behavior and using approximate first mode period of the structure may introduce some uncertainty in calculating collapse risk. In this study, however, the FEMA P695 procedure was followed.

Table 9.13 provides the Far-Field record set which includes twenty-two records (44 individual components) selected from the PEER-NGA database including name of the event, as well as the name of the station, the magnitude, peak ground acceleration and scaling factors for anchoring the normalized Far-Field record set to the MCE demand level SDC D. Scaling factors depend on the fundamental period of the building $(\mathrm{T})$, which is related to height of LCF buildings (Table 9.12).

The procedures for scaling ground motions are illustrated in Figure 9.9, The first Figure 
shows the MCE spectral acceleration of SDC $D_{\max }$ and the fundamental period of the 3-story LCF system. In second Figure, the response spectra of the forty-four individual components of the normalized Far-Field record set and their median are shown. Finally, third Figure shows the scaled response spectra and the scaled median response spectra. Figure 9.10 shows response spectra for all scaled ground motions for the 3- 6- and 9-story LCF buildings.

\subsubsection{Nonlinear Static Analysis}

Nonlinear static analysis or pushover analyses were performed and included factored gravity loads of $1.05 \mathrm{D}+0.25 \mathrm{~L}$. The lateral seismic force distribution based on the distribution $F_{x}$ was determined from the following equations as specified for the equivalent lateral force procedure (ASCE/SEI 7-05, Equation:12.8-11,12):

$$
\begin{gathered}
F_{x}=C_{v x} V \\
C_{v x}=\frac{W_{x} h_{x}^{k}}{\sum_{i=1}^{n} W_{i} h_{i}^{k}}
\end{gathered}
$$

Where $C_{v x}$ is vertical distribution factor, $V$, is the total design lateral force, $W_{i}$ and $W_{x}$ are the portion of the total effective seismic weight of the structure assigned to level $i$ or $x$, $h_{i}$ and $h_{x}$ are the height from the base to level $i$ or $x$ and $k$ is 1 for LCF buildings since the period of theses structures is less than $2.5 \mathrm{sec}$.

The purpose of pushover analysis is to obtain the system overstrength factor (the ratio ratio of the maximum base shear resistance, $V_{\max }$, to the design base shear, $V$ ) and the system ductility (the ratio of ultimate displacement, $\Delta_{u l t}$ and yield displacement, $\Delta_{y}$ ) for each of the index archetype buildings using following equations:

$$
\begin{gathered}
\mu_{c}=\frac{\Delta_{u l t}}{\Delta_{y}} \\
\Omega=\frac{V_{\max }}{V}
\end{gathered}
$$



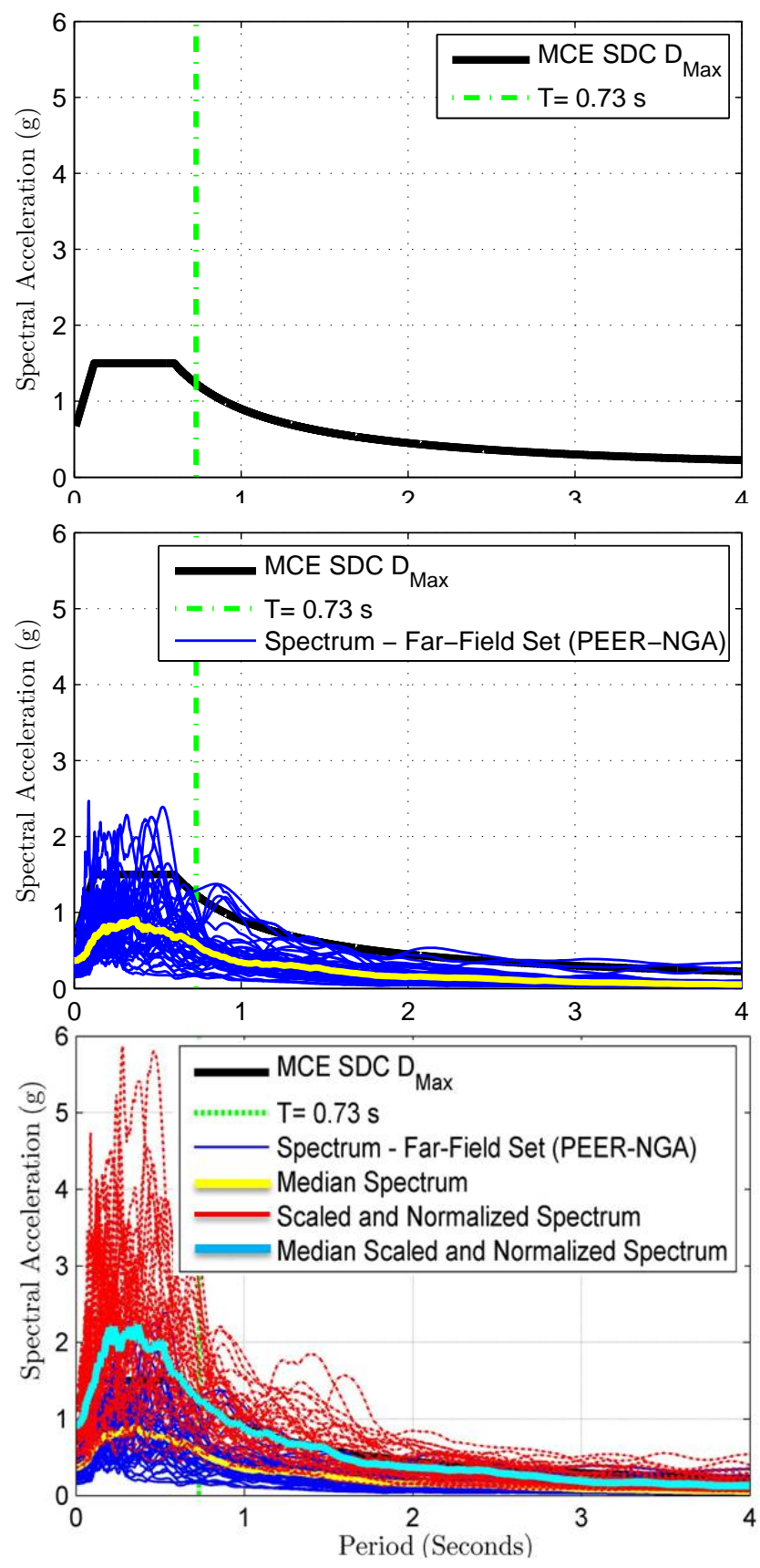

Figure 9.9: Response Acceleration Spectra, Median, Scaled Response Spectra and Scaled Median Spectra for 3-Story LCF 
Table 9.12: Values of the Fundamental Period, T, for Index Archetype LCFs

\begin{tabular}{ccccccc}
\hline LCF System Properties & $h_{n}(f t)$ & $C_{u}$ & $C_{t}$ & $x$ & $T($ sec $)$ & $T_{n}(\mathrm{sec})$ \\
\hline $3-$ Story $_{\left(D_{\max }\right)}$ & 39 & 1.4 & 0.028 & 0.8 & 0.73 & $0.89-0.95$ \\
\hline $6-$ Story $_{\left(D_{\max }\right)}$ & 78 & 1.4 & 0.028 & 0.8 & 1.27 & $1.23-1.27$ \\
\hline $9-$ Story $_{\left(D_{\max }\right)}$ & 117 & 1.4 & 0.028 & 0.8 & 1.76 & $1.55-1.66$ \\
\hline $9-$ Story $_{\left(D_{\min }\right)}$ & 117 & 1.5 & 0.028 & 0.8 & 1.89 & $2.22-2.62$ \\
\hline
\end{tabular}

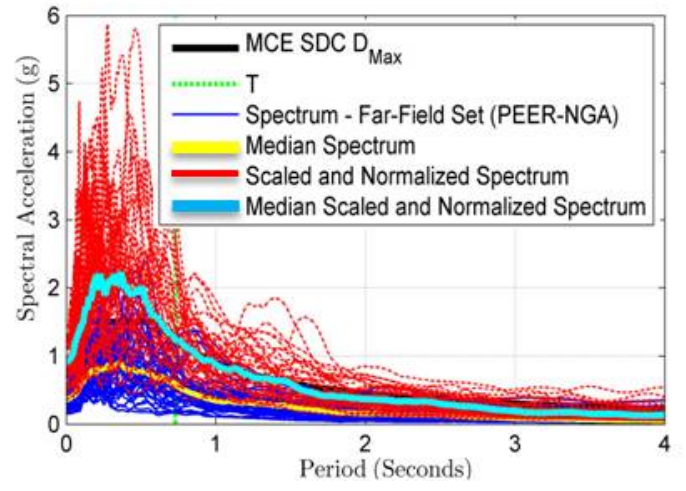

(a)

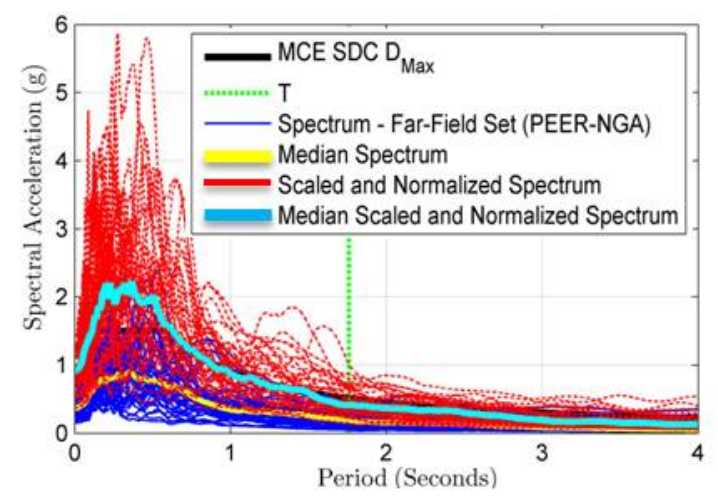

(c)

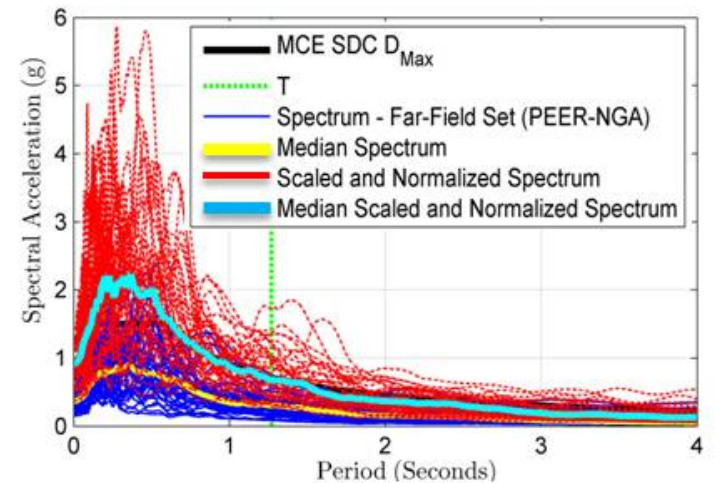

(b)

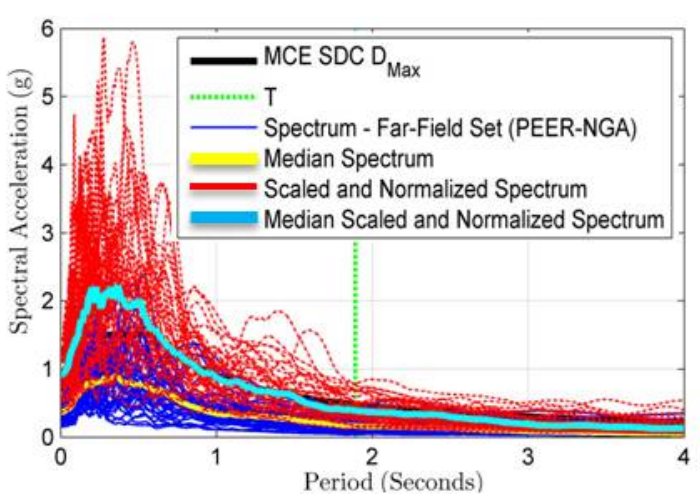

(d)

Figure 9.10: Scaled Response Acceleration Spectra (a) 3-story ( $\mathrm{T}=0.76 \mathrm{~s})$ (b) 6-story $(\mathrm{T}=1.27 \mathrm{~s})(\mathrm{c})$ 9-story $D_{\operatorname{Max}}(\mathrm{T}=1.76 \mathrm{~s})(\mathrm{d})$ 9-story $D_{\text {Min }}(\mathrm{T}=1.89 \mathrm{~s})$. 
Table 9.13: Earthquake Event, Station and Scaling Factors for the Far-Field Record Set

\begin{tabular}{|c|c|c|c|c|c|c|c|c|}
\hline \multirow[b]{2}{*}{ ID No. } & \multirow[b]{2}{*}{ Name } & \multirow[b]{2}{*}{$\mathrm{M}$} & \multirow[b]{2}{*}{$d_{t}$} & \multirow[b]{2}{*}{ PGA (g) } & \multicolumn{4}{|c|}{ Anchor Scale Factor } \\
\hline & & & & & $T=0.73_{S}$ & $T=1.27_{S}$ & $T=1.76_{S}$ & $T=1.89_{S}$ \\
\hline 1 & Northridge-BH & 6.7 & 0.01 & 0.27 & 2.42 & 2.50 & 2.92 & 3.05 \\
\hline 2 & Northridge-BH & 6.7 & 0.01 & 0.33 & 2.42 & 2.50 & 2.92 & 3.05 \\
\hline 3 & Northridge-CC & 6.7 & 0.01 & 0.34 & 2.42 & 2.50 & 2.92 & 3.05 \\
\hline 4 & Northridge-CC & 6.7 & 0.01 & 0.40 & 2.42 & 2.50 & 2.92 & 3.05 \\
\hline 5 & Duzce-Bolu & 7.1 & 0.01 & 0.45 & 2.42 & 2.50 & 2.92 & 3.05 \\
\hline 6 & Duzce-Bolu & 7.1 & 0.01 & 0.51 & 2.42 & 2.50 & 2.92 & 3.05 \\
\hline 7 & Hector-Hector & 7.1 & 0.01 & 0.28 & 2.42 & 2.50 & 2.92 & 3.05 \\
\hline 8 & Hector-Hector & 7.1 & 0.01 & 0.36 & 2.42 & 2.50 & 2.92 & 3.05 \\
\hline 9 & Imperial Valley-Delta & 6.5 & 0.01 & 0.31 & 2.42 & 2.50 & 2.92 & 3.05 \\
\hline 10 & Imperial Valley-Delta & 6.5 & 0.01 & 0.45 & 2.42 & 2.50 & 2.92 & 3.05 \\
\hline 11 & Imperial Valley-ECC & 6.5 & 0.005 & 0.36 & 2.42 & 2.50 & 2.92 & 3.05 \\
\hline 12 & Imperial Valley-EC & 6.5 & 0.005 & 0.38 & 2.42 & 2.50 & 2.92 & 3.05 \\
\hline 13 & Kobe-Nishi Akashi & 6.9 & 0.01 & 0.52 & 2.42 & 2.50 & 2.92 & 3.05 \\
\hline 14 & Kobe-Nishi Akashi & 6.9 & 0.01 & 0.51 & 2.42 & 2.50 & 2.92 & 3.05 \\
\hline 15 & Kobe-Shin Osaka & 6.9 & 0.01 & 0.26 & 2.42 & 2.50 & 2.92 & 3.05 \\
\hline 16 & Kobe-Shin Osaka & 6.9 & 0.01 & 0.23 & 2.42 & 2.50 & 2.92 & 3.05 \\
\hline 17 & Kocaeli-Duzce & 7.5 & 0.005 & 0.21 & 2.42 & 2.50 & 2.92 & 3.05 \\
\hline 18 & Kocaeli-Duzce & 7.5 & 0.005 & 0.24 & 2.42 & 2.50 & 2.92 & 3.05 \\
\hline 19 & Kocaeli-Arcelik & 7.5 & 0.05 & 0.29 & 2.42 & 2.50 & 2.92 & 3.05 \\
\hline 20 & Kocaeli-Arcelik & 7.5 & 0.05 & 0.20 & 2.42 & 2.50 & 2.92 & 3.05 \\
\hline 21 & Landers-Yermo & 7.3 & 0.02 & 0.24 & 2.42 & 2.50 & 2.92 & 3.05 \\
\hline 22 & Landers-Yermo & 7.3 & 0.02 & 0.15 & 2.42 & 2.50 & 2.92 & 3.05 \\
\hline 23 & Landers-Coolwater & 7.3 & 0.0025 & 0.32 & 2.42 & 2.50 & 2.92 & 3.05 \\
\hline 24 & Landers-Coolwater & 7.3 & 0.0025 & 0.47 & 2.42 & 2.50 & 2.92 & 3.05 \\
\hline 25 & Loma Prieta-Capitola & 6.9 & 0.005 & 0.57 & 2.42 & 2.50 & 2.92 & 3.05 \\
\hline 26 & Loma Prieta-Capitola & 6.9 & 0.005 & 0.48 & 2.42 & 2.50 & 2.92 & 3.05 \\
\hline 27 & Loma Prieta-Gilroy & 6.9 & 0.005 & 0.48 & 2.42 & 2.50 & 2.92 & 3.05 \\
\hline 28 & Loma Prieta-Gilroy & 6.9 & 0.005 & 0.32 & 2.42 & 2.50 & 2.92 & 3.05 \\
\hline 29 & Manjil-Abbar & 7.4 & 0.02 & 0.40 & 2.42 & 2.50 & 2.92 & 3.05 \\
\hline 30 & Manjil-Abbar & 7.4 & 0.02 & 0.39 & 2.42 & 2.50 & 2.92 & 3.05 \\
\hline 31 & Superstition Hills-EC & 6.5 & 0.005 & 0.31 & 2.42 & 2.50 & 2.92 & 3.05 \\
\hline 32 & Superstition Hills-EC & 6.5 & 0.005 & 0.22 & 2.42 & 2.50 & 2.92 & 3.05 \\
\hline 33 & Superstition Hills-Poe & 6.5 & 0.01 & 0.52 & 2.42 & 2.50 & 2.92 & 3.05 \\
\hline 34 & Superstition Hills-Poe & 6.5 & 0.01 & 0.35 & 2.42 & 2.50 & 2.92 & 3.05 \\
\hline 35 & Cape Mendocino-Rio & 7.0 & 0.02 & 0.31 & 2.42 & 2.50 & 2.92 & 3.05 \\
\hline 36 & Cape Mendocino-Rio & 7.0 & 0.02 & 0.45 & 2.42 & 2.50 & 2.92 & 3.05 \\
\hline 37 & Chi Chi-CHY & 7.6 & 0.005 & 0.14 & 2.42 & 2.50 & 2.92 & 3.05 \\
\hline 38 & Chi Chi-CHY & 7.6 & 0.005 & 0.18 & 2.42 & 2.50 & 2.92 & 3.05 \\
\hline 39 & Chi Chi-TCU & 7.6 & 0.005 & 0.45 & 2.42 & 2.50 & 2.92 & 3.05 \\
\hline 40 & Chi Chi-TCU & 7.6 & 0.005 & 0.49 & 2.42 & 2.50 & 2.92 & 3.05 \\
\hline 41 & San Fernando-LA & 6.6 & 0.01 & 0.44 & 2.42 & 2.50 & 2.92 & 3.05 \\
\hline 42 & San Fernando-LA & 6.6 & 0.01 & 0.36 & 2.42 & 2.50 & 2.92 & 3.05 \\
\hline 43 & Friuli-Tolmezzo & 6.5 & 0.005 & 0.50 & 2.42 & 2.50 & 2.92 & 3.05 \\
\hline 44 & Friuli-Tolmezzo & 6.5 & 0.005 & 0.45 & 2.42 & 2.50 & 2.92 & 3.05 \\
\hline
\end{tabular}


Figure 9.11 shows the three pushover curves for 3-, 6- and 9-story LCFs as a representation of the index archetype models. Based on the FEMA P695 procedure and as shown in Figure 9.11, $V_{\max }$ is taken as the maximum base shear strength at any point on the pushover curve (limited to $8 \%$ drift), $\Delta_{y}$ is the displacement where a tangant of initial stiffness line through the origin intersects a horizontal line projected from $V_{\text {max }} . \Delta_{u l t}$ is taken as the roof displacement on the descending part of the curve at the the point of $0.8 V_{\max }$ or maximum $8 \%$ drift.

\subsubsection{Nonlinear Dynamic Analyses}

Nonlinear dynamic analyses were performed with input of ground motions from the FarField record set that was described earlier and included the factored gravity load of 1.05D $+0.25 \mathrm{~L}$

The purpose of the analyses was to establish the median collapse capacity, $\hat{S}_{C T}$, and collapse margin ratio (CMR) for all the index archetype buildings. FEMA P695 adopts the Incremental Dynamic Analysis (IDA) (Vamvatsikos and Cornell, 2002) method to determine the median collapse capacity, $\hat{S}_{C T}$, of the models. IDA makes use of multiple response history analyses for a given ground motion record of increasing intensity until collapse occurs. This process is repeated for a set of ground motion records of sufficient number to determine median collapse capacity and record-to-record variability.

Following the FEMA P695 Methodology, each scaled ground motion (each component of the 22 pairs of ground motion records) is re-scaled with increasing intensity to the point at which the model reaches a collapse limit state. For each record, five analyses of increasing intensity were conducted and in total 220 nonlinear response history analyses were run for each index archetype model.

For each archetype the median collapse capacity, $\hat{S}_{C T}$, was found. This is the spectral acceleration at which $50 \%$ of the ground motions cause collapse for an index archetype

model.After $\hat{S}_{C T}$ was established for each index archetype, the CMR was computed as the ratio between the median collapse intensity $\left(\hat{S}_{C T}\right)$ and the MCE intensity $\left(S_{M T}\right)$ : 


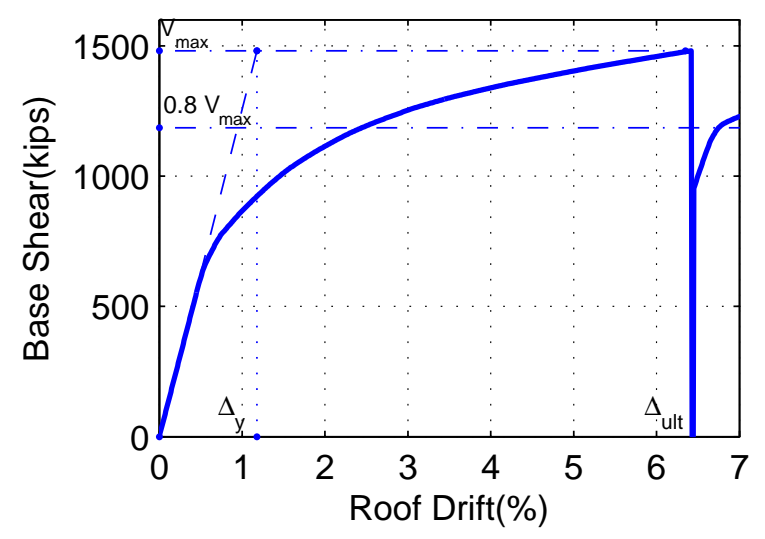

(a)

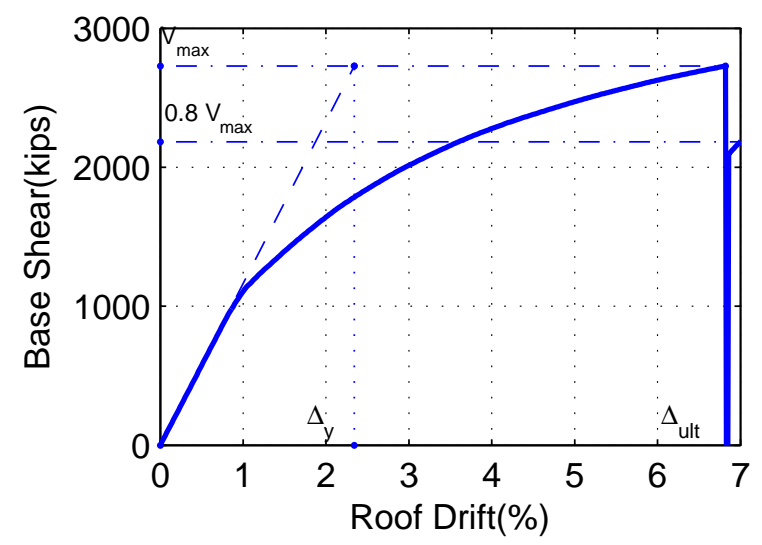

(b)

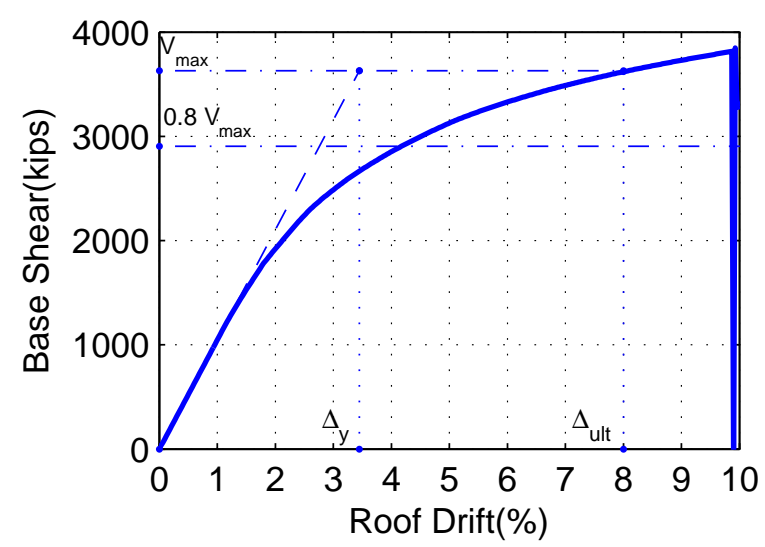

(c)

Figure 9.11: Nonlinear Static Pushover Curve of Base Shear vs Maximum Drift (a) 3-story (b) 6-story (c) 9-story 


$$
C M R=\frac{\hat{S}_{C T}}{S_{M T}}
$$

$S_{M T}$ is the median MCE intensity obtained from the response spectrum of MCE ground motions at the index archetype's fundamental period, T.

\section{Collapse Limit State}

In order to compute the $\hat{S}_{C T}$, the following two commonly used collapse limit states are defined:

- For a particular ground motion, collapse is said to occur if the slope of the IDA curve for that ground motion drops below $10 \%$ of the initial slope. This indicates that small increases in spectral acceleration are causing large increases in roof drift, which is consistant with a collpase condition.

- The second collapse limit state possible is defined by drift limit of the gravity frame. Test results from Liu and Astaneh-Asl (2000) indicate 8\% drift for the collapse of simple connections in gravity frame is reasonable (ATC-58 SSP, 2009). However, previous studies have used 5\% drift as an upper bound for the gravity frame. Here, both are considered and the sensitivity of the result to this variable are studied.

The IDA curves for selected 3-, 6- and 9-story LCFs are illustrated in Figure 9.12 as a representation of the response of the index archetype models. Each point in any of these figures corresponds to the results of a single response history analysis of one index archetype model subjected to one ground motion record scaled to one intensity level. The lines correspond to plots for different ground motion records, each scaled to the full range of intensity values.

Referring to Figure $9.12, \hat{S}_{C T}$ was obtained by scaling all the records in the Far-Field record set to the MCE intensity, $S_{M T}$, and then scaling them individually from small accelerations to large accelerations until one-half of the scaled ground motion records caused collapse. The lowest intensity at which one-half of the records caused collapse (story drift greater than $8 \%$ or $5 \%$ or a slope less than $10 \%$ of initial slope) is the median collapse intensity, $\hat{S}_{C T}$. 


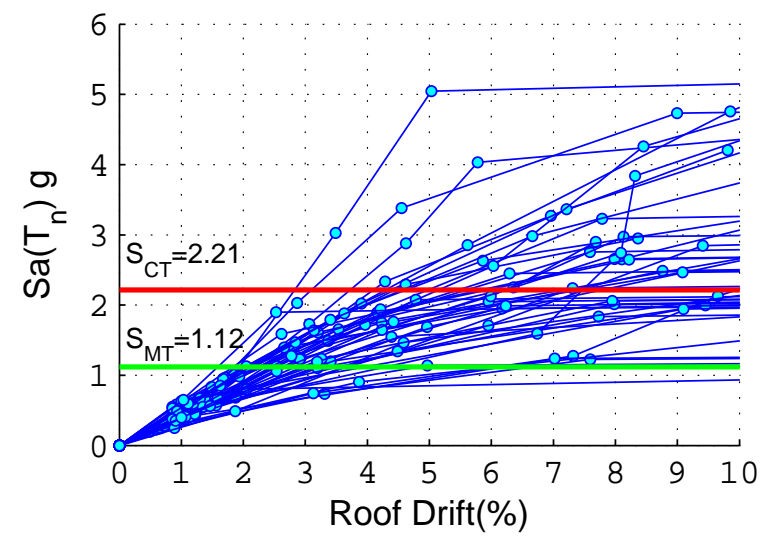

(a)

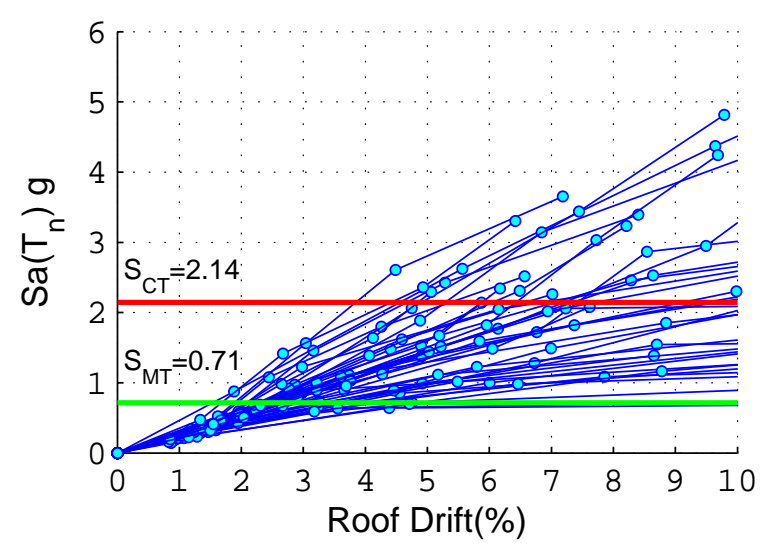

(b)

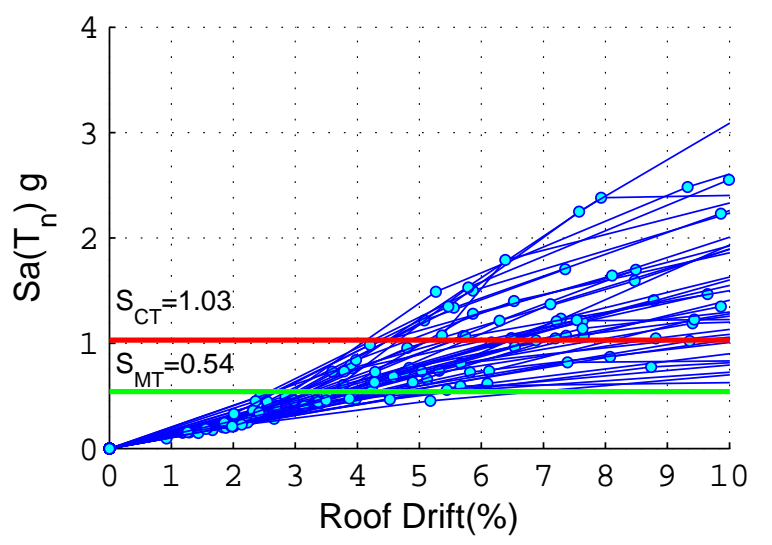

(c)

Figure 9.12: Incremental Dynamic Analysis Response Plot of Spectral Acceleration vs Maximum Drift (a) 3-story (b) 6-story (c) 9-story 


\subsection{Performance Evaluation}

In Section 9.5.2 fundamental period of the structure, $T$, static overstrength factor, $\Omega_{0}=$ $V_{\max } / V$, and ductility capacity, $\mu_{c}=\Delta_{u l t} / \Delta_{y}$, from nonlinear static analyses were obtained.

In Section 9.5.3. MCE ground motion intensity, $S_{M T}$, median collapse intensity, $\hat{S}_{C T}$, and collapse margin ratio, $C M R=\hat{S}_{C T} / S_{M T}$ from nonlinear dynamic analyses were obtained. In this section, the trial value of the response modification, $R$, system overstrength, $\Omega_{0}$, and deflection amplification factor, $C_{d}$ are assessed utilizing these results.

To evaluate the acceptability of a trial $R$ value used in design of the index archetypes, the CMR ratio was compared to acceptable values that depend on the system uncertainty (quality of design requirements, test data, numerical modeling, and a prescribed set of ground motions) and collapse probability. The system overstrength factor, $\Omega_{0}$, is based on the most critical (largest) calculated value of overstrength, $\Omega$, for all archetype designs. The deflection amplification factor, $C_{d}$, is derived from an acceptable value of $R$.

\subsubsection{Adjusted Collapse Margin Ratio}

The spectral shape of the ground motion record set impacts collapse capacity and the calculation of collapse margin ratio. Studies show that some ground motions have a unique spectral shape that is different from the shape of the design spectrum which causes the record to be less damaging than expected, based on the design spectrum shape (Baker and Cornell (2006)). Therefore, FEMA P695 (2009) uses statistical variations to modify the CMR by multiplying it by a simplified Spectral Shape Factor (SSF). This produces the Adjusted Collapse Margin Ratio (ACMR). The SSF values specified in FEMA P695 vary with the period, $T$, of the structures and the building ductility capacity, $\mu_{c}$. Figure 9.13 shows the values of SSF for $S D C D_{\max }$.

$$
A C M R=S S F \times C M R
$$




\begin{tabular}{|c|c|c|c|c|c|c|c|c|}
\hline \multirow{2}{*}{$\begin{array}{c}\boldsymbol{T} \\
\text { (sec.) }\end{array}$} & \multicolumn{10}{|c|}{ Period-Based Ductility, $\boldsymbol{\mu}_{\boldsymbol{T}}$} \\
\cline { 2 - 9 } & $\mathbf{1 . 0}$ & $\mathbf{1 . 1}$ & $\mathbf{1 . 5}$ & $\mathbf{2}$ & $\mathbf{3}$ & $\mathbf{4}$ & $\mathbf{6}$ & $\mathbf{2}$ \\
\hline $\mathbf{5 . 5}$ & 1.00 & 1.05 & 1.1 & 1.13 & 1.18 & 1.22 & 1.28 & 1.33 \\
\hline $\mathbf{0 . 6}$ & 1.00 & 1.05 & 1.11 & 1.14 & 1.2 & 1.24 & 1.3 & 1.36 \\
\hline $\mathbf{0 . 7}$ & 1.00 & 1.06 & 1.11 & 1.15 & 1.21 & 1.25 & 1.32 & 1.38 \\
\hline $\mathbf{0 . 8}$ & 1.00 & 1.06 & 1.12 & 1.16 & 1.22 & 1.27 & 1.35 & 1.41 \\
\hline $\mathbf{0 . 9}$ & 1.00 & 1.06 & 1.13 & 1.17 & 1.24 & 1.29 & 1.37 & 1.44 \\
\hline $\mathbf{1 . 0}$ & 1.00 & 1.07 & 1.13 & 1.18 & 1.25 & 1.31 & 1.39 & 1.46 \\
\hline $\mathbf{1 . 1}$ & 1.00 & 1.07 & 1.14 & 1.19 & 1.27 & 1.32 & 1.41 & 1.49 \\
\hline $\mathbf{1 . 2}$ & 1.00 & 1.07 & 1.15 & 1.2 & 1.28 & 1.34 & 1.44 & 1.52 \\
\hline $\mathbf{1 . 3}$ & 1.00 & 1.08 & 1.16 & 1.21 & 1.29 & 1.36 & 1.46 & 1.55 \\
\hline $\mathbf{1 . 4}$ & 1.00 & 1.08 & 1.16 & 1.22 & 1.31 & 1.38 & 1.49 & 1.58 \\
\hline $\mathbf{1 . 5}$ & 1.00 & 1.08 & 1.17 & 1.23 & 1.32 & 1.4 & 1.51 & 1.61 \\
\hline
\end{tabular}

Figure 9.13: Spectral Shape Factor for SDC $D_{\max }$ - FEMA P695 (2009) Table 7-1b .

\subsubsection{System Collapse Uncertainty}

The collapse prediction is strongly dependent on many sources of uncertainty. Studies show that uncertainty can influence the collapse margin ratio noticeably (FEMA P695, 2009) . Uncertainty sources include:

- Ground motion records uncertainty $\left(\beta_{R T R}\right)$

- Design requirements uncertainty $\left(\beta_{D R}\right)$

- Test data uncertainty $\left(\beta_{T D}\right)$

- Nonlinear modeling uncertainty $\left(\beta_{M D L}\right)$

The total uncertainty was calculated by combining all above uncertainties. Values of total system collapse uncertainty are provided in Tables 7-2a through Table 7-2d of FEMA P695 (2009) for index archetype models with a period-based ductility, $\mu \geq 3$. For the 


\begin{tabular}{|l|l|l|l|l|}
\hline \multirow{2}{*}{ Quality of Test Data } & \multicolumn{4}{|l|}{ Quality of Design Requirements } \\
\cline { 2 - 5 } & (A) Superior & (B) Good & (C) Fair & (D) Poor \\
\hline (A) Superior & 0.475 & 0.500 & 0.575 & 0.675 \\
\hline (B) Good & 0.500 & 0.525 & 0.600 & 0.700 \\
\hline (C) Fair & 0.575 & 0.600 & 0.675 & 0.750 \\
\hline (D) Poor & 0.675 & 0.700 & 0.750 & 0.825 \\
\hline
\end{tabular}

Figure 9.14: Total System Collapse Uncertainty $\left(\beta_{T O T}\right)$ for Model Quality (B) Good FEMA P695 (2009) Table 7-2b .

LCF system, considering the completeness and robustness of design requirements, test data used to validate the components of the system and numerical modeling that simulate LCF behavior, the scale of (B) "Good" was selected for all types of uncertainties (case1).

As shown in Figure 9.14, which is specified for model quality (B) Good, and considering scale (B) for all other types of uncertainties, the total system collapse uncertainty is $\beta_{T O T}=$ 0.525 for LCFs with $\mu \geq 3$. For LCFs with $\mu<3$, the total uncertainty was calculated by following approach.

First, the record-to-record uncertainty, $\beta_{R T R}$ was computed by the following equation:

$$
\beta_{R T R}=0.1+0.1 \mu \leq 0.4
$$

Second, the uncertainties of design requirements, test data, and nonlinear models are scaled based on the following values: (A)Superior, $\beta=0.10$; (B) Good, $\beta=0.20$; (C) Fair, $\beta$ $=0.35$; and $(\mathrm{D})$ Poor, $\beta=0.50$. Finally, the total uncertainty for each LCF was calculated through the following equation:

$$
0.275 \leq \beta_{T O T}=\sqrt{\beta_{R T R}^{2}+\beta_{D R}^{2}+\beta_{T D}^{2}+\beta_{M D L}^{2}} \leq 0.95
$$

Tables 7-2a through Table 7-2d of FEMA P695 (2009) were developed based on this method, with this difference that a fix value of $\beta_{R T R}=0.4$ was assumed for models with 
significant period elongation $(\mu \geq 3)$ and the final result for $\beta_{T O T}$ was rounded to the nearest 0.025 .

Two additional comparisons were also performed. First, considering scale (C) "Fair" for all types of uncertainties (case2) and second, considering scale (C) "Fair" for Quality of test data and scale (B) "Good" for quality of design requirements and model quality (case3). These three cases were studied to evaluate the sensitivity of the impact of three different quality assessments (test data, design recommendations and model quality) on the values of ACMR.

Table 9.14 shows the total uncertainty for different index archetype LCFs.

Table 9.14: Total System Collapse Uncertainty, $\beta_{T O T}$ for Index Archetype Models

\begin{tabular}{|c|c|c|c|c|c|c|c|c|c|c|c|c|c|c|}
\hline \multirow[b]{2}{*}{ NO. } & \multirow[b]{2}{*}{$\mu_{c}$} & \multirow[b]{2}{*}{$\beta_{R T R}$} & \multicolumn{4}{|c|}{$\begin{array}{l}\text { Case } 1 \\
\text { "Good" }\end{array}$} & \multicolumn{4}{|c|}{$\begin{array}{l}\text { Case } 2 \\
\text { "Fair" }\end{array}$} & \multicolumn{4}{|c|}{$\begin{array}{c}\text { Case } 3 \\
\beta_{T D} \text { "Fair", } \beta_{D R}, \beta_{M D L} \text { "Good" }\end{array}$} \\
\hline & & & $\beta_{D R}$ & $\beta_{T D}$ & $\beta_{M D L}$ & $\beta_{T O T}$ & $\beta_{D R}$ & $\beta_{T D}$ & $\beta_{M D L}$ & $\beta_{T O T}$ & $\beta_{D R}$ & $\beta_{T D}$ & $\beta_{M D L}$ & $\beta_{T O T}$ \\
\hline 1 & 5.38 & 0.400 & 0.20 & 0.20 & 0.20 & 0.525 & 0.35 & 0.35 & 0.35 & 0.725 & 0.20 & 0.35 & 0.20 & 0.600 \\
\hline 2 & 5.55 & 0.400 & 0.20 & 0.20 & 0.20 & 0.525 & 0.35 & 0.35 & 0.35 & 0.725 & 0.20 & 0.35 & 0.20 & 0.600 \\
\hline 3 & 5.38 & 0.400 & 0.20 & 0.20 & 0.20 & 0.525 & 0.35 & 0.35 & 0.35 & 0.725 & 0.20 & 0.35 & 0.20 & 0.600 \\
\hline 4 & 2.99 & 0.399 & 0.20 & 0.20 & 0.20 & 0.525 & 0.35 & 0.35 & 0.35 & 0.725 & 0.20 & 0.35 & 0.20 & 0.600 \\
\hline 5 & 2.93 & 0.393 & 0.20 & 0.20 & 0.20 & 0.525 & 0.35 & 0.35 & 0.35 & 0.725 & 0.20 & 0.35 & 0.20 & 0.600 \\
\hline 6 & 3.30 & 0.400 & 0.20 & 0.20 & 0.20 & 0.525 & 0.35 & 0.35 & 0.35 & 0.725 & 0.20 & 0.35 & 0.20 & 0.600 \\
\hline 7 & 3.39 & 0.400 & 0.20 & 0.20 & 0.20 & 0.525 & 0.35 & 0.35 & 0.35 & 0.725 & 0.20 & 0.35 & 0.20 & 0.600 \\
\hline 8 & 3.43 & 0.393 & 0.20 & 0.20 & 0.20 & 0.525 & 0.35 & 0.35 & 0.35 & 0.725 & 0.20 & 0.35 & 0.20 & 0.600 \\
\hline 9 & 3.48 & 0.400 & 0.20 & 0.20 & 0.20 & 0.525 & 0.35 & 0.35 & 0.35 & 0.725 & 0.20 & 0.35 & 0.20 & 0.600 \\
\hline 10 & 2.32 & 0.332 & 0.20 & 0.20 & 0.20 & 0.475 & 0.35 & 0.35 & 0.35 & 0.700 & 0.20 & 0.35 & 0.20 & 0.550 \\
\hline 11 & 2.32 & 0.332 & 0.20 & 0.20 & 0.20 & 0.475 & 0.35 & 0.35 & 0.35 & 0.700 & 0.20 & 0.35 & 0.20 & 0.550 \\
\hline 12 & 2.33 & 0.333 & 0.20 & 0.20 & 0.20 & 0.475 & 0.35 & 0.35 & 0.35 & 0.700 & 0.20 & 0.35 & 0.20 & 0.550 \\
\hline 13 & 2.28 & 0.328 & 0.20 & 0.20 & 0.20 & 0.475 & 0.35 & 0.35 & 0.35 & 0.700 & 0.20 & 0.35 & 0.20 & 0.550 \\
\hline 14 & 2.08 & 0.308 & 0.20 & 0.20 & 0.20 & 0.475 & 0.35 & 0.35 & 0.35 & 0.675 & 0.20 & 0.35 & 0.20 & 0.550 \\
\hline 15 & 2.02 & 0.302 & 0.20 & 0.20 & 0.20 & 0.450 & 0.35 & 0.35 & 0.35 & 0.675 & 0.20 & 0.35 & 0.20 & 0.550 \\
\hline 16 & 2.16 & 0.316 & 0.20 & 0.20 & 0.20 & 0.475 & 0.35 & 0.35 & 0.35 & 0.675 & 0.20 & 0.35 & 0.20 & 0.550 \\
\hline 17 & 2.16 & 0.316 & 0.20 & 0.20 & 0.20 & 0.475 & 0.35 & 0.35 & 0.35 & 0.675 & 0.20 & 0.35 & 0.20 & 0.550 \\
\hline
\end{tabular}




\subsubsection{Acceptable Values of Adjusted Collapse Margin Ratio}

Table 7-3 of FEMA P695 (2009) provides acceptable values for ACMR10\% and ACMR20\% based on total system collpase uncertainty and values of acceptable collapse probability, taken as $10 \%$ and $20 \%$, respectively. Table 9.15 shows the acceptable values of ACMR ratio for $10 \%$ and $20 \%$ collpase probability for the total uncertainty, $\beta_{T O T}$, found for the three cases described above that considered different quality assessments of the test data, design recomendations and models.

Table 9.15: Acceptable Values of Adjusted Collapse Margin Ratio (ACMR10\% and ACMR20\%) adopted from FEMA P695 (2009)

\begin{tabular}{|c|c|c|c|c|c|c|c|c|c|}
\hline \multirow[b]{2}{*}{ NO. } & \multicolumn{3}{|c|}{$\begin{array}{l}\text { Case } 1 \\
\text { "Good" }\end{array}$} & \multicolumn{3}{|c|}{$\begin{array}{l}\text { Case } 2 \\
\text { "Fair" }\end{array}$} & \multicolumn{3}{|c|}{$\begin{array}{c}\text { Case } 3 \\
\beta_{T D} \text { "Fair", } \beta_{D R}, \beta_{M D L} \text { "Good" }\end{array}$} \\
\hline & $\beta_{T O T}$ & $A C M R_{10 \%}$ & $A C M R_{20 \%}$ & $\beta_{T O T}$ & $A C M R_{10 \%}$ & $A C M R_{20 \%}$ & $\beta_{T O T}$ & $A C M R_{10 \%}$ & $A C M R_{20 \%}$ \\
\hline 1 & 0.525 & 1.96 & 1.56 & 0.725 & 2.53 & 1.84 & 0.600 & 2.16 & 1.66 \\
\hline 2 & 0.525 & 1.96 & 1.56 & 0.725 & 2.53 & 1.84 & 0.600 & 2.16 & 1.66 \\
\hline 3 & 0.525 & 1.96 & 1.56 & 0.725 & 2.53 & 1.84 & 0.600 & 2.16 & 1.66 \\
\hline 4 & 0.525 & 1.96 & 1.56 & 0.725 & 2.53 & 1.84 & 0.600 & 2.16 & 1.66 \\
\hline 5 & 0.525 & 1.96 & 1.56 & 0.725 & 2.53 & 1.84 & 0.600 & 2.16 & 1.66 \\
\hline 6 & 0.525 & 1.96 & 1.56 & 0.725 & 2.53 & 1.84 & 0.600 & 2.16 & 1.66 \\
\hline 7 & 0.525 & 1.96 & 1.56 & 0.725 & 2.53 & 1.84 & 0.600 & 2.16 & 1.66 \\
\hline 8 & 0.525 & 1.96 & 1.56 & 0.725 & 2.53 & 1.84 & 0.600 & 2.16 & 1.66 \\
\hline 9 & 0.525 & 1.96 & 1.56 & 0.725 & 2.53 & 1.84 & 0.600 & 2.16 & 1.66 \\
\hline 10 & 0.475 & 1.84 & 1.49 & 0.700 & 2.45 & 1.80 & 0.550 & 2.02 & 1.59 \\
\hline 11 & 0.475 & 1.84 & 1.49 & 0.700 & 2.45 & 1.80 & 0.550 & 2.02 & 1.59 \\
\hline 12 & 0.475 & 1.84 & 1.49 & 0.700 & 2.45 & 1.80 & 0.550 & 2.02 & 1.59 \\
\hline 13 & 0.475 & 1.84 & 1.49 & 0.700 & 2.45 & 1.80 & 0.550 & 2.02 & 1.59 \\
\hline 14 & 0.475 & 1.84 & 1.49 & 0.675 & 2.38 & 1.76 & 0.550 & 2.02 & 1.59 \\
\hline 15 & 0.450 & 1.78 & 1.46 & 0.675 & 2.38 & 1.76 & 0.550 & 2.02 & 1.59 \\
\hline 16 & 0.475 & 1.84 & 1.49 & 0.675 & 2.38 & 1.76 & 0.550 & 2.02 & 1.59 \\
\hline 17 & 0.475 & 1.84 & 1.49 & 0.675 & 2.38 & 1.76 & 0.550 & 2.02 & 1.59 \\
\hline
\end{tabular}

\subsubsection{Evaluation of the Seismic Performance Factors}

To evaluate the trial response modification factor, $R$, FEMA P695 introduced two collapse prevention objectives for accepting the ACMR ratio: 
1. Index archetype designs are required to meet collapse probability for MCE ground motions of $10 \%$, on average. That means the probability of collpase for MCE ground motions is $10 \%$, or less, on average for all index archetype designs.

$$
A C \bar{M} R \geq A C M R 10 \%
$$

2. Each individual archetype is required to meet MCE ground motions collapse probability limit of $20 \%$. That means the probability of collapse for MCE ground motions is approximately $20 \%$, or less, for each index archetype.

$$
A C M R_{i} \geq A C M R 20 \%
$$

If index archetype models satisfy the above conditions, the trial value of $R$ is accepted; otherwise, the process should begin with new trail $R$ value.

To evaluate overstrength factor, $\Omega_{0}$, the average value of archetype overstrength, $\Omega$ was calculated and that value would be considered as $\Omega_{0}$. The deflection amplitude factor, $C_{d}$, value is based on the acceptable value of $\mathrm{R}$, following this equation:

$$
C_{d}=\frac{R}{B_{1 E}}
$$

Where, $B_{1 E}$ is numerical coefficient as set forth in Table 18.6-1 of ASCE 7-05 for effective damping and period, T. For the LCF system, $5 \%$ damping is assumed, and based on Table 18.6-1, ASCE 7-05 a corresponding value of the damping coefficient is $B_{1 E}=1$. Therefore, for $\mathrm{LCF}$ the value of $C_{d}$ is equal to $R$.

Table 9.16, summarizes the parameters and the results of the evaluations for the Index Archetype Designs with design $R$ values equal to 8 .

Table 9.17 shows the evaluation of index archetype designs for the $8 \%$ drift limit state. As illustrated in Table 9.17, for all uncertainty cases, each individual LCF of index archetype models has the ACMR value larger than ACME20\% for 8\% drift limit state. Additionally, the average of ACMR for the index archetype model is 3.66 and is larger than ACMR10\% 
Table 9.16: Summary of the Evaluations of the Archetype for 5\% and $8 \%$ Drift Limit State

\begin{tabular}{|c|c|c|c|c|c|c|c|c|c|c|c|}
\hline \multirow[b]{2}{*}{ NO. } & \multirow[b]{2}{*}{$\mu_{c}$} & \multirow[b]{2}{*}{$T_{n s e c}$} & \multirow[b]{2}{*}{$\Omega$} & \multirow[b]{2}{*}{$\mathrm{SSF}$} & \multirow[b]{2}{*}{$S_{M T}(g)$} & \multicolumn{3}{|c|}{$8 \%$ Drift Limit } & \multicolumn{3}{|c|}{$5 \%$ Drift Limit } \\
\hline & & & & & & $\hat{S}_{C T}(g)$ & CMR & ACMR & $\hat{S}_{C T}(g)$ & CMR & ACMR \\
\hline 1 & 5.38 & 0.89 & 3.64 & 1.29 & 1.12 & 2.24 & 2.00 & 2.58 & 1.57 & 1.40 & 1.81 \\
\hline 2 & 5.55 & 0.95 & 3.21 & 1.30 & 1.12 & 2.21 & 1.97 & 2.56 & 1.72 & 1.53 & 1.99 \\
\hline 3 & 5.38 & 0.95 & 3.06 & 1.29 & 1.12 & 2.12 & 1.90 & 2.45 & 1.76 & 1.57 & 2.02 \\
\hline 4 & 2.99 & 1.27 & 3.42 & 1.28 & 0.71 & 1.98 & 2.79 & 3.57 & 1.35 & 1.90 & 2.43 \\
\hline 5 & 2.93 & 1.26 & 3.40 & 1.28 & 0.71 & 2.14 & 3.01 & 3.85 & 1.42 & 2.00 & 2.56 \\
\hline 6 & 3.30 & 1.19 & 3.82 & 1.30 & 0.71 & 2.26 & 3.18 & 4.13 & 1.49 & 2.09 & 2.73 \\
\hline 7 & 3.39 & 1.25 & 3.51 & 1.29 & 0.71 & 2.22 & 3.12 & 4.02 & 1.43 & 2.01 & 2.59 \\
\hline 8 & 3.43 & 1.27 & 3.39 & 1.30 & 0.71 & 2.12 & 2.98 & 3.87 & 1.66 & 2.33 & 3.03 \\
\hline 9 & 3.48 & 1.23 & 3.54 & 1.30 & 0.71 & 2.23 & 3.14 & 4.08 & 1.81 & 2.55 & 3.31 \\
\hline 10 & 2.32 & 1.66 & 3.47 & 1.25 & 0.54 & 1.03 & 1.91 & 2.39 & 0.75 & 1.39 & 1.74 \\
\hline 11 & 2.32 & 1.65 & 3.55 & 1.25 & 0.54 & 1.09 & 2.02 & 2.52 & 0.77 & 1.42 & 1.77 \\
\hline 12 & 2.33 & 1.58 & 3.78 & 1.25 & 0.54 & 1.26 & 2.33 & 2.91 & 0.89 & 1.65 & 2.06 \\
\hline 13 & 2.28 & 1.55 & 3.99 & 1.24 & 0.54 & 1.51 & 2.79 & 3.46 & 1.06 & 1.96 & 2.43 \\
\hline 14 & 2.08 & 2.48 & 5.09 & 1.23 & 0.12 & 0.47 & 3.92 & 4.82 & 0.29 & 2.42 & 2.97 \\
\hline 15 & 2.02 & 2.61 & 4.84 & 1.23 & 0.12 & 0.48 & 4.00 & 4.92 & 0.30 & 2.50 & 3.07 \\
\hline 16 & 2.16 & 1.66 & 3.31 & 1.23 & 0.54 & 1.04 & 1.92 & 2.36 & 0.76 & 1.41 & 1.73 \\
\hline 17 & 2.16 & 1.68 & 3.22 & 1.23 & 0.54 & 1.17 & 2.17 & 2.67 & 0.80 & 1.48 & 1.82 \\
\hline Mean & - & - & 3.66 & - & - & - & - & 3.36 & - & - & 2.39 \\
\hline
\end{tabular}

equals $1.96,2.53$ and 2.16 for case 1,2 and 3 , respectively. It can be concluded that with the $8 \%$ drift limit state the trial $\mathrm{R}$ value equal of 8 is acceptable.

Table 9.18 shows the evaluation for the index archetype models for the $5 \%$ drift limit state. As shown, when the quality of test data, design requirments and models were assumed to be "Good" (case 1) or when all were assumed "Good" except the quality of the test data, which was assumed to be "Fair" (case 3), all models passed the ACMR20\% re- 
Table 9.17: Evaluating Index Archetype Designs Based on Acceptable Values of Adjusted Collapse Margin Ratio for 8\% Drift Limit.

\begin{tabular}{|c|c|c|c|c|c|c|c|}
\hline \multirow[b]{2}{*}{ NO. } & \multirow[b]{2}{*}{ ACMR } & \multicolumn{2}{|c|}{$\begin{array}{l}\text { Case } 1 \\
\text { "Good" }\end{array}$} & \multicolumn{2}{|c|}{$\begin{array}{l}\text { Case } 2 \\
\text { "Fair" }\end{array}$} & \multicolumn{2}{|c|}{$\begin{array}{c}\text { Case } 3 \\
\beta_{T D} \text { "Fair", } \beta_{D R}, \beta_{M D L} \text { "Good" }\end{array}$} \\
\hline & & $A C M R_{20 \%}$ & Pass/Fail & $A C M R_{20 \%}$ & Pass/Fail & $A C M R_{20 \%}$ & Pass/Fail \\
\hline 1 & 2.58 & 1.56 & Pass & 1.84 & Pass & 1.66 & Pass \\
\hline 2 & 2.56 & 1.56 & Pass & 1.84 & Pass & 1.66 & Pass \\
\hline 3 & 2.45 & 1.56 & Pass & 1.84 & Pass & 1.66 & Pass \\
\hline 4 & 3.57 & 1.56 & Pass & 1.84 & Pass & 1.66 & Pass \\
\hline 5 & 3.85 & 1.56 & Pass & 1.84 & Pass & 1.66 & Pass \\
\hline 6 & 4.13 & 1.56 & Pass & 1.84 & Pass & 1.66 & Pass \\
\hline 7 & 4.02 & 1.56 & Pass & 1.84 & Pass & 1.66 & Pass \\
\hline 8 & 3.87 & 1.56 & Pass & 1.84 & Pass & 1.66 & Pass \\
\hline 9 & 4.08 & 1.56 & Pass & 1.84 & Pass & 1.66 & Pass \\
\hline 10 & 2.39 & 1.49 & Pass & 1.80 & Pass & 1.59 & Pass \\
\hline 11 & 2.52 & 1.49 & Pass & 1.80 & Pass & 1.59 & Pass \\
\hline 12 & 2.91 & 1.49 & Pass & 1.80 & Pass & 1.59 & Pass \\
\hline 13 & 3.46 & 1.49 & Pass & 1.80 & Pass & 1.59 & Pass \\
\hline 14 & 4.82 & 1.49 & Pass & 1.76 & Pass & 1.59 & Pass \\
\hline 15 & 4.92 & 1.46 & Pass & 1.76 & Pass & 1.59 & Pass \\
\hline 16 & 2.36 & 1.49 & Pass & 1.76 & Pass & 1.59 & Pass \\
\hline 17 & 2.67 & 1.49 & Pass & 1.76 & Pass & 1.59 & Pass \\
\hline Mean & 3.66 & 1.96 & Pass & 2.53 & Pass & 2.16 & Pass \\
\hline
\end{tabular}

quirements. However, in case 2, where "Fair" quality was assumed for test data, design requirments and models, one 3-story model and most 9-story models failed to meet the required collpase probability. It should be noted that failing here means the model has higher collapse probability than $20 \%$ for MCE ground motion. The average of ACMR for the index archetype model is 2.39 and is larger than ACMR10\% equals 1.96 and 2.16 for case 1 and 3, respectively. However, this value is smaller than ACMR10\% $=2.53$ for case 2.

It seems case 3, in which "Fair" was selected for the quality of test data, but "Good" was assigned to quality of design requirements and model quality, is the most reasonable 
Table 9.18: Evaluating Index Archetype Designs Based on Acceptable Values of Adjusted Collapse Margin Ratio for 5\% Drift Limit.

\begin{tabular}{|c|c|c|c|c|c|c|c|}
\hline \multirow[b]{2}{*}{ NO. } & \multirow[b]{2}{*}{ ACMR } & \multicolumn{2}{|c|}{$\begin{array}{l}\text { Case } 1 \\
\text { "Good" }\end{array}$} & \multicolumn{2}{|c|}{$\begin{array}{l}\text { Case } 2 \\
\text { "Fair" }\end{array}$} & \multicolumn{2}{|c|}{$\begin{array}{c}\text { Case } 3 \\
\beta_{T D} \text { "Fair", } \beta_{D R}, \beta_{M D L} \text { "Good" }\end{array}$} \\
\hline & & $A C M R_{20 \%}$ & Pass/Fail & $A C M R_{20 \%}$ & Pass/Fail & $A C M R_{20 \%}$ & Pass/Fail \\
\hline 1 & 1.81 & 1.56 & Pass & 1.84 & Fail & 1.66 & Pass \\
\hline 2 & 1.99 & 1.56 & Pass & 1.84 & Pass & 1.66 & Pass \\
\hline 3 & 2.02 & 1.56 & Pass & 1.84 & Pass & 1.66 & Pass \\
\hline 4 & 2.43 & 1.56 & Pass & 1.84 & Pass & 1.66 & Pass \\
\hline 5 & 2.56 & 1.56 & Pass & 1.84 & Pass & 1.66 & Pass \\
\hline 6 & 2.73 & 1.56 & Pass & 1.84 & Pass & 1.66 & Pass \\
\hline 7 & 2.59 & 1.56 & Pass & 1.84 & Pass & 1.66 & Pass \\
\hline 8 & 3.03 & 1.56 & Pass & 1.84 & Pass & 1.66 & Pass \\
\hline 9 & 3.31 & 1.56 & Pass & 1.84 & Pass & 1.66 & Pass \\
\hline 10 & 1.74 & 1.49 & Pass & 1.80 & Fail & 1.59 & Pass \\
\hline 11 & 1.77 & 1.49 & Pass & 1.80 & Fail & 1.59 & Pass \\
\hline 12 & 2.06 & 1.49 & Pass & 1.80 & Pass & 1.59 & Pass \\
\hline 13 & 2.43 & 1.49 & Pass & 1.80 & Pass & 1.59 & Pass \\
\hline 14 & 2.97 & 1.49 & Pass & 1.76 & Pass & 1.59 & Pass \\
\hline 15 & 3.07 & 1.46 & Pass & 1.76 & Pass & 1.59 & Pass \\
\hline 16 & 1.73 & 1.49 & Pass & 1.76 & Fail & 1.59 & Pass \\
\hline 17 & 1.82 & 1.49 & Pass & 1.76 & Fail & 1.59 & Pass \\
\hline Mean & 2.39 & 1.96 & Pass & 2.53 & Fail & 2.16 & Pass \\
\hline
\end{tabular}

one among the others, due to lacking test results on system level for LCF system. Adding the experimental test results on the system level for the LCF may decrease the test data uncertainty.

Moreover, the results show that the analyses are sensitive to the total uncertainty values. The total uncertainty is based on the quality (between (A) superior and (D) poor) for the robustness of the design requirements, experimental data and numerical model. FEMA P695 does not precisely define guidelines for this rating procedure.

Furthermore, the results show that for a ductile system like LCF, non simulated limit states such as the drift limit state govern the collapse behavior and the CMR values. The 
direct simulation of collapse through modeling the degradation of elements (link, beam and connections) flattens the IDA curve in larger drift than the non simulated limit state. The results can again be sensitive of what this non simulated limit state is.

Finally, based on the result of this chapter, the trial value of $R=8$ is acceptable for using in LCF designs. The average of $\Omega$ for all index archetype designs is near to 3.66. However, as discussed before in Section 7.1.2 and Figure 7.1, when comparing LCF and moment frame system, LCF overall has lower overstrength than moment frame. Thus, $\Omega=3$, would be a reasonable assumption for LCF. $\mu_{C}=5.5$ is suggested for LCF, similar to special moment frame; although, based on FEMA P695 procedure, $\mu_{C}=8$, may be acceptable. 


\section{Chapter 10}

\section{DEVELOPMENT OF THE ANALYTICAL COMPONENT OF LCF HYBRID TESTING}

Experimental testing is essential to fully understand the LCF's seismic response, evaluate of its constructibility and to verify of analytical models. Such tests are especially important in the case of the LCF system, since it is a new system in which the behavior of the total system and its components must be demonstrated and proven effective for engineers to begin using it in practice.

In this Chapter, the development of a hybrid structure involving the combined use of physical and numerical experimental components for the seismic simulation of a linked column frame system is discussed. The combination of physical testing and numerical simulation through hybrid testing allows key subassemblages to be physically tested while, as in this case, the entire LCF frame is considered as the full specimen. For hybrid testing of the LCF system, a planar LCF frame will be simulated using experimental and computational substructures, then the dynamic response of the LCF to selected ground motions is calculated numerically on a computer. In general, displacements at interface degrees of freedom between the experimental and computational components are applied by actuators to the experimental subassemblage and resulting forces are returned to the numerical model.

\subsection{Introduction}

There are several methods in which experimental tests can be used to directly determine the behavior of structural systems under earthquake events, such as the pseudo-dynamic testing, shake-table testing and hybrid testing. In hybrid testing, a combination of analytical and physical models of a structure's components are used to simulate the structure's total response in the time domain. The analytically represented aspects of the structure are modeled and simulated on a computer while the physical parts are constructed and tested in the laboratory. Therefore, the hybrid simulation method gives the researcher the ability 
to model the well understood parts of a structure in a finite element program on a computer and test the highly nonlinear and/or numerically complicated parts of the structure in the laboratory. Hybrid simulation does not face the difficulties of imposing proper boundary conditions due to the fact that test specimens can be built in full scale and can be deformed quasi-statically instead of dynamically. Further, hybrid testing faces fewer restrictions on the size, weight and strength of a specimen compared to shaking table testing (Schellenberg et al., 2006).

This makes hybrid testing an efficient and economical experimental method of investigating the performance of large-scale structural components with the nonlinear behavior of the entire structural system considered during the test. The main reason for the limited use of hybrid simulation for seismic experiments is the lack of a common framework for developing and deploying the method. To realize the full potential of hybrid simulation, an environmentally independent software framework is needed that is robust, transparent, scalable and easily extensible. Recently, OpenSees (Mazzoni et al., 2009) has been utilized frequently for this purpose. OpenSees provides a wide variety of high performance computational features as well as network based simulation and communications capabilities, making geographically distributed and other advanced forms of hybrid simulations possible (Schellenberg et al., 2006).

For evaluating the LCF response, hybrid tests will be performed for ground motion at three different intensities. The target LCF performance includes specific damage states for each of the three different earthquake levels.

1. Damage State 1: Elastic behavior, no repair is needed after a $50 \%$ in 50 year event.

2. Damage State 2: Rapid repair, only links are damaged after a 10\% in 50 year event.

3. Damage State 3: Collapse prevention, links and moment frame beams are damaged for the $2 \%$ in 50 year hazard level.

Figure 10.1 shows a schematic for the implementation of hybrid testing for the LCF system. In general, the hybrid test setup has four components that are specialized here for the LCF: 
1. A nonlinear discrete model: This model is able to capture all significant behaviors of the LCF. The finite element method is used to discretize the problem using a timestepping integration algorithm for the time discretization. The resulting dynamic equations of motion for the finite number of discrete degrees of freedom are a system of second-order time ordinary differential equations. The numerical model here is developed in OpenSees.

2. Transfer system: The incremental displacements determined by the time-stepping integration algorithm can be applied to the physical portions of the structure using a controller and actuators. This is accomplished using OpenFresco.

3. Physical specimen: The LCF specimen is being tested in the laboratory and against a support in which the actuators of the transfer system can react. Also, there is a floor bracket connecting the LCF specimen to the strong floor (Figure 10.2 Lopez (2013)).

4. Data acquisition system: This data, including displacement transducers and load cells, is responsible for measuring the response of the test specimen and returning the resisting forces to the time-stepping integration algorithm to advance the solution to the next step in the analysis.

\subsection{LCF Hybrid Test Models}

To validate the response at a system level, the proposed experimental test setup, as illustrated in Figure 10.4, was designed at Portland State University (PSU). The goals of the tests are to understand how the LCF system components interact together as a unit, to monitor the progression of damage in the replaceable links and to ultimately validate the rapid repair performance-based design methodology. As shown in Figure 10.4, the LCF system has been investigated experimentally as a full-scale 1-bay and 2-story structure. The typical bay width is $7.5 \mathrm{~m}$, the typical story height is $3.65 \mathrm{~m}$, and each linked column is spaced $1.5 \mathrm{~m}$ apart. The LCF moment frame is expected to remain elastic, while links 


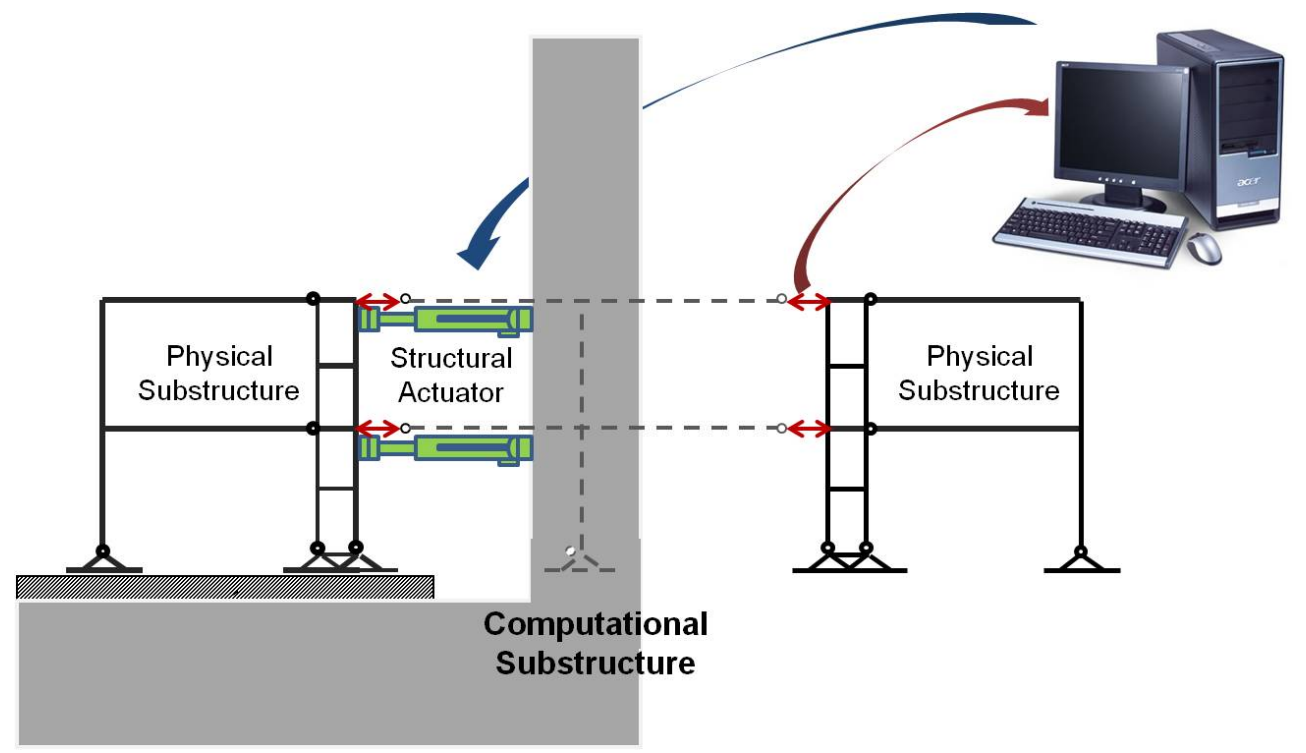

Figure 10.1: Hybrid Testing Method for LCF.

are expected to yield and deform plastically. Links are bolted to the columns to facilitate post-earthquake replacement.

Hybrid simulation is needed to investigate the overall structure response, due to differences on lateral parameters between the numerical and experimental models. The numerical model is a 4-bay and 2-story as shown in Figure 10.3(a) and the experimental model is 1-bay and 2-story, due to the limitations of laboratory space, as shown in Figures 10.3(b) and 10.2 (Lopez, 2013).

To perform the LCF hybrid simulation, the Open System for Earthquake Engineering Simulation, OpenSees (Mazzoni et al., 2009), has been used as a finite element software to model and analyze the LCF. The Open-source Framework for Experimental Setup and Control, OpenFresco (Takahashi et al., 2005), will also be used to connect the finite element analysis software with a control and data acquisition software. 


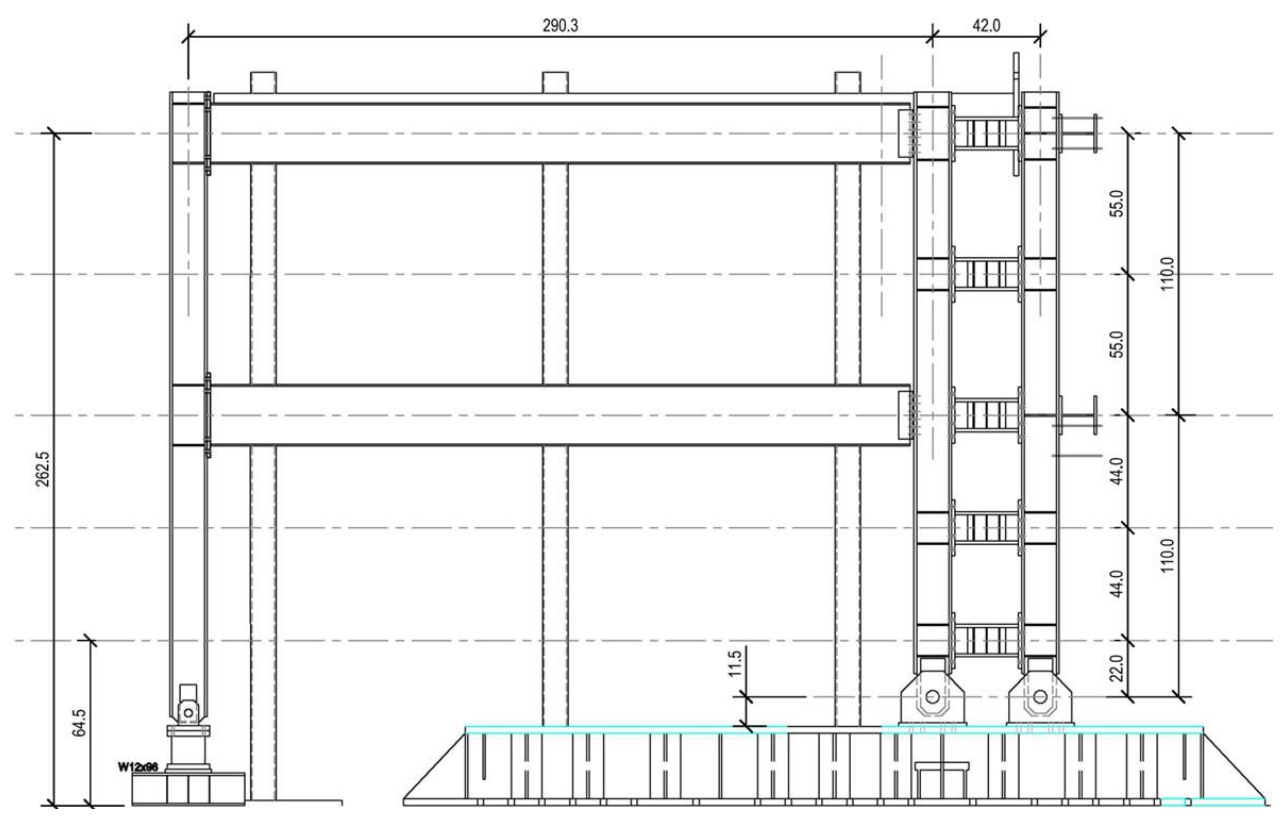

Figure 10.2: Test Set-up Elevation (Lopez, 2013).

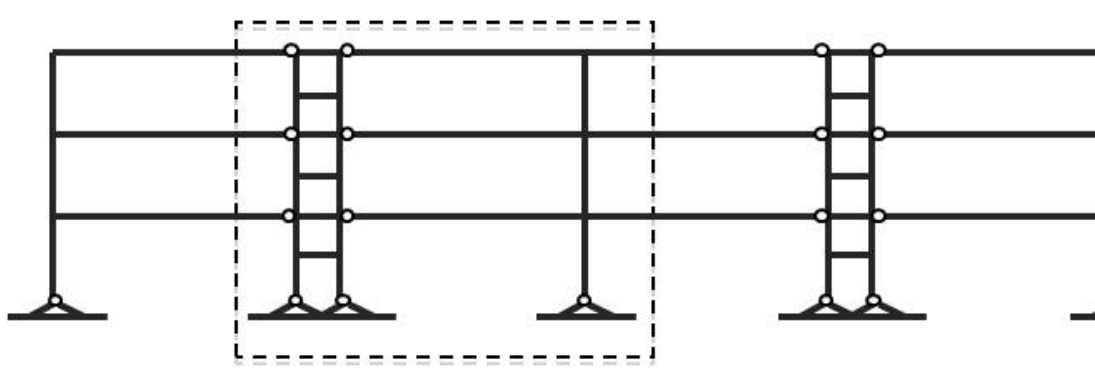

(a)

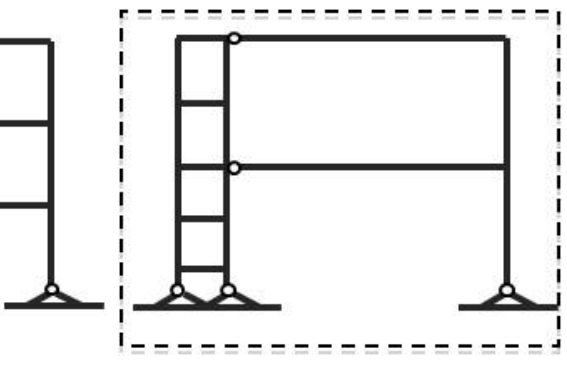

(b)

Figure 10.3: (a) Numerical LCF Model, 4-bay and 2-story (Computational Substructure)(b) Experimental LCF Model, 1-bay and 2-story (Physical Substructure).

\subsection{Experimental Component Model Analysis}

Nonlinear static and dynamic analyses were conducted to investigate the experimental specimen (2-story, 1-bay, Figure 10.5) demands under pushover loading and ground motions, characterizing the component demands, and investigating the overall behavior of the LCF. The results of this chapter provide the details for LCF experimental test set-up and com- 


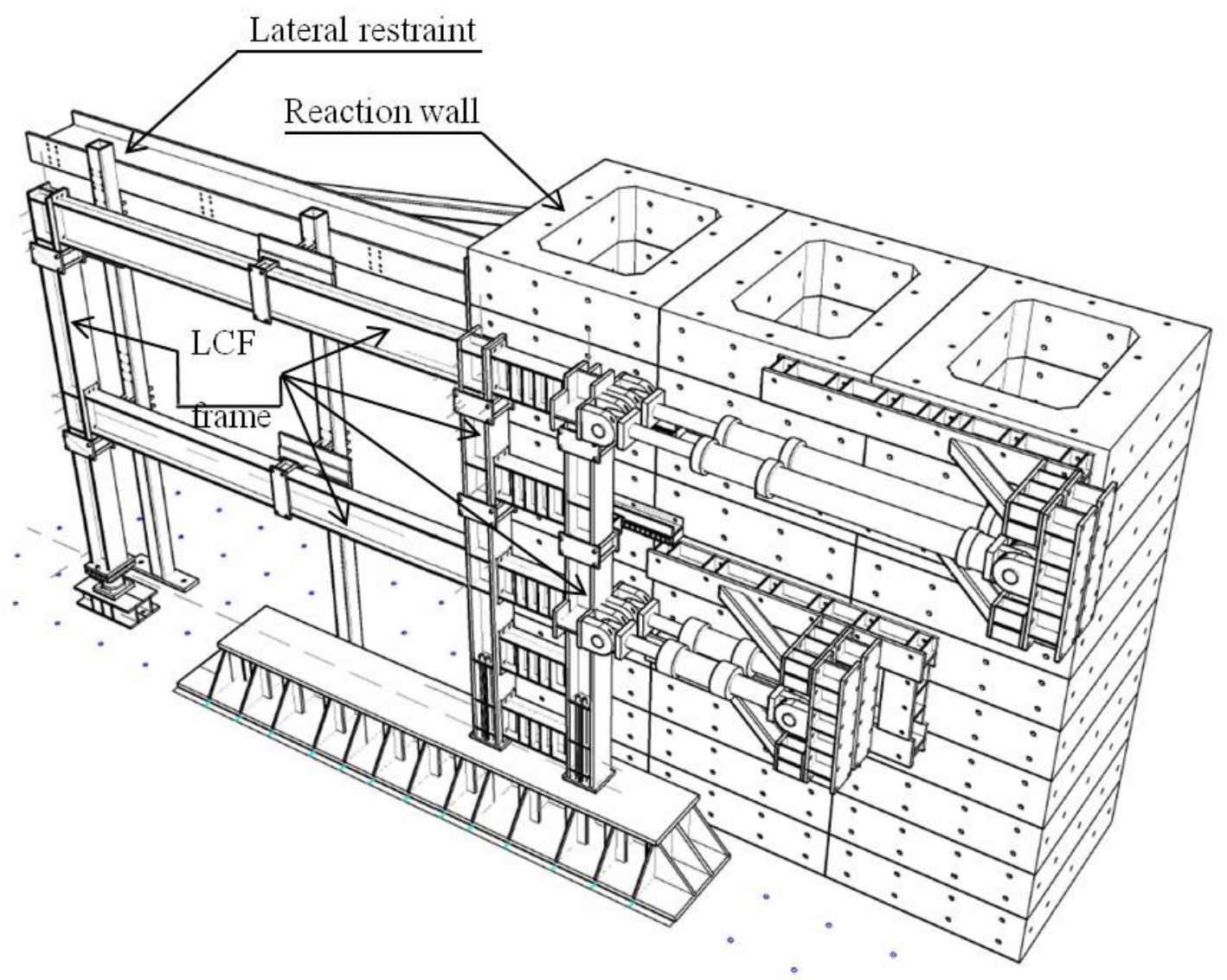

Figure 10.4: Proposed Experimental Setup for the LCF (Lopez et al., 2012b).

ponents' design.

In this case, just the pushover analysis was performed. Figures 10.6 10.7 show the pushover curve and model components demands. These demands help to design the support at base and connection for test set-up. It should be noted that 800 kips column axial force is large for pinned connection. The design of these connections is in progress. 


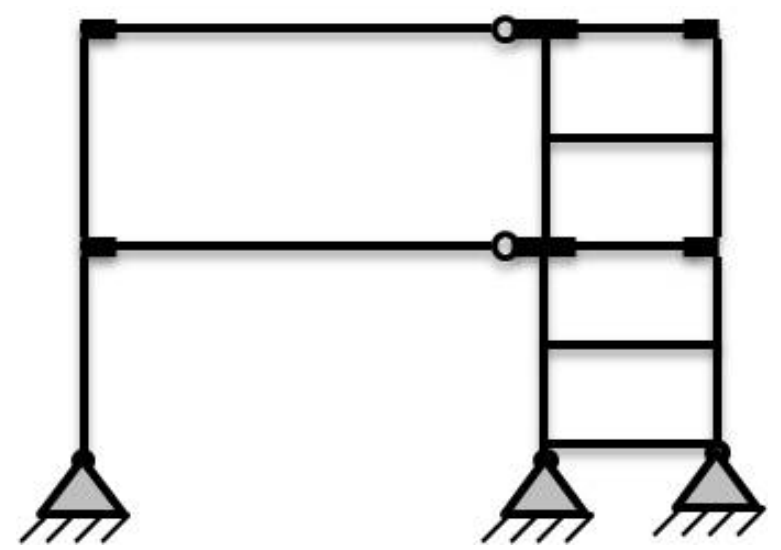

Figure 10.5: Experimental Model, 2-Story, 1-bay LCF.

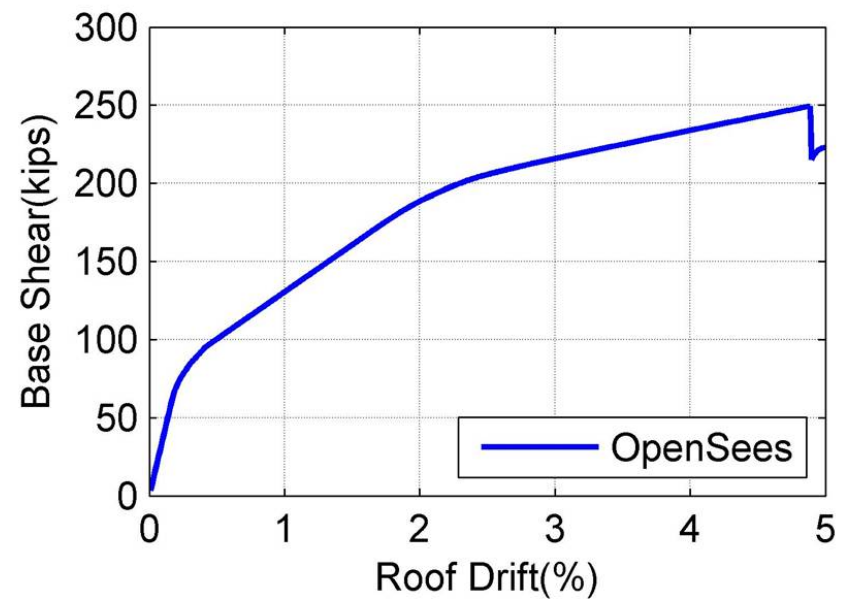

Figure 10.6: Pushover Curve for Model Number 2.

\subsection{Computational Component Model Analysis}

A model developed for simulating the behavior of the computational component ( $\mathrm{T}$ shape moment frame inbetween two experimental parts) is shown in Figure 10.8(b). To perform this simulation, the model with four truss elements with roller support at the node connected to $\mathrm{T}$ shape frame were used to connect the middle $\mathrm{T}$ shape moment frame to two experimental models, as shown in Figure 10.8(c). The purpose of this simulation is to compute the axial force that will be applied to experimental model by the $\mathrm{T}$ shape frame. 


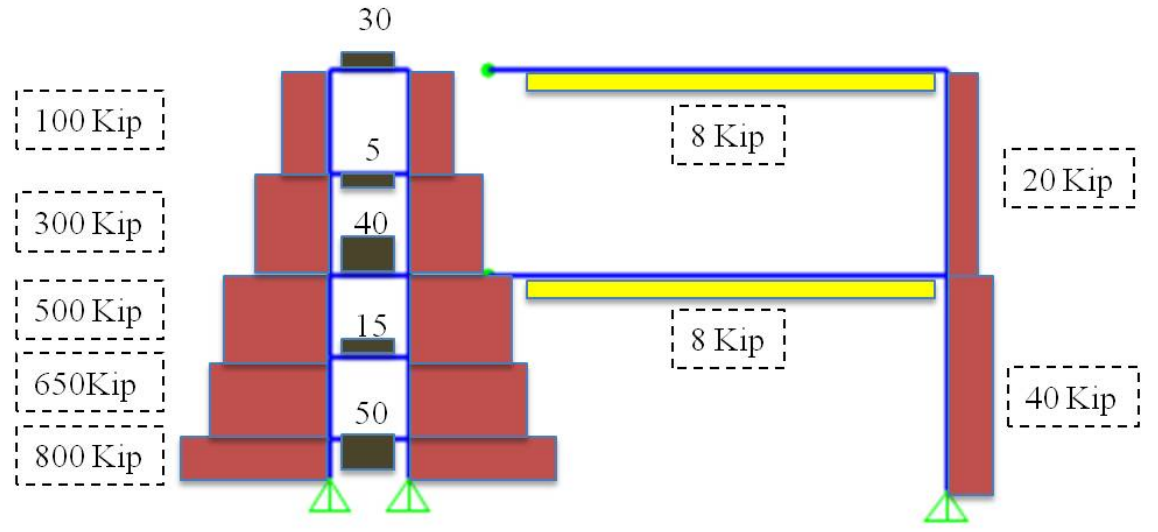

(a)

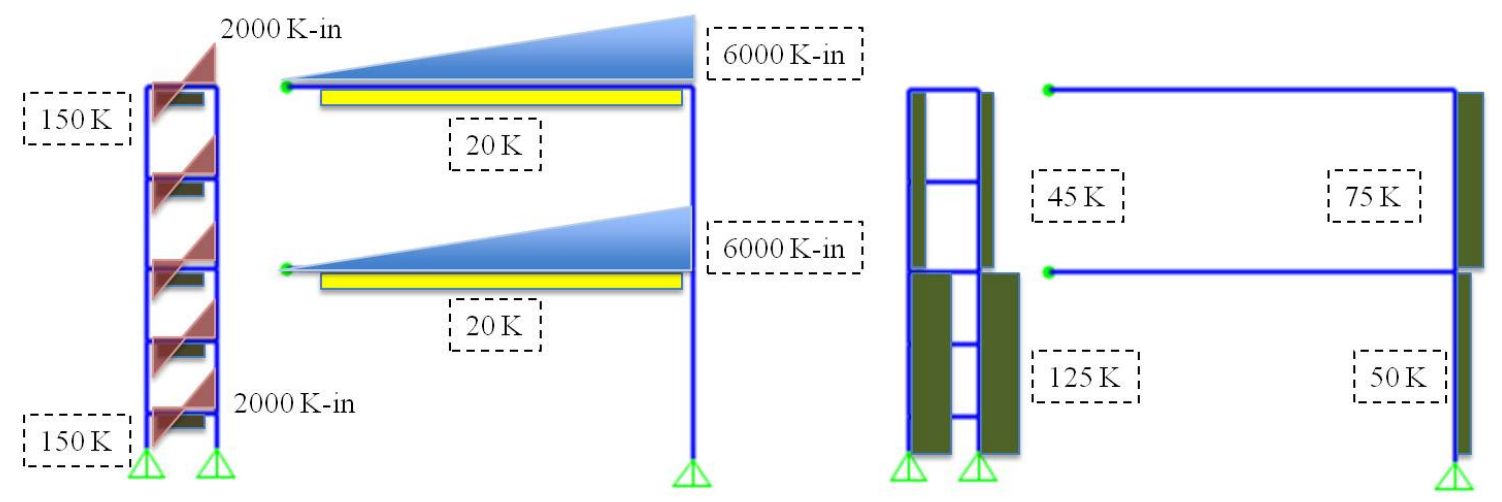

(b)

Figure 10.7: (a) Axial Demands for Model Number 2 (b) Moment and Shear Demands for Model Number 2.

\subsubsection{Base Model}

At first, to understand the system behavior, the base model was developed. The base model is the whole computational model, 2-story and 4-bay LCF using normal OpenSees analysis parameters, as shown in Figure 10.8(a), The purpose of this modeling is to observe the demands in LCF components and also determine the basis for system behavior. The results were used to compare with the second model which simulates the computational components of the hybrid test (Figure 10.8(b) .

The pushover analysis and dynamic analysis were both run for the this model. Fig- 
ure 10.9 shows the pushover curve for this system. Examples of beam, column and link demands are shown in Figure 10.11, 10.13 form static pushover analysis. The location in LCF that these demands belong to is specified in Figure 10.10.

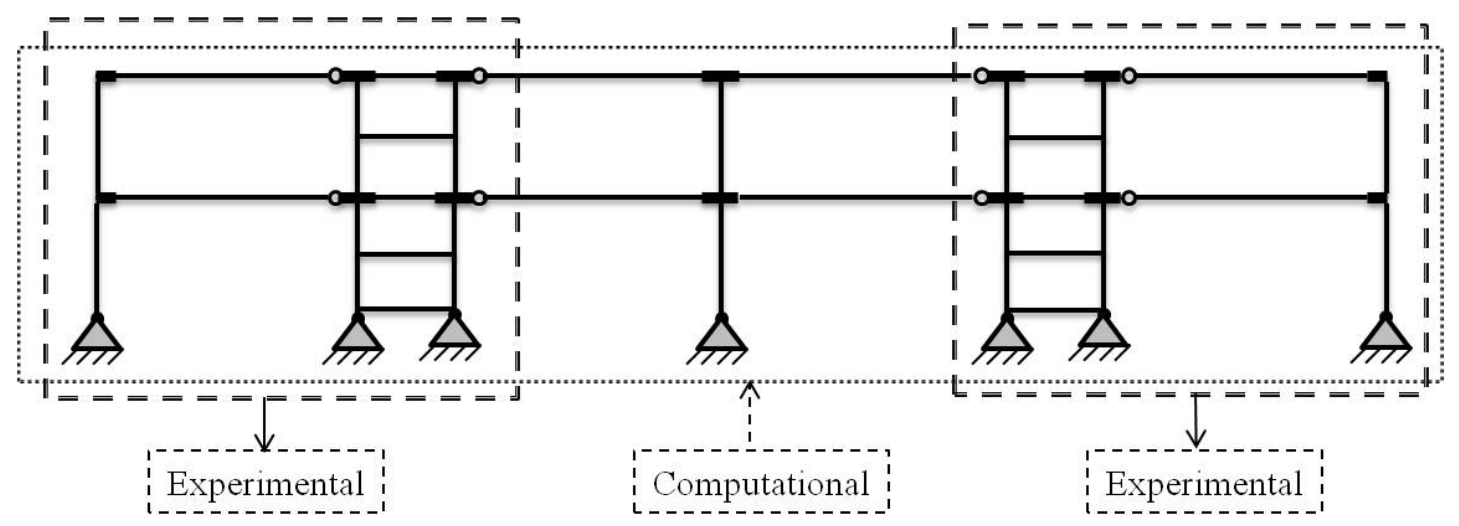

(a)

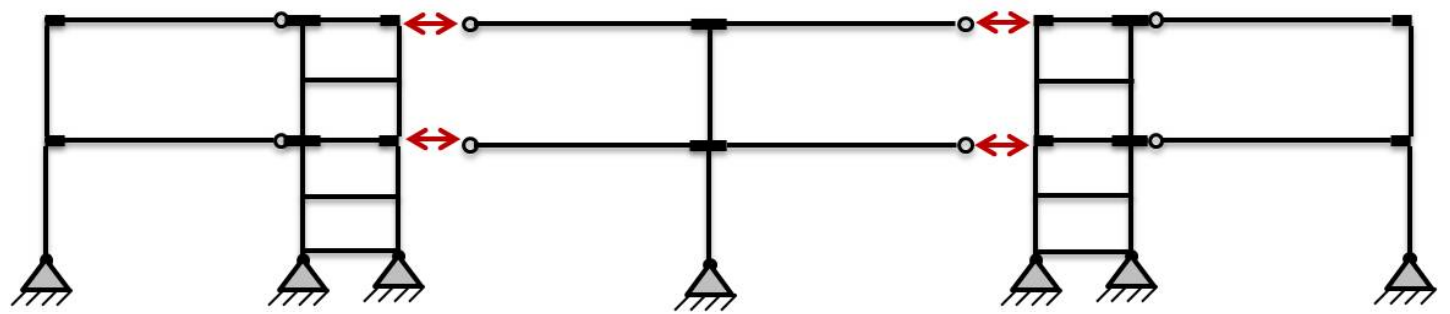

(b)

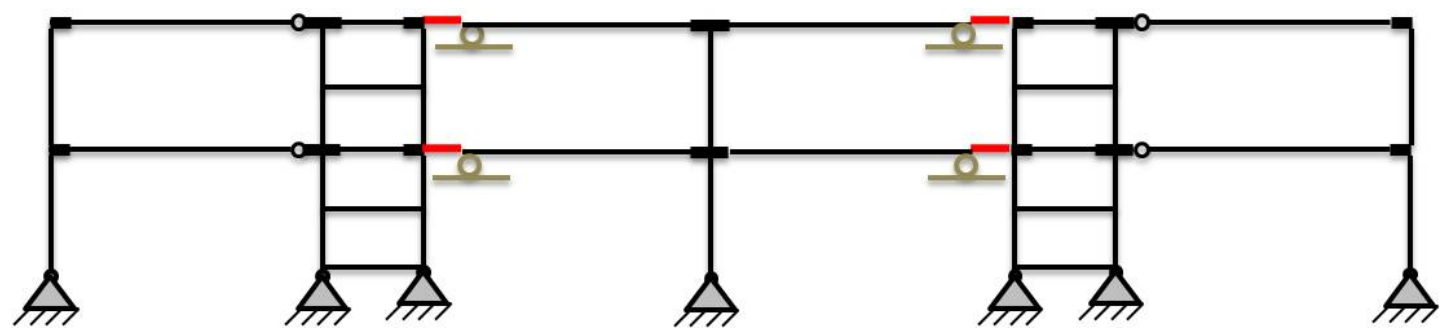

(c)

Figure 10.8: (a) Model Number One, Computational Model, 2-story, 4-bay LCF (b) Relation Between Computational and Experimental substructure (c) Model Number 2, the Simulation of the Moment Frame

Also, two suites of 20 earthquake ground motion records were used in the nonlinear analyses. The ground motions were those developed in the SAC project for the Seattle site by Somerville et al. (1997) for soil type D. These two suites of ground motions represent the 


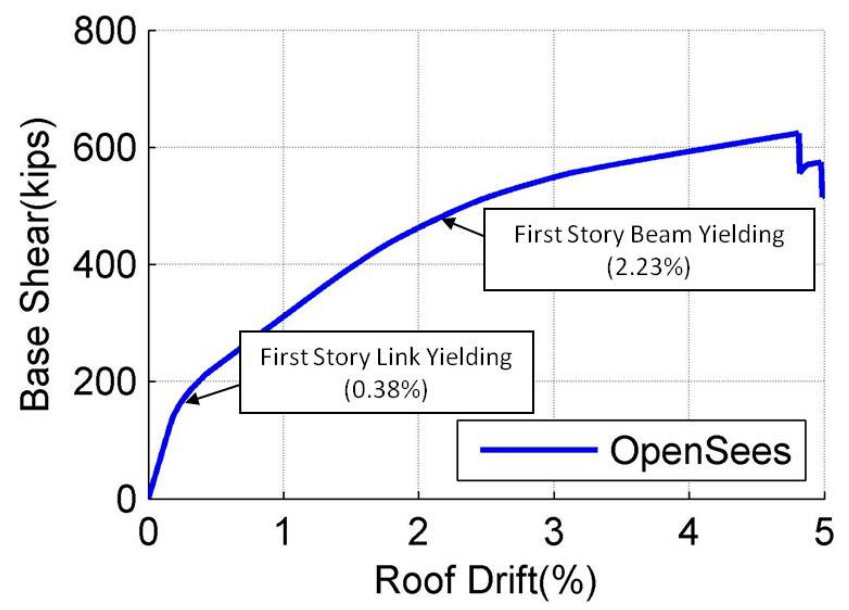

Figure 10.9: Pushover Curve for Model Number 1.
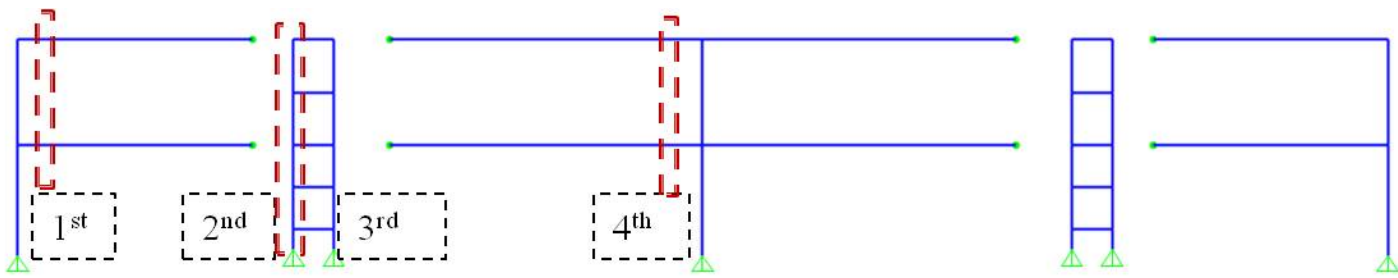

Figure 10.10: Specific Loaction for Reading Components Demands.

following seismic hazard levels: $10 \%$ in 50 year, and $2 \%$ in 50 year earthquakes. Figure 10.14 shows the median and 84th percentile values for maximum story drift, normalized link shear force, beam moment and column axial force. The column demands were just shown for the first floor (at base), and as shown, no yielding occured even in $2 \%$ hazard level. The beam demands show the rapid repair concept is valid here, due to the fact that the beam is not yielding until $2 \%$ in 50 year event.

\subsubsection{T shape Model}

A mentioned earlier, truss elements on the roller support were used to connect the computational component ( $\mathrm{T}$ shape) to the experimental component, as shown in Figure 10.8(c). The axial forces in these trusses represent the axial force in the actuator. There models 


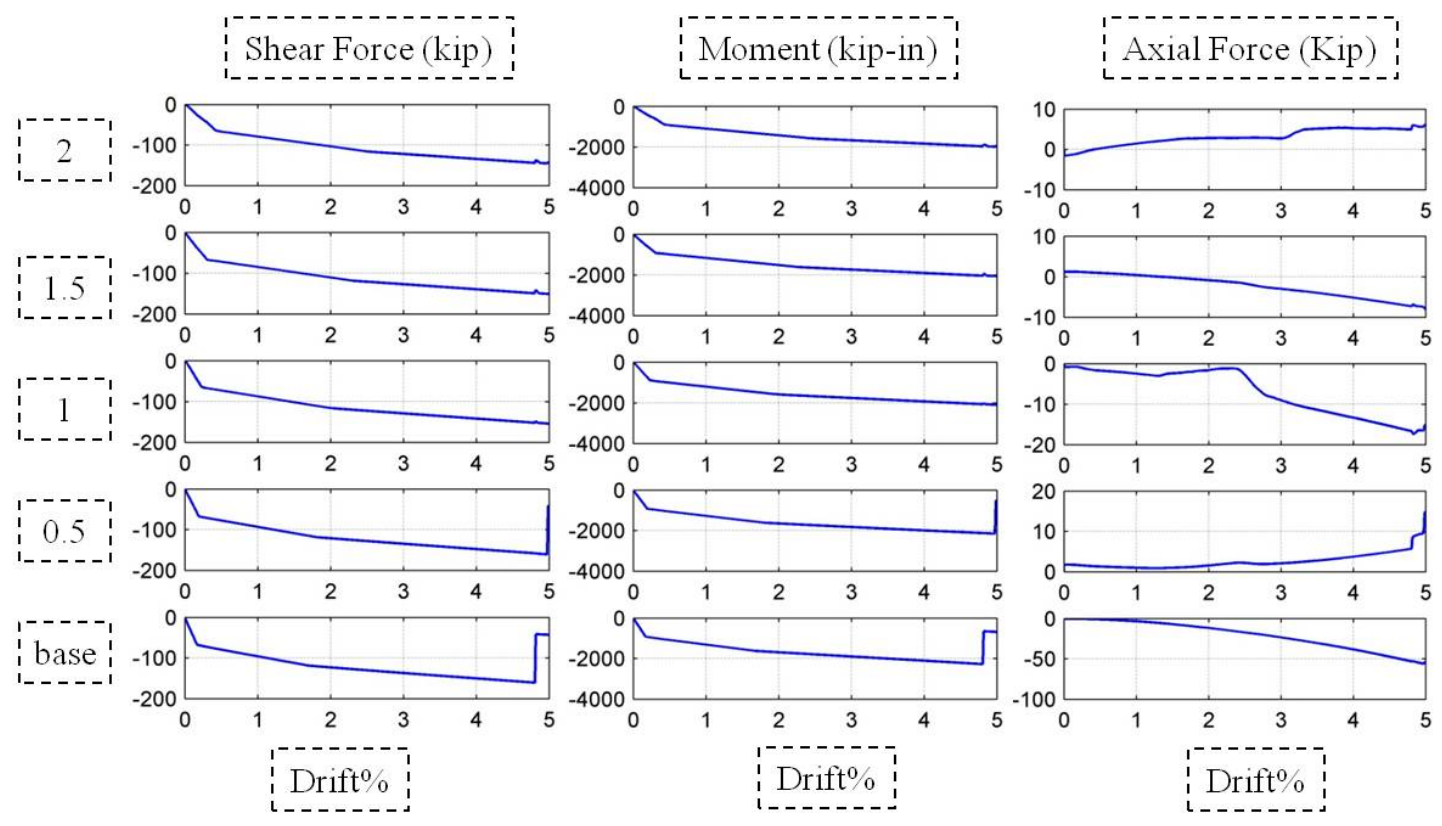

Figure 10.11: Link Demands Form Pushover Analysis for Model Number 1.
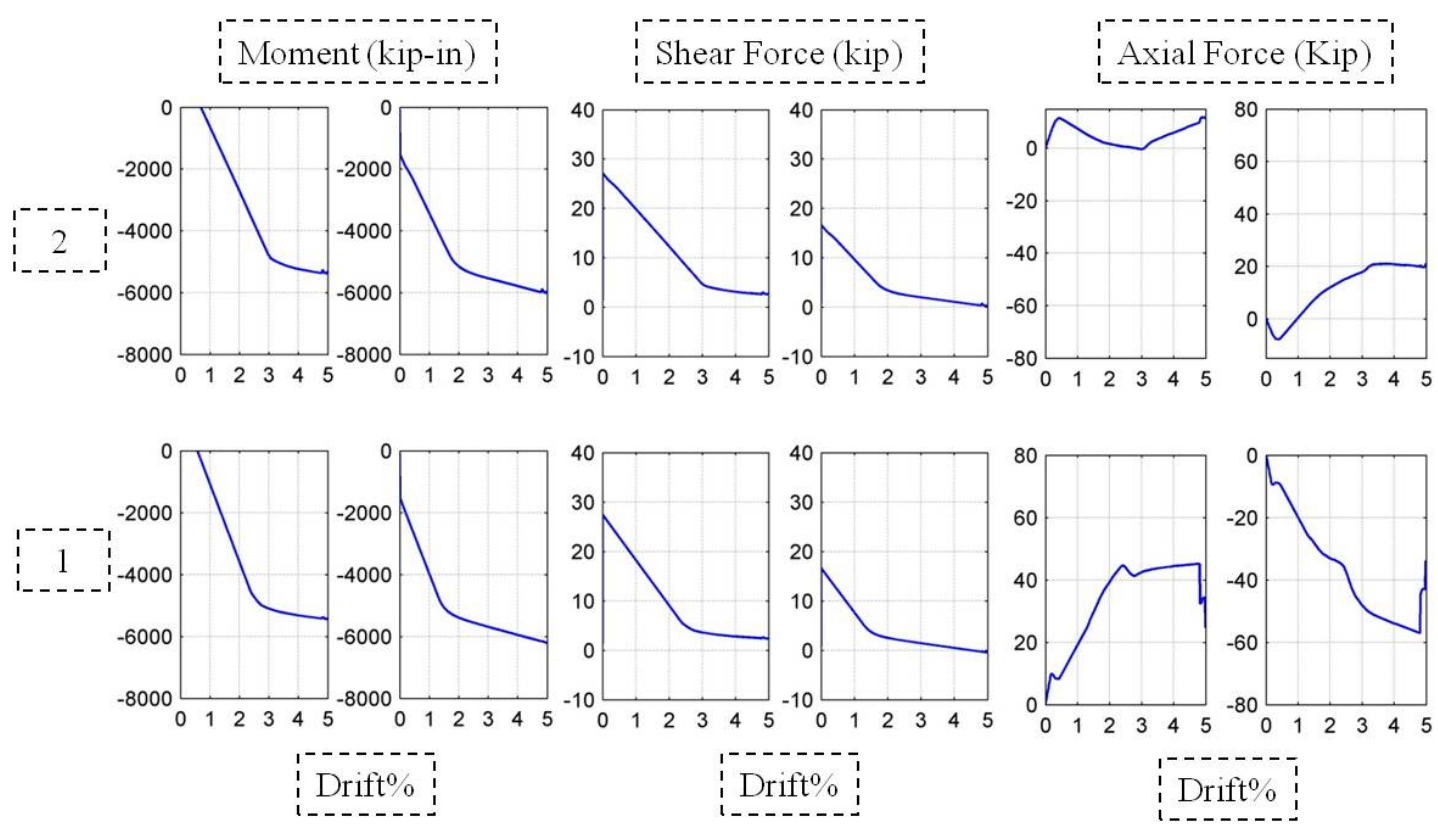

Figure 10.12: Beam Demands Form Pushover Analysis for Model Number 1. 


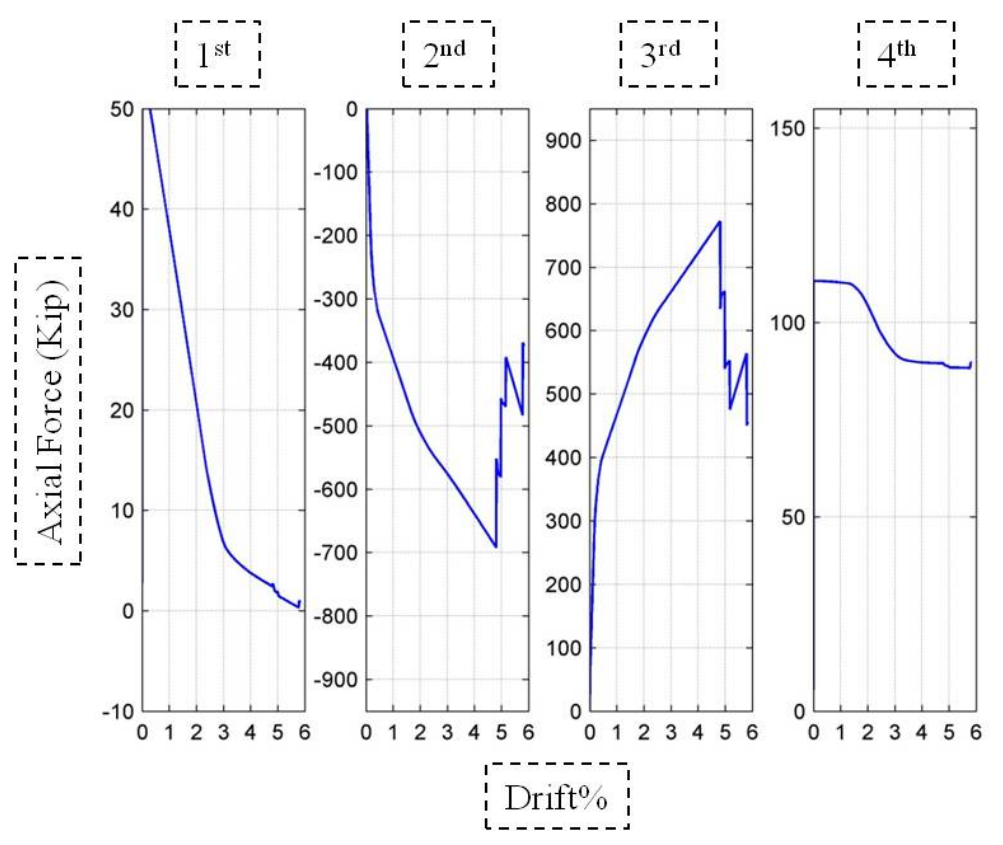

Figure 10.13: Column Demands Form Pushover Analysis for Model Number 1.
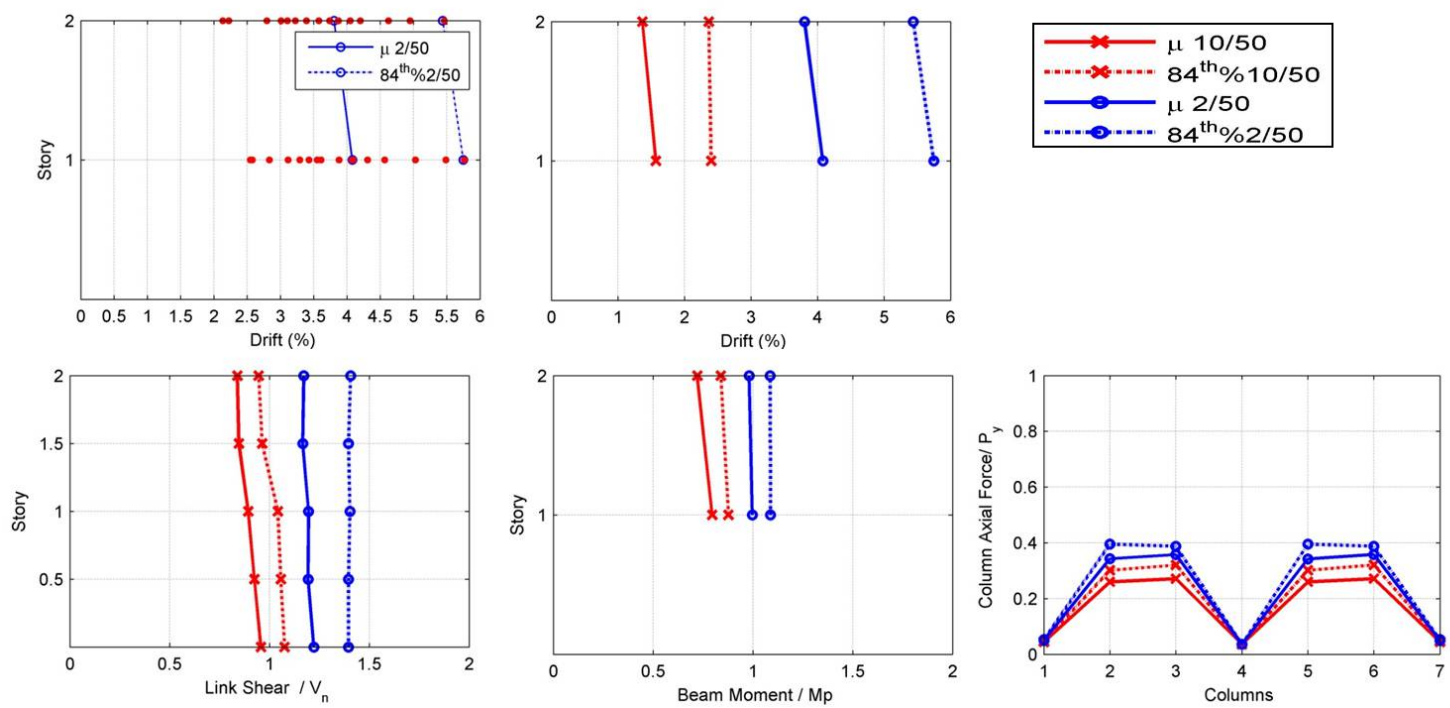

Figure 10.14: Dynamic Results, Maximum Story Drift and Link, Beam and Column Demands for Model Number 1.

were developed to investigate the different mass and diaphragm constraints distribution. 
As shown in Figure 10.15, Model 1 was developed by having the mass and diaphragm constraint assigned to eight nodes per floor. These eight nodes are the start and the end nodes of each beam (four beams per floor). In model 2, all of the mass and diaphragm constraints are concentrated on four nodes on the $\mathrm{T}$ shape frame; one node at the start and one at the end of each of the two beams of the T shape frame per story. Model 3 is the same as model 2, except the mass distribution is slightly different. Instead of the nodes at the end of the beam, the nodes at the end of truss elements (near LC columns) were used for half of the mass distribution.

Figure 10.16 shows the truss elements axial force demand comparison obtained from nonlinear analysis using Seattle ground motion records. The results were compared at both median and eight four percentile. Model numbers 1 and 3 have identical results while model number 2 has a larger axial force demand, that indicate that model 3 is a better model for the numerical simulation.

\subsubsection{Hybrid Simulation Analysis Vs Normal Analysis in OpenSees}

In this section, the hybrid simulation modeling in OpenSees and the difference between this modeling with normal OpenSees modeling is discussed. For more illustration on these differences, OpenSees framework components and procedure were briefly explained, as shown in Figures 10.17 and 10.18

As illustrated in Figure 10.17, the finite element model for LCF was constructed in ModelBuilder object and added to Domain object. The main objective in OpenSees is Domain, including other objects such as Node, Element,Constraint and LoadPattern, as shown in Figure 10.18. After the final model was created and the Domain was built, the Analysis object continued the analysis of the model at state $t$ to state $t d_{t}$. Finally, the Record object enabled post processing and monitoring of the results during and after the analysis.

To utilize OpenSees as a simulation software in combination with experimental methods, the ExperimentalElement object was added to Element object. This new object was in charge as an interface between OpenSees and OpenFresco (Takahashi et al., 2005). 


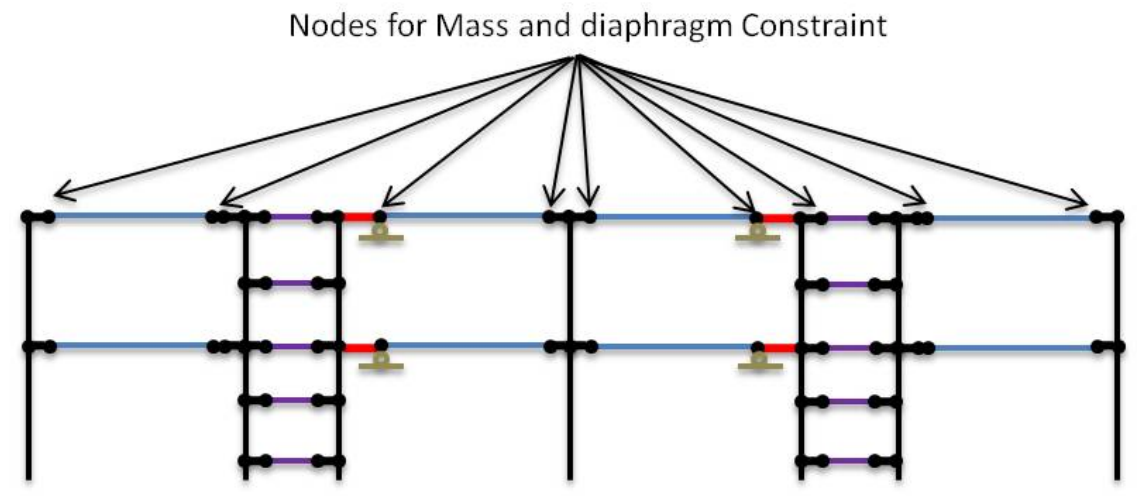

(a)

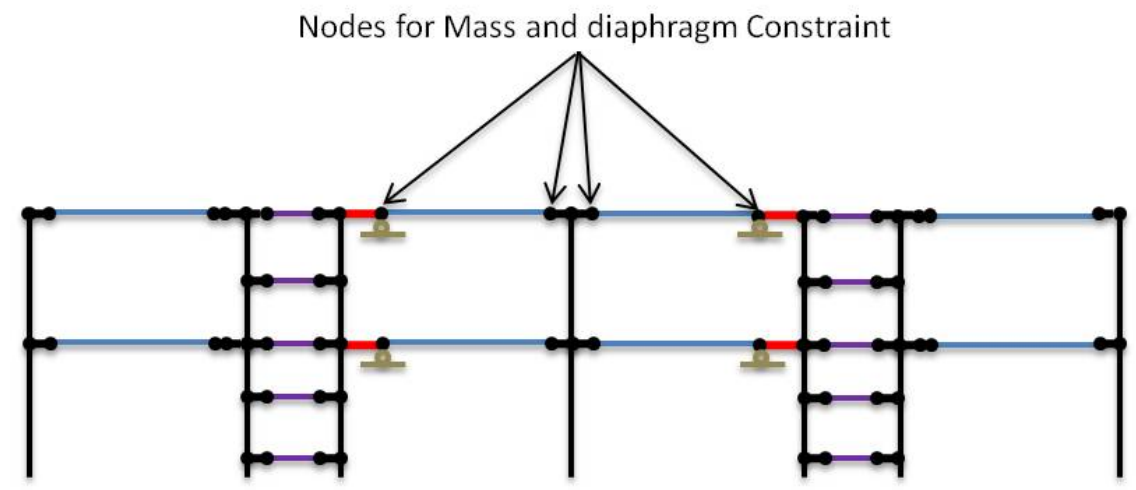

(b)

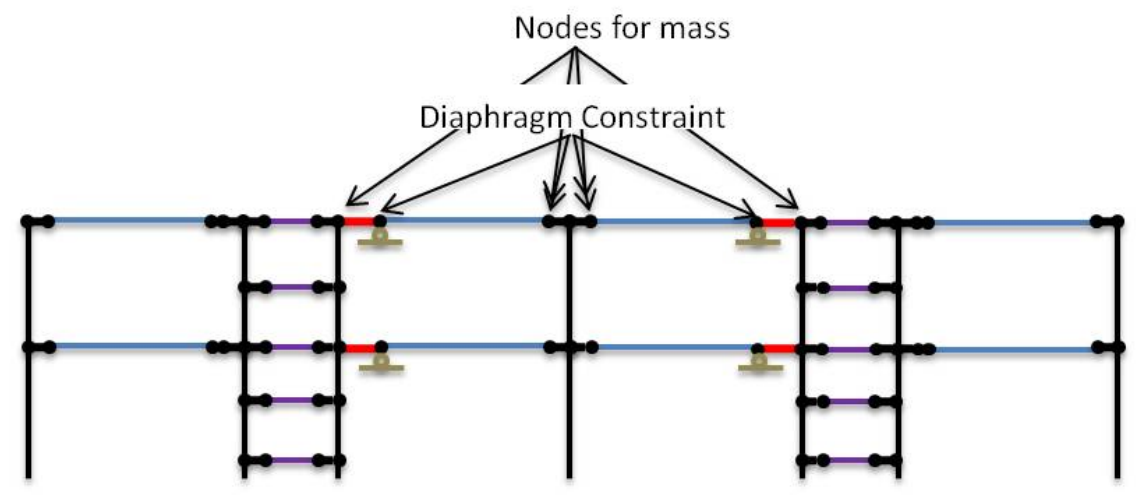

(c)

Figure 10.15: (a) Model 1 (b) Model 2 (c) Model 3

The main differences between a computational element and an experimental element are that an experimental element cannot, in current implementations, return a tangent 


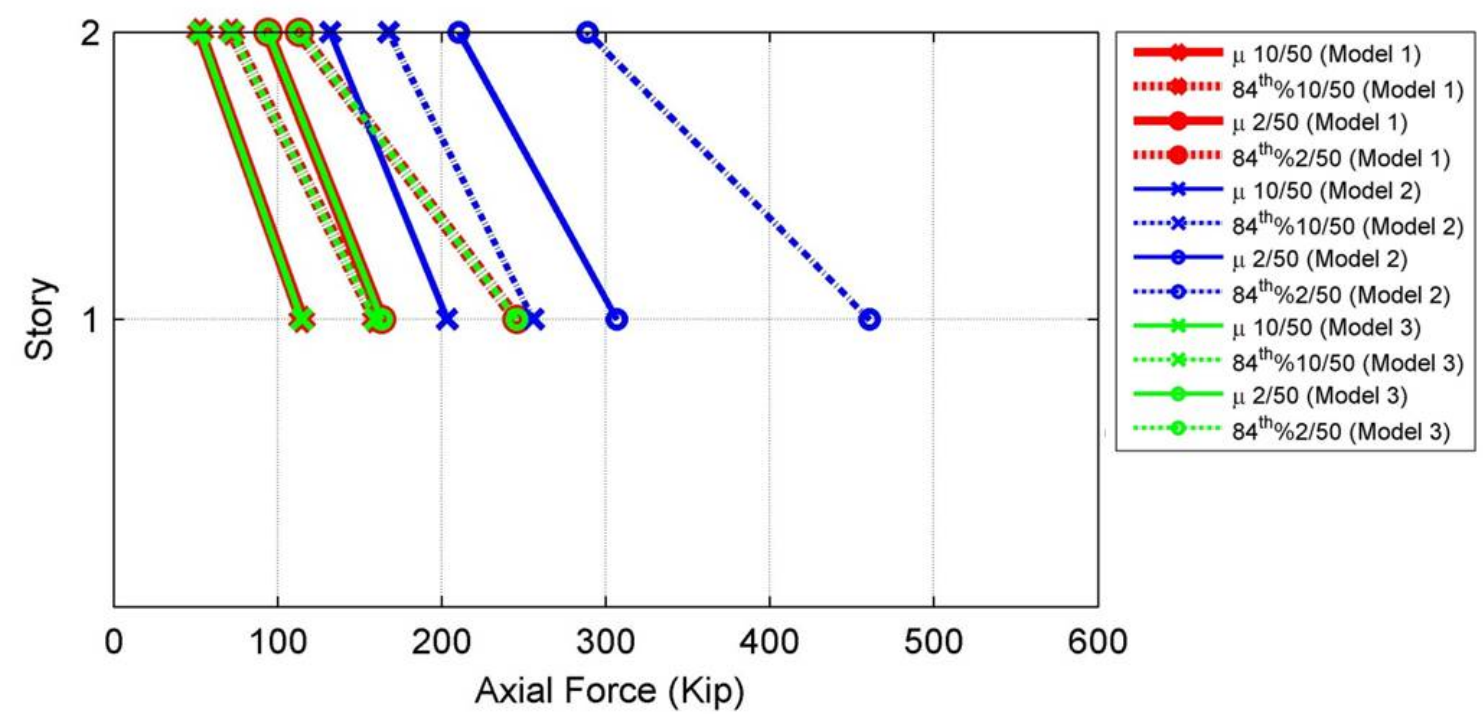

Figure 10.16: Dynamic Results, Maximum Story Drift and Link, Beam and Column Demands for Model Number 1 .

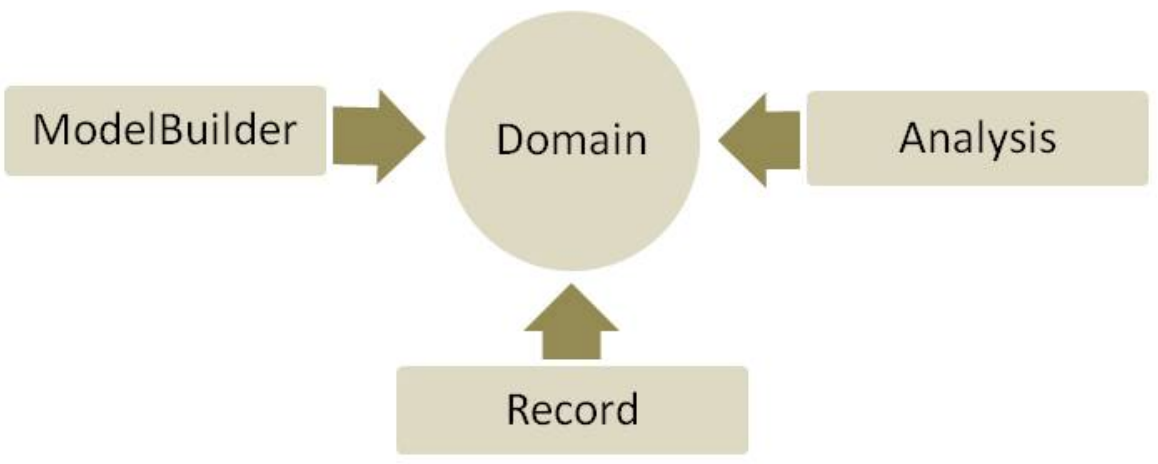

Figure 10.17: OpenSees Software Framework Components.

stiffness matrix, and cannot revert to a previous state in a case in which the analysis does not converge. An experimental element will return an initial stiffness matrix instead of a 


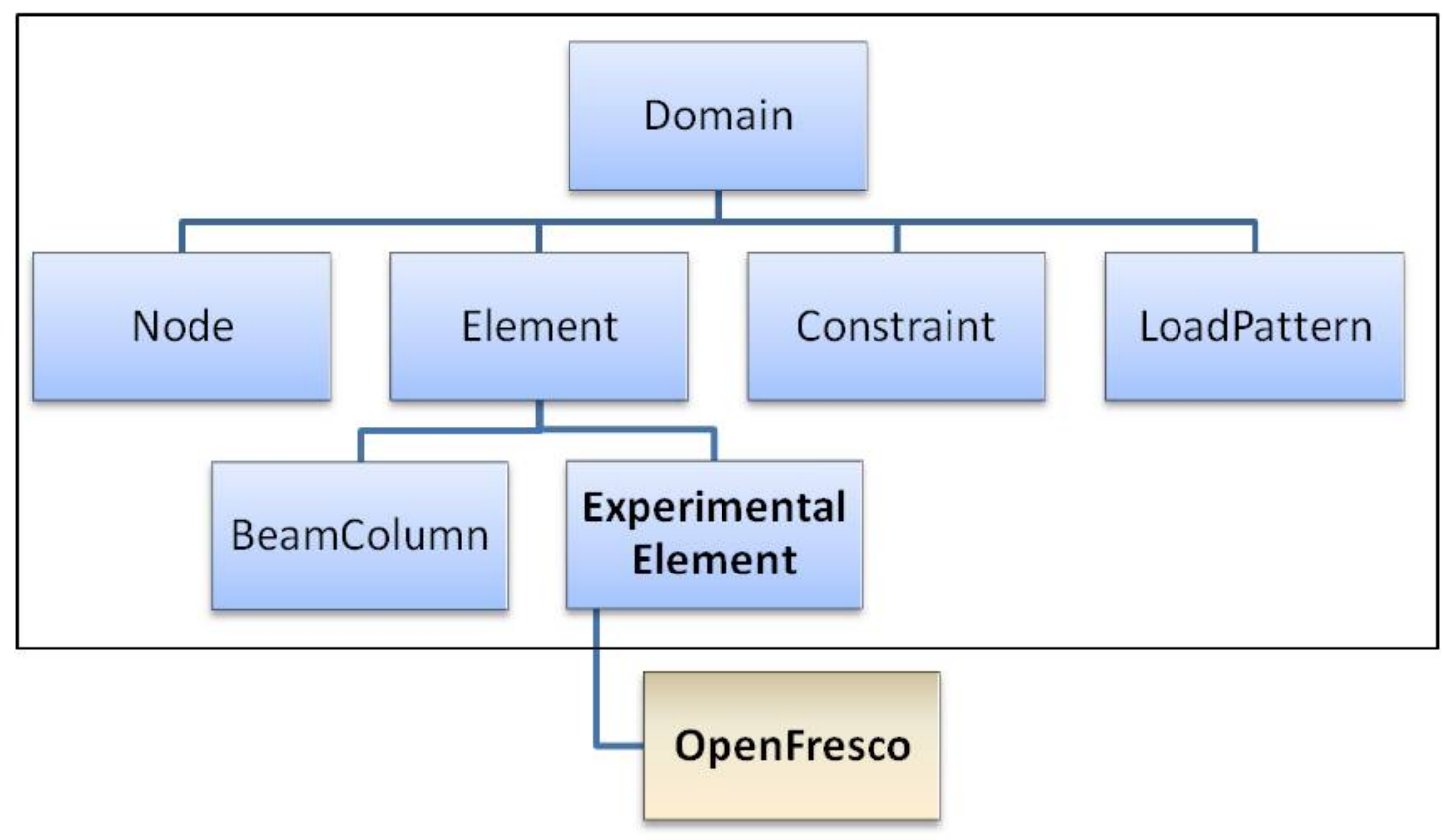

Figure 10.18: OpenSees Domain Object with Added Experimental Element.

tangent stiffness matrix, and it will fail if asked to revert to a previous state.

As shown in Figure 10.19, both normal and hybrid analyses utilize Nemmark as nonlinear analysis with Transformation method as Constraint (this command determines how the constraint equations are enforced in the analysis). Both methods use RCM (Reverse Cuthill-McKee Number) as Number (this command determines the mapping between equation numbers and degrees-of-freedom) and UmfPack as System (this command is used to construct the LinearSOE and LinearSolver objects to store and solve the system of equations in the analysis). Finally, both analyses employ Newton as Algorithm (this command is used to construct a SolutionAlgorithm object, which determines the sequence of steps taken to solve the non-linear equation) and Transient as Analysis (This command is used to construct the Analysis object, which defines what type of analysis is to be performed).

The only changes between normal and hybrid analysis is in Test, (this command is used to construct a ConvergenceTest object. Certain SolutionAlgorithm objects require a 
ConvergenceTest object to determine if convergence has been achieved at the end of an iteration step. The convergence test is applied to the matrix equation, $\mathrm{AX}=\mathrm{B}$ stored in the LinearSOE) and Integrator command (This command is used to construct the Integrator object. The Integrator object determines the meaning of the terms in the system of equation object $\mathrm{Ax}=\mathrm{B})$ (Mazzoni et al., 2009).

In hybrid simulation, convergence test is "FixedNumIter" instead of "Energy Norm" or "Disp Norm". This command is used to construct a test that performs a fixed number of iterations without testing for convergence. This test is useful for hybrid simulation because of the residual error is corrected for in this method. In Test FixedNumIter 10 2, 10 represents the fixed number of iterations test and 2 represents the flag, it is optional and it is the same as other tests. This Convergence test can only be used in combination with certain implicit integration methods that are specialized for hybrid simulation. Here, NewmarkHSFixedNumIter 0.50 .25 was used, in which 0.5 represents gama and 0.25 represents beta (Mazzoni et al., 2009).

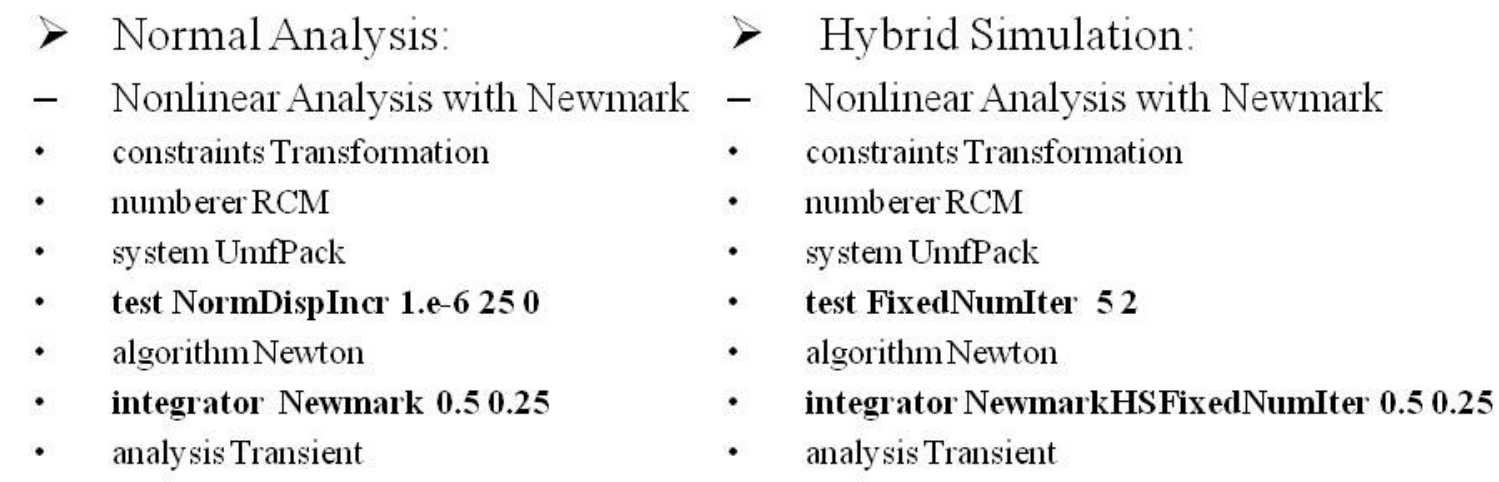

Figure 10.19: Comparison Between Hybrid Simulation Analysis Algorithm and Normal Analysis.

For this evaluation, two analyses were performed; normal analysis and analysis with fix iteration points. Seattle ground motion, SE38, for $2 \%$ in 50 year hazard level was picked. The first and second story drift responses from this ground motion represent the median drift response of all twenty $2 \%$ in 50 year ground motions (Figure 10.14). For hybrid analysis, five 
iterations with analysis time step equal to $0.005 \mathrm{sec}$ were used. No convergence problems were observed in this analysis, even when increasing the ground motion. Figure 10.20 shows the axial demands in those truss elements and each demonstrated exactly the same results.
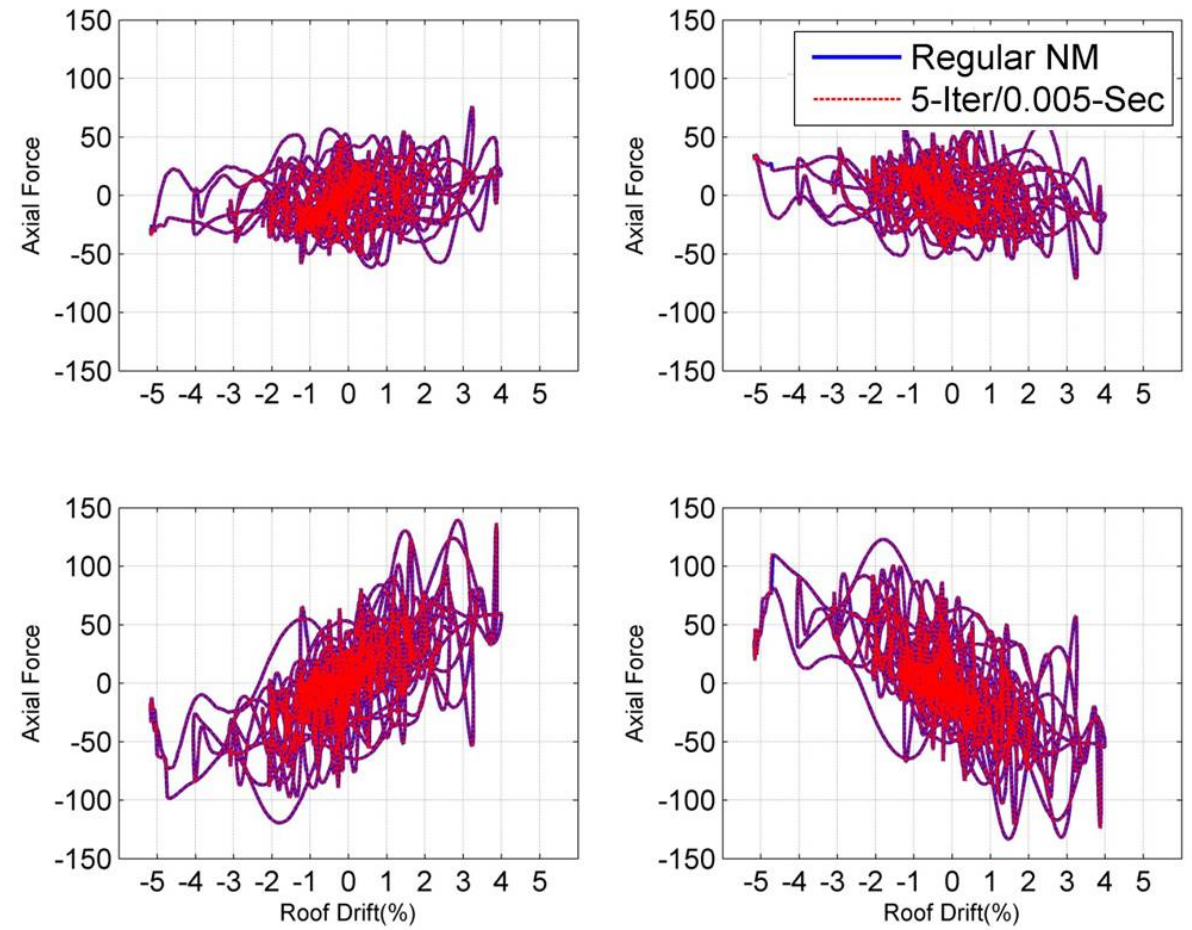

Figure 10.20: Axial Demands in Truss Elements in Model Number 3. 


\section{Chapter 11 \\ SUMMARY, CONCLUSIONS AND FUTURE WORK}

\subsection{Summary}

- The research has investigated a new steel seismic load resisting system: the Linked Column Frame (LCF) system. LCFs use flexible moment resisting frames (MF), where the beam of the frame has a moment resisting connection at one end and a simple connection at the other, in combination with linked columns (LC), which are two closely spaced columns connected by steel links that are similar in behavior to links in eccentrically braced frames. LCFs are also capable of limiting damage to the more easily replaced links, in most seismic events. They provide for collapse prevention in very large events by engaging additional energy dissipation through yielding of the moment resisting frame. Bolted end plate connections with end stiffener details were developed as part of the project, and are used to ensure the links have adequate ductility and are relatively easy to replace following an earthquake. Further, the system is architecturally appealing as it does not require braced bays.

- The LCF system has been developed with performance-based seismic design in mind. It was designed to consist of two parallel seismic force resisting systems that would yield at significantly different story drift levels. This allows the system to be designed explicitly for two different seismic performance objectives: (i) rapid repair, where damage is limited to the more easily repaired links and (ii) collapse prevention, where damage occurs in both the links and moment resisting frame. This research suggests three damage states (DS) for use in performance-based design of the LCF that correspond to three seismic hazard levels (\% probability of occurrence in 50 years). Damage State 1 (DS1) is undamaged elastic response and is used for the response in the $50 \%$ in 50 year event, DS2 is yielding and damage only in the links and is used for the 
response in the $10 \%$ in 50 year event and DS3 is yielding and damage in both the links and the moment frame and is used for the response in the $2 \%$ in 50 year event.

- Analytical models of the LCF components were developed. The development process included gathering experimental data from previous tests (selecting appropriate material models, section behavior, and element type) and then calibrating the models using the gathered data. Nonlinearity in the links, moment frame beams, and partially restrained connections required experimental data for model development.

- The links were modeled assuming that the shear and flexural response is uncoupled, which is adequate for links having wide-flange cross-sections that are not overly deep. The selected method for modeling the link behavior uses a distributed plasticity beam-column element with a fiber cross-section that controls the axial and flexural response, and is aggregated with an independent nonlinear shear force versus shear deformation section. The OpenSees hysteretic material combined with the $\min / \max$ material wrapper and fatigue material (for simulating degradation) was utilized for modeling the links.

- The beam-to-column connection of the LCF moment frame was modeled using a hysteretic material combined with a fatigue material (for simulating degradation) and beam-column elements with fiber cross sections available in OpenSees. The connection behavior was simulated through the beam response and the model was calibrated to the prequalified connection types for use in connecting beams to columns in Intermediate Moment Frames (IMF).

- Models were also developed for capturing the contribution of the simple connections to the lateral resistance of an LCF system. These simple connection models were calibrated to experimental results available and detailed in the literature.

- Two design procedures were developed. The first LCF design procedure is based on story drift requirements and the key constraint of this design procedure is:

$$
1.2<\frac{\Delta_{Y M F}}{\Delta_{Y L F}}<3
$$


This enables the plastification to occur in links in lower drift compared to beams in higher drifts. The second procedure was developed based on spectral parameters, which generalize design parameters as a function of site specific seismic hazard parameters. The LCF design parameters, i.e., the linked column and moment frame strengths and yield displacements, were related to the site specific spectral acceleration at 1s period (SM1) for different hazard levels. This ensures that the LCF can achieve multiple performance objectives for locations with different seismicity. The general equation for design parameters as a function of site specific spectral parameters is as follows:

$$
\sqrt{\frac{V_{P L C F} \Delta_{P L C F}}{V_{Y L C F} \Delta_{Y L C F}}} \geq \frac{S_{M 1(2 \% i n 50)}}{S_{M 1(10 \% i n 50)}}
$$

- A prototype three-story LCF model, including P-Delta effects, was used to perform cyclic nonlinear pushover analysis to examine the modeling methods.

- System level analysis was performed to assess performance relative to the objectives of rapid repair and collapse prevention for different seismic hazard levels. LCFs were designed for 3-, 6- and 9- story versions of the SAC buildings for the Los Angeles location with 60 ground motions. The LCFs were designed using conventional seismic design methods and loads (per ASCE 7), including strict capacity design of the columns and $R$ and $C_{d}$ factors for EBFs. A number of designs were considered such that the relative strengths of the MF and LC were varied, as were the link lengths and yield modes. Nonlinear response history analysis was performed for ground motions representing hazard levels of $50 \%, 10 \%$ and $2 \%$ probability of exceedence in 50 years.

- To evaluate the robust nature of the design procedure, the performance of an LCF designed for Seattle has been evaluated using the same design procedure that was followed for the Los Angeles seismic region. This is to ensure that the design procedure achieves multiple performance objectives as intended for various seismic regions.

- To improve the LCF performance and ensure more uniformly in demands, an addi- 
tional link was inserted to the LCF system at the base and the nonlinear dynamic results were compared to a system without additional links. The same comparison was performed with the fixed base column connection models. An additional link or fixing the base adds more stiffness at the lower stories, which originally have the largest story drifts, link rotations and beam rotations.

- Parametric studies have been conducted to investigate the impact of individual components of the LCF (the stiffness of links and columns of the linked columns, moment frame stiffness, and the overturning stiffness of the linked columns) on the stiffness of the overall system. For this, closed-form equations were developed using approximate frame analysis methods.

- Seismic response parameters including the response modification coefficient $(R$ factor), the system over-strength factor $\left(\Omega_{0}\right)$, and deflection amplification factor $\left(C_{d}\right)$, have been determined for the LCF system. The ATC-63 (FEEMA P695) procedures have been employed, which provides a probabilistic assessment of collapse risk. The procedure explicitly considers uncertainties in ground motion, modeling, design and test data. A full suite of archetype structures (fifteen LCFs reflecting the range of design parameters and system attributes that have significant impacts on LCF response) were designed and incremental dynamic analysis was conducted using modeling methods similar to those used for the system analyses described before. All designs used trial values of $R=8, \Omega_{0}=3$ and $C_{d}=5.5$, which are the same values used for Special Moment Frame.

- The system and component behaviors of LCFs are being investigated experimentally through a hybrid test at University of California, Berkeley on 2-story, 1-bay LCF specimens to study the effects of various design parameters on overall cyclic response, component demands and overall system behavior. This test program also investigates the proposed details for the links and beam-to-column connections. Nonlinear static and dynamic analyses were conducted to investigate the experimental specimen demands under pushover loading and ground motions, characterizing the component 
demands, and investigating the overall behavior of the LCF. The analyses were also used to select suitable ground motions for the hybrid simulation and the models will be used as the numerical component of the hybrid simulation. 


\subsection{Conclusions}

- The new lateral load resisting system, denoted the Linked Column Frame (LCF) system developed as part of this research was shown, numerically, to provide for rapid repair following moderate earthquakes and collapse prevention following severe earthquakes. It was shown that under lateral earthquake loading, the links yield before the beams of the secondary moment frame. LCF systems have the potential for relatively simple repair in moderate earthquakes because no gravity members would be damaged and the links use a specially designed bolted connection.

- Design of the LCF was found to be largely drift controlled for high seismic zones using the equivalent static lateral force procedure.

- When designed correctly, there is a significant difference in the drifts where link yielding and beam yielding occur, as demonstrated through the analysis of 3-, 6-, and 9-story prototype LCFs for Los Angeles and Seattle sites. Two methods for ensuring the drift difference were found to be adequate:

$$
1.2<\frac{\Delta_{Y M F}}{\Delta_{Y L F}}<3
$$

or

$$
\sqrt{\frac{V_{P L C F} \Delta_{P L C F}}{V_{Y L C F} \Delta_{Y L C F}}} \geq \frac{S_{M 1(2 \% i n 50)}}{S_{M 1(10 \% i n 50)}}
$$

- The results of nonlinear response history analysis for a series of 3-, 6- and 9-story LCFs for the Los Angeles location show that all LCFs achieved the key design objectives. Namely, no repair is needed after a $50 \%$ in 50 year event as only minor link yielding was observed, rapid repair by replacing the damaged link is applicable after a $10 \%$ in 50 hazard level as only links yield, and collapse prevention for $2 \%$ in 50 year hazard level since the story drifts was generally less than $5 \%$. Additionally, even though most LCF designs were drift controlled, all story drifts from response history analyses were less than $2 \%$ for $10 \%$ in 50 year earthquake, which approximated the design seismic 
demands. This performance for design seismic demands is acceptable.

- The results of nonlinear response history analysis of LCFs for the Seattle location with 40 ground motions show the same results as before: no repair is needed after a $50 \%$ in 50 year event as only minor link yielding was observed, rapid repair by replacing the damaged link is applicable after a 10\% in 50 hazard level as only link yield, and collapse prevention for $2 \%$ in 50 year hazard level since the story drifts were generally less than $5 \%$.

- Based on analysis results for regions with different seismic hazards, Los Angeles and Seattle, the design procedure was found to be broadly adequate.

- Of the 3-story LCF designs, the design with shear links out-performed those with flexural or intermediate links in terms of story drift, link rotation and beam rotation demands at almost all hazard levels. The shear link design was also more effective at achieving all performance objectives. In taller LCFs, overturning demands become more important and LCFs with larger spacing between the linked columns and corresponding longer links had smaller drifts due to better overturning resistance. It is recommended that shear links be used for low-rise LCFs and flexural or intermediate links be used for taller LCFs.

- For both low-rise and mid-rise LCFs, the best performance and most efficient design (in terms of weight of steel) was achieved when the LCs were used as the primary means of achieving drift criteria rather than the MFs. This also resulted in lighter frames in comparison to special moment resisting frames in moderate seismic zones (i.e. the Seattle site used in this study). However, this was not the case in the highest seismic zones (i.e. the Los Angeles site used in this study) where the LCF was found to use more steel than a similar special moment resisting frame.

- Capacity design resulted in large columns for the 9-story LCF yet the columns remained elastic in almost all of the $2 \%$ in 50 year ground motions. However, larger 
story drifts, link rotations and beam rotations were observed in the lower stories of the 6- and 9-story LCFs for the $2 \%$ in 50 year hazard level. Considering the column sizes and performance, the feasible upper height limit of the LCF in high seismic regions is 9 or 10 stories.

- LCF design has a lower overstrength relative to a comparable SAC moment frame, which results in lower foundation demand for the LCF building. Although the short spans of the links do create large axial load demands on the columns of the LCs, the system can be effectively designed with much lower overstrength than moment resisting frames. Thus, there is a trade-off in selecting an LCF that requires the foundation to be designed for smaller base shear but larger localized overturning demands under the linked columns. In general, this results in potential cost savings for the building.

- The stiffness of 3-story LCFs is most greatly impacted by the area of the links' webs compared to the other component section properties. The stiffness of 6-story LCFs is most greatly impacted by the beam moment of inertia. Based of this, using built-up sections instead of W-shape sections for links in 3-story LCFs has considerable benefits for the overall efficiency because the web area can be controlled independent of the other cross section properties.

- Adding stiffness at lower levels by inserting an additional link at the first floor or fixing the base connections, improves LCF performance through the delivery of more uniform demand distribution.

- The trial values used for evaluating seismic response parameters were found acceptable according to the FEMA p695 procedure. The resulting recommended values are as follows: $R=8, \Omega_{0}=3$ and $C_{d}=5.5$. 


\subsection{Future Work}

- As previously discussed, story drifts, link rotations and beam rotations were all observed to be largest on the lower stories of taller LCF's which is not ideal, even given that the overall performance achieved the performance objectives. The columns in these lower stories remain elastic so the solutions to ensure more uniform story drift and link and beam rotation must focus on adding stiffness. Adding additional links was investigated in this study, however, for taller LCFs, some other possible solutions for improving drift distribution are worth investigating in the future work. These include the following:

- Embedding the column base and dealing with the consequences of larger column flexural demands.

- Using alternative geometries by leveraging two side-by-side LC's to increase the overturning resistance.

- Using built-up column sections or concrete-filled steel tube columns (CFT) to leverage column stiffness to help increase story stiffness and column strength. It is acknowledged that connection design may be difficult.

- Experimental and analytical research results must be synthesized: experimental results are needed to evaluate the constructability of the LCF system and to validate the analytical model. Currently, a full scale 2-story, 1-bay LCF has been designed at Portland State University (PSU) to be tested (hybrid test) at University of California, Berkeley. This research should include studies of the link, link-to-column connection details, the effects that links and beams have on the energy dissipation, column behavior and determination of construction and repair methods. Experimental results then should be compared with the developed model for model validation and refinement. Both system and component level refinements should be considered in test comparisons.

- Limitations of the test set-up at Portland State University prevented the testing of 
shear links with sections deeper than 12 in. and several of the prototype designs require deeper links (up to about 24 in.). The effectiveness of the parallel web stiffeners in reducing plastic strains at the end plates must be considered for deeper links prior to implementation. More testing and detailed analysis on deeper links may be essential.

- Further analysis of the simulated dynamic results is required as future work to evaluate the accelerations at floor levels for an LCF building and compare these floor accelerations with those of other structural systems. For the LCF system to provide enhanced building performance, damage to nonstructural components must also be limited. To determine damage of acceleration controlled nonstructural elements using the performance-based design methodology, floor acceleration spectra for an LCF should be developed to evaluate the demands on these nonstructural elements at various levels in the building.

- Specifications and design examples must be produced for the system to be considered for adoption in the AISC Seismic Provisions. 


\section{BIBLIOGRAPHY}

Aiken, I., Clark, P., Trajirian, F., Kasai, K., Kimura, I., , and Ko, E. (1999). "Unbonded braces in the united states - design studies, large-scale testing and the first building application." Proceedings of the International Post-SMiRT Conference Seminar, Vol. I, Korea. Earthquake Engineering Research Center, 317-337.

AISC (2005a). Seismic Provisions for Structural Steel Buildings, ANSI/AISC 341-05. American Institute of Steel Construction, Chicago, IL.

AISC (2005b). Specification for Structural Steel Buildings, ANSI/AISC 360-05. American Institute of Steel Construction, Chicago, IL.

AISC (2005c). Specification for Structural Steel Buildings, ANSI/AISC 360-05. American Institute of Steel Construction, Chicago, IL.

ANSI/AISC 358-05 (2005). Prequalified Connections for Special and Intermediate Steel Moment Frames for Seismic Applications. American Institute of Steel Construction, Chicago, IL.

Arce, G. (2002). "Impact of higher strenght steels on local buckling and overstrength of links in eccentrically braced frames. Master's thesis, Civil and Environmental Engineering Dept., The University of Texas at Austin, Austin, TX.

ASCE (2005). Minimum Design Loads for Buildings and Other Structures. ASCE/SEI 7-05, Reston, VA.

ATC-40 (1996). "Seismic evaluation and retrofit of concrete building." Report no., Applied Technology Council, Redwood City, California.

ATC-58 (2009). "Guidelines for seismic performance assessment of buildings: ATC-58 50\% draft." Report no., Applied Technology Council, Washington, D.C. 
ATC-58 SSP (2009). "Fragility curves for components of steel smf systems." Report no., Applied Technology Council, Washington, D.C.

Chen, L. (2011). "Innovative bracing system for earthquake resistant concentrically braced frame structures. Master's thesis, Concordia University, Montreal, Quebec, Canada.

Chopra, A. and Goel, R. K. (1999). "Capacity-demand-diagram methods for estimating seismic deformation of inelastic structures: Sdf systems." Report No. PEER-1999/02, Pacific Earthquake Engineering Research Center, University of California, Berkeley, CA.

Chopra, A. K. (2007). Earthquake Dynamics of Structures: Theory and Applications to Earthquake Engineering. Prentice Hall, 3 edition.

Christopoulos, C., Filiatrault, A., and Folz, B. (2002). "Seismic response of self-centring hysteretic sdof systems." Earthquake Engineering and Structural Dynamics, 31, 11311150.

Christopoulos, C., Filiatrault, A., Uang, C.-M., and Folz, B. (2002). "Posttensioned energy dissipating connections for moment-resisting steel frames." Journal of Structural Engineering, 128(9), 1111-1120.

Christopoulos, C., Tremblay, R., Kim, H.-J., , and Lacerte, M. (2008). "Self-centering energy dissipative bracing system for the seismic resistance of structures:development and validation." Journal of Structural Engineering, 134(1), 96-107.

Clayton, P. M. (2010). "Self-centering steel plate shear walls: Development of design procedure and evaluation of seismic performance. Master's thesis, Civil and Environmental Engineering Dept., University of Washington, Seattle, WA.

Dargush, G. and Soong, T. (1995). "Behavior of metallic plate dampers in seismic passive energy dissipation systems." Earthquake Spectra, 11(4), 545-568.

Dusicka, P. and Iwai, R. (2007). "Development of linked column frame system for seismic lateral loads." Proceedings of the SEI Structures Congress, Vancouver, B.C. American Society of Civil Engineers. 
Dusicka, P. and Lewis, G. (2010). "Investigation of replaceable sacrificial steel links." Proceedings of the 9th U.S. National and 10th Canadian Conference on Earthquake Engineering, number 1659. EERI.

Engelhardt, M. (1989). "Behavior of long links in eccentrically braced frames," Ph.D. dissertation, Civil and Environmental Engineering Dept., University of California, Berkeley.

Engelhardt, M. D. and Sabol, T. A. (1997). "Testing of weld steel moment connections in reponse to the northridge earthquake." Progress in Structural Engineering and Materials, $1(1), 68-77$.

FEMA-267 (1995). "Evaluation, repair, modification and design of welded steel moment frame structures." Report No. 267, SAC Joint Venture for the Federal Emergency Management Agency, Washington, D.C.

FEMA-350 (2000). "Recommended seismic design criteria for new steel moment-frame buildings." Report No. 350, SAC Joint Venture for the Federal Emergency Management Agency, Washington, D.C.

FEMA-351 (2000). "Recommended seismic evaluation and upgrade criteria for existing welded steel moment-frame buildings." Report No. 351, SAC Joint Venture for the Federal Emergency Management Agency, Washington, D.C.

FEMA-352 (2000). "Recommended postearthquake evaluation and repair criteria for welded steel moment-frame buildings." Report No. 352, SAC Joint Venture for the Federal Emergency Management Agency, Washington, D.C.

FEMA-353 (2000). "Recommended specifications and quality assurance guidelines for steel moment-frame construction for seismic applications." Report No. 353, SAC Joint Venture for the Federal Emergency Management Agency, Washington, D.C.

FEMA-354 (2000). "A policy guide to steel moment-frame construction." Report No. 354, SAC Joint Venture for the Federal Emergency Management Agency, Washington, D.C. 
FEMA-355 C (2001). "State of the art report on systems performance of steel moment frames subject to earthquake ground shaking." Report No. 355, Helmut Krawinkler, Team Leader, SAC Joint Venture for the Federal Emergency Management Agency, Washington, D.C.

FEMA-450 (2003). "NEHRP recommended provisions for seismic regulations for new buildings and other structure." Report No. 450, Building Seismic Safety Council for the Federal Emergency Management Agency, Washington, D.C.

FEMA P695 (2009). "Quantification of building seismic performance factors." Report No. P695, Applied Technology Council for the Federal Emergency Management Agency, Washington, D.C.

FEMA222A (1995). "1994 edition:nehrp recommended provisions for seismic regulations for new buildings." Report No. 222A, Helmut Krawinkler, Team Leader, SAC Joint Venture for the Federal Emergency Management Agency.

Freeman, S. A. (1998). "The capacity spectrum method as a tool for seismic design." 11th European Conference on Earthquake Engineering, Paris, A.A. Balkema, Rotterdam.

Garlock, M. (2002). "Full-scale testing, seismic analysis, and design of post-tensioned seismic resistant connections for steel frames," Ph.D. dissertation, Civil and Environmental Engineering Dept., Lehigh University.

Garlock, M. M., Ricles, J. M., and Sause, R. (2005a). "Experimental studies of full-scale posttensioned steel connections." Journal of Structural Engineering, 131(3), 438-448.

Garlock, M. M., Ricles, J. M., and Sause, R. (2005b). "Experimental studies of full-scale posttensioned steel connections." Journal of Structural Engineering, 131(3), 438-448.

Goodyear, D. and Sun, J. (2003). "New developments in cable-stayed bridge design, san francisco." Structural Engineering International, 13(1).

Gupta, A. and Krawinkler, H. (1999). "Seismic demands for performance evaluation of 
steel moment resisting frame structures." Report No. 132, John A. Blume Earthquake Engineering Center, Stanford University, Stanford, CA.

Hajjar, J. F., L. R. T. G. M. A., , and Shield, C. (1998). "Seismic response of composite moment-resisting connections. ii: Behavior." Journal of Structural Engineering, 124(8), $877-885$.

Ibarra, L., Medina, R., , and Krawinkler, H. (2005). "Hysteretic models that incorporate strength and stiffness deterioration." International Journal for Earthquake Engineering and Structural Dynamics, 34(12), 1489-1511.

Iwata, M., Kato, T., , and Wada, A. (2000). "Buckling-restrained braces as hysteretic dampers." Behavior of Steel Structures in Seismic Areas, Vol. STESSA. 33-38.

Kasai, K. (1985). "A study of seismically resistant eccentrically braced steel frame systems," Ph.D. dissertation, Civil and Environmental Engineering Dept., University of California, Berkeley.

Kaufman, E. J. and Fisher, J. W. (1995). "Fracture analysis of failed moment frame weld joints produced innfull scale laboratory tests and buildings damaged in the northridge earthquake." Technicla Report: Experimental investigation of material weldments, and nondestructive examination techniques SAC95-08, SAC Joint Venture, Sacramento, CA.

Kaufman, E. J., Fisher, J. W., Di Julio, R. M., , and Gross, J. L. (1997). "Failur analysis of welded steel moment frames damaged in the northridge earthquake." Report No. NISTIR 5944, National Institute of Standards and Technology, Gaithersburg, MD.

Kolkan, E. (2006). "Analytical models of instrumented moment frame steel buildings in opensees." Report no., Calliifforniia Geollogiicall Survey, Sacramento, CA.

Kolkan, E. and Kunnath, S. (2007). "Assessment of current nonlinear static procedures for seismic evaluation of buildings." Engineering Structures, 29, 305-316.

Lin, Y, Y., , and Chang, K.-C. (2003). "An improved capacity spectrum method for atc-40." Earthquake Engng Struct. Dyn., 32, 2013-2025. 
Liu, J. and Astaneh-Asl, A. (2000). "Cyclic testing of simple connections including effects of slab." Journal of Structural Engineering, 126(1), 32-39.

Liu, J. and Astaneh-Asl, A. (2004). "Moment-rotation parameters for composite shear tab connections." Journal of Structural Engineering, 130(9), 1371.

Lopez, A. P. (2013). "Experimental behavior of the linked column frame system. Ph.d. dissertation, Civil and Environmental Engineering Dept., Portland State University, Portland, OR.

Lopez, A. P., Dusicka, P., , and Berman, J. (2012a). "Design of the linked column frame structural system." In Proceedings of the STESSA 2012, London.

Lopez, A. P., Dusicka, P., , and Berman, J. (2012b). "Linked column framing system analyses toward experimental validation." In Proceedings of the Structures Congress, Chicago, Il.

Lu, A.-C. and MacRae, G. (2011). "Residual stress effects on the seismic performance of lowrise steel frames." Proceedings of the Ninth Pacific Conference on Earthquake Engineering Building an Earthquake-Resilient Society, Auckland, New Zealand.

Mathur, K. (2011). "Effects of residual stresses and initial imperfections on earthquake response of steel moment frames. Master's thesis, University of Illinois at UrbanaChampaign, Urbana, Illinois.

Mazzoni, S., McKenna, F., Scott, M. H., and Fenves, G. L. (2009). Open System for Earthquake Engineering Simulation User Command-Language Manual - OpenSees Version 2.0. Pacific Earthquake Engineering Research Center, University of California, Berkeley, Berkeley, CA.

Miyama, T., Tanaka, K., Meng, L., Kato, Y., Hirasawa, M., , and Sasaki, M. (1996). "Study on the highly damped building with low-yield-point steel shear panel." Proceedings of the Elenenth Conference on Earthquake Engineering, number 416. Elsevier Science, Ltd. 
Nader, M., Lopez-Jara, J., , and Mibelli, C. (2002). "Seismic design strategy of the new san francisco-oakland bay bridge self-anchored suspension span." Proceedings of the Third National Seismic Conference and Workshop on Bridges, Portland, OR.

Naeim, F. (2001). The Seismic Design Handbook. Springer Science, Reston, VA, 2 edition.

Nakashima, M. (1995). "Strain-hardening behavior of shear panels made of low-yield steel. i:test." Journal of Structural Engineering, 121(12), 1742-1749.

Nakashima, M., Akazawa, T., , and Tsuji, B. (1995). "Strain-hardening behavior of shear panels made of low-yield steel. ii:model." Journal of Structural Engineering, 121(12), $1750-1757$.

Popov, E. P., Balan, T. A., , and Yang, T.-S. (1998). "Post-northridge earthquake seismic steel moment connections." Earthquake Spectra, 14(4), 659-677.

Ricles, J., Garlock, M. M., , and Zhao, C. (2001). "Post-tensioned seismic resistant connections for steel frames." Journal of Structural Engineering, 127(2), 113-121.

Ricles, J. M., M. C., , and Lu, L.-W. (2002). "Ductile details for welded unreinforced moment connections subject to inelastic cyclic loading." Engineering Structures, 25(5), 667-680.

Rojas, P., Ricles, J. M., and Sause, R. (2005). "Seismic performance of post-tensioned steel moment resisting frames with friction devices." Journal of Structural Engineering, 131(4), $529-540$.

Roke, D., Sause, R., Ricles, J., , and Conner, N. (2008). "Design concepts for damagefree seismic-resistant self-centering steel concentrically-braced frames." The 14th World Conference on Earthquake Engineering, Beijing, China.

Sabelli, R., Mahin, S., , and Chang, C. (2003). "Seismic demands on steel braced buildings with buckling-restrained braces." Engineering Structures, 25(5), 665-666.

Saeki, E., Iwamatu, K., , and Wada, A. (1996). "Analytical study by finite element method and comparison with experiment results concerning buckling-restrained unbonded 
braces." Journal of Structural and Construction Engineering, Architectural Institute of Japan, 484, 111-120.

Sause, R., Ricles, J., Roke, D., Seo, C., , and Kyung-Sik Lee, K. (2006). "Design of self-centering steel concentrically-braced frames." Proceedings of Sessions of the 4th International Conference on Earthquake Engineering, Taipei, Taiwan.

Schellenberg, A., , and Mahin, S. (2006). "Integration of hybrid simulation within the general-purpose computational framework opensees." 8th National Conference on Earthquake Engineering, EERI, San Francisco, CA. 1624.

Shimizu, K., Hashimoto, J., Kawai, H., , and Wade, A. (1998). "Application of damage control structure using energy absorption panel." Structural Engineering World Wide, number T105-2. Elsevier Science, Ltd.

Shuey, B. D., Engehardt, M. D., , and Sabol, T. A. (1996). "Testing repair concepts for damaged steel moment connections." Experimental investigation of Beam column subassemblages SAC96-01, SAC Joint Venture, Sacramento, CA.

Somerville, P., Smith, N., Punyamurthula, S., , and Sun, J. (1997). "Development of ground motion time histories for phase 2 of the FEMA/SAC steel project." Report No. SAC/BD97/04, SAC Background Document.

Sumner, E. and Murray, T. (2002). "Behavior of extended end-plate moment connections subject to cyclic loading." Journal of Structural Engineering, 128(4), 501-508.

Takahashi, Y., , and Fenves, G. L. (2005). "Software framework for distributed experimentalcomputational simulation of structural systems." Earthquake Engineering and Structural Dynamics.

Tanaka, K., Torii, T., Sasaki, Y., Miyama, T., Kawai, H., Iwata, M., , and Wade, A. (1998). "Practical application of damage tolerant structures with seismic control panel using low-yield-point-steel to a high-rise steel buildingl." Structural Engineering World Wide, number T190-4. Elsevier Science, Ltd. 
Tena-Colunga, A. (1997). "Mathematica modeling of the adas energy dissipation device." Engineering Structures, 19(10), 811-820.

Thorburn, L. J., Kulak, G. L., and Montgomery, C. J. (1983). "Analysis of steel plate shear walls." Structual Engineering Report 10\%, Dept. of Civil Engineering, University of Alberta, Edmonton, Alberta, Canada.

Tremblay, R., Lacerte, M., , and Christopoulos, C. (2008). "Seismic response of multistory buildings with self-centering energy dissipative steel braces." Journal of Structural Engineering, 134(1), 108-120.

Tsai, K. C., Chen, H.W. andHong, C., , and Su, Y. (1993). "Design of steel triangular plate energy absorbers for seismic-resistant construction." Earthquake Spectra, 9(3), 505-528.

Uang, C. M., B. D., , and Lee, C.-H. (1998). "Cyclic performance ofhaunch repaired steelmoment connections." Engineering Structures, 20(4-6), 522-561.

UBC 1994 (1994). "Structural engineering design provisions." Report no., Uniform Building Code, International Conference of Building Officials.

Uriz, P. (2005). "Towards earthquake reisitant design of concentrically braced steel structures," Ph.D. dissertation, Civil and Environmental Engineering Dept., University of California, Berkeley.

Vargas, R. and Bruneau, M. (2009a). "Experimental response of buildings designed with metallic structural fuses. i." Journal of Structural Engineering, 135(4), 386-393.

Vargas, R. and Bruneau, M. (2009b). "Experimental response of buildings designed with metallic structural fuses. ii." Journal of Structural Engineering, 135(4), 394-403.

Xuewei, C., Xiaolei, H., Cheang, J., , and Guiniu, M. (2008). "Dynamic inelastic numerical simulation for a shaking table test of a full scale steel moment frame structure based on opensees." Proceedings of the 14th World Conference on Earthquake Engineering, Beijing, China. 
Zhu, S. and Zhang, Y. (2008). "Seismic analysis of concentrically braced frame systems with self-centering friction damping braces." Journal of Structural Engineering, 134(1), $121-131$. 